\title{
Critical Assessment of Seismic and Geomechanics Literature Related to a High-Level Nuclear Waste Underground Repository
}

Manuscript Completed: February 1990

Date Published: June 1991

Prepared by

D. D. Kana, B. H. G. Brady*, B. W. Vanzant, P. K. Nair

Center for Nuclear Waste Regulatory Analyses

6220 Culebra Road

P.O. Drawer 28510

San Antonio, TX 78228-0510

\section{Prepared for}

Division of Engineering

Office of Nuclear Regulatory Research

U.S. Nuclear Regulatory Commission

Washington, DC 20555

NRC FIN B6643

*ITASCA, Minneapolis, MN 


\section{DISCLAIMER}

This report was prepared as an account of work sponsored by an agency of the United States Government. Neither the United States Government nor any agency thereof, nor any of their employees, make any warranty, express or implied, or assumes any legal liability or responsibility for the accuracy, completeness, or usefulness of any information, apparatus, product, or process disclosed, or represents that its use would not infringe privately owned rights. Reference herein to any specific commercial product, process, or service by trade name, trademark, manufacturer, or otherwise does not necessarily constitute or imply its endorsement, recommendation, or favoring by the United States Government or any agency thereof. The views and opinions of authors expressed herein do not necessarily state or reflect those of the United States Government or any agency thereof. 


\section{DISCLAIMER}

Portions of this document may be illegible in electronic image products. Images are produced from the best available original document. 


\begin{abstract}
A comprehensive literature assessment has been conducted to determine the nature and scope of technical information available to characterize the seismic performance of an underground repository and associated facilities. Significant deficiencies were identified in current practices for prediction of seismic response of underground excavations in jointed rock. Conventional analytical methods are based on a continuum representation of the host rock mass. Field observations and laboratory experiments indicate that, in jointed rock, the behavior of the joints controls the overall performance of underground excavations. Further, under repetitive seismic loading, shear displacement develops progressively at block boundaries.

Currently, there are only a few computational methods for the seismic analysis of jointed rock masses, and the models of joint deformation incorporated in them were developed from pseudostatic tests. The discontinuum computational analysis codes are largely untested for dynamic analysis, and the joint static deformation models have not been demonstrated to describe joint performance under dynamic conditions. The complexity of the dynamics of jointed rock indicates that joint deformation models and the related computer codes need to be verified by comparison with physical experiments on rock joints. In the context of the proposed siting of a repository at Yucca Mountain, the requirement is to conduct well-controlled tests on joints in tuff. The applied loads should simulate seismic load histories and spectra.

Field observations correlating seismicity and groundwater conditions have provided significant information on hydrological response to seismic events. However, lack of a comprehensive model of geohydrological response to seismicity has limited the transportability of conclusions from field observations.

Based on the literature study, matters requiring further research in relation to the Yucca Mountain repository are identified. The report focuses on understanding seismic processes in fractured tuff, and provides a basis for work on the geohydrologic response of a seismically disturbed rock mass.
\end{abstract}





\section{TABLE OF CONTENTS}

\section{Page}

ABSTRACT $\ldots \ldots \ldots \ldots \ldots \ldots \ldots \ldots \ldots \ldots \ldots \ldots \ldots \ldots \ldots \ldots \ldots \ldots$

LIST OF FIGURES $\ldots \ldots \ldots \ldots \ldots \ldots \ldots \ldots \ldots \ldots \ldots \ldots$

LIST OF TABLES $\ldots \ldots \ldots \ldots \ldots \ldots \ldots \ldots \ldots \ldots \ldots \ldots \ldots \ldots \ldots \ldots \ldots$

ACKNOWLEDGEMENTS ....................... xi

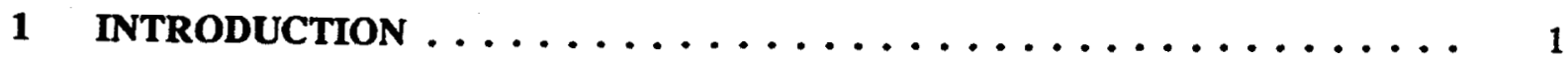

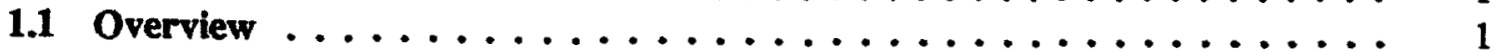

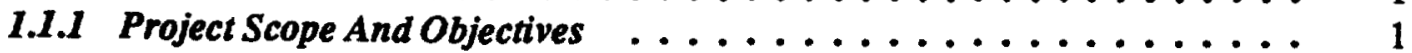

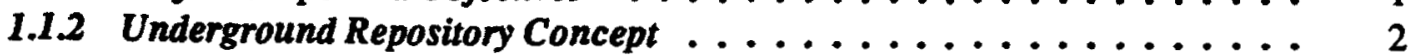

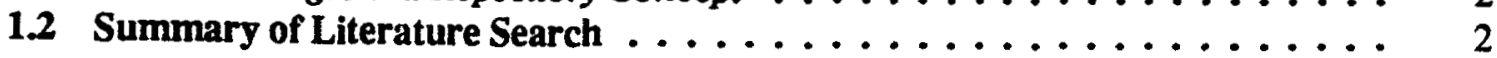

2 DESCRIPTION OF DESIGN PROBLEM ................ S

2.1 Basic Design Principles . . . . . . . . . . . . . . . . . . . . 5

2.2 Special Features of the Mixed Geologic Disposal System ... . . . . . . 7

2.3 Validation of Design Procedure . . . . . . . . . . . . . . . . 8

3 CHARACTERIZATION OF GROUND MOTION ............... 10

3.1 Source-Generated Ground Motion . . . . . . . . . . . . . . . . 10

3.2 Natural Earthquakes . . . . . . . . . . . . . . . . . . . 14

33 Underground Nuclear Explosions $\ldots \ldots \ldots \ldots \ldots$

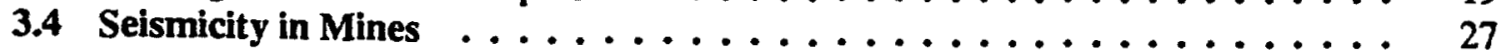

3.5 Comparison of Explosive and Seismic Ground Shock $\ldots \ldots \ldots \ldots$

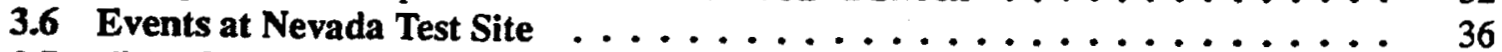

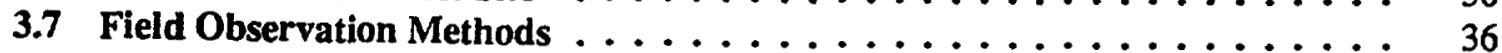

3.7.1 Ground Motion Measurements .................. 38

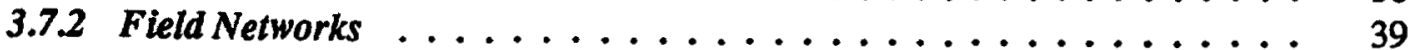

4 DYNAMIC PERFORMANCE OF UNDERGROUND FACILITIES . . . . 42

4.1 General Observations ......................... 42

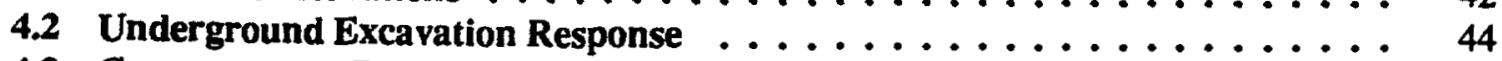

4.3 Contemporary Design Criteria ..................... 52

$5 \quad$ ROCK MASS PROPERTIES ....................... 54

5.1 Rock as an Engineering Medium .................... 54

5.2 Rock Material Properties . . . . . . . . . . . . . . . . . 54

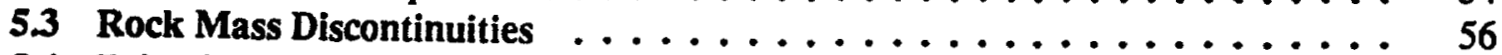

5.4 Behavior of Discontinuous Rock Masses ................ 66

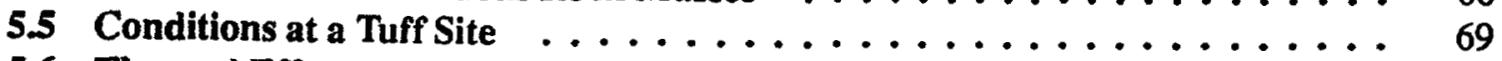

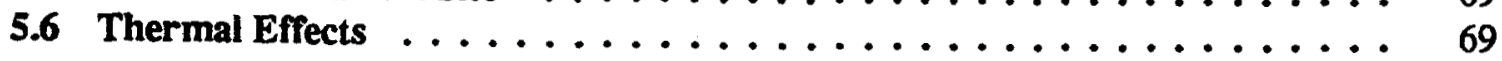




\section{TABLE OF CONTENTS (CONT'D)}

Page

6 GROUNDWATER RESPONSE TO DYNAMIC EVENTS . . . . . . . . . . 76

6.1 General Observations ......................... 76

6.2 Soil Liquefaction ............................... 79

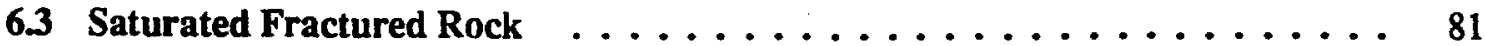

6.4 Unsaturated Porous and Fractured Rock ................ 81

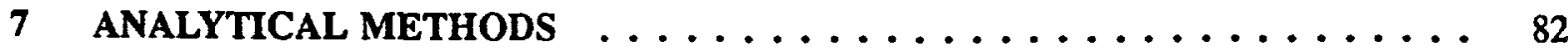

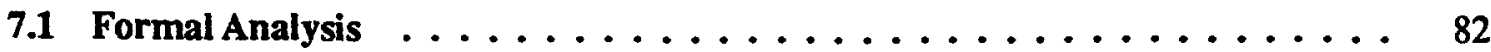

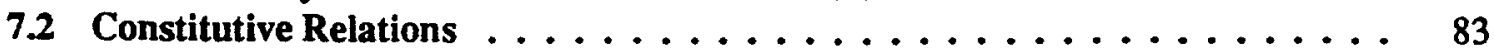

7.3 Computational Dynamic Analysis of Granular Media . . . . . . . . . 84

7.4 Computational Dynamic Analysis of Rock Masses . . . . . . . . . . 85

7.5 Soil-Structure Interaction Analysis ... . . . . . . . . . . . 88

7.6 Computer Programs for Dynamic Analysis . . . . . . . . . . . . . . . 90

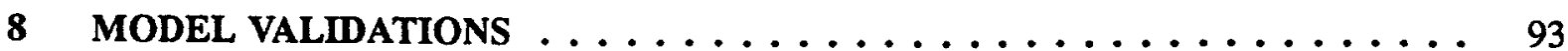

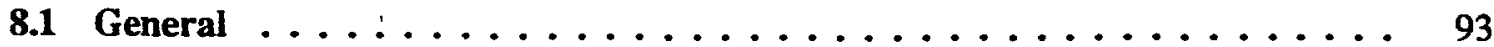

8.2 Full Scale Studies . . . . . . . . . . . . . . . . . . . . . 93

8.2.1. Related Component Validations . . . . . . . . . . . . . . 93

8.2.2 Underground Nuclear Test for Tunnels . . . . . . . . . . . . 99

8.3 Scale Model Studies . . . . . . . . . . . . . . . . . . . . . . . . . . 99

8.4 Requirements for Dynamic Validation . . . . . . . . . . . . . 105

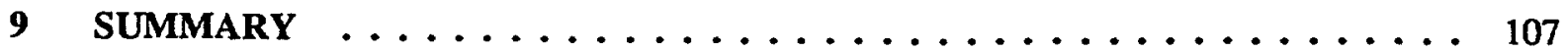

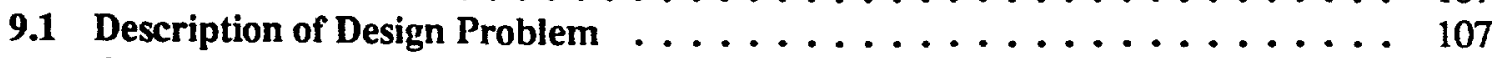

9.2 Ground Motions from Earthquakes and Explosions . . . . . . . . . . . . 108

9.3 Seismic Performance and Design of Underground Facilities . . . . . . . . . 109

9.4 Rock Mass Properties . . . . . . . . . . . . . . . . . . . . . 110

9.5 Groundwater Response $\ldots \ldots \ldots \ldots \ldots \ldots \ldots \ldots$

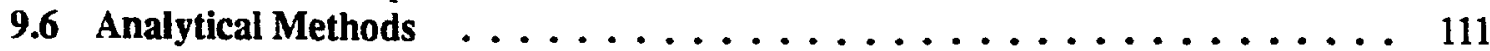

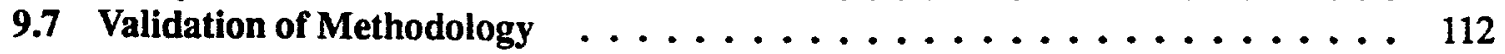

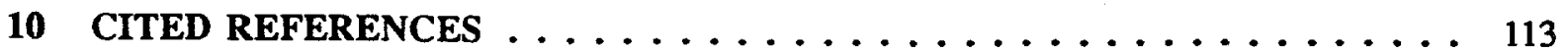

APPENDIX A - ADDITIONAL BIBLIOGRAPHY . . . . . . . . . . . . . 129

APPENDIX B - LIST OF ROCK MECHANICS COMPUTER CODES (REF) — _ . 157 


\section{LIST OF FIGURES}

Figure

Page

1.1 Perspective of the Proposed Yucca Mountain Repository (From Site Characterization Plan, Draft, DOE/RW-0160, 1988)

2.1 Typical Panel Layout for Vertical Emplacement (From Site Characterization Plan, Draft, DOE/RW-0160, 1988) . . . . . . . . . . 6

3.1 Fracture Surface. An earthquake is the fracturing of the rocks along a fault plane. If the fracture reaches the ground surface a visible ground fracture line is created. The hypocenter is the point on the fracture surface where the earthquake begins; the epicenter is at the ground surface, directly over the hypocenter. (From Gere and Shah, 1984) . . . . . . . .

3.2 Seismic Waves. The $P$ and $S$ waves are body waves that radiate outward in all directions from the places where fractures are occurring. The first motion you feel during an earthquake is usually the $p$ wave. Surface waves travel along the surface, somewhat like water waves, and typically arrive after the $\mathrm{P}$ and $\mathrm{S}$ waves. (From Gere and $\mathrm{Shah}, 1984) \ldots \ldots \ldots$

3.3 Modes of Travel for Seismic Waves (From Asmis, 1984 and Bolt, 1978) . .

3.4 Taft, Calif., Accelerogram Record of Arvin-Tehachapi, Calif., Earthquake, July 21,1952 . Earthquake recorded approximately 30 miles from center of fault. Magnitude, $M=7.7$ (Data from U.S. Coast and Geodetic Survey) . .

3.5 Horizontal Control Motion Accelerograms (Normalized to $0.5 \mathrm{~g}$ ) (From

Luco, et al, 1986) ........................

3.6 Response Spectra of Horizontal Components of Control Motions (Normalized to $0.5 \mathrm{~g}$ ), Damping $=0.02$ (From Luco, et al., 1986) . . . . . 18

3.7 Calculated Time Histories at Specified Depths (From Asmis, 1984) . . . . 20

3.8 Vertical Distribution of Maximum Accelerations at the Kannonzaki Site (From Asmis, 1984, and Iwasaki, et al., 1977) . . . . . . . . . . . 2

3.9 Peak Acceleration versus Depth for ' $P$ ' and ' $S$ ' Waves (From Asmis, 1984) .

3.10 Acceleration vs Time for Fondutta Underground Nuclear Event (From

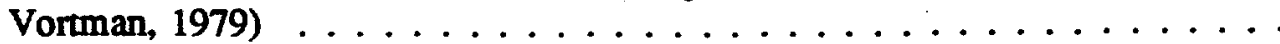

3.11 Pseudo Relative Response Velocity for Fondutta Underground Nuclear Event (From Vortman, 1979) . . . . . . . . . . . . . . . . . . . . . . 


\section{LIST OF FIGURES (CONT'D)}

Figure

Page

3.12 Ratio (Top/Bottom) for Peak Vector Acceleration Plotted vs Station Depth (From Vortman and Long, 1982) . . . . . . . . . . . . . . .

3.13 Ratio (Top/Bottom) for "Vector" PSRV Mean Values Plotted vs Station Depth (From Vortman and Long, 1982) . . . . . . . . . . . . . . .

3.14 Conditions for Stability and Instability in a Loaded Element of Rock Arising from Brittle Fracture (From Cook, 1965, and Salamon, 1970)

3.15 Relation Between Frequency of Rock Bursts, Local Ground Conditions, and Energy Release Rate in Longwall Mining of Gold Reefs (From Cook, 1978)

3.16 Conditions for Stable and Unstable Slip in a Single-Degree-of-Freedom Spring-Slider Fault Model (From Rice, 1983)

3.17 Retrospective Analysis of a Large Seismic Event in Terms of Excess Shear Stress (From Ryder, 1987) $\ldots \ldots \ldots \ldots$

3.18 Acceleration as a Function of Period for the $1940 \mathrm{El}$ Centro Earthquake and a Buried 1MT Nuclear Event (From Pratt, Hustrulid, and Stephenson, 1978)

3.19 Comparison of PSRV's for Vertical Component for Earthquake and Underground Nuclear Event C (From Vortman, 1982) . . . . . . . . . . .

3.20 Comparison of PSRV's for Horizontal Component for Earthquake and Underground Nuclear Event C (From Vortman, 1982) . . . . . . . . . . . .

4.1 Ratio of In-Situ Strength to Laboratory Strength as a Function of Tunnel Diameter to Joint Spacing (From Hendron and Aiyer, 1972) . . . . . . . .

4.2 Calculated Peak Velocities and Associated Damage Observations for Earthquakes (From Owen and Scholl, 1981) . . . . . . . . . . .

4.3 Calculated Peak Surface Accelerations and Associated Damage Observations for Earthquakes (From Owen and Scholl, 1981) . . . . . . 49

4.4 Damage in Terms of Peak Ground Velocity (v) (From Lenhardt, 1988) . . . 51

5.1 Typical Results of a Uniaxial Compression Test on Rock (From Brady \& Brown, 1985)

5.2 Axial Force - Axial Displacement $\ldots \ldots \ldots \ldots \ldots \ldots$ 


\section{LIST OF FIGURES (CONT'D)}

Figure

Page

5.3 Shear Force - Shear Displacement (Solid Line) and Dilitation - Shear Displacement Curves for a Direct Shear Test on Graphite-Coated Joint (From Jaeger, 1971) . . . . . . . . . . . . . . . . . . . . . .

5.4 Typical Peak and Residual Shear Strength Envelopes . . . . . . . . . . 60

5.5 Coulombic Friction Linear Deformation Model for a Joint: (a) Normal Deformation, (b) Shear Deformation, (c) Shear Strength (From Crotty \& Wardle, 1985)

5.6 Properties of the Barton-Bandis Joint Model: (a), (b) Normal and Shear Deformation (From Barton, et al., 1985); (c) Nonlinear Shear Strength Envelope (From Brady \& Brown, 1985); (d) Hysteresis on Cyclic Shear Loading (From Barton, 1988) . . . . . . . . . . . . . . .

5.7 Exercising the Continuous-Yielding Joint Model: (a) a Single Load Reversal Cycle, (b) Cyclic Loading (From Lemos, 1987) . . . . . . . . . .

5.8 Summary of Constitutive Behavior for Sliding Friction, (a) and (b): Response to Step Changes of Velocity at Constant Normal Force, (c) and (d): Response to Step Changes in Normal Force at Constant Load Point Velocity (From Hobbs, 1988) . . . . . . . . . . . . . . . . . .

5.9 Physiographic Features of Yucca Mountain and Surrounding Region. Modified from SNL (1987) (From Site Characterization Plan, Draft, DOE/RW-0160, 1988)

5.10 Correlation Between the Thermal/Mechanical Stratigraphy and the Geologic Stratigraphy. Modified from SNL (1987) (From Site Characterization Plan, Draft, DOE/RW-0160, 1988)

6.1 Hydrograph of a Well Near Perry, Florida, Showing Fluctuation Caused by the Alaskan "Good Friday" Earthquake, March 27, 1964 (From Bredehoeft, et al., 1987)

6.2 Hydrographs of Four Observation Wells at Parkfield Which Show the Water Level Declines Caused by the August 4, 1985, Kettleman Hills Earthquake (From Bredehoeft, et al., 1987) . . . . . . . . . . . . .

8.1 Comparison of Experimental and Theoretical Response of Super Lean Grout Hydrostatic Compression (From Butters, et al., 1974) 


\section{LIST OF FIGURES (CONT'D)}

Figure

8.2 Comparison of Experimental and Theoretical Deviatoric Stress-Strain Response for Super Lean Grout Under Triaxial Loading Conditions at Confining Pressures of 0 and 4 kbar (From Butters, et al., 1974)

8.3 Potentially Damaging Effects of Block Motion to a Deep-Based Facility Caused by Surface Explosion (From Blouin, 1984)

8.4 Jointed Model Configurations (From Rosenblad, 1971) . . . . . . . . . . 101

8.5 Design of Frame for Plain Stress Loading of Jointed Rock Mass with Tunnel (From Goodman, Heuze, and Bureau, 1972) . . . . . . . . . . . . 102 


\section{LIST OF TABLES}

No.

Title

Page

1.1 Data Bases Searched for Rock Mechanics/Seismic Information . . . . . . . . 4

3.1 Seismic Magnitude Parameters (Housner \& Jennings, 1982) . . . . . . . . . 16

3.2 Data for Earthquake at Nevada Test Site (Vortman and Long, 1982) . . . . 37

3.3 Sensing Elements for Ground Motion and Shock Parameters . . . . . . . . 39

4.1 Summary of Rockburst Damage to Underground Excavations (Wagner, 1984) . . . . . . . . . . . . . . . . . . . 50

5.1 Mechanical Properties of Intact Rock for Thermal/Mechanical Units at Yucca Mountain (From Site Characterization Plan, Draft, DOE/RW-0160, 1988) . . . . . . . . . . . . . . . . . . . .

5.2 Mechanical Properties and Modeling Parameters for Fractures in Thermal/Mechanical Units at Yucca Mountain (From Site Characterization

5.3 Mechanical Properties of the Rock Mass for Thermal/Mechanical Units at Yucca Mountain (From Site Characterization Plan, Draft, DOE/RW-0160, 1988)

8.1 Summary of Investigations for Site Characterization (From Sues \& Short, 1986)

8.2 Significant Variables for Jointed Rock Mass Failure under Plane Stress (From Rosenblad, 1971) 100

8.3 Mechanical Properties of Rock Material (From Bakhtar and DiBona, 1985) . . 104 


\section{ACKNOWLEDGEMENTS}

The authors are indebted to the patience and untiring efforts of people who contributed significantly to the material in and the preparation of this report. By its very nature, a preponderance of literature sources were sought, ordered, perused, and summarized for inclusion in the report. We appreciate and gratefully acknowledge Biswajet das Gupto and Sui-Min Hsuing for their technical contributions; and Wanda Owens, Bonnie Garcia, Donna Alexander, Alana Woods, Corky Gray, Kathy Sikora, and Amy Pratt for their help in typing, assembling, editing, and proofing. 


\section{INTRODUCTION}

\subsection{Overview}

This document represents a state of the art review for seismic and geomechanics aspects applicable to design considerations of the Yucca Mountain Site high level nuclear waste repository. It represents the results of Task 1 for the Seismic Rock Mechanics Project, which is being conducted by the Center For Nuclear Waste Regulatory Analyses (CNWRA) in support of the licensing activities of the Nuclear Regulatory Commission (NRC).

\subsubsection{Project Scope and Objectives}

Literature reviewed in this document has been selected primarily to enable the CNWRA, and therefore the NRC, to develop the technical capability and the necessary experimental data to review the Department of Energy submittals to the NRC for seismic effects on the long-term performance of underground repository structures. Generally this includes the following objectives:

(1) To obtain an understanding of the important parameters associated with the response of shaft liners and underground repository structures in tuff due to seismic motion. This objective supports the requirements of 10CFR60 for repository design, safe operations, waste retrievability options, and integrity of the engineered barriers.

(2) To obtain an understanding of the alterations of the groundwater regime and modification of the permeability and flow patterns by seismic events. This objective supports the waste containment and release rate requirements of 10CFR60. Here the long-term postclosure hydrological conditions in the vicinity of the repository and its various components are evaluated.

(3) To develop methodologies to evaluate, validate, and reduce uncertainties in the prediction models used in seismic assessment of tuff media. This objective is directed toward decreasing the uncertainties in predicting the pre-closure and post-closure seismic performance of the repository tuff medium.

Furthermore, specific objectives of the Seismic Rock Mechanics Project are as follows:

- To develop a good understanding of the information currently available on the seismic effects on underground structures.

- To evaluate the extent and nature of instrumented field studies now being conducted in tuff-type materials.

- To assess critically the capabilities and limitations of analytical and numerical modeling methods currently in use.

- To demonstrate by experimental physical model studies the degree of validity of the analytical and numerical models used for seismic analysis in a tuff media. 
- To identify and assess the key seismic-related parameters that are applicable to the Yucca Mountain Site.

- To develop technical data for preparing licensing positions as they relate to effects of seismic action on the underground repository in a tuff medium.

Therefore, this report presents a discussion of pertinent information which forms the basis for subsequent tasks of the Seismic Rock Mechanics Project.

\subsubsection{Underground Repository Concept}

A conceptual description of the Yucca Mountain repository system is shown in Figure 1.1, which is taken from Chapter 6 of the Site Characterization Plan, Consultation Draft (Jan. 1988). This document describes various aspects of the overall design of the repository, and is especially useful herein to indicate the parts of the overall design which are being addressed by the Seismic Rock Mechanics Project. The system can be seen to contain 1) central surface facilities which are designed to accept shipments of waste and provide maintenance capabilities; 2) underground facilities which provide the storage area for waste material canisters; and 3) a tuff pile which consists of a surface deposit of the material excavated to form the underground facilities and their access paths.

From the Site Characterization Plan it may be deduced that several components of the system are subject to seismic design considerations. Shafts and boreholes are nearly-vertical holes which may or may not be lined, and provide access to lower levels to transport materials or equipment. Tunnels, drifts, or ramps are nearly-horizontal underground rooms or passageways that also may or may not be lined, and form the main storage area, or provide access to and from this area. Various surface buildings can be important to safety. Ventilation systems must provide life support and remove heat generated by the waste material. A series of mechanical conveyors for both personnel and material are included. Finally a variety of miscellaneous equipment is necessary for operation of the facility.

Although the seismic resistance of all of the above components must be considered in design, generally the adequacy of supported equipment can be determined by procedures similar to those prescribed in IEEE Standard 344 (June 1987) for electrical equipment, and in ASME Standard for Mechanical Equipment (1986) for mechanical equipment. Furthermore, design of surface buildings can be accomplished according to various well-known structural standards and codes. On the other hand, seismic design of the first two categories of components which are constructed in a faulted, jointed, and fractured rock mass and include underground structural supports, is not very well developed and therefore is the primary subject addressed in the Seismic Rock Mechanics Project. It is also then the primary subject of this report. Furthermore, because of their close relation with ground shock design, response to rockburst and underground explosions is also included.

\subsection{Summary of Literature Search}

A literature search was performed on the databases enumerated in Table 1.1 using the query: "Effects of Seismic/Tectonic Activity on Underground Structures in Rock or Tuff Media." Out of over 800 abstracts requested and reviewed, 133 papers were ordered and perused for applicability to the Yucca Mountain sites. Other articles came from perusal of the authors' files or from the reference listings of the Consultation Draft of the Site Characterization Plan, Yucca Mountain Site, Nevada Research and Development area, Nevada (DOE/RW-0160). Additional articles of interest arose from contacts with NRC personnel and special committees of national technical societies. Sources cited in this 
$\omega$ OPERATIONS ARTE (SUDSURF ACE)

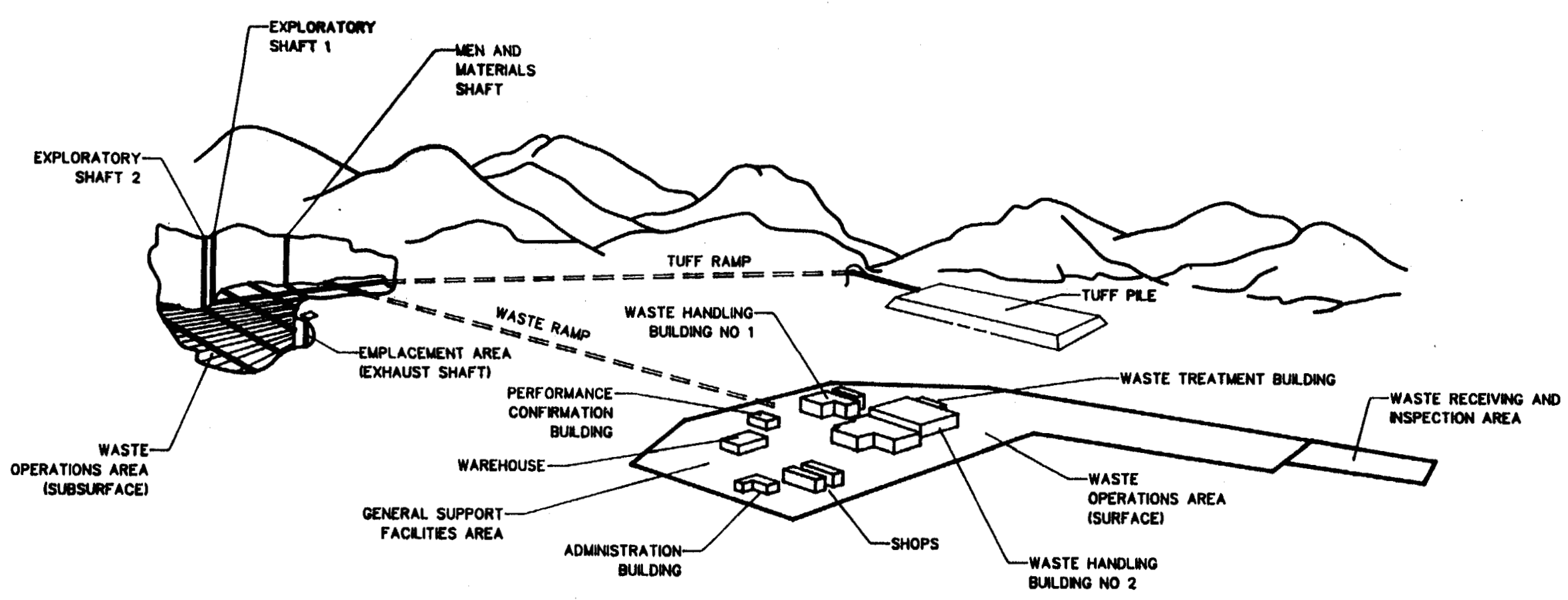

FIGURE 1.1

PERSPECTIVE OF THE PROPOSED YUCCA MOUNTAIN REPOSITORY (FROM SITE CHARACTERIZATION PLAN, DRAFT-DOE/RW-0160, 1988) 
Table 1.1 Data Bases Searched for Rock Mechanics/Seismic Information

Data Bases Searched

NTIS

COMPENDEX PLUS

GEOARCHIVE

GEOREF

NUCLEAR SCIENCE ABST.

DOE ENERGY

ENERGY LINE

GEO BASE

GEOMECHANICS

\section{Papers w/Abstracts}

179

55

13

146

36

394

5

2

6

\section{Query:}

Effects of Seismic/Tectonic activity on underground structures in rock or tuff media.

review are listed in Section 10, while Appendix A constitutes an enumeration of additional articles considered or perused. Critical reviews were conducted on all articles from the computer search and entered along with all cataloguing information and abstracts into a digital computer retrieval system.

During the literature search it was found that several reviews of certain parts of the overall subject of seismic design of underground structures had already been published. However, none of these reviews covered the complete range of topics appropriate for this report. The emphasis for this report will be on the state of the art, particularly on methods whereby analytical response predictions can be validated by independent experiments. 


\section{DESCRIPTION OF DESIGN PROBLEM}

\subsection{Basic Design Principles}

Current planning for isolation of high-level nuclear waste involves its emplacement in a repository or Mined Geologic Disposal System at a site at Yucca Mountain, Nevada. The site consists of a layered sequence of welded, non-welded and bedded tuff. The unit nominated as the waste emplacement horizon is the welded ash-flow portion of the Topopah Spring Member of the Paintbrush Tuff. At this horizon, the rock mass is unsaturated, with the water table $200 \mathrm{~m}$ to $400 \mathrm{~m}$ below the emplacement horizon (U.S. DOE, 1988). In this medium, it is anticipated that conventional practices for underground design and construction in hard-rock mining will provide stable underground excavations.

Geomechanical conditions at the emplacement horizon are characterized by a competent rock material, prominent vertical and sub-vertical jointing, and faults which transgress the site environs (Johnson, 1986, et al., Johnstone, et al., 1984, St. John, 1987, and Thomas, 1980). These include the Bow Ridge, Paintbrush, Ghost Dance, Midway Valley and Severe Wash faults. Detailed site investigation during repository construction may reveal other faults and prominent structural features. In geomechanical terms, the conditions described for the repository domain are in no way exceptional relative to underground hard-rock mining experience.

The conceptual design for the repository resembles a room-and-pillar mine in a shallow dipping orebody. A general isometric view of the underground facilities is shown in Fig. 1.1, and a detailed plan view of a repository panel is shown in Fig. 2.1. Independently of whether canister emplacement holes are oriented vertically or horizontally, by mining standards the area extraction ratio over the repository horizon will be low, probably less than $20 \%$.

Irrespective of the type of operation to be conducted in an underground mine or similar excavated rock structure at depth, there are four common geomechanics objectives for the performance of the structure (Brady and Brown, 1985):

(a) to ensure the overall stability and integrity of the complete rock structure, defined by mine excavations, pillar support elements, and adjacent country rock;

(b) to protect the major service openings throughout their designed duty life;

(c) to provide secure access to safe working places in and around centers of operating activity; and

(d) to preserve the integrity of and limit disruption to the host rock mass.

In the case of a mined geologic disposal system, achievement of these objectives will serve other purposes, such as restriction of disruption to the natural environment, and inhibition of surface subsidence over the repository domain. 


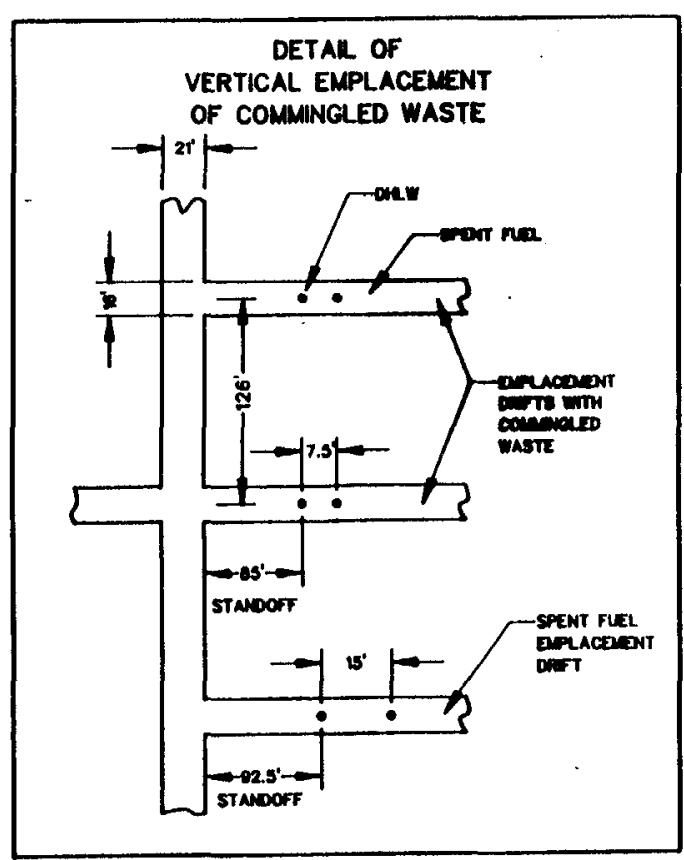

OHWW - DEFENGE HeH LEVEL WASTE

- $=0$

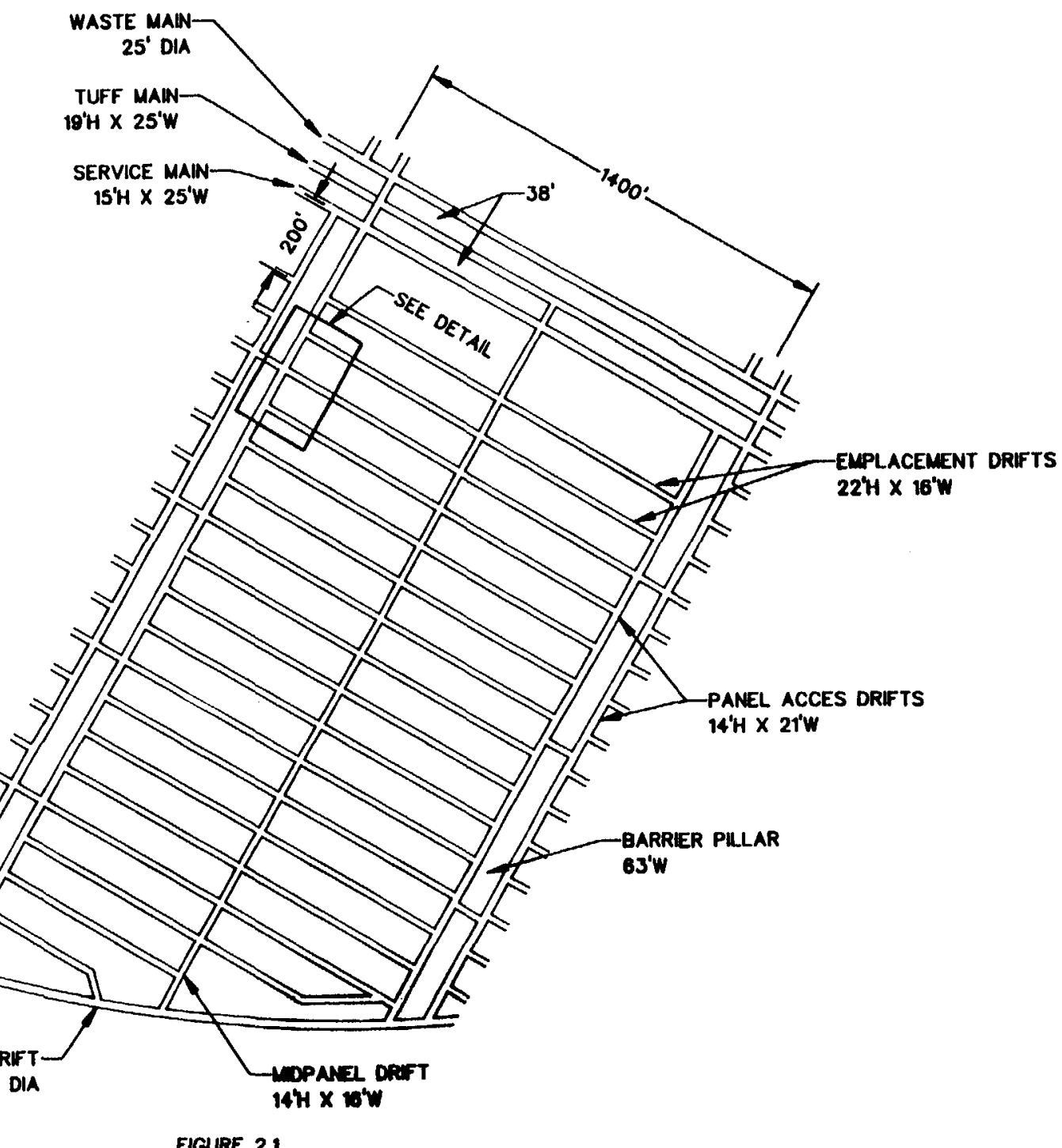

FIGURE 2.1

TYPICAL PANEL LAYOUT FOR VETTOAL EVPACENENT

(FROM SITE CHARACTERIZATION PLAN, DRAFT-DOE/RW-0160, 1988) 
The objectives noted above are not mutually independent, and many other performance objectives must be satisfied in terms of equipment operation, ventilation, environmental impact, drainage, scheduling and cost, for example. However, considering the geomechanics objectives separately, they may be realized from a comprehensive knowledge of the geotechnical conditions in the mine area, and a capacity for analysis of the response of the rock mass to excavation activity within it. The adequacy of these practices is affirmed by the success of mining operations under a broad range of site conditions, mining methods, and extraction ratios.

\subsection{Special Features of the Mined Geologic Disposal System}

Despite the similarity between an underground mine and a mined geologic disposal system, some substantial differences exist in design practice because of the nature of nuclear waste, the time scale required for effective waste isolation, and the legal and regulatory environment in which waste isolation is to be engineered and managed. Sections of Part 60 of Title 10 of the Code of Federal Regulations (10CFR60) direct specific attention to technical criteria, performance objectives and design criteria which impose particular requirements in repository design and performance assessment. Compliance with 10CFR60 Regulations in general leads to a need for more extensive site characterization, consideration of a wider range of factors influencing long-term behavior of the site, and more comprehensive analysis of the performance of the site under both operating and post-closure conditions. These include geomechanics issues which arise from the regulatory environment pertaining mainly to citations concerning performance objectives related to safety, retrievability, system performance and performance of particular barriers after permanent closure. For example, 10CFR60.111(a) cites the need to assure protection, through permanent closure, against radiation exposures and releases of radioactive material. Retrievability of waste is required in the citation 10CFR60.111(b). It specifies that the geologic disposal system should be designed so that any or all of the emplaced waste could be retrieved starting at any time up to 50 years after waste emplacement is initiated. Overall system performance after permanent closure is cited in 10CFR60.112, and required performance of particular barriers after permanent closure is cited in 10CFR60.113. Interaction between the host rock mass and the waste canisters, and long-term geomechanical performance of the host rock mass, impinge directly on these performance objectives. Compliance with the regulatory citations related to safety, retrievability and long-term repository performance therefore requires analysis of the performance of the components of the system. It is generally accepted that numerical analysis will play a major role in performance assessment studies of the type required to demonstrate compliance.

In specifying suitable, site conditions for a repository, 10CFR60.122 specifically requires consideration of natural phenomena and site conditions which could adversely affect achievement of the prescribed performance objectives. An important phenomenon which could conceivably affect both the short- and long-term performance of a repository is ground motion due to seismic activity. Similarly, ground motion due to underground nuclear explosions at the Nevada Test Site needs to be evaluated. Conceivably, ground motion from either source could cause rock displacements on the canister-, room- and repository-scales, any or all of which could violate the established repository

performance objectives. For example, joint slip in a canister hole associated with seismically-induced ground motion might prevent canister retrievability. Falls of rock in repository emplacement rooms could result in canister damage, and increase staff exposure to radiation. Disruption of the geologic barrier after permanent closure by fault or joint displacement could significantly increase the gross permeability of the rock mass (Obert, 1967). 
Evaluation of the effects of seismic events, both natural and explosion-induced, at the Yucca Mountain site can best be performed by definition of the likely ground motion associated with representative events, and by execution of analyses taking account of states of stress, rock material strengths and rock structural conditions at the various scales of interest in repository response. It is particularly important to account for rock structural conditions in the analyses, since the probable mode of rock response involves slip or separation on the planes of weakness, and rigid body translation and rotation of the rock blocks in the jointed mass.

In the analysis, computational schemes must be employed which will model the dynamic behavior of jointed rock to a prescribed engineering tolerance. In this regard, it is notable that dynamic soil-structure interaction schemes have been applied in the nuclear industry for some time. However, the nature of ground motion in the subsurface is different from that on the surface, and jointed rock exhibits constitutive behavior quite different from that of soil. Thus, experience gained in design analysis and performance prediction for surface structures founded on soil is not highly relevant to the problem of dynamic analysis of underground excavations in rock. Compared with the amount of attention devoted to dynamic analysis of ground structure interaction for surface structures, effort expended on observation and analysis of the dynamic performance of underground excavations and rock structures has been limited.

\subsection{Validation of Design Procedure}

In engineering practice, system design is based on a capacity to characterize the mechanical properties of the system components, and analysis to predict the performance of the system under the prescribed duty loads. Satisfactory performance in a design is associated with deflections or other modes of response calculated to be within a previously defined range of acceptability.

A key element of this design method is the existence of a validated analytical technique for prediction of system performance. In this context, a validated analytical technique is one which has been shown to predict system response to a tolerance which assures specified system performance. In most areas of engineering, validation of a design technique has resulted from application of the technique in retrospective analysis of documented case histories, and demonstration that the technique can predict, a priori, the behavior of a specific engineering system. In soil mechanics practice, such validation practice has been considered by Gibson (1974).

In rock mechanics practice', the need for validation of computational methods used in design of rock structures has been considered by Brady and St. John (1982), Bieniawski (1984), and Brown (1985), who observe that unvalidated codes are virtually useless. They propose that code validation by field observations, reconciling field observations with model predictions, is complicated in rock mechanics practice by poor definition of the initial conditions in a rock mass. In these circumstances, validation may be conducted best by seeking correspondence between results of a benchmark physical model test and numerical modeling of the test. There are now many examples of the validation of computer codes in this way, one of which is provided by the Q.A. exercise on the code FLAC (Itasca, 1987a).

The particular need for validation of codes for dynamic analysis of underground excavations for nuclear waste isolation arises from the comparative novelty of the codes, the complexity of the processes involved in deformation of block-jointed media, and prevailing questions about the adequacy of the constitutive relations describing the dynamic behavior of rock joints and faults. There is also a stringent need, in geoengineering for underground isolation of waste, to ensure that 
computer codes can represent physical reality tolerably, independent of any questions about a capacity to characterize a rock mass or repository site adequately. For this reason, the main emphasis in validation of codes for dynamic analysis of repository design problems must be placed on execution of dynamic physical model tests, and related computational analysis. 


\section{CHARACTERIZATION OF GROUND MOTION}

\subsection{Source-Generated Ground Motion}

In seeking to understand the dynamic behavior of underground facilities, a basic requirement is a formal description of the transient ground motion generated by the energy sources anticipated to affect that design. The source of dynamic loading may be natural earthquakes, conventional or nuclear underground explosions, or induced seismicity due to mining, fluid injection or withdrawal, or rockbursts. In the simplest treatment, energy transmission from such sources in geologic media may be represented by a damped, elastic progressive wave (Desai and Christian, 1977), for which the governing principles have been described by Kolsky (1963) and Achenbach (1975). In the context of seismic wave interaction with underground excavations, ground motion has been reviewed in detail by Bolt (1978), Asmis (1984), and St. John and Zarah (1987).

For the purpose of this report, seismic disturbances within the earth will be considered for natural earthquakes, explosions, and rockbursts. A general description of the ground motions which occur as a result of such events is given in Figs. 3.1 and 3.2, (Gere and Shah, 1984). Energy release occurs at the underground hypocenter, or focus. For an earthquake, the energy is released by sudden rupture or movement of interacting surfaces which were subject to a gradual buildup of strain due to lockup and opposing creep at a ground fault of several possible types. For a rockburst, the source is excess sheer stress, generated by mining, acting on natural or induced planes of weakness. For an explosion, the energy source is chemical or nuclear. In each case the magnitude (amplitude) of the resulting disturbance depends on the amount of energy present in the source at the time of the release event.

Once energy release occurs, as shown in Fig. 3.2, seismic waves of several types emanate away from the hypocenter, and their character changes with distance of propagation, the type of material through which they pass, and interaction with the surface and other boundaries. Seismic waves associated with dynamic events are of two types: body waves and surface waves. Body waves account for energy transmission from its source in the interior of a rock mass, while surface waves are restricted to the vicinity of the ground surface. The transmission and generation of body and surface waves from an underground blast site are illustrated in Figs. 3.2, 3.3. It is shown that the disturbance is a source for P-waves (also called pressure or dilatational waves), in which the direction of particle motion is parallel to the direction of wave propagation, and $S$-waves (also called shear or transverse waves), in which the direction of particle motion is transverse to the direction of wave propagation. Along the transmission path, internal reflections and refractions due to cracks and variations in rock material properties lead to S-wave generation from the propagating $\mathrm{P}$-wave. A further property distinguishing $P$-waves from S-waves is in propagation velocity: for Poisson's ratio of $0.25, C_{s}=$ $0.58 C_{p}$ where $C_{p}$ and $C_{s}$ are $P$ - and S-wave propagation velocities respectively.

Surface waves originate on the ground surface, notionally at the epicenter, which is a point overlying the dynamic source, as indicated in Fig. 3.1. Two waves, with different propagation velocities and polarization, propagate radially from the epicenter surface source. In the Rayleigh wave, a surface particle executes retrograde motion in a vertical plane, as indicated in Fig. 3.3. The motion is that 


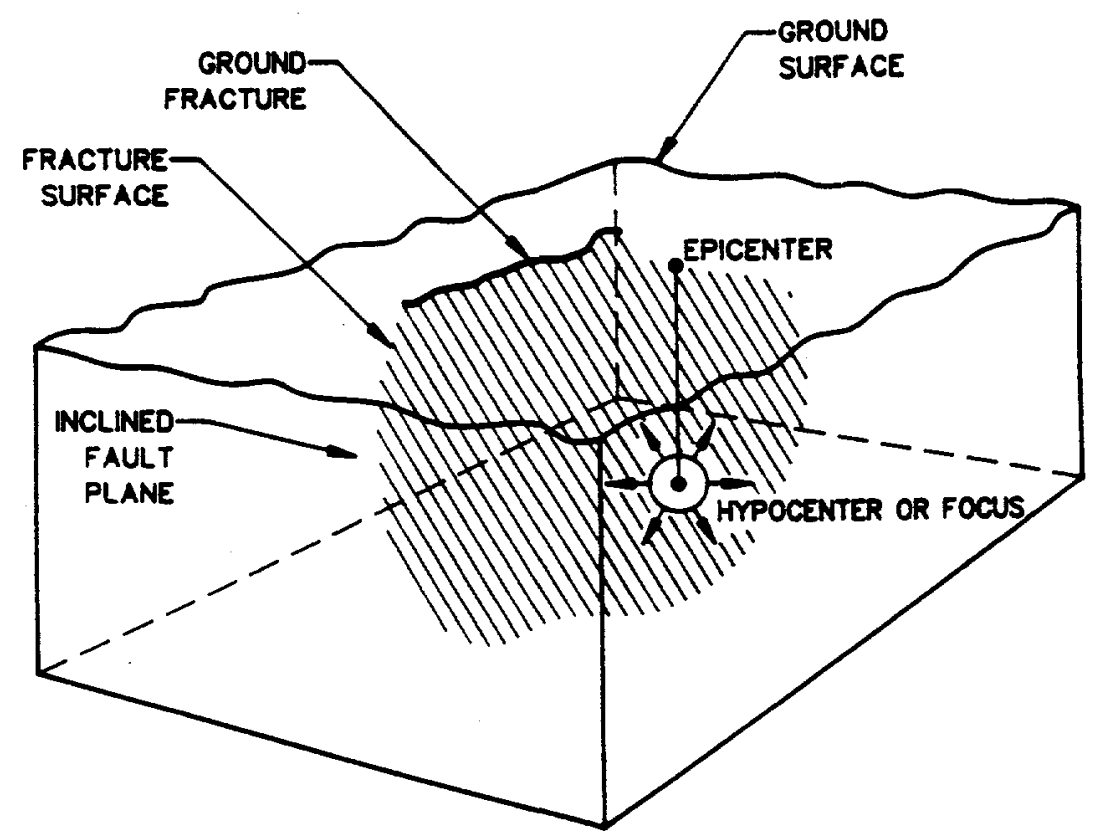

FIGURE 3.1

FRACTURE SURFACE. AN EARTHQUAKE IS THE FRACTURING OF THE ROCKS ALONG A FAULT PLANE. IF THE FRACTURE REACHES THE GROUND SURFACE, A VISIBLE GROUND FRACTURE LINE IS CREATED. THE HYPOCENTER IS THE POINT ON THE FRACTURE SURFACE WHERE THE EARTHQUAKE BEGINS; THE EPICENTER IS AT THE GROUND SURFACE, DIRECTLY OVER THE HYPOCENTER. (C 1984, J.M. GERE AND H.G. SHAH, FROM THE PUBLICATION TERRA NON FIRYA: UNDFRSTANDING AND PRAPARING FOR EARTHOUAKES.) 

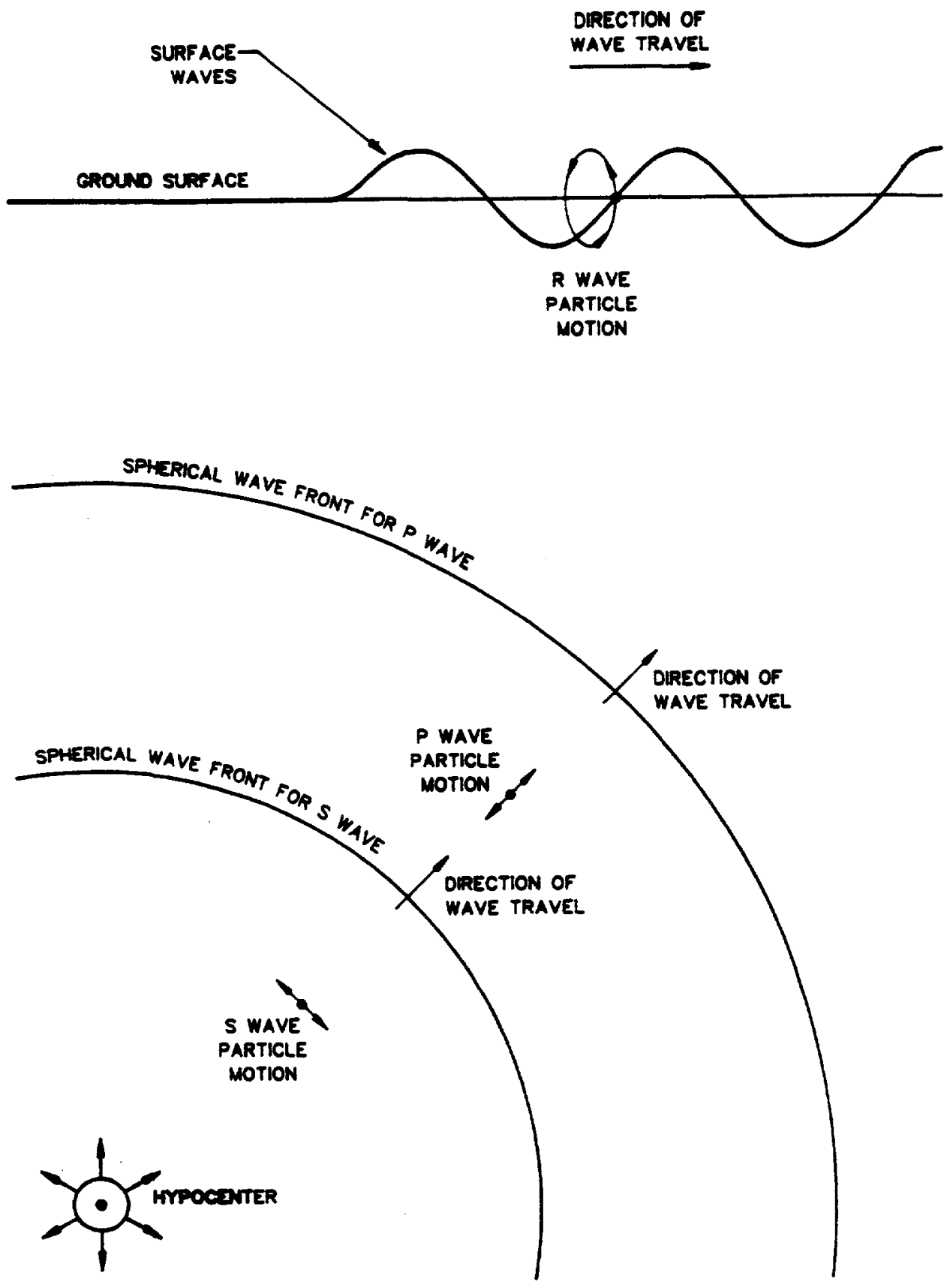

FIGURE 3.2

SEISMIC WAVES. P AND $S$ WAVES ARE BODY WAVES THAT RADIATE OUTWARD IN AIL DIRECTIONS FROM THE PLACES WHERE FRACTURES ARE OCCURRIKG. THE FIRST MOTION YOU FEEL DURING AN EARTHQUAKE IS USUALLY THE $P$ WAVE. SURFACE WAVES TRAVEL ALONG THE SURFACE, SOMEWHAT LIKE WATER WAVES, AND TYPICALLY ARRIVE AFTER THE P AND $S$ WAVES. (C 1984, J.M. GERE AND H.G. SHAH, FROM THE PUBLICATION TERRA NON FIRYA: UNDERSTANDING AND PRFPARING FOR EARTHOUAKES.) 


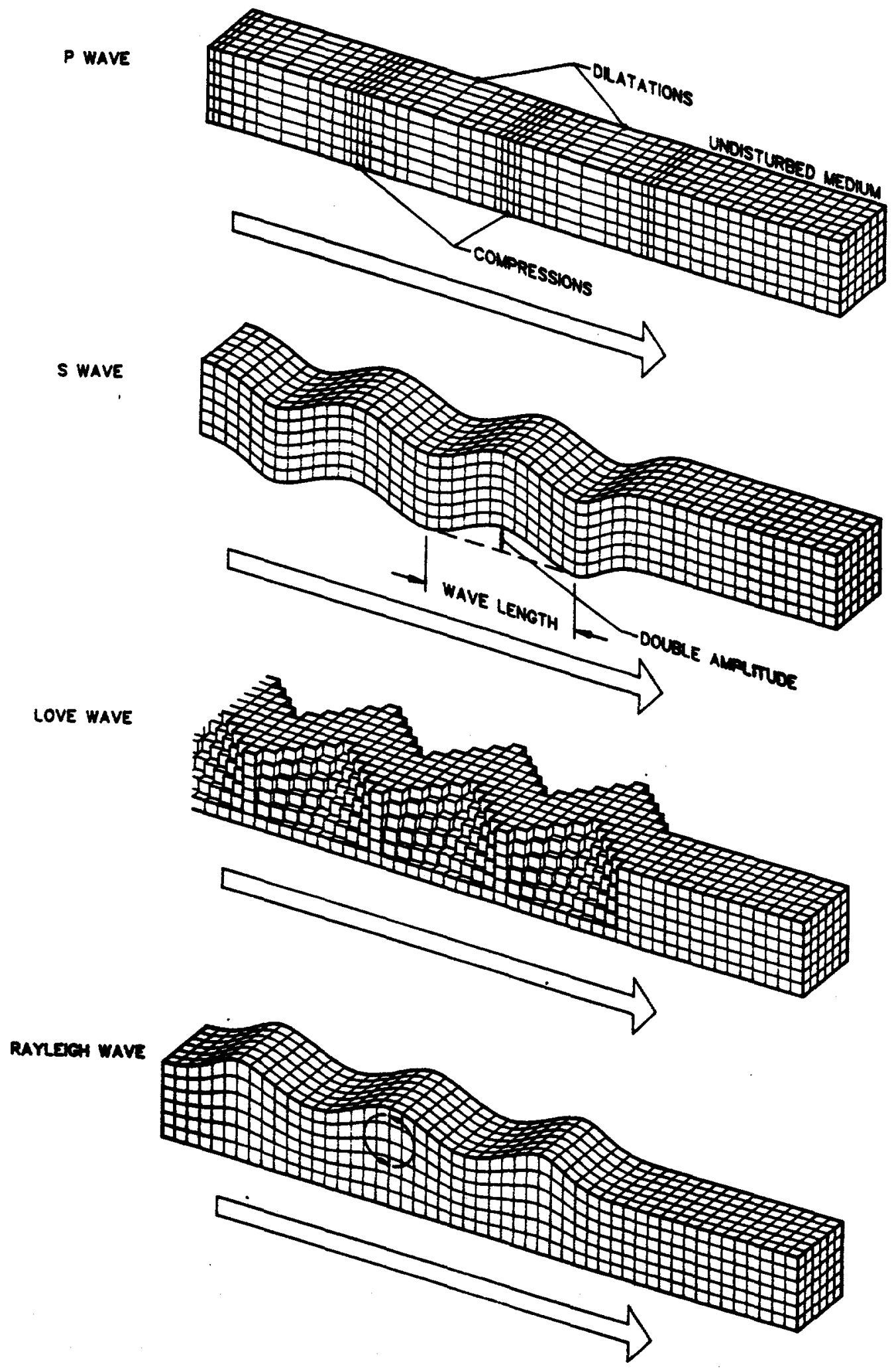

FIGURE 3.3

MODES OF TRAVEL FOR SEISMIC WAVES (REPRIMTED BY PERHISSION OF W.H. FREEKAN, FROM B.A. BOLT, ENRTHQUAKES, A PRIMER, 1978.) 
due to a coupled P- and SV- (vertically-polarized shear) wave. A Love wave is generated where a soft layer, such as soil or weathered rock, overlies a stiffer medium. Motion in the wave occurs in a flat ellipse, corresponding to coupled P- and SH-waves, as shown in Fig. 3.3. Rayleigh and Love waves are characterized by motion that dies out with depth, and distinguished by different propagation velocities. For the Love wave and a wavelength much less than the depth of the soft layer, $\mathrm{Cl}_{\mathrm{l}} \approx$ $\mathrm{C}_{s}$, where $\mathrm{C}_{\mathrm{s}}$ is the shear'wave velocity in the soft layer, and $\mathrm{C}_{\mathrm{l}}$ is the Love wave velocity. For Poisson's ratio of 0.25 , Rayleigh wave velocity is given by $C_{I}=0.92 C_{S}$.

An important feature of surface waves pointed out by Asmis (1984) is that, because propagation velocity and frequency are less than that for the subsurface body waves, conservation of energy leads to higher amplitude motion in a soft layer. For this reason, the ground motion experienced by surface excavations and structures is distinctly different from that experienced by subsurface facilities. This has substantial implications for underground mines and similar facilities, since the shaft collar or portal for an adit must be designed to tolerate more intense ground motion than subsurface excavations.

Various texts and papers are available which describe seismology of the resulting complex earth motions at various depths and distances from the hypocenter. Here, we will only summarize the ground motions in terms of how they form the excitation or dynamic input to underground facilities. That is, we will be interested in the various ways that the motion at a point can be described, so that its effects on underground facilities can be predicted. Much of the discussion follows that previously reported by Asmis (1984). In effect, at a given point in space within the earth, a time history of motions is formed by a complex combination of all the waves as they pass the given point in space. For example, an earthquake motion at the surface quite distant from the hypocenter can be of rather long duration and comprised of three dimensional multifrequency components, as shown in Fig. 3.4. However, several factors influence the exact nature of the motion, as will be described.

\subsection{Natural Earthquakes}

Quantification of ground motion due to a dynamic event such as an earthquake may be represented by several parameters, including magnitude, velocity and acceleration history, and response spectrum. Housner and Jennings (1982) describe the various magnitude parameters given in Table 3.1, the most common of which are local magnitude, $\mathrm{M}_{1}$; surface wave magnitude $\mathrm{M}_{\mathbf{s}}$; body wave magnitude $\mathrm{M}_{b}$; and the moment magnitude $\mathrm{M}_{w}$. Magnitude is related directly to energy released by an earthquake, which is determined by seismic moment, itself a function of area of the slip surface, shear stress drop, and rock mass shear modulus (Aki and Richards, 1980). Estimation of ground motion is based on locally applicable empirical relations which take account of field attenuation conditions. An example is provided by Seed and Idriss (1982).

An alternative presentation of the description of ground motion is provided by records of the time history of acceleration (such as Fig. 3.4), velocity, or displacement which are measured for a particular earthquake that occurs at a given site. Furthermore, given acceleration, the other records can be obtained by its successive mathematical integration. Regardless of what type of fault mechanism is involved, earthquake ground motion tends to be rather long in time duration, but the exact character is dependent on the distance to the hypocenter. The surface ground motion depicted in the accelerograms of Fig. 3.4 was pointed out to occur distant (i.e., $30 \mathrm{mi}$ ) from the hypocenter of the earthquake. They are similar in frequency content and duration to the first three accelerograms in Fig. 3.5, which also represent far-field earthquake surface motion (Luco, et al, 1986). Near-field 

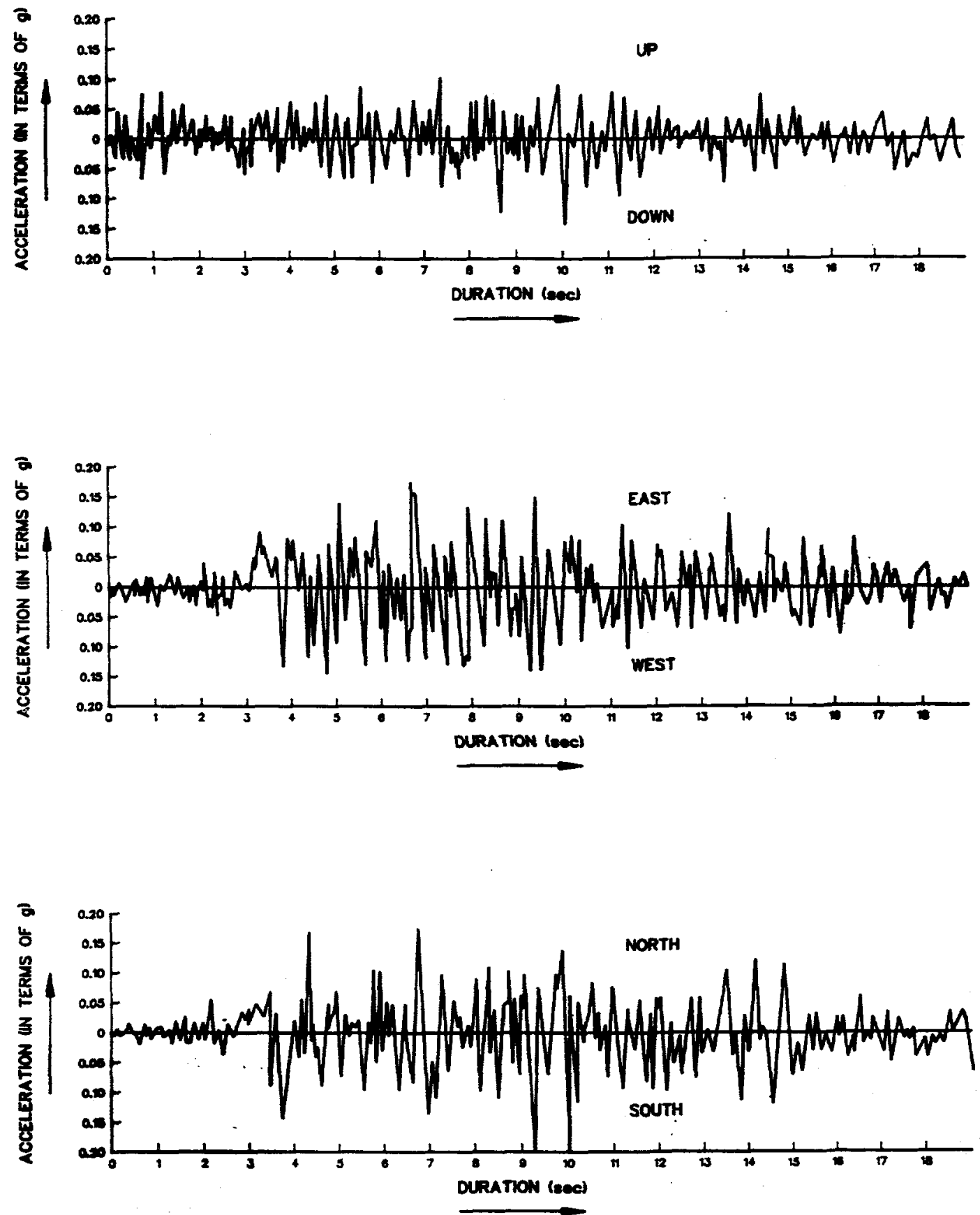

FIGURE 3.4

TAFT, CALIF., ACCELEROGRAM RECORD OF ARVIN-TEHACHAPI, CALIF., EARTHOUAKE. JULY 21, 1952. EARTHQUAKE RECORDED APPROXIMATELY 30 MILES FROM CENTER OF FAULT. MAGNITUDE, $M=7.7$.

(DATA FROM U.S. COAST AND GEODETIC SURVEY) 
Table 3.1 Seismic Magnitude Parameters

(Housner and Jennings, 1982)

\begin{tabular}{|c|c|c|}
\hline Magnitude & Definition & Application \\
\hline Local, ML & $\begin{array}{l}\text { Logarithm of peak amplitude (in microns) } \\
\text { measured on Wood-Anderson seismograph at } \\
\text { distance of } 100 \mathrm{~km} \text { from source and on firm } \\
\text { ground. In practice, corrections made to ac- } \\
\text { count for different instrument types, dis- } \\
\text { tances, site conditions. }\end{array}$ & $\begin{array}{l}\text { Used to represent size of moder- } \\
\text { ate earthquake. More closely re- } \\
\text { lated to damaging ground motion } \\
\text { than other magnitude scales. }\end{array}$ \\
\hline Surface wave, $M_{s}$ & $\begin{array}{l}\text { Logarithm of maximum amplitude of surface } \\
\text { waves with } 20 \text {-s period. }\end{array}$ & $\begin{array}{l}\text { Used to represent size of large } \\
\text { earthquakes. }\end{array}$ \\
\hline Body wave, $\mathrm{M}_{\mathrm{b}}$ & $\begin{array}{l}\text { Logarithm of maximum amplitude of } P \text { - } \\
\text { waves with 1-s period. }\end{array}$ & $\begin{array}{l}\text { Useful for assessing size of large, } \\
\text { deep-focus earthquakes which do } \\
\text { not generate strong surface } \\
\text { waves. }\end{array}$ \\
\hline Moment, $\mathbf{M}_{\mathbf{w}}$ & $\begin{array}{l}\text { Based on total elastic strain-energy released } \\
\text { by fault rupture, which is related to seismic } \\
\text { moment } M_{0}\left(M_{0}=G \cdot A \cdot D \text {, where } G=\right. \\
\text { modulus of rigidity of rock, } A=\text { area of fault } \\
\text { rupture surface and } D=\text { average fault dis- } \\
\text { placement). }\end{array}$ & $\begin{array}{l}\text { Avoids difficulty associated with } \\
\text { inability of surface wave magni- } \\
\text { tudes to distinguish between two } \\
\text { very large events of different fault } \\
\text { lengths (saturation). }\end{array}$ \\
\hline
\end{tabular}

ground motion is represented by the lower three accelerograms in this figure. Generally they are much shorter in duration, and more pulse-like.

A third method of characterizing ground motion takes account of the frequency content of the motion, by computation of the shock spectrum, or response spectrum (Clough and Penzien, 1975) for a seismic event. This parameter is defined as a plot of the maximum or peak response of a single degree of freedom, damped oscillator, as a function of its natural frequency for a given damping ratio. Acceleration response spectra are given in Fig. 3.6 for the various time histories presented in Fig. 3.5. Primary frequency content occurs in the amplified regions of each plot. It can be seen that the near-field ground motions tend to be higher in frequency content, although no information on duration can be obtained from the response spectrum. Thus, as is the case for application to surface structural design, use of the response spectrum for design of underground facilities is also limited to indication of frequency content and peak acceleration (or zero period acceleration) which occurs in the ground motion excitation. Furthermore, if the reciprocal of the basic frequency content (i.e., wavelength) of the transient is of the same order as the dimensions of the underground facilities, then phase information also becomes important, since the time history at one point on the structure can be different from that at another point on the structure. In this case a power spectral density and cross-spectral density (Bendat and Piersol, 1980) representation of the motion may be of use in a spectral description for describing the spatial variation of the excitation field. 


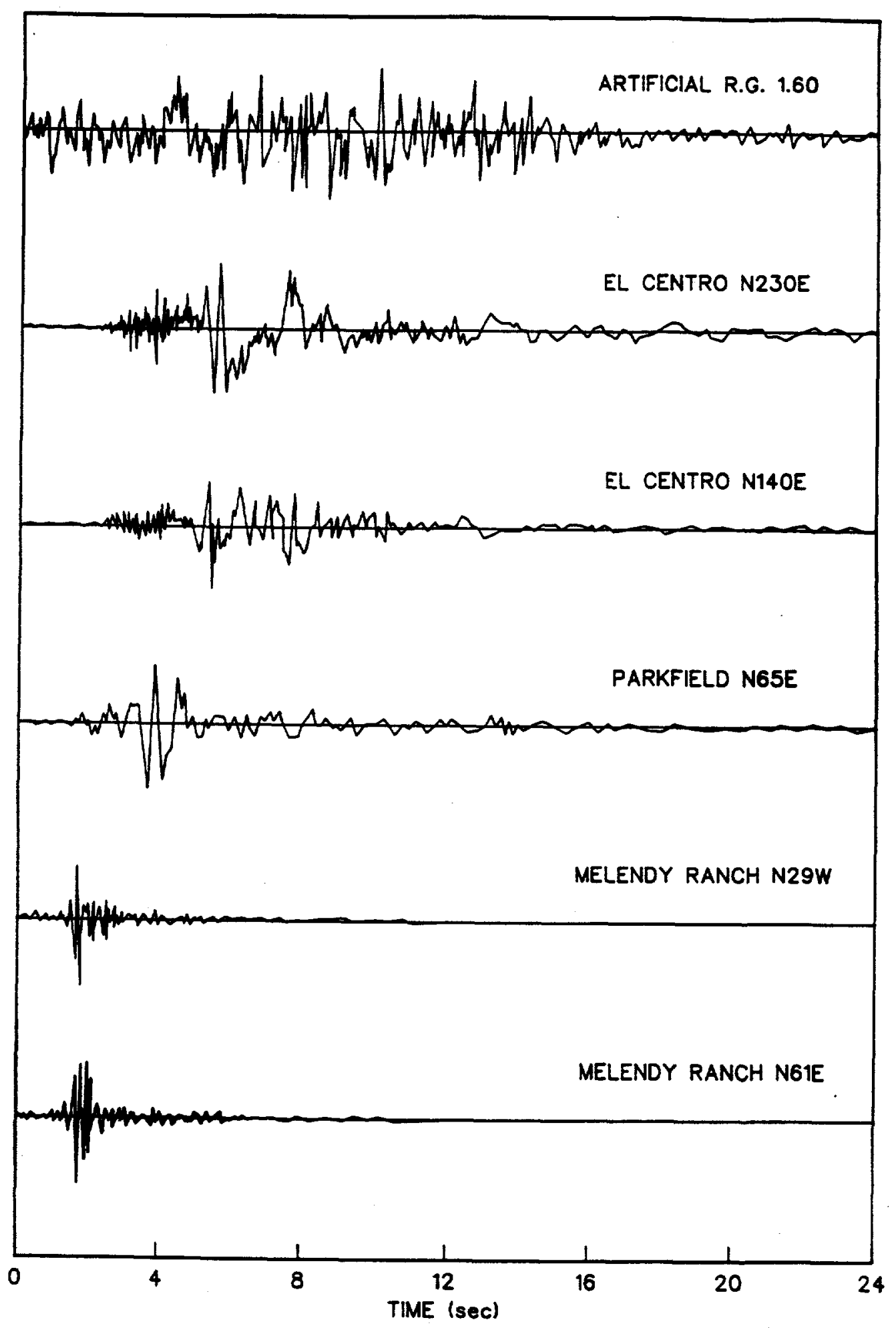

FIGURE 3.5

HORIZONTAL CONTROL MOTION ACCELEROGRAMS (NORMALIZED TO 0.5g) (FROM LUCO, et al, 1986) 

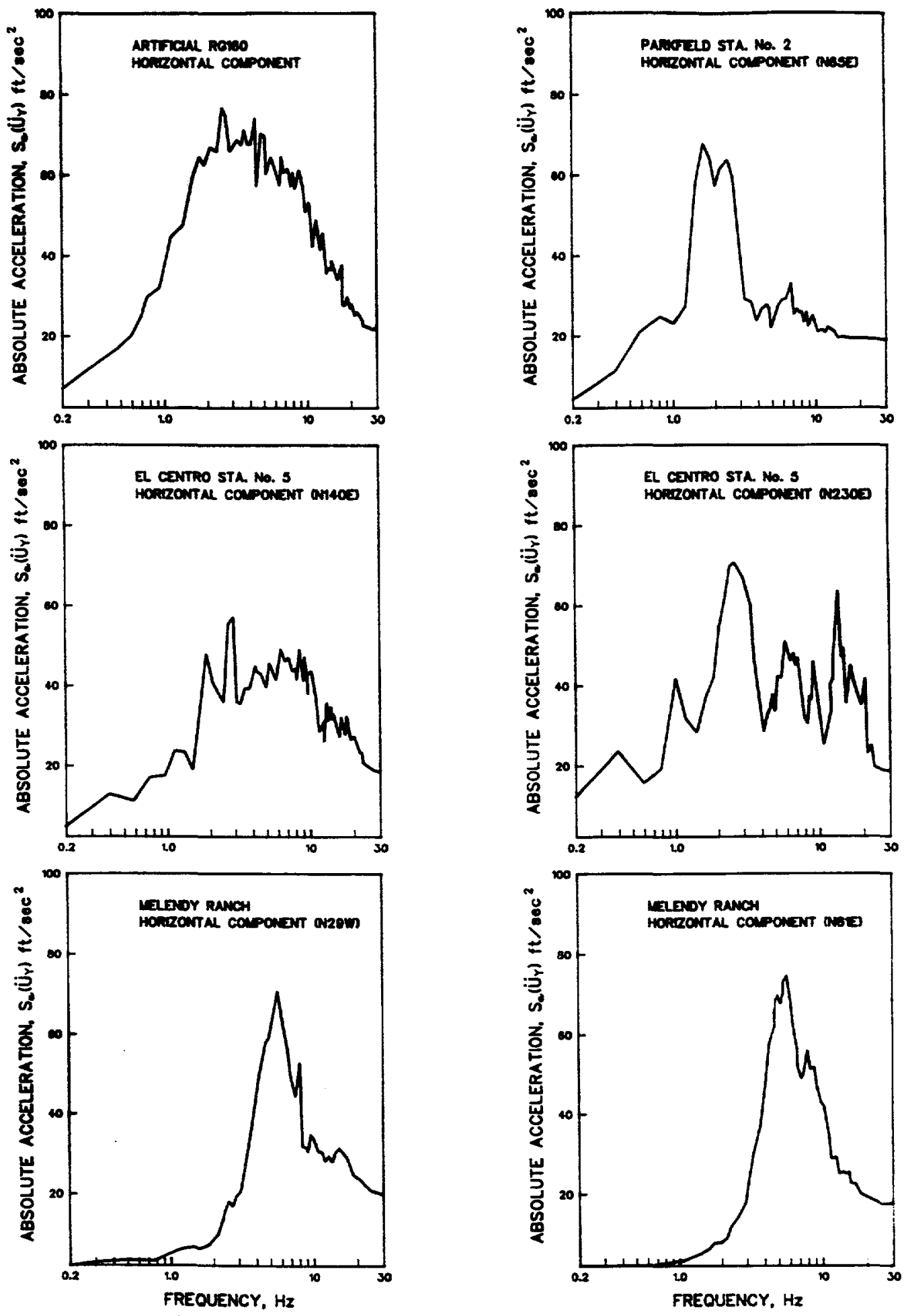

FIGURE 3.6

RESPONSE SPECTRA OF HORIZONTAL COMPONENTS OF CONTROL MOTIONS (NORMALIZED TO $0.5 \mathrm{~g}$ ), DAMPING $=0.02$

(FROM LUCO, et al, 1986) 
Variation of ground motion with depth is another special consideration for design of underground facilities. Although detailed measurements for an actual earthquake at a series of depths has not been obtained, Asmis (1984) used an analytical model to predict ground motion response to a component of the Blue Mountain Lake earthquake, whose horizontal surface component was similar to that for Parkfield N65E, shown in Fig. 3.5. The result is shown in Fig. 3.7, where it can be seen that the small number of pulses is attenuated in amplitude, and the duration becomes more prolonged. The effect on amplitude is shown in Fig. 3.8, while the effect on peak acceleration is shown in Fig. 3.9. Thus, earthquake ground motion can display a relatively broad range of amplitude, frequency, and duration characteristics, depending on the distance from the hypocenter, the depth from the surface, and the type of rocks in which the event occurs.

The nature of surface ground motion arising from earthquakes is recorded in archives maintained by the various national seismological bureaus, such as the U.S. National Earthquake Information Center, Rockville, Maryland. Most of the records are accelerograms, from which other motion variables are readily determined. As was previously mentioned, there appears to be little data available on subsurface motion generation from natural earthquakes. However, earthquakes (rockbursts) induced by mining are measured routinely at mine sites, both on the surface and underground. The characteristics of these seismic events are considered in Section 3.4.

\subsection{Underground Nuclear Explosions}

Similar to how they occur in air, shock waves due to underground explosions are rather short duration pulses as shown in Fig. 3.10., so long as they are felt in a direct line relatively near the source (Vortman 1979). However, when reflections from the surface and other boundaries take place before they are felt, they tend to be smeared out to longer duration and frequency multiplications take place. A typical pseudo relative velocity response spectrum is shown in Fig. 3.11. Thus, amplitudes, frequency content, and durations are all subject to the location and distance of the sensing point from the source of energy release, as was the case for earthquakes. Therefore, the time histories tend to change from a relatively short to a somewhat longer duration transient random excitation, although the duration is usually less than that of earthquakes.

Ground motion from underground nuclear explosions is an important consideration in the design and performance of a nuclear waste repository on or near the Nevada Test Site. Ground motion, both on the surface and at depth, is important in relation to the performance of, respectively, shaft collars and surface facilities, and the repository and its near-field rock. Thus, the reports by Vortman (1981) and Vortman and Long (1982) are an important record of the surface and deep subsurface ground motion induced by nuclear explosions.

For the measurement of surface and subsurface ground motion, subsurface measurement stations in boreholes were at depth ranging from $60 \mathrm{~m}$ to $762 \mathrm{~m}$, in a total of six observation holes. Results from these data are shown in Fig's 3.12 and 3.13. Here, the peak vector acceleration is defined as the square root of the squared sum of the peaks for three orthogonal motion components (Vortman and Long, 1982). The ratio of surface to underground peak vector value is developed as a function of depth for many different explosive experiments. The results indicate that accelerations diminish rapidly with depth. Similar trends were found for peak velocity and acceleration ratios. Furthermore, similar results were found for average pseudorelative velocity ratios (accelertaion/frequency) taken off the same data, as shown in Fig. 3.13. 


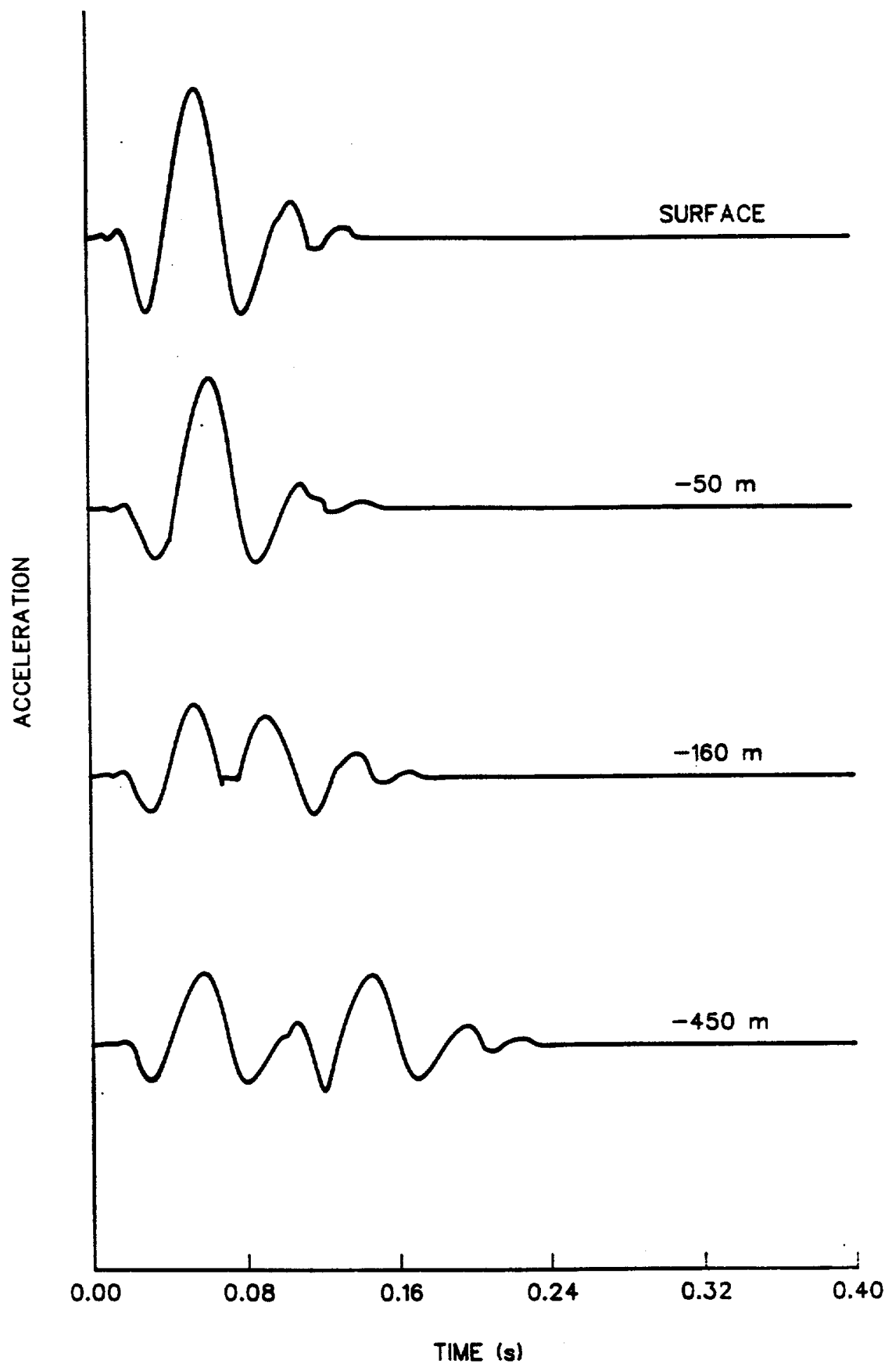

FIGURE 3.7

CALCULATED TIME HISTORIES AT SPECIFIED DEPTHS

(FROM ASMIS, 1984) 
EARTHOUAKE No. $9(M=5.0)$

DISTANCE $=55 \mathrm{~km}$

PEAK ACCELERATION $\left(\mathrm{m} / \mathrm{s}^{2}\right)$

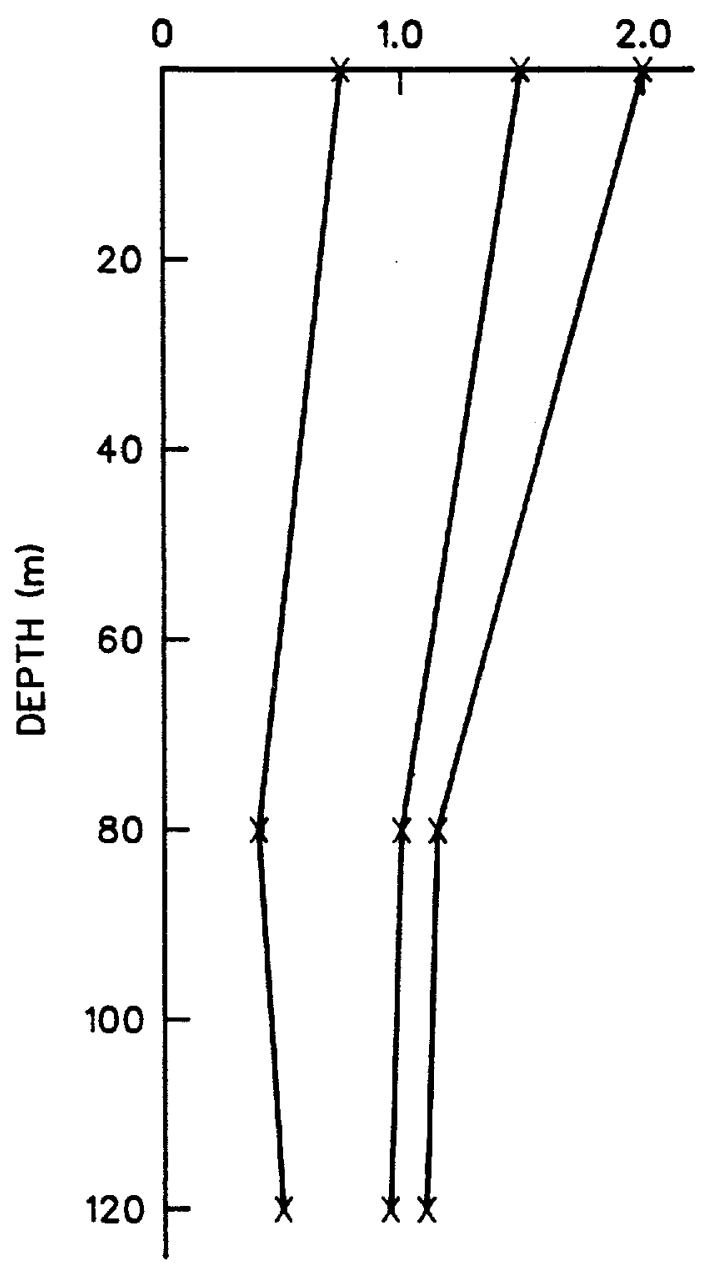

EARTHOUAKE No. $12(M=5.8)$ DISTANCE $=80 \mathrm{~km}$

PEAK ACCELERATION $\left(\mathrm{m} / \mathrm{s}^{2}\right)$

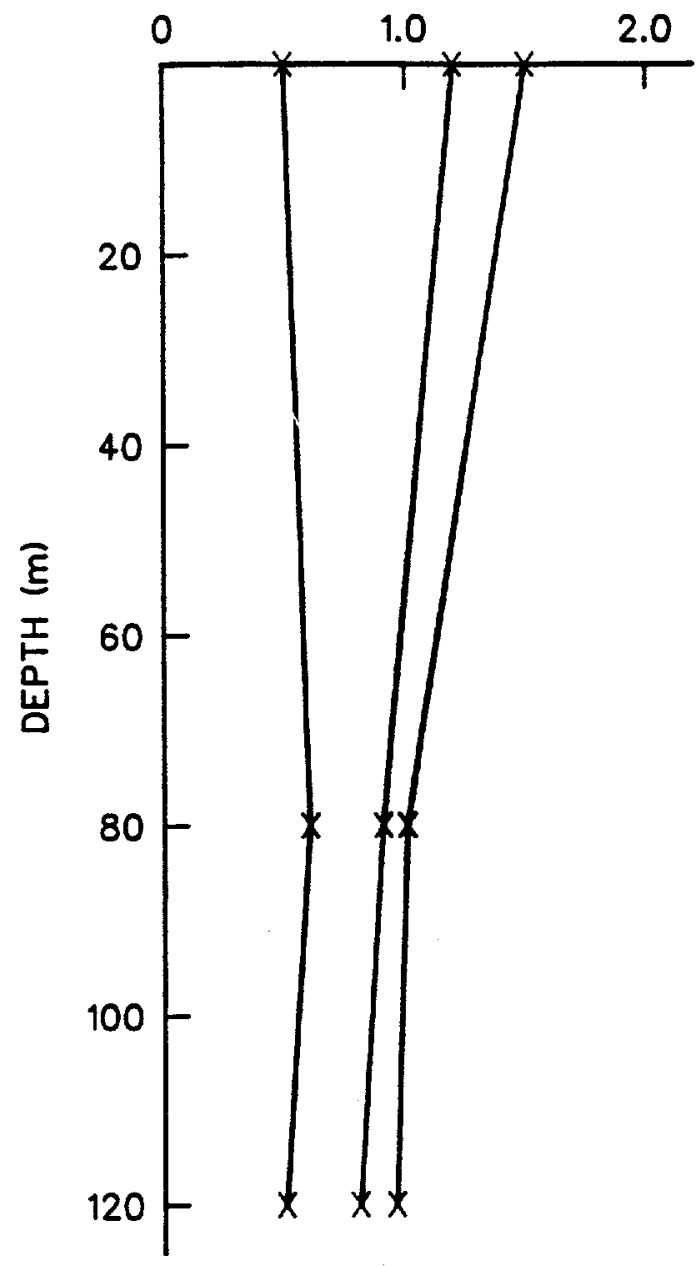

FIGURE 3.8

VERTICAL DISTRIBUTION OF MAXIMUM ACCELERATIONS

AT THE KANNONZAKI SITE

(FROM ASMIS, 1984 AND IWASAKI et. al., 1977) 


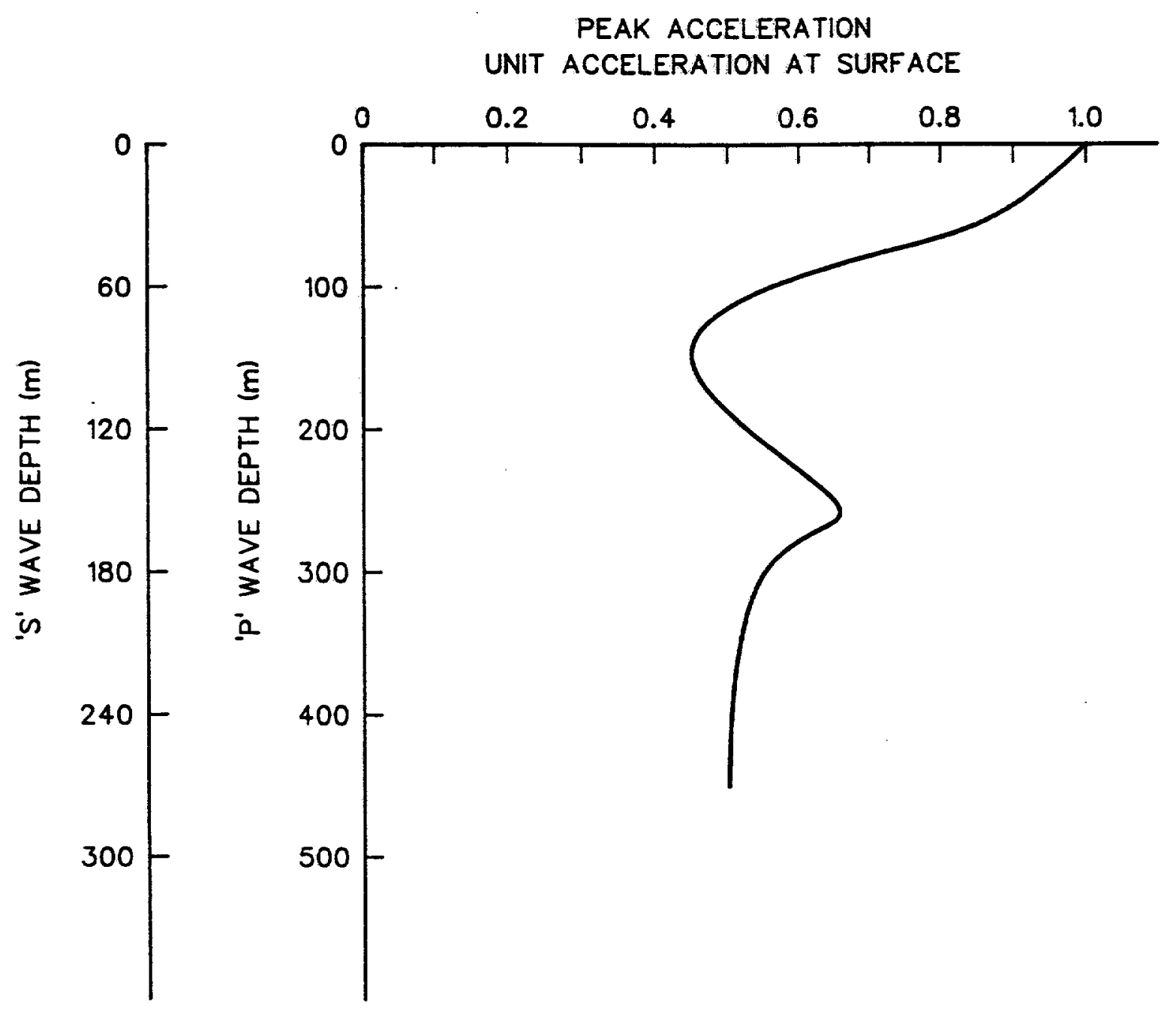

FIGURE 3.9

PEAK ACCELERATION VERSUS DEPTH FOR ' $P$ ' AND ' $S$ ' WAVES

(FROM ASMIS, 1984) 


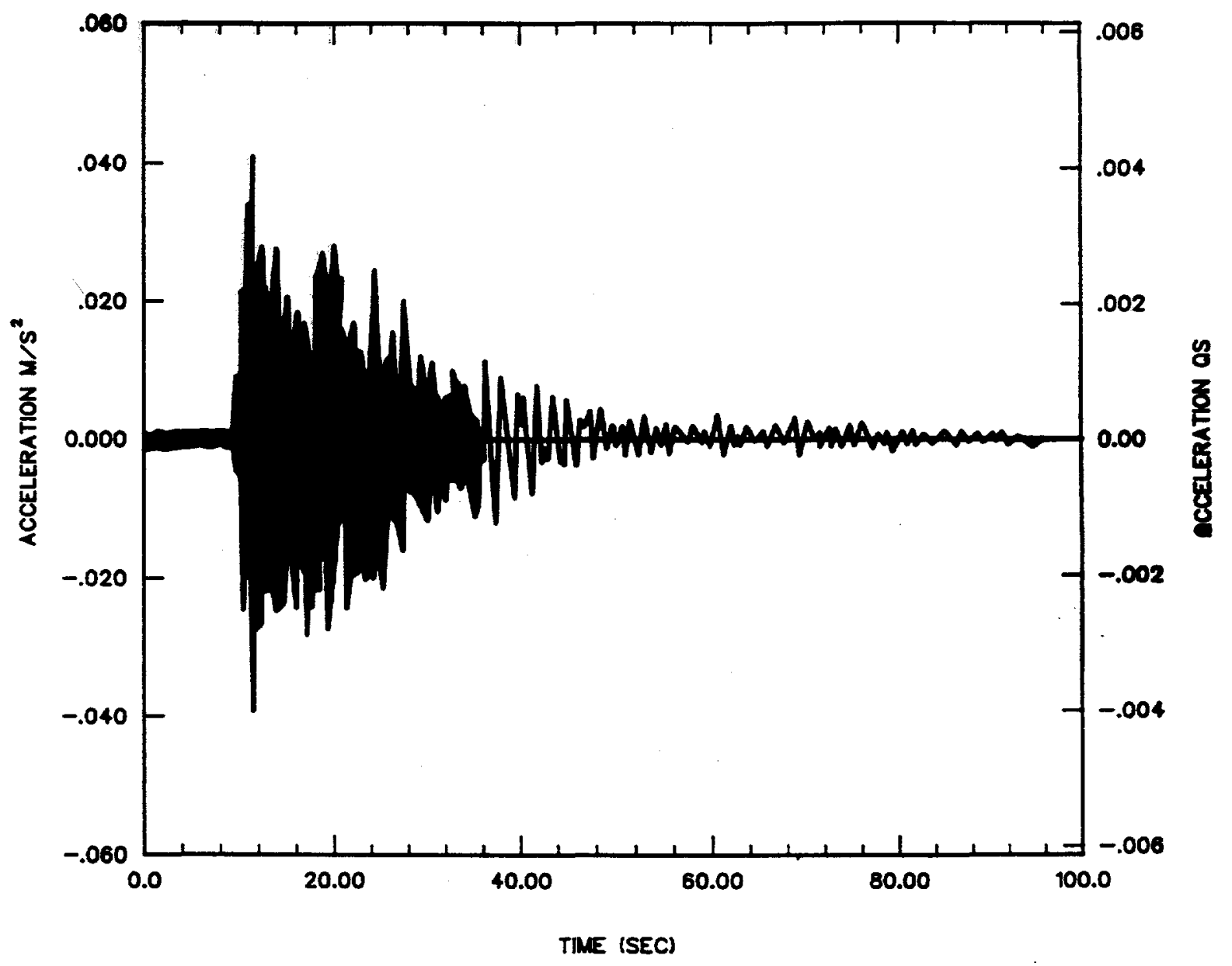

FIGURE 3.10

ACCELERATION VS TIME FOR FONDUTTA EVENT

(FROM VORTMAN, 1979) 


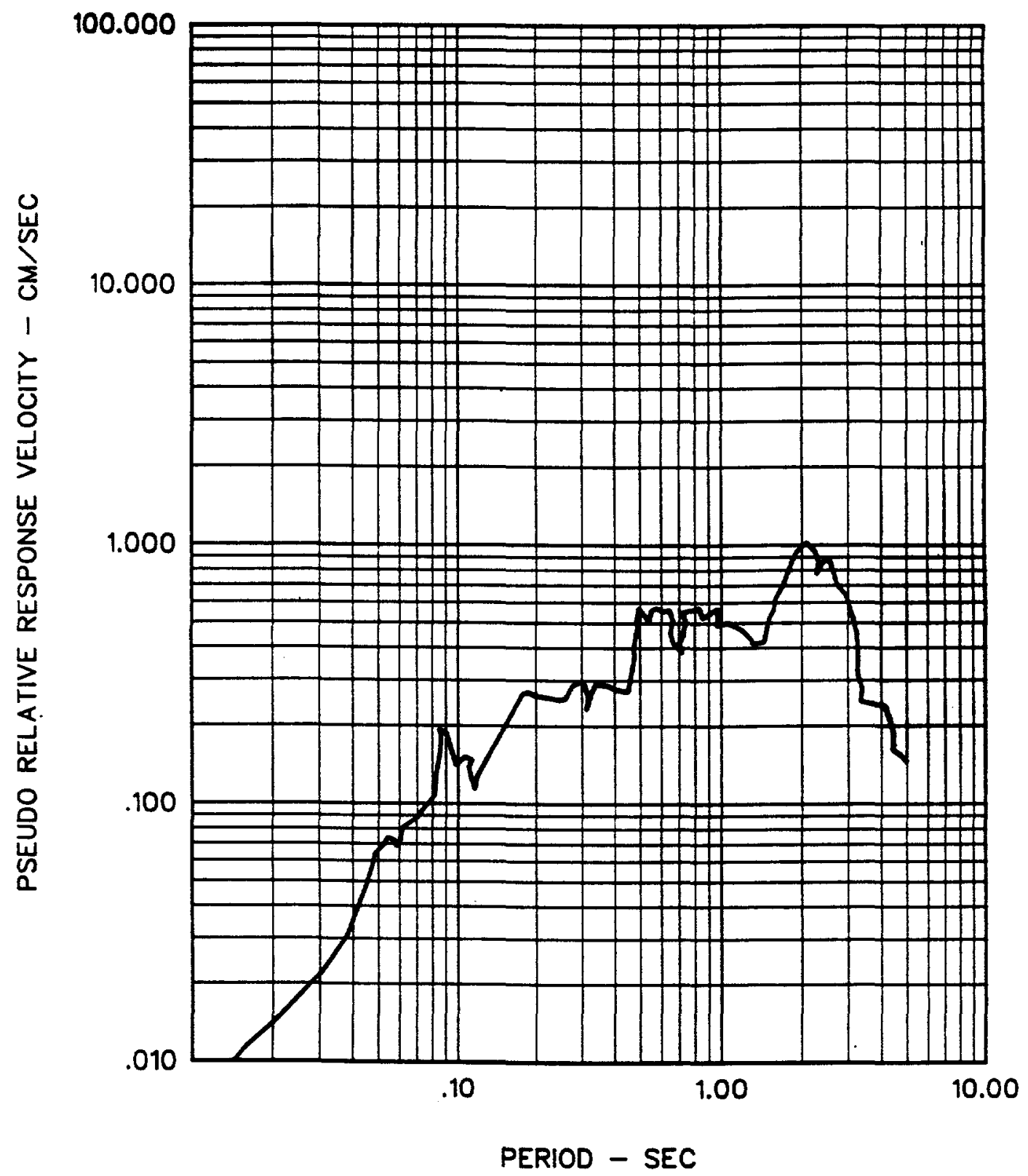

FIGURE 3.11

PSEUDO RELATIVE RESPONSE VELOCITY FOR FONDUTTA EVENT (FROM VORTMAN, 1979) 


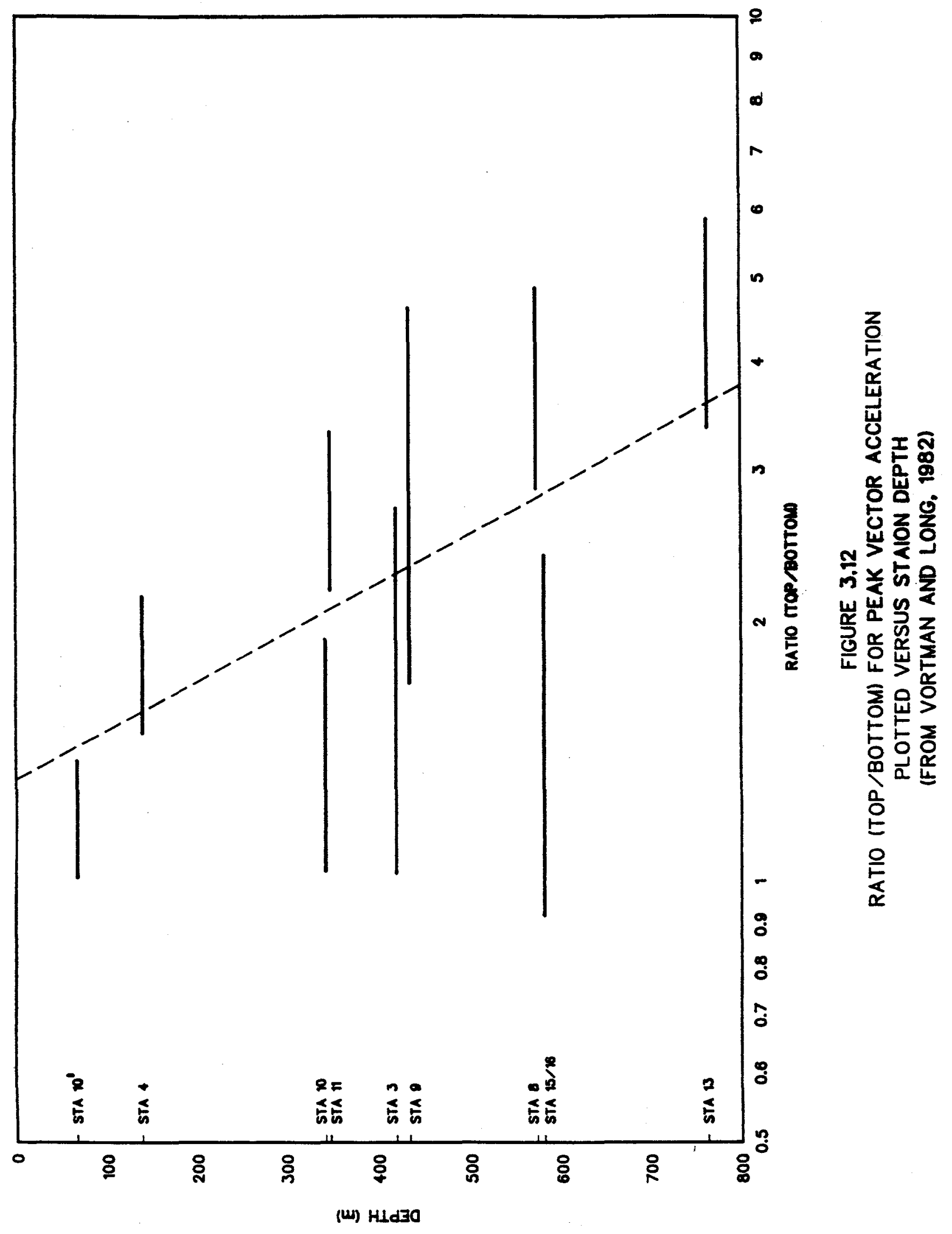




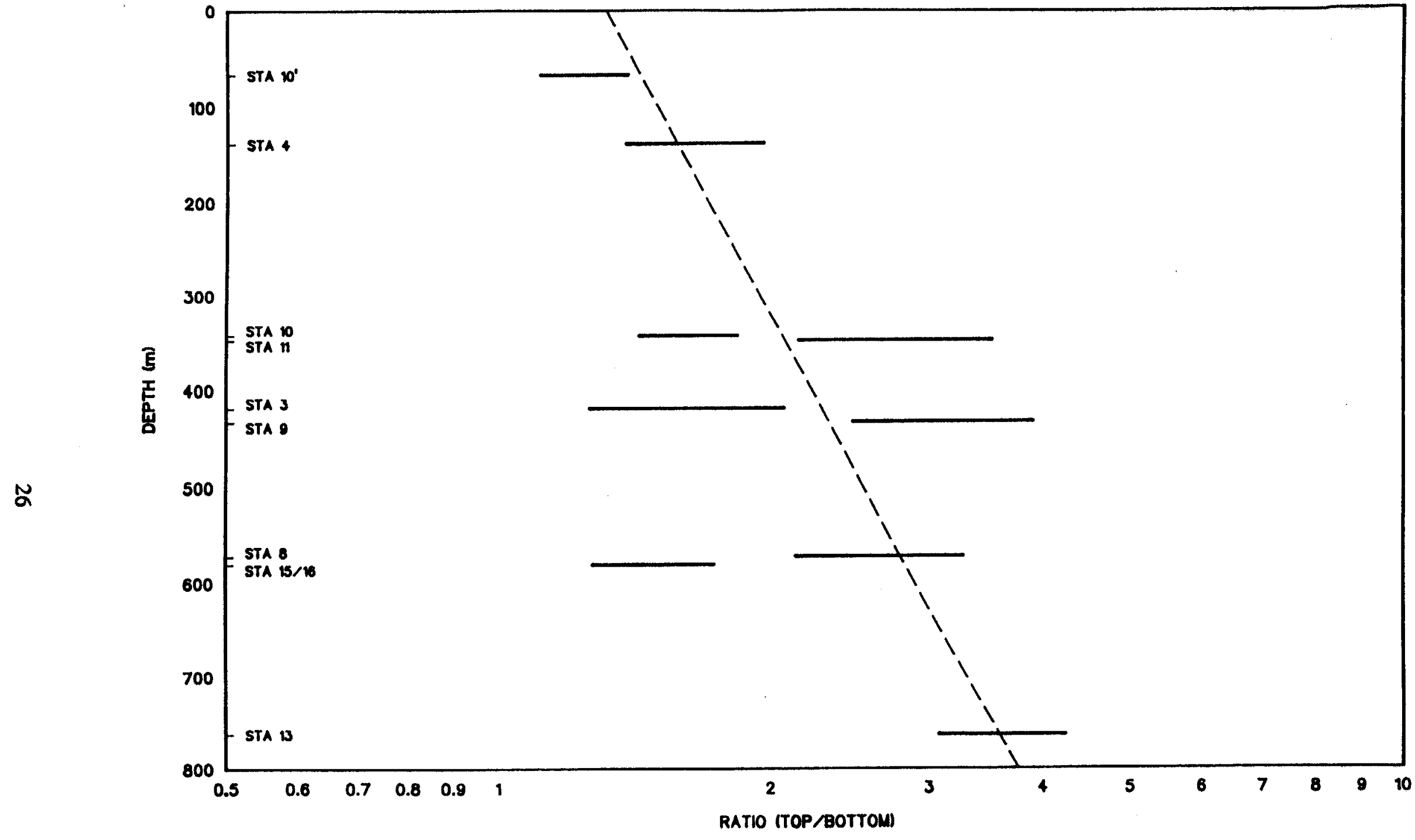

FIGURE 3.13

RATIO (TOP/BOTTOM) FOR "VECTOR" PSRV MEAN VALUES

PLOTTED VERSUS STATION DEPTH

(FROM VORTMAN AND LONG, 1982) 


\subsection{Seismicity in Mines}

Seismic events in mines (called rockbursts when they result in excavation damage) are by far the most prolific source of information on the response of underground excavations to seismic loading. Also, since groundwater response and its relation to seismicity are key issues in the prospective long term performance of a nuclearwaste repository, mine sites present the opportunity for understanding seismically induced changes in groundwater conditions in an active rock mass.

According to Johnston and Einstein (1988) and Gibowicz (1988), there are two distinct modes of mine seismic activity. The first mode is associated with rock material rupture and the formation of new fractures adjacent to stope faces. In the second mode, seismic activity is associated with displacement on major natural geological features. In both cases, mine seismicity is related to local geology and rock structure, and the interaction of the mine structure and its induced stress field with the natural lithostatic, residual and tectonic stresses operating locally and regionally (Brady, 1988).

The first mode of mine seismicity may be considered in terms of the conceptual model of rock instability illustrated in Fig. 3.14, due to Cook (1965) and Salamon (1970). It is a special case of structural instability, the principles of which are considered by Croll and Walker (1973). The condition for instability is related to the post-peak stiffness of the rock specimen, compared with the stiffness of the loading system represented by the spring in Fig. 3.14. The damage potential of seismic events arising from this mode has been related to the Energy Release Rate, which is a direct function of the strain energy density adjacent to mine excavations. The frequency of rockbursts for South African gold mines as a function of Energy Release Rate is illustrated in Fig. 3.15. Of course, the relation of rockburst frequency and intensity to Energy Release Rate is determined by site specific factors such as rock mass strength and structure. The general relevance of this near-field instability in longwall mining is indicated by Syrek and Kijko (1988).

Rockbursts arising from fault-slip instability, representing the second mode of mine seismic activity, are mechanically identical to natural earthquakes. The conceptual model for the instability is illustrated in Fig 3.16. In support of this model, Rorke and Roering (1984) report first motion studies which indicate a source mechanism involving shear motion. Stiller et al. (1983) record the similarity between many mine seismic events and natural earthquakes in terms of the seismic signatures generated by the seismicity. Morrison (1987), in describing seismic activity at the Strathcona Mine, Canada, suggested that damage in the mine was consistent with slip on planes of weakness. A dominant role for unstable fault slip as the source of major rockbursts in South Africa gold mines has been proposed by McGarr et al. (1979) and Spottiswoode (1984), and is supported by interpretation reported by Ortlepp (1978) of field observations of rock mass deformation accompanying rockbursts. Most recently, Ryder (1987) has reviewed the relation between rockbursts involving a crushing mode of failure and those involving unstable slip on a plane of weakness.

Prediction of the potential for instability and seismic activity from fault slip is conducted in terms of conventional principles of seismology (Aki and Richards, 1980) involving stress drop (Excess Shear Stress) and seismic moment. In retrospective analysis of a major seismic event, Ryder (1987) reports good agreement between computed Excess Shear Stress and field observations of the behavior of a faulted rock mass. The position and geometry of some mine excavations relative to a major mine fault are indicated in Fig. 3.17, together with the response of the rock mass in terms of shear displacement on the fault. Measurements of shear displacements showed that the region of maximum fault ride is concentrated in the zone of relatively high Excess Shear Stress. 


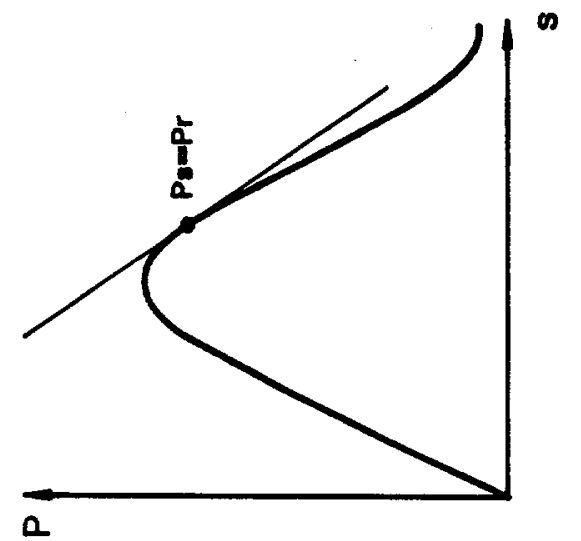

త

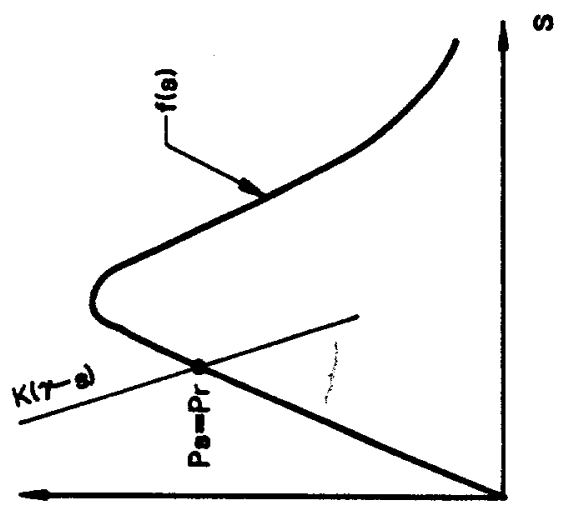

อิ

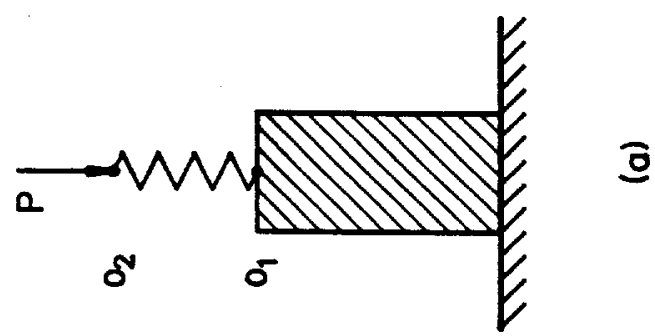

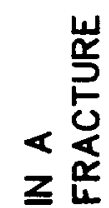

능ㅇ 틀오 商 要之 는 홍

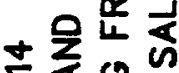
宛方的 山己铝 容要 可品 正近告 n $\alpha$ 뜽 농 능 只衣 으 뻪 웃 튼 릉 80 㟋 옹 


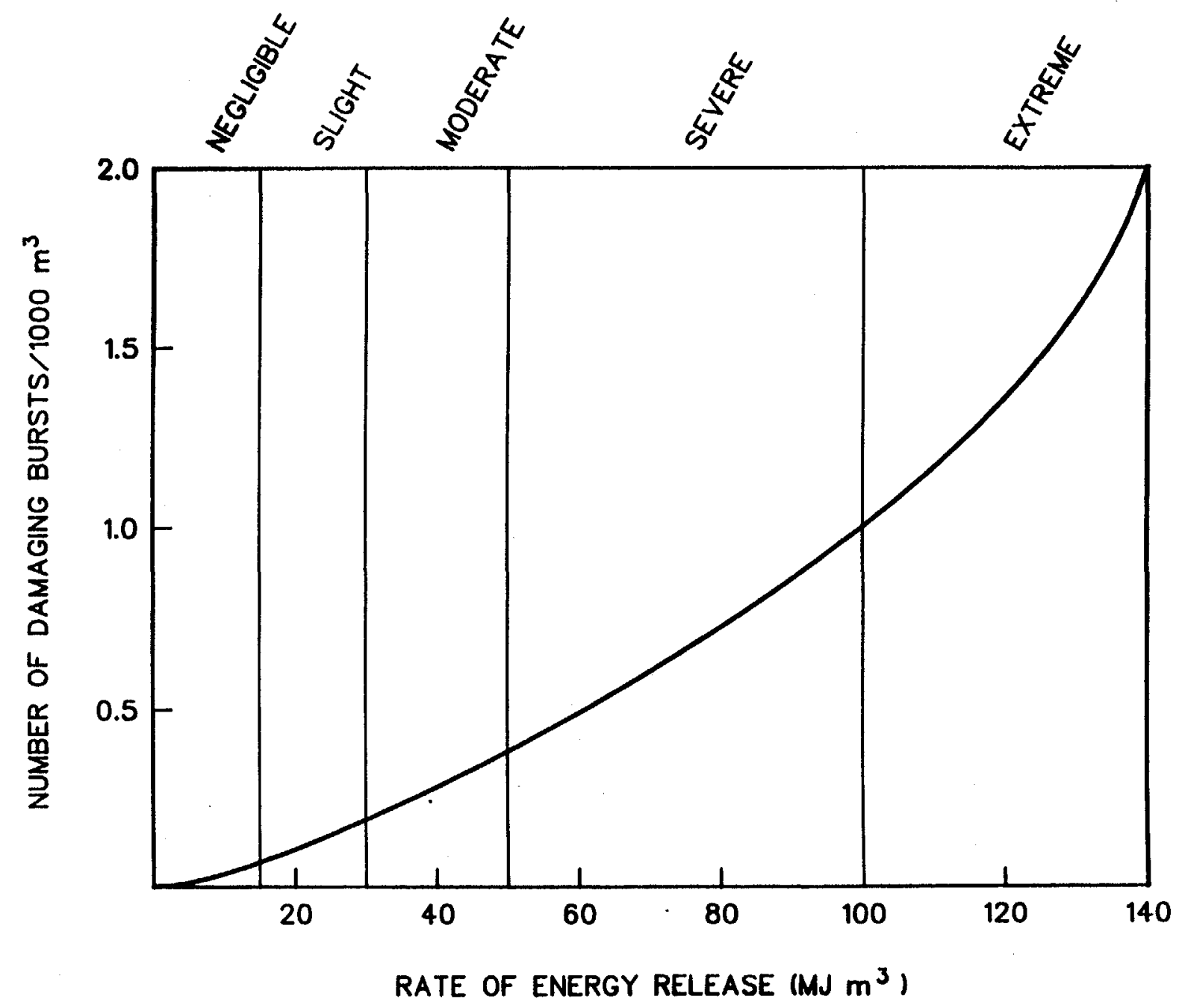

FIGURE 3.15

RELATION BETWEEN FREOUENCY OF ROCK BURSTS, LOCAL GROUND CONDITIONS, AND ENERGY RELEASE RATE IN LONGWALL MINING OF GOLD REEFS

(FROM COOK, 1978) 
(a)

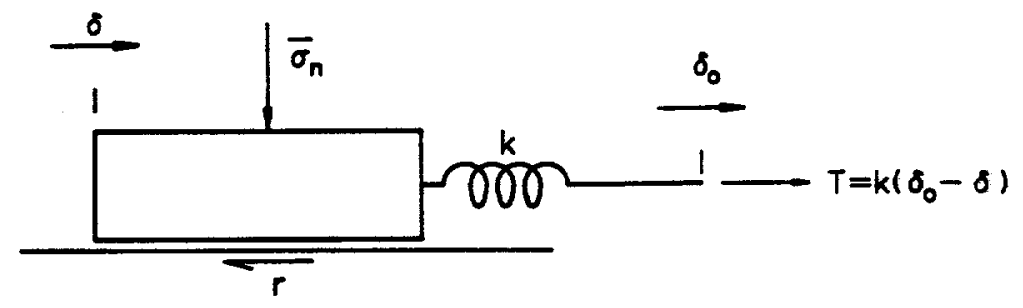

(b)

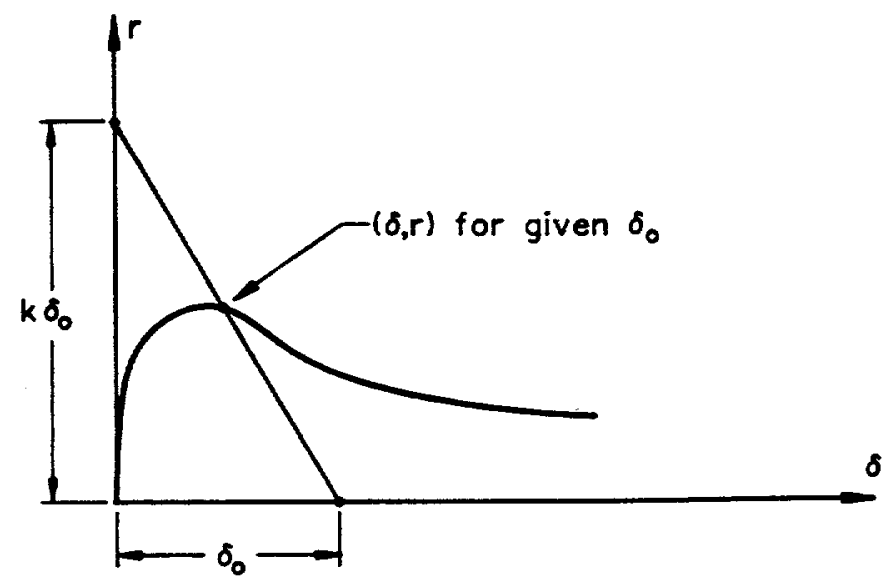

(c)

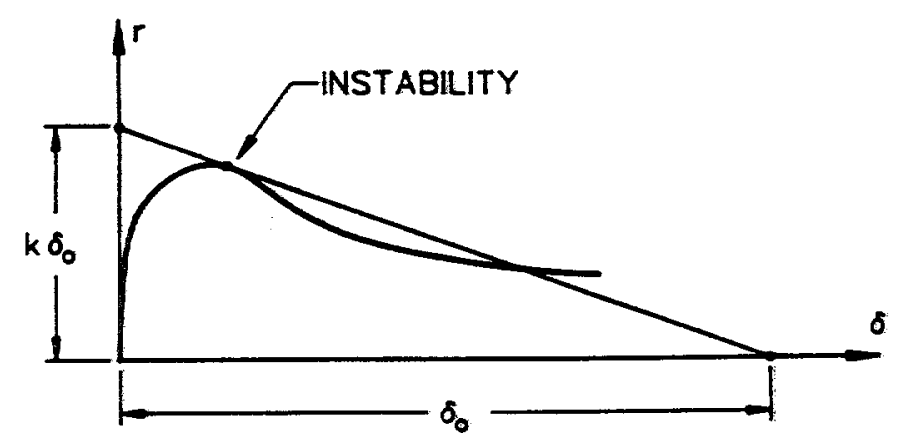

(d)

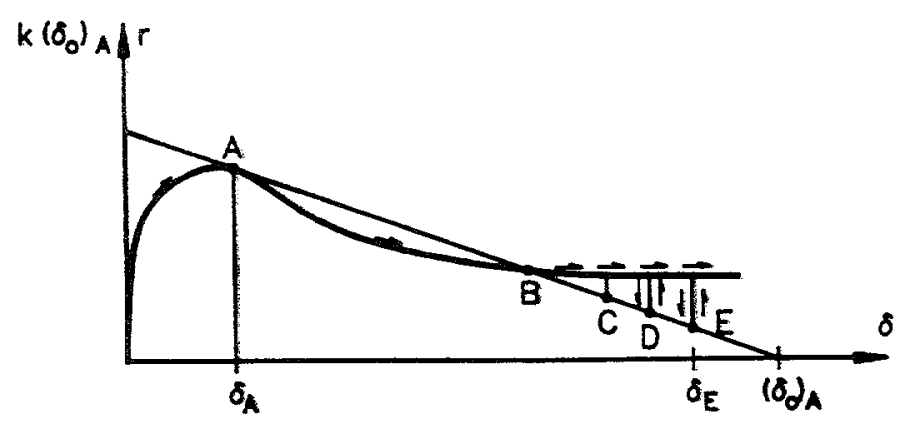

FIGURE 3.16

CONDITIONS FOR STABLE AND UNSTABLE SLIP IN A SINGLE-DEGREE-OF-FREEDOM SPRING-SLIDER FAULT MODEL (FROM RICE, 1983) 


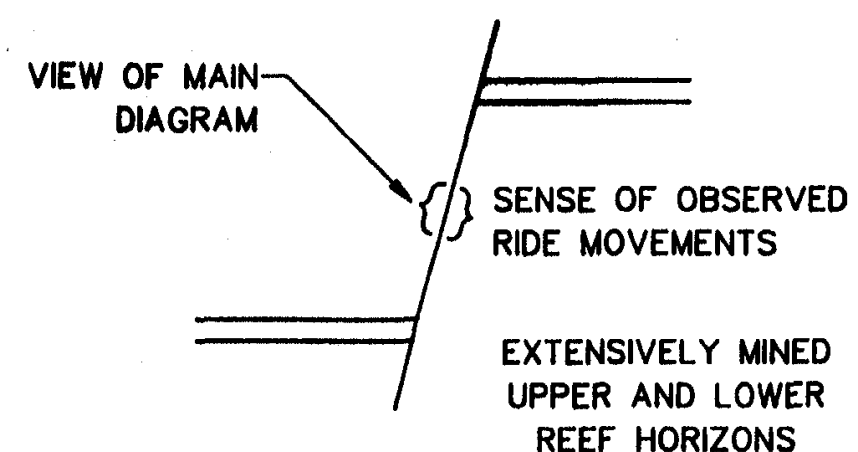

REEF HORIZONS

SECTION

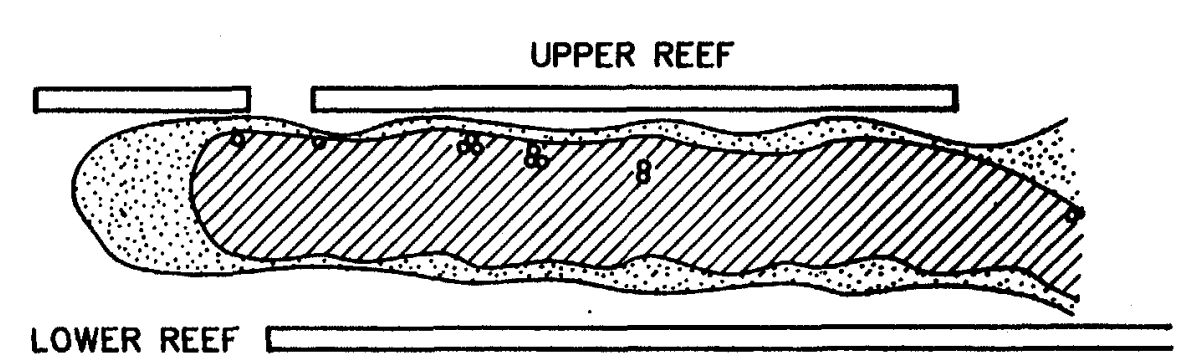

ESS $=0-8 \mathrm{MPa}$

Z $E S S=8-20 \mathrm{MPa}$

- 25 = OBSERVED RIDE ON FAULT $(\mathrm{cm})$

PROJECTION OF PLANE ON FAULT

FIGURE 3.17

RETROSPECTIVE ANALYSIS OF A LARGE SEISMIC

EVENT IN TERMS OF EXCESS SHEAR STRESS

(FROM RYDER, 1987) 
There are several characteristics of fault-slip rockbursts which distinguish them from crushing events. Some of these are that they often occur at some distance from mine excavations, they are generally related to major geological features such as faults and dikes, their time distribution is erratic, and usually they seem to respond to stress changes on a whole-mine scale, rather than to an identified area of mining (Gibowicz, 1988). It is notable also that no systematic differences have been observed between these mine seismic events and natural earthquakes. Thus, most of the physical and geomechanical principles which have been established for natural earthquakes also apply to mine seismic events and rockbursts (McGarr, 1984). This is an extremely important observation, because it implies that observed underground mine response to rockbursts can be applied in predicting repository response to natural earthquakes.

\subsection{Comparison of Explosive and Seismic Ground Shock}

During the 1970's various investigations were performed to determine whether underground nuclear explosions could be used realistically to simulate earthquake events. Extensive discussions of this subject are given by Miscellaneous Paper S-71-17 of the U.S. Army Waterways Experimental Station (Anon, 1972), and by Pratt, Hustrulid, and Stephenson (1978). Although the results of their studies concentrated primarily on comparisons of damage effects, they are useful to the current project in that they demonstrate essential differences in the two types of excitation, so that simulation of one type of event by the other is not generally practical. Among other differences, such as those associated with types of wave content for a given magnitude, the frequency content tends to be different depending on the distance of either of the events from the hypocenter, as was discussed in Section 3.2. A comparison of acceleration response spectra for the farfield of the $1940 \mathrm{El}$ Centro earthquake and two underground nuclear events is shown in Figure 3.18, where the frequency content of the explosions is higher than that of the earthquake. On the other hand, if the earthquake event occurs in the nearfield, the results can be opposite, as will be shown in the next section. It is conceivable that some situations could exist where the explosive shock and earthquake ground motions spectra are very similar. However, the time duration of an earthquake is generally quite longer, and damage effects from repeated cycles of stress can be much more pronounced for earthquakes at a given magnitude level.

A comparison of ground motion produced by an earthquake and underground nuclear explosions is provided by Vortman (1981). The comparison involves ground response to a strike slip seismic event at a depth of about $4 \mathrm{~km}$ on the Nevada Test Site with body wave magnitude, $\mathrm{Mb}$, of 4.3 , Richter local magnitude, $\mathrm{M}_{1}$, of about 3.5, and ground motion from four underground nuclear explosions. The depth of placement of the nuclear explosives was considerably less than the depth of the earthquake, providing the expectation that a much higher relative proportion of the transmitted energy from the explosions would be expressed as surface waves.

A typical comparison between the response spectra for vertical motion for the earthquake and a nuclear explosion is shown in Fig. 3.19 while corresponding spectra for horizontal motion are shown in Fig. 3.20. It is observed that the velocity peaks are of similar magnitude. However, acceleration is always smaller for the nuclear explosion than for the earthquake. The period of the earthquake signal has a broad peak from about 0.10 to 0.37 seconds, while the nuclear explosions produced a sharper, longer peak period in the range of 0.5 to 0.9 seconds. This is consistent with the body wave motion due to the earthquake, versus the surface wave motion due to the nuclear explosion. The body wave magnitude, $\mathrm{Mb}$, of 4.4, from the earthquake, is equivalent to an explosion yield at the seismic source of $5 \mathrm{kt}$. Thus, Vortman (1981) proposed that, while there are differences between earthquake and UNE-induced ground motion, comprehension of such differences would allow the 
Spectral acceleration, $g$
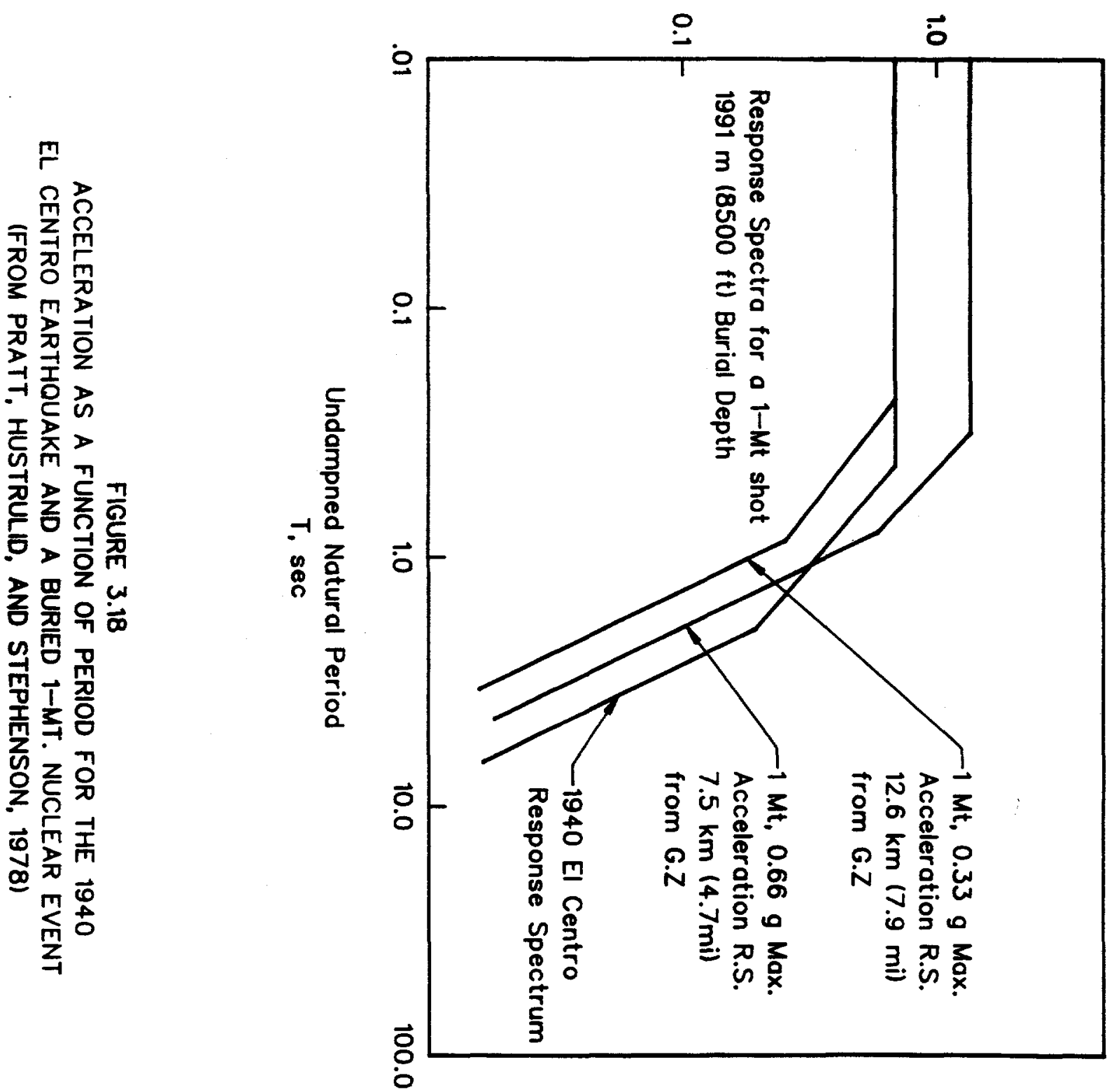


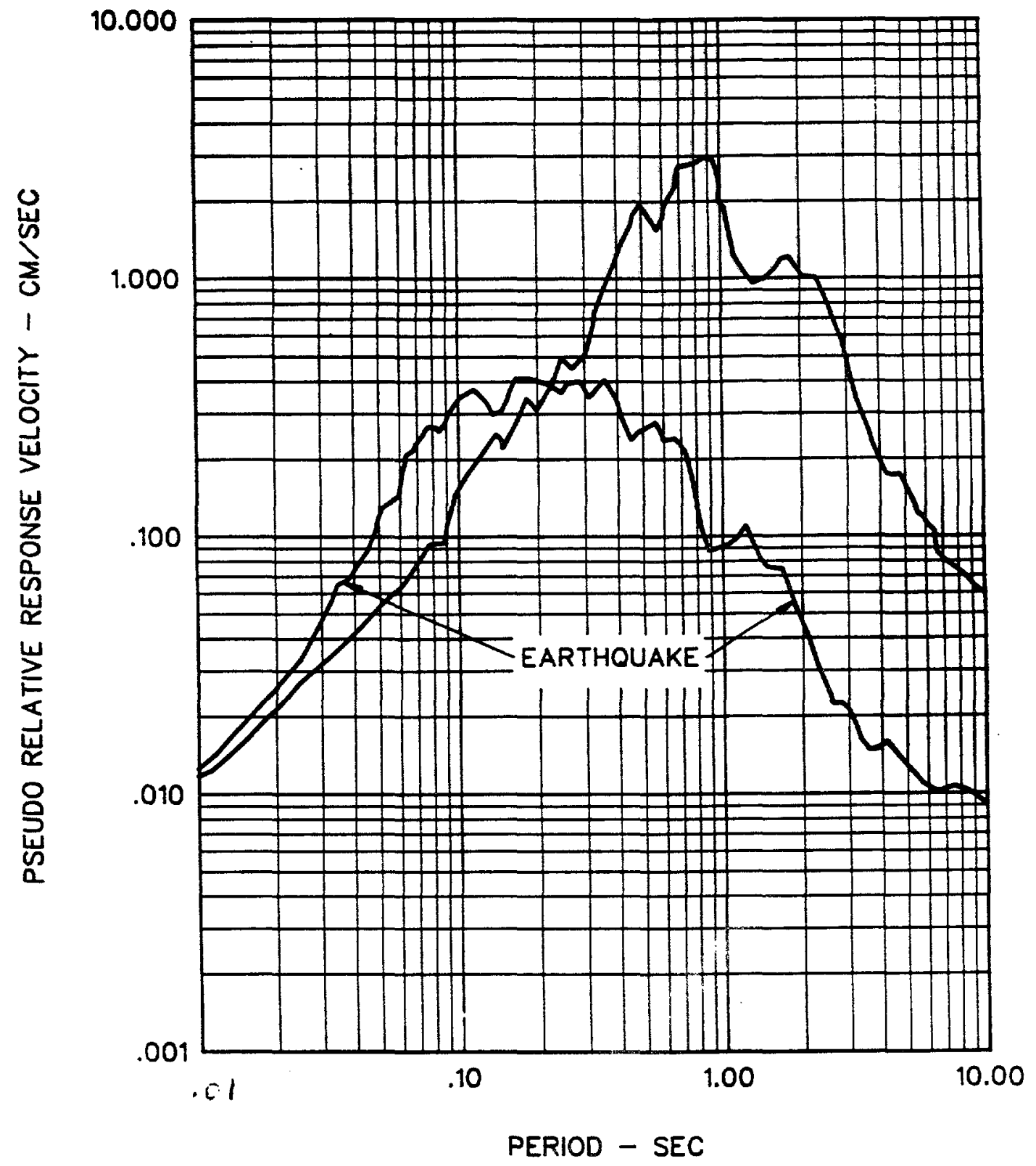

FIGURE 3.19

COMPARISON OF PSRV'S FOR VERTICAL COMPONENT

FOR EARTHQUAKE AND EVENT $C$

(FROM VORTMAN, 1982) 


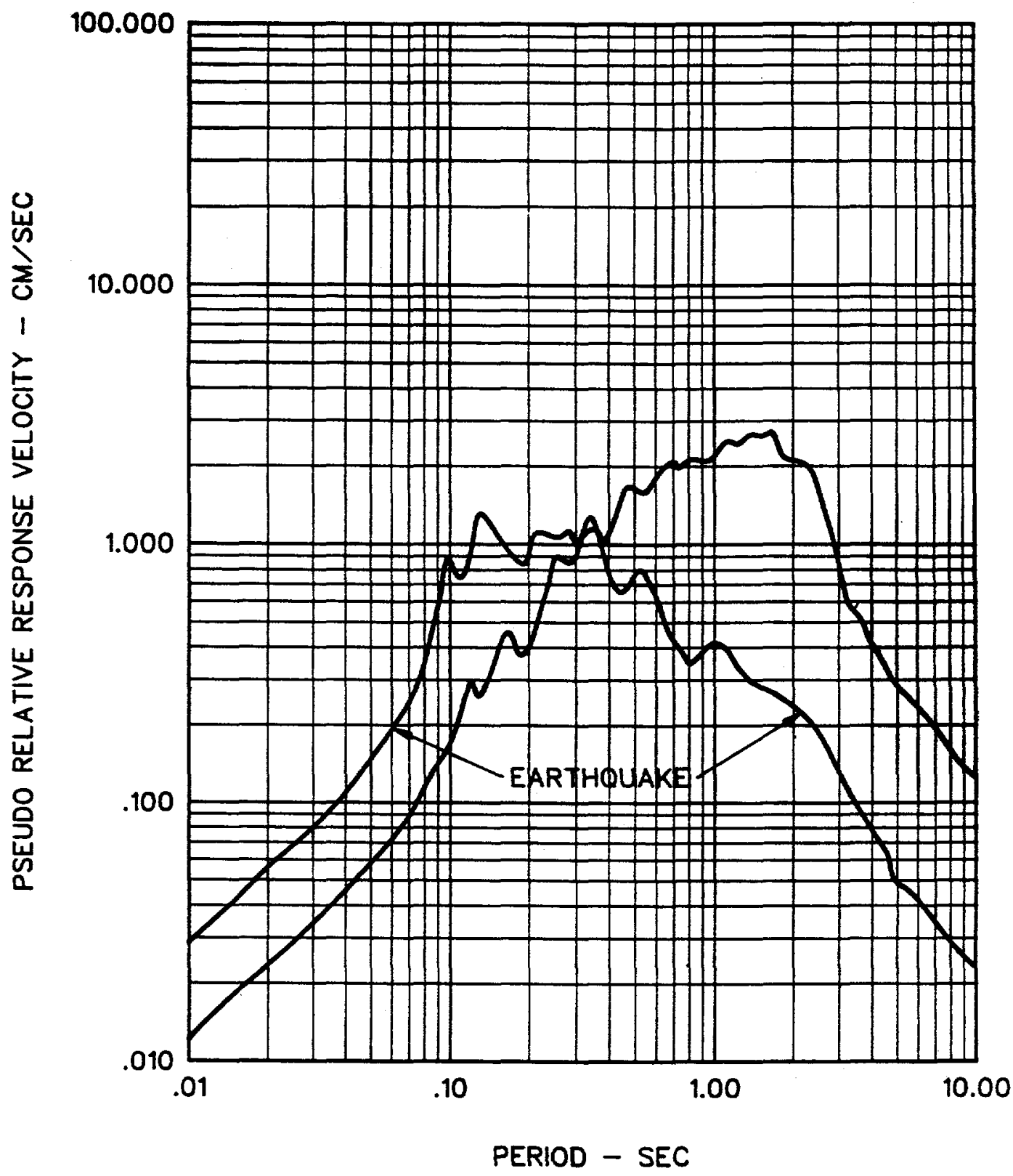

FIGURE 3.20

COMPARISON OF PSRV'S FOR HORIZONTAL COMPONENT

FOR EARTHOUAKE AND EVENT $C$

(FROM VORTMAN, 1982) 
large data bank of weapons test ground motion to be applied to earthquake engineering of structures on the Nevada Test Site.

The results of the study by Vortman (1981) are supported by some earlier investigations (Anon, 1972) related to a proposed study, using underground nuclear explosions, of earthquake effects on earthand rock-fill dams. Peak values of ground motion parameters, acceleration time histories, various response spectra and other parameters are presented for ground motion caused by earthquakes and underground nuclear explosions. It is proposed that underground nuclear explosions produce ground motion that is very similar to that from earthquakes, except that in some cases the vertical motion is larger for the explosions than for the earthquakes whose horizontal motions are at a comparable level. However, it is notable that these conclusions do not consider the duration or time history of strong ground motion, concentrating instead on peak values of the acceleration, velocity, or displacement.

\subsection{Events at Nevada Test Site}

In view of the rather significant differences that can occur in ground shock and earthquake motions, depending on the various conditions at the site of the event, it becomes necessary to consider what are representative motions at the Nevada Test Site. The data for ground shock by Vortman (1981) has already been cited. However, further analyses of these data for the earthquake which occurred at NTS has also been published by Vortman and Long (1982). Some information about this earthquake is given in Table 3.2. Furthermore, time histories for it, given by Vortman (1982), show it to be of the near-field type. This is also supported by the sample velocity response spectrum given and compared with a spectrum from an underground nuclear event in Figs. 3.19, 3.20. These spectra can be used to provide frequency content for representative ground motions at NTS, while the time durations can be estimated from previous data given in this section. The magnitude of an appropriate event may be estimated by the zero period accelerations of these types of spectra. Thus, whether for analysis or experiment, synthetic ground motion time histories can be generated to match these required characteristics. Techniques for accomplishing this have been reported in a variety of sources, including Unruh, 1982.

\subsection{Field Observation Methods}

Field observations are of consequence for long-term monitoring of the repository as well as laboratory instrumentation techniques needed to parallel field scenarios and validate model propriety. Earthquakes, rockbursts and blasting have long been of interest in mining activities and attempts have been made to correlate surface events with reactions at depth in the ground. With the advent of nuclear technology and underground testing, capabilities for monitoring surface effects from detonations at depth have evolved.

Collection, assessment, and comparison of data from nuclear sources and monitoring networks for mines and mining districts needs to be pursued. To accomplish proper assimilation of these data for comparative purposes, it is expedient to have access to personnel who have participated in instrumenting operations at the Nevada Test Site (NTS) and who are cognizant of limitations of the data acquisition systems and the subsequent interpretations. Similar constraints apply for data available from mining operations.

Data from NTS that have been declassified are reported in articles written for specialized construction problems, but the totality of data in a functional assimilation for the range of problems to be addressed for the proper functioning of the repository over an extended time period is not identified in the 
Table 3.2 Data for Earthquake at Nevada Test Site

(Vortman and Long, 1982)

Azimuth and Distances from Stations to Reported Epicenter

\begin{tabular}{|c|c|c|c|c|c|c|c|}
\hline $\begin{array}{c}\text { Coordinates } \\
\text { Nevada East } \\
\text { Grid } \\
(\mathrm{m})\end{array}$ & $\begin{array}{c}\text { Surface } \\
\text { Elevation } \\
(\mathrm{m})\end{array}$ & $\begin{array}{c}\text { Azimuth } \\
\text { to CP-1A } \\
(\mathrm{deg})\end{array}$ & $\begin{array}{c}\text { Horizontal } \\
\text { Distance } \\
(\mathrm{km})\end{array}$ & $\begin{array}{c}\text { Slant } \\
\text { Distance } \\
(\mathbf{k m})\end{array}$ & $\begin{array}{c}\text { Azimuth } \\
\text { to CP-1H } \\
(\mathrm{deg})\end{array}$ & $\begin{array}{c}\text { Horizontal } \\
\text { Distance } \\
(\mathrm{km})\end{array}$ & $\begin{array}{c}\text { Slant } \\
\text { Distance } \\
(\mathrm{km})\end{array}$ \\
\hline $\begin{array}{c}\text { N240,477 } \\
\text { E212,664 }\end{array}$ & 1250 & 286.71 & 6.100 & 7.480 & 283.98 & 6.260 & 7.630 \\
\hline $\begin{array}{c}\text { N237,938 } \\
\text { E214,525 }\end{array}$ & 1237 & 299.14 & 8.820 & 9.830 & 297.05 & 8.910 & 9.930 \\
\hline $\begin{array}{l}\text { N239,406 } \\
\text { E212,791 }\end{array}$ & 1237 & 295.34 & 6.600 & 7.900 & 29262 & 6.770 & 8.020 \\
\hline
\end{tabular}

Peak Values of Acceleration, Velocity, and Displacement

\begin{tabular}{|c|c|c|c|c|c|c|c|c|c|c|}
\hline & \multicolumn{5}{|c|}{$C P-1 A$} & \multicolumn{5}{|c|}{$\mathrm{CP}-1 \mathrm{H}$} \\
\hline & $\mathbf{v}$ & $\begin{array}{c}R \\
(288 \\
\text { deg) }\end{array}$ & $\begin{array}{c}\mathrm{T} \\
(18 \mathrm{deg})\end{array}$ & $\begin{array}{c}\text { 3-d } \\
\text { Vector }\end{array}$ & $\begin{array}{c}\text { 2-d } \\
\text { Vector }\end{array}$ & $\mathbf{V}$ & $\begin{array}{c}R \\
(288 \\
\text { deg })\end{array}$ & $\begin{array}{c}T \\
(18 \mathrm{deg})\end{array}$ & $\begin{array}{c}3-d \\
\text { Vector }\end{array}$ & $\begin{array}{c}2-d \\
\text { Vector }\end{array}$ \\
\hline $\begin{array}{l}\text { Accel } \\
\text { (g) }\end{array}$ & $\begin{array}{c}+0.00538 \\
- \\
0.00732\end{array}$ & $\begin{array}{l}+0.0189 \\
-0.0232\end{array}$ & $\begin{array}{l}+0.0260 \\
-0.0134\end{array}$ & 0.0250 & 0.0249 & $\begin{array}{c}+0.00990 \\
- \\
0.00619\end{array}$ & $\begin{array}{l}+0.0172 \\
+0.0184\end{array}$ & $\begin{array}{l}+0.0228 \\
+0.0157\end{array}$ & 0.0258 & 0.0258 \\
\hline $\begin{array}{c}\text { Vel } \\
(\mathrm{cm} / \mathrm{s})\end{array}$ & $\begin{array}{l}+0.191 \\
-0.167\end{array}$ & $\begin{array}{l}+0.602 \\
-0.542\end{array}$ & $\begin{array}{l}+0.688 \\
-0.452\end{array}$ & 0.849 & 0.839 & $\begin{array}{l}+0.233 \\
-0.182\end{array}$ & $\begin{array}{l}+0.529 \\
-0.451\end{array}$ & $\begin{array}{l}+0.590 \\
-0.505\end{array}$ & 0.667 & 0.659 \\
\hline $\begin{array}{l}\text { Displ } \\
(\mathrm{cm})\end{array}$ & $\begin{array}{l}+0.0155 \\
-0.0121\end{array}$ & $\begin{array}{l}+0.0351 \\
-0.0332\end{array}$ & $\begin{array}{l}+0.0345 \\
-0.0727\end{array}$ & 0.0766 & 0.0768 & $\begin{array}{c}+0.0173 \\
- \\
0.0161\end{array}$ & $\begin{array}{l}+0.0325 \\
-0.0447\end{array}$ & $\begin{array}{l}+0.0310 \\
-0.0757\end{array}$ & 0.0804 & 0.0804 \\
\hline
\end{tabular}


literature. Likewise, systems are described for the monitoring of mines and regions, but a collective assemblage of data is not identified. Mining seismicity records are of consequence since ground motion at depth differs from the characteristic surface motions used for structural design considerations.

\subsubsection{Ground Motion Measurements}

Data from ground motion may be termed static, dynamic or transient, where dynamic refers to recurring cycles and transient to a peak with a decay. Accelerations, velocities or relative displacements may be monitored to represent ground motion, with attendant differentiations or integrations relating the parameters. In general, however, it is desirable to measure directly the parameter of interest, since data manipulation tends to give rise to uncertainties in the correct values for boundary conditions, constants of integrations, etc.

Measurement systems are comprised of sensing devices (transducers); signal conditioning and transmitting equipment and circuits (amplifiers, multiplexers, cabling, etc.) and recording capabilities (magnetic tape recorders, computers, oscillographs, etc). The quantities of interest for ground motion studies (acceleration, velocity, displacement, force, stress) can be monitored using transducing sensing elements as shown generically in Table 3.3 Depending on requirements of size, length of service, hostility of environment, etc, an acceptable transducer device can be designed, calibrated and synthesized into the domain to be monitored for the particular parameter of consequence.

Signal conditioning has two primary functions: 1) to satisfy the input requirements of the read-out device or recorder and 2) to provide a higher degree of accuracy or sensitivity of the measurement. Zero suppression, calibration, channel identification, etc., may be integrated into the signal conditioning system. Wire sizes, cable characteristics and routing geometry are parameters to be considered.

Recording or indication instruments may be classified as analog devices; numerical/digital devices, cameras; magnetic tape recorders, oscillographs/oscilloscopes; printers/punches. Data handling and processing considerations have a direct influence on the choice of recording devices, along with the recording/scanning interval. The recording device must be compatible with the transmission system, so that in some cases signal conditioning is required both at the transducer and again at the recorder.

For repository operations, the transducer and its installation are of primary significance. Seismic devices must be affixed to the structure being monitored. In rock formations at depth this usually requires that a grouting mixture with mechanical properties similar or equivalent to the host formation be used to cement or "glue" the sensing element and its associated circuitry into place. As early as 1970, it was noted that backfill was important (Ingram, 1970) and in 1976, the prime requisite for successful monitoring of ground shock was determined to be the interface bond between the formation and the transducer (Balachandra, et al, 1976). A stiff, expansive grout was recommended. In 1986, it was again reported that field installation was of prime importance for using commercially available transducers (Groethe, et al, 1986). Specially designed "friction-coupled" isolators were employed to allow transducers to sense accelerations in a preferred direction. Gauge canisters were specially constructed to house the transducers. Protection of cabling was also noted.

Instrumentation arrays are required to document directional characteristics of the incident seismic disturbance by sensing the time of arrival (TOA). Early efforts to distinguish arrival times are described in Forrester and Barkhurst (1969), in which the TOA signals were programmed for an 
Table 3.3 Sensing Elements for Ground Motion and Shock Parameters

\begin{tabular}{|l|c|c|c|c|c|}
\hline \multicolumn{5}{|c|}{ Parameter } & Stress \\
\hline Sensing Element & Acceleration & Velocity & $\begin{array}{c}\text { Displace- } \\
\text { ment }\end{array}$ & Force & ( \\
\hline Capacitive & $\mathrm{X}$ & $\mathrm{X}$ & $\mathrm{X}$ & & $\mathrm{X}$ \\
\hline Inductive & $\mathrm{X}$ & $\mathrm{X}$ & $\mathrm{X}$ & $\mathrm{X}$ & $\mathrm{X}$ \\
\hline Magnetoelectric & $\mathrm{X}$ & $\mathrm{X}$ & $\mathrm{X}$ & & $\mathrm{X}$ \\
\hline Magnetostrictive & $\mathrm{X}$ & & & & $\mathrm{X}$ \\
\hline Photoelectric & & $\mathrm{X}$ & $\mathrm{X}$ & & \\
\hline Piezoelectric & $\mathrm{X}$ & & $\mathrm{X}$ & & \\
\hline Piezoresistive & $\mathrm{X}$ & & $\mathrm{X}$ & $\mathrm{X}$ & $\mathrm{X}$ \\
\hline Radioactive & & $\mathrm{X}$ & $\mathrm{X}$ & $\mathrm{X}$ & $\mathrm{X}$ \\
\hline Resistive & $\mathrm{X}$ & $\mathrm{X}$ & $\mathrm{X}$ & $\mathrm{X}$ & $\mathrm{X}$ \\
\hline Thermoelectric & & & & & $\mathrm{X}$ \\
\hline
\end{tabular}

initial response only so that reflected waves would not trigger the sensor. Subsequent improvements in transducers and recording/scanning equipment and techniques have allowed for the monitoring of larger regions.

\subsubsection{Field Networks}

As reported by Green (1988), early attempts to monitor tremors in and around mines in South Africa began in the 1930's with surface arrays of seismometers and mechanical recorders. Dynamic range (ratio of signal to noise) was limited so that magnification was difficult and it was necessary to use a magnifying glass to discern the records with any degree of propriety. It was observed, however, that mine tremors and rock bursts were similar to natural crustal earthquakes with regard to stress drops and relations between moment and magnitude, and particle velocity and acceleration. These early attempts were limited to a dynamic range of 100:1 (40 dB). Today, dynamic ranges of 80-120 $\mathrm{dB}$ are the norm. From theoretical and experimental considerations of dynamic rock motions, velocities may range from $10^{-3} \mathrm{~mm} / \mathrm{sec}$ (noise) to $5000 \mathrm{~mm} / \mathrm{sec}$ (extrapolated), which gives a dynamic range of about $134 \mathrm{~dB}$. It is possible to assemble a relatively inexpensive system having an acceptable dynamic range to gather high quality data, using PC's and digital techniques.

The Welkom Seismological Network (WSN) covers 400 square kilometers of the OFS gold field in S. Africa with up to 48 surface and underground seismic stations (Mendicki, et al, 1988). The system is fully digital and has a signal-to-noise ratio of $138 \mathrm{~dB}$ deliverable. It is capable of a resolution of up to $152 \mathrm{~dB}$. Each seismic event can be described in terms of average background noise, arrival $P$, 
arrival S, initial pulse width, initial pulse amplitude, amplitude $\mathrm{P}$, max amplitude $\mathrm{S}$, strong ground motion duration, tremor duration, (and reference file). (These parameters have been determined to be of consequence for the current study.).

Most mines which have rockbursting problems have monitoring stations for seismic activity. The list below gives some mines in North America with monitoring stations.

\begin{tabular}{lll}
\multicolumn{1}{c}{ Mine } & \multicolumn{1}{c}{ Owner } & \multicolumn{1}{c}{ Location } \\
Lucky Friday & Hecla Mining Co. & Mullan, Idaho \\
Star Mine & Hecla Mining Co. & Burke, Idaho \\
Galena Mine & ASARCO & Wallce, Idaho \\
Sunshine Mine & Sunshine Mining Co. & Kellogg, Idaho \\
Strathcona Mine & Falconbridge & Onaping, Ontario \\
Fraser Mine & Falconbridge & Onaping, Ontario \\
Creighton Mine & INCO & Lively, Ontario \\
Frood-Stobie Mine & INCO & Sudbury, Ontario \\
Campbell-Red Lake Mine & Campbell Red Lake Mines & Balmertown, Ontario
\end{tabular}

The tectonic history and structural geology of Yucca Mountain is presented in Section 1.3 of the Department of Energy Site Characterization Plan (SCP), December 1988, and supporting documents. Subsections of particular interest include:

1.3.2

1.3.2.2.2

1.3.2.5.3
Tectonic History

Structures and Structural History of Yucca Mountain Implications for Repository Design and Performance Assessment

Long-term regional stability with respect to tectonic and geological processes is described in Section 1.5 of the SCP.

Rockbursts in the Sudbury mining area in Canada have contributed to deaths and lost production. To identify their sources and characteristics with better accuracy as to mitigate their effects, the Canada-Ontario-Industry Rockburst Project was initiated (Plouffe, et al, 1988). A state-of-the-art three-station digital seismograph network was deployed around the perimeter of the basin. The network senses about 550 triggers per month of which about $50 \%$ are located in the basin and related to mining activities. Of these, about 10 are confirmed by the mines.

Data are copied to the national seismological laboratory in Ottawa where they are compared with regional earthquake data. Findings are related back to the mines. Out-stations are linked by dedicated phone lines to a processing facility. A vertical single-component short period Teledyne-Geotech S13 seismometer is enclosed in a surface vault at each out-station location, along with a 60-hz digitizing package. Ground motion is detectable to $2 \mathrm{~nm} / \mathrm{s}$ (equivalent to the amplitude of a magnitude 1.5 event located at $100 \mathrm{~km}$ ). The dynamic range is $126 \mathrm{~dB}$ for a frequency range of 1 to $16 \mathrm{~Hz}$. All data transmitted (by phone) to the Sudbury site for processing. These data are transferred (again by phone) to Ottawa, where they are merged with other network and event files for earthquakes or teleseisms as appropriate and stored on magnetic tape. A monthly activity report is compiled to show the events attributed to mining activity. 
A system similar to the ones described for Welkom or Sudbury can be installed at Yucca Mountain to monitor events through the mandated years. Subsurface monitoring is desirable, but if the subsurface transducers become inoperative, sufficient relations between subsurface and surface recordings should by then exist to allow for surface monitoring to provide a proper scenario for the situation at depth. Under any event, it is desirable to obtain data from these monitoring operations and compare it with readings from the Nevada Test Site. It remains to compile a data bank for use in guiding this program. 


\section{DYNAMIC PERFORMANCE OF UNDERGROUND FACILITIES}

\subsection{General Observations}

The performance of an underground excavation in meeting its duty role is determined by the stresses and displacements which develop around the excavation under the loads arising from the prevailing field conditions. These conditions include rock mass strength, deformability, initial in-situ stresses, groundwater pressure distribution, thermal stress field, and dynamic loading. Apart from dynamic loading, these excavation performance factors are considered routinely in conventional pseudo-static design of underground excavations. The source of the dynamic loading may be transients which result from any of the energy sources whose ground motions were previously described. In all cases, transient stresses and displacements are associated with the dynamic event. Prediction and control of excavation response to dynamic events may be considered in terms of the interaction of transient motion with the static state arising from the prevailing field conditions.

The discussion of ground motion in Section 3 considered infinitesimal strain behavior of rock under the influence of a propagating wave. The unusual fabric of NTS tuff, as a porous and fractured or jointed medium, has required elucidation of its wave transmission and attenuation properties. In analyzing dynamic processes in tuff, Blatz (1975) demonstrated how jointed tuff might be analyzed as an equivalent continuum. The work is interesting from the point of view of the method proposed for synthesizing the equivalent continuum properties of tuff from the material and joint properties. However, the examination of $\mathrm{P}$-wave interaction with a fault presented in this paper appears unsatisfactory, due to invalid assumptions about the initial state of shear stress on the discontinuity.

The behavior of tuff under dynamic loading is dependent on porosity and saturation, particularly in the near-field of a nuclear explosion. Crowley (1972) reported results of laboratory investigations of tuff dynamic properties and concluded that peak particle velocity is directly related to peak stress, but inversely dependent on the density and acoustic velocity of the medium. It was observed that less porous and more saturated materials produce larger stresses, but they also have higher density and acoustic velocity. Finally, the attenuation of a stress wave is directly related to both void ratio and degree of unsaturation.

For the better prediction of ground motion due to nuclear and conventional explosions, Fogel, et al, (1985) developed a material model which took account of air-void content and the strain rate dependence of material properties. The model was exercised against laboratory-scale and large-scale test blasts, where it performed satisfactorily. Other investigations of strain-rate and water content dependence of material properties are reported by Froula, et al, (1988). The report emphasizes the effect of void ratio and degree of saturation on rock dynamic performance.

Early calculations of rock response to a nuclear explosion were based on simple models of material behavior and explosive source performance. Allen and Duff (1969) considered the rock mass as an elastoplastic solid whose yield surface is pressure and temperature dependent. A significant conclu- 
sion from the study was that rock mass strength parameters were scale dependent, a notion now firmly established in rock materials science.

In the transient states of stress associated with wave propagation, dilatancy is unlikely during the loading phase. However, Butcher and Costin (1985) propose that dilatancy may occur during dynamic loading as the rock unloads to the residual stress state. The effect is important because it can modify predictions of residual stress states and the final radii of the explosion cavities. Presumably, it may also modify predicted attenuation of ground motion.

The importance of wave propagation factors on both near- and far-field effects of nuclear explosives is indicated in the paper by Terhune, et al, (1979). They reported that seismic coupling efficiency is related to initial source radius, and is reflected in peak particle velocity and pulse duration of the outward propagating stress wave. Appropriate representation of the properties of the transmitting medium is also indicated in the paper by Patch, et al, (1978), which is concemed with dynamic interactions between an underground nuclear explosion and existing chimneys caused by prior nuclear blasts.

Early analysis of ground motion observed in underground nuclear explosions in the U.S.S.R. is reported by Kuznetsov and Baranov (1974). Using elementary empirical formulae, data are presented on the radius of seismic danger caused by underground explosions of varying power, and the particle velocity at various distances from the epicenter of a nuclear explosion. The authors conclude that the formulae used for determining accelerations and velocities provide good approximation to observed motion under full-scale nuclear explosion conditions. They also confirmed that prediction of the performance of structures under blast-induced seismic motion cannot be based on peak ground acceleration or velocity, but must take into account the velocity frequency composition, duration of motion and site geology. These conclusions are consistent with those proposed in later sections of this report.

For earthquake ground motion, it is notable that it is the complete time history of acceleration or motion which determines damage to structures, and not merely peak acceleration. St. John and Zahrah (1987) suggest that it is repetitive shaking with strong energy content which results in damage. In that case, "effective peak acceleration" has been proposed by Newmark and Hall (1982) as a parameter more representative of the damage potential of a seismic wave. Notwithstanding this, in mining and civil engineering practice, particle velocity history, and peak particle velocity, have become accepted as the determinants of wave damage potential (McGarr, 1983).

Extensive study of ground motion from conventional blasting has been conducted by the U.S. Bureau of Mines. A summary of results from such studies is provided by Snodgrass and Siskind (1974). It is found that, for both surface and underground blasts, ground motion can be related to charge weight per delay by a square root prediction expression of the form

$$
v=k\left(D / w^{1 / 2}\right)^{-n}
$$

$$
\begin{aligned}
& \text { where } v=\text { peak particle velocity, } \\
& \mathrm{D}=\text { shotpoint-receiver distance } \\
& \mathrm{w}=\text { maximum charge weight per delay, and } \\
& \mathbf{k} \text { and } \mathbf{n} \text { are empirical constants. }
\end{aligned}
$$

It is noted that there has been considerable argument about whether a square-root or cube-root prediction relation is appropriate in this expression. Either may be used, provided that the empirical 
constants are determined appropriately, and, in predicting blast performance, peak velocity data are interpolated from the established site data set.

The prediction of ground motion based on gross empirical expressions is generally inaccurate, and improved methods have been sought through detailed investigation of wave propagation in geologic media. Such media are characterized by elastoplastic (hardening or softening) constitutive behavior of the rock material, and the presence of joints and other discontinuities on a macroscopic scale. In this context, Higgins (1983) reports studies of such behavior under blast-induced near-field motion. The main conclusions of the study are that:

(1) dimensional analysis and scaling are useful in interpreting data and developing predictive relations, but the analysis and developed relations are more complex than reflected in the prevailing schemes;

(2) the properties of the explosive source (not a simple pressure boundary) need to be included in dimensional analysis;

(3) material inelasticity dominates system response, including attenuation rates and relation of stress to particle velocity, with a marked difference between wet and dry soils; and

(4) the data from experiments suggest that different coupling relations apply for different ground shock parameters and that, because the source decay exponent varies with depth of charge, a simple coupling factor is not appropriate.

In a review of constitutive analysis of blast-induced wave propagation, Drumm (1985) considered problems of design of underground structures arising from inaccurate description of the stress-time history at the structure. It was found that wave attenuation during propagation is a function of the inelastic performance of the soil, and this is related to the loading rate. Soil behavior may change from hardening to softening, depending on the loading rate. Thus, description of ground motion at a structure may be based most appropriately on a wave propagation analysis taking into account the observed constitutive behavior of the host medium.

\subsection{Underground Excavation Response}

The usual range of site characteristics and excavation design variables determines the response of an excavation to seismic loading. These include the mechanical properties, structure and ambient state of stress in the host rock mass, the shape and dimensions of the excavation, the properties and design of any support and reinforcement systems, and the nature of the imposed ground motion. While considerable information has been collected on seismic damage to excavations, it is unusual for both the ground motion and the rock mass motion to be defined sufficiently comprehensively to allow well founded determination of conditions leading to dynamic failure of openings. This has led to a significant margin of uncertainty in establishing relations between rock mass properties, excavation design factors, imposed ground motion, and excavation response.

The duration of strong ground motion is intuitively a major determinant of rock response to seismic loading, since rock and rock-like materials are subject to fatigue failure (Balachandra, et al., 1978) and rock joints and faults accumulate damage and decrease in shear strength under cyclic loading (Brown and Hudson, 1974). St. John and Zahrah (1987) observe that there is currently no generally accepted method of describing the duration of strong ground motion, and that the effects of repeated, cyclic loading on underground excavation performance are not well known. (Indeed, these issues are major motivation for the current project.) 
Seismic effects on underground excavations have been subject to several reviews in the recent past, due to interest in mine and tunnel stability during earthquakes, proposals for subsurface siting of nuclear power plants, and military interest in dynamic integrity of subsurface defense installations. Of these reviews, that conducted by Stevens (1977), concemed with earthquake effects on underground mines, provides a very qualitative introduction to mine excavation response to natural earthquakes. The main conclusions are:

(1) severe damage occurs when a mine is transgressed by a fault along which movement occurs during an earthquake;

(2) mines in the epicentral region of a strong earthquake, but not transgressed by fault displacement, may suffer severe damage from shaking; and

(3) mines outside the epicentral region are likely to suffer little or no damage from a strong earthquake.

Some features of this review are that no data are presented in the report which are usable in any analytical sense, and experience on excavation performance arising from mine earthquakes and rockbursts is considered only superficially.

In a more recent review, Owen and Scholl (1981) considered that seismic damage to underground excavations reflected three modes of rock response, consistent with the observations by Stevens (1977): (1) fault slip, (2) rock mass failure, and (3) shaking.

Excavation damage due to fault slip (also called block motion in design of defense structures) is recognized to be the most destructive mode of response, since no lining or reinforcement technique can conceivably resist the imposed shear motion at the fault. On the other hand, rock mass failure leading to excavation damage occurs most frequently as a diffuse mode of deformation involving slides, subsidence or collapse, and may be controlled through appropriate siting, support and reinforcement of excavations.

Excavation damage due to oscillatory motion or shaking appears to be the most prevalent and the most widely studied of the response modes. Damage to an unlined excavation is expressed as cracking and spalling of the rock mass, and rigid body displacement at joint surfaces, perhaps involving rock falls. For lined excavations, cracking, spalling and rupture of the liner may occur.

Although explosive loading of an underground excavation results in transient loading, the resulting state of stress may be either dynamic or pseudostatic. As noted by Labreche (1983), the type of loading to be considered depends on the ratio $(\lambda / D)$ of the wavelength $(\lambda)$ of the stress or velocity waveform to the excavation diameter (D). When the duration of loading is short, corresponding to a small $\lambda / D$ ratio, excavation response is dynamic. A large $\lambda / D$ ratio corresponds to a long duration loading, and the response is effectively static. The loading considered here relates to dynamic conditions.

Rock structure is a critical determinant of rock mass performance under dynamic loading. The effect of joints is to reduce rock mass modulus and strength, and to provide planes of weakness on which slip, separation and rigid body translation of blocks can occur preferentially. Model tests by Hendron and Aiyer (1972) confirmed that shear deformation was concentrated on joint planes, while tests on unlined excavations by Kennedy and Lindberg (1976) and Bureau (1972) indicated that both falling of rock blocks and rock mass rupture could occur. Some account of the role of rock structure on tunnel performance is reflected in the graphical relation shown in Fig. 4.1, due to Hendron and Aiyer 


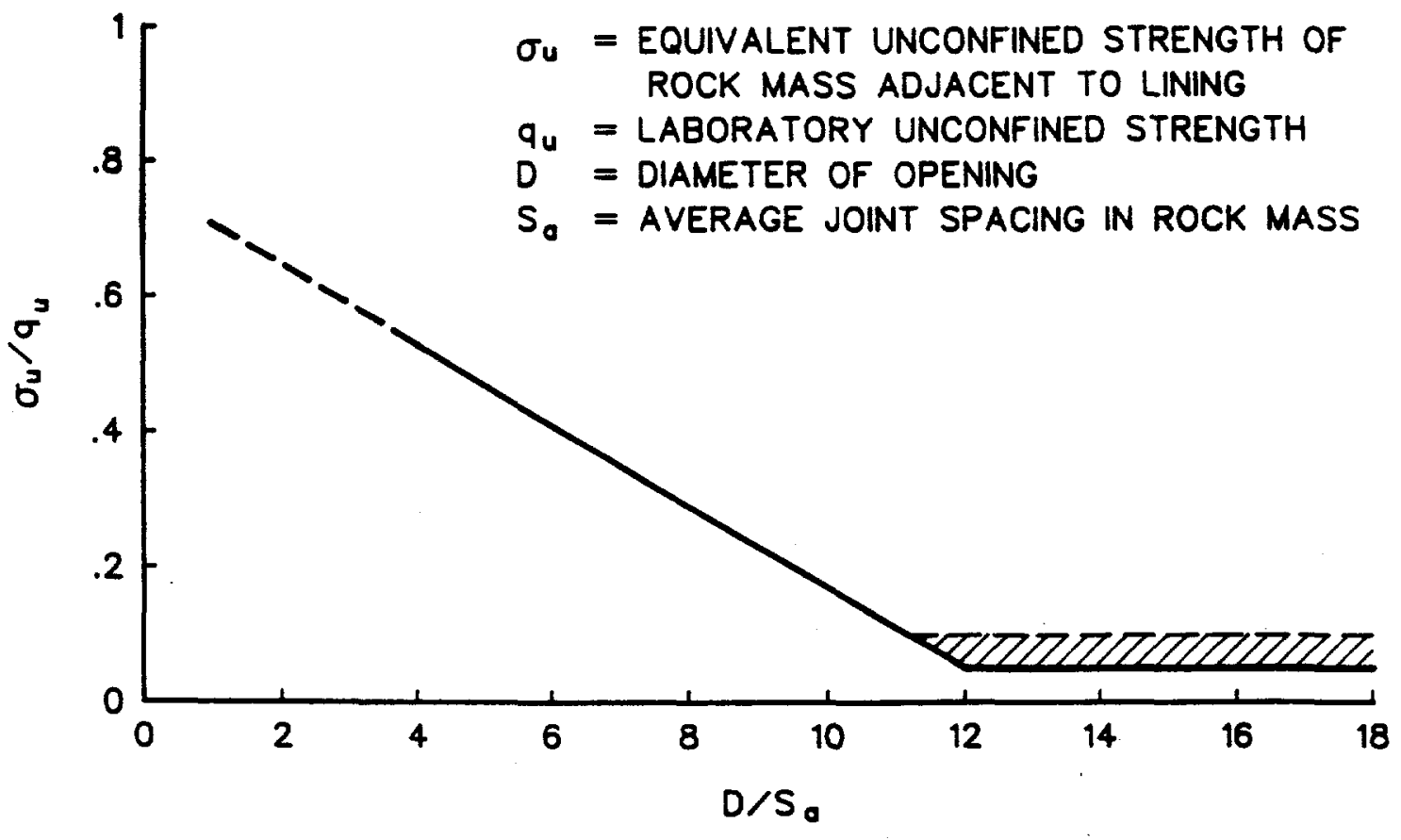

FIGURE 4.1

RATIO OF IN-SITU STRENGTH TO LABORATORY STRENGTH AS A FUNCTION OF TUNNEL DIAMETER TO JOINT SPACING (FROM HENDRON AND AIYER, 1972) 
(1972). However, the orientation of structural features is ignored in this strength scaling relation, whereas it can be expected to exert substantial control on the mode of excavation response.

In reporting conditions under which damage occurred around underground excavations, Dowding and Rozen (1978) proposed three levels of damage due to ground motion: no damage, minor damage, and damage. A condition of no damage corresponded to development of no new cracks, spalls, or falls of ground; that of minor damage to new cracking and minor rockfalls; that of damage to severe cracking, major rockfalls, and closure. Since direct measurements of ground motion at the subject sites were not available, ground motion data were estimated from empirical relations. The results of correlating underground excavation damage with peak acceleration and peak velocity at the ground surface are shown in Figures 4.2 and 4.3.

Evaluation of the data presented by Dowding and Rozen suggests that no damage should be sustained if the peak surface acceleration is below $0.2 \mathrm{~g}$, and only minor damage in the range $0.2 \mathrm{~g}$ to $0.4 \mathrm{~g}$. However, McGarr, et al., (1981) and McGarr (1983) propose that damage to mining excavations adjacent to rockbursts can be more suitably and readily correlated with peak velocity than with peak acceleration. This is reasonable because particle velocity can be related directly to transient stress, and the second power of velocity to strain energy in the wave. The corresponding threshold values for minor damage and damage observed by Dowding and Rozen are $200 \mathrm{~mm} / \mathrm{s}$ and $400 \mathrm{~mm} / \mathrm{s}$. It should be noted that these results relate motion at the ground surface with damage to subsurface excavations. From the preceding discussions of the relation between surface and subsurface ground motion, it is clear that the ground velocity and velocity history experienced at a subsurface site may be substantially different from that observed at the surface. That is to say, correlation of surface velocity with damage to an underground excavation is a procedure about which some uncertainty should be entertained.

It has been noted that rockbursts are mechanically similar to natural earthquakes. Since rockbursts occur in a restricted domain, and fairly frequently, it is not surprising that most data on earthquake response of underground excavations has been derived from deep-level hard rock mines. In this respect, the survey by Wagner (1984) provided in Table 4.1 is an informative view of excavation response under extreme conditions of strong ground motion. The data are apparently consistent with the preceding observations concerning thresholds for excavation damage obtained from earthquake studies.

In a more recent study of excavation damage by rockbursts, Lenhardt (1988) correlated distance from a seismic event, magnitude of the event, particle velocity and damage. The correlation is shown in Figure 4.4. The plot indicates that the threshold for fall of loose rock is $50 \mathrm{~mm} / \mathrm{s}$, for ground falls is $300 \mathrm{~mm} / \mathrm{s}$, and for severe damage $600 \mathrm{~mm} / \mathrm{s}$. There is clearly a measure of consistency between this data and the damage thresholds suggested by Dowding and Rozen (1978), if not a close correspondence.

The damage threshold values proposed by Lenhardt (1988) appear to be based on those proposed by Langfors and Kihlstrom (1973) for excavation damage due to conventional blasting. They proposed that a particle velocity of $300 \mathrm{~mm} / \mathrm{s}$ induces fall of rock, and a velocity of $600 \mathrm{~mm} / \mathrm{s} \mathrm{causes} \mathrm{generation}$ of new fractures.

According to St. John and Zahrah (1987), the damage thresholds proposed above are conservative when compared with the results of the Underground Explosion Test (UET) Program, which involved the detonation of large charges adjacent to excavations with the purpose of establishing dynamic 


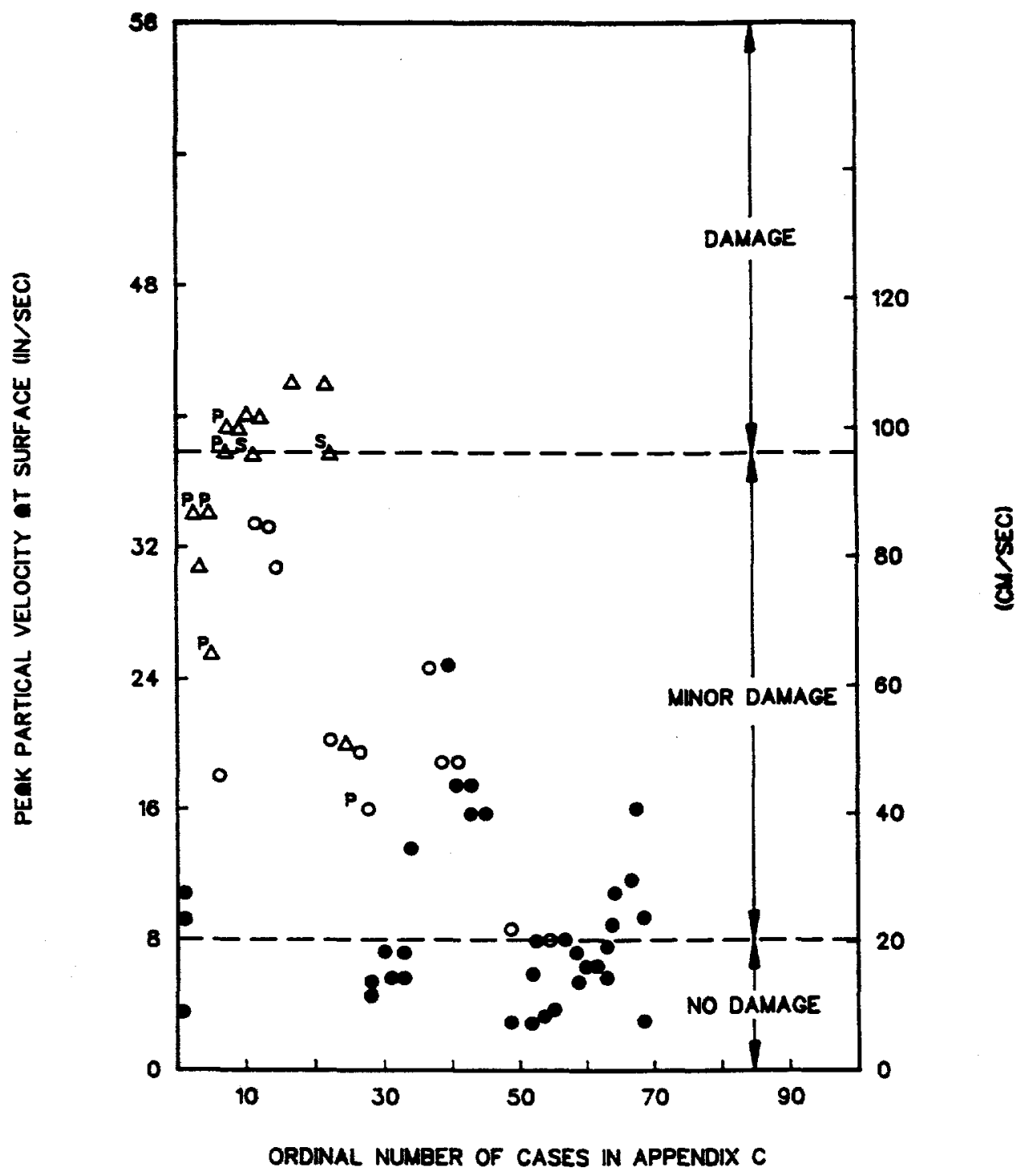

LEGEND

- no damage

- maror DAMAGe

$\triangle$ DAMAGE FROM SHAKING
PA NEAR PORTAL

$S_{\triangle}$ SHALLOW COVER

FIGURE 4.2

CALCULATED PEAK VELOCITIES AND ASSOCIATED DAMAGE OBSERVATIONS FOR EARTHQUAKES

(FROM OWEN AND SCHOLL, 1981) 


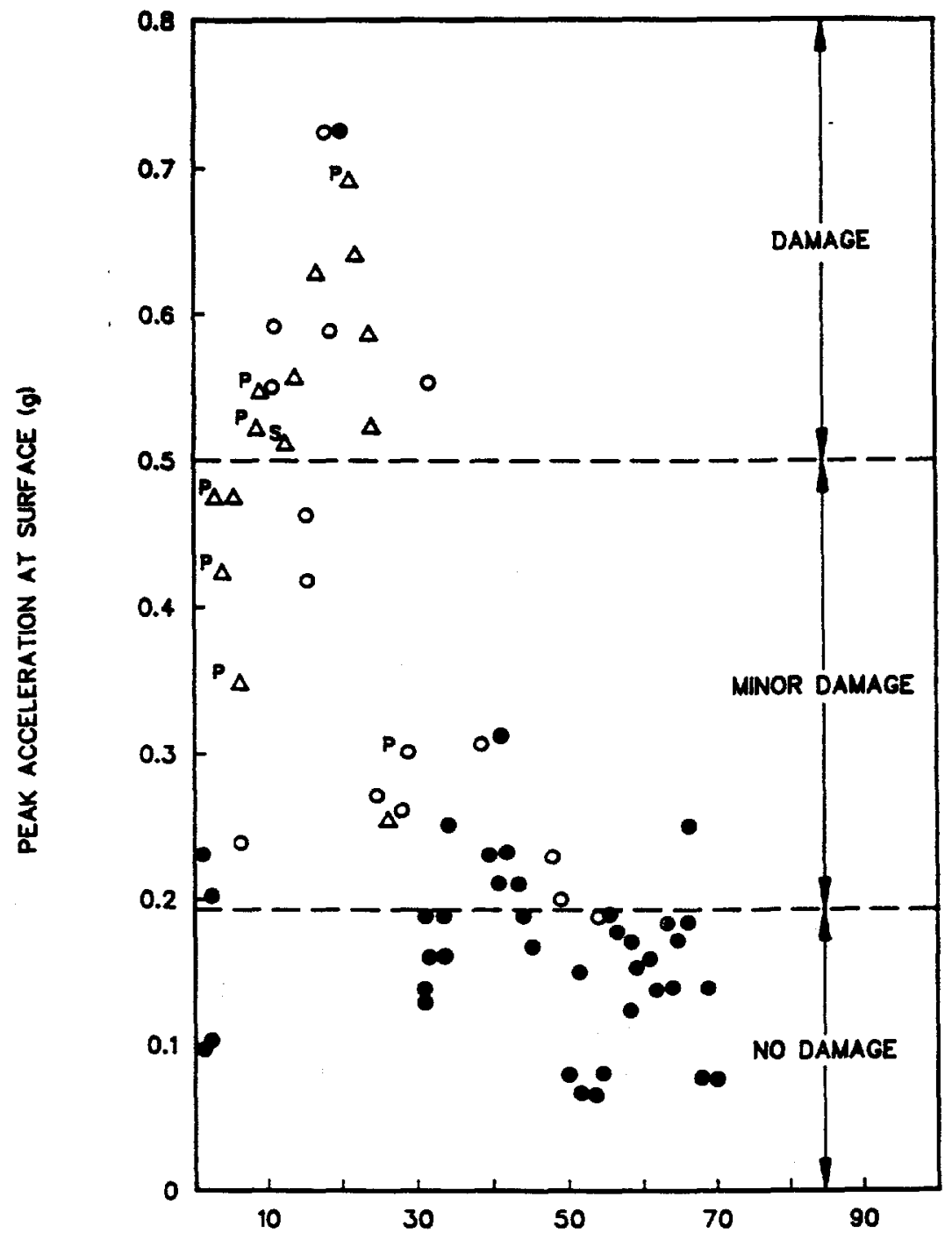

ORDNAL NUMEER OF CASES IN APPENDIX C

LEGEND

- no damage

- MINOR DAMAGE

$\triangle$ DAMAGE FRON SHAKING

FIGURE 4.3

CALCULATED PEAK SURFACE ACCELERATIONS AND ASSOCIATED DAMAGE OBSERVATIONS FOR EARTHOUAKES (FROM OWEN AND SCHOLL, 1981) 
Table 4.1 Summary of Rockburst Damage to Underground Excavations

(Wagner, 1984)

\begin{tabular}{|c|c|c|c|c|}
\hline Mining District & $\begin{array}{l}\text { Magnitude } \\
\text { of Event }\end{array}$ & $\begin{array}{l}\text { Distance of } \\
\text { Damaged Areas } \\
\text { from Source of } \\
\text { Event }(\mathbf{m})\end{array}$ & Nature of Damage & Estimated Peak Velocity \\
\hline Klerksdorp & 4.4 & $200 \mathrm{~m}$ & $\begin{array}{l}\text { Faces within } 100 \mathrm{~m} \text { from source } \\
\text { completely closed. } \\
\text { Extensive damage to sidewalls of } \\
\text { tunneis. }\end{array}$ & $\begin{array}{l}\text { at } 200 \mathrm{~m}, \overline{\mathrm{v}}=2 \mathrm{~m} / \mathrm{s} \\
\text { at } 100 \mathrm{~m}, \overline{\mathrm{v}}=3.5 \mathrm{~m} / \mathrm{s}\end{array}$ \\
\hline Klerksdorp & 5.0 & up to $750 \mathrm{~m}$ & $\begin{array}{l}\text { Faces within } 250 \mathrm{~m} \text { from source } \\
\text { completely closed. } \\
\text { Stope faces up to } 750 \mathrm{~m} \text { from } \\
\text { source showed appreciable } \\
\text { damage. }\end{array}$ & $\begin{array}{l}\text { at } 750 \mathrm{~m}, \overline{\mathrm{v}}=0.9 \mathrm{~m} / \mathrm{s} \\
\text { at } 250 \mathrm{~m}, \overline{\mathrm{v}}=2.6 \mathrm{~m} / \mathrm{s}\end{array}$ \\
\hline Klerksdorp & 3.9 & $100 \mathrm{~m}$ & $\begin{array}{l}\text { Extensive sidewall damage in } \\
\text { tunnels. }\end{array}$ & at $100 \mathrm{~m}, \overline{\mathrm{v}}=1.7 \mathrm{~m} / \mathrm{s}$ \\
\hline Klerksdorp & 2.7 & $\pm 100 \mathrm{~m}$ & $\begin{array}{l}40 \mathrm{~m} \text { of stope face damaged. } 90 \mathrm{~m} \\
\text { from event extensive roof falls in } \\
\text { tunnel. }\end{array}$ & $\begin{array}{l}\text { at } 100 \mathrm{~m}, \overline{\mathrm{v}}=0.4 \mathrm{~m} / \mathrm{s} \\
\text { at } 50 \mathrm{~m}, \overline{\mathrm{v}}=1 \mathrm{~m} / \mathrm{s}\end{array}$ \\
\hline Klerksdorp & 1.1 & $\pm 10 \mathrm{~m}$ & Stope travelling way collapsed. & at $10 \mathrm{~m}, \overline{\mathrm{v}}=0.4 \mathrm{~m} / \mathrm{s}$ \\
\hline Carletonville & 4.0 & $\pm 100 \mathrm{~m}$ & $\begin{array}{l}\text { Total closure of stope for a } \\
\text { distance of } 100 \text { m either side of } \\
\text { focus of event. Follow-on tunnels } \\
\text { not affected. }\end{array}$ & $\begin{array}{l}\text { at } 100 \mathrm{~m}, \overline{\mathrm{v}}=1.7 \mathrm{~m} / \mathrm{s} \\
\text { at } 50 \mathrm{~m}, \overline{\mathrm{v}}=3.5 \mathrm{~m} / \mathrm{s}\end{array}$ \\
\hline East Rand & 2.9 & $\pm 50 \mathrm{~m}$ & $\begin{array}{l}\text { Stope face completely closed for a } \\
\text { distance of } 30 \mathrm{~m} \text { and extensive } \\
\text { falls for another } 10 \mathrm{~m} \text {. } \\
\text { Cross-cut to stope collapsed but } \\
\text { post developed footwall tunneis } \\
\text { undamaged. }\end{array}$ & $\begin{array}{l}\text { at } 50 \mathrm{~m}, \overline{\mathrm{v}}=0.26 \mathrm{~m} / \mathrm{s} \\
\text { at } 15 \mathrm{~m}, \overline{\mathrm{v}}=1.2 \mathrm{~m} / \mathrm{s}\end{array}$ \\
\hline Central Rand & 2.0 & $\pm 50 \mathrm{~m}$ & $\begin{array}{l}\text { Main haulage almost completely } \\
\text { closed over a distance of } 20 \mathrm{~m} \\
\text { and showing appreciable damage } \\
\text { for over a total distance of } 90 \mathrm{~m} \text {. }\end{array}$ & $\begin{array}{l}\text { at } 50 \mathrm{~m}, \overline{\mathrm{v}}=0.26 \mathrm{~m} / \mathrm{s} \\
\text { at } 10 \mathrm{~m}, \overline{\mathrm{v}}=1.2 \mathrm{~m} / \mathrm{s}\end{array}$ \\
\hline
\end{tabular}




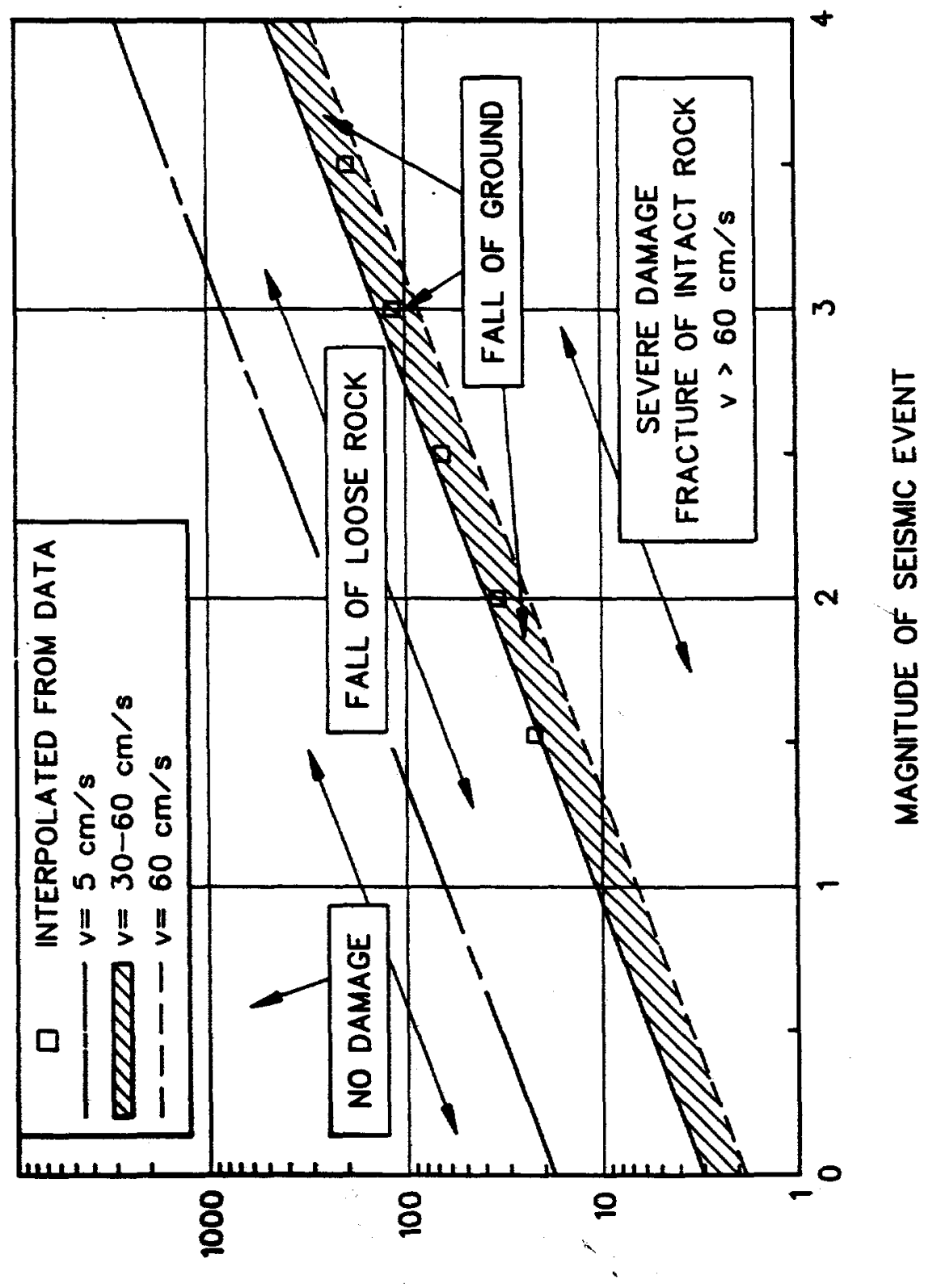

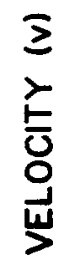

윽

+ 告

w文

号稆

은 는

岁光

옹

迹足

w

$\underline{Z}$

岁

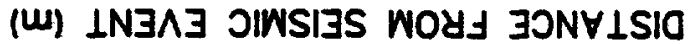


design criteria. Damage caused by intermittent spalling was observed at $900 \mathrm{~mm} / \mathrm{s}$, and continuous damage at $1800 \mathrm{~mm} / \mathrm{s}$. In other tests involving nuclear explosions, it was suggested that the threshold for damage to unlined excavations is $1800 \mathrm{~mm} / \mathrm{s}$. These damage threshold velocities derived from explosion-induced loading are obviously considerably higher than those reported for earthquake loading.

Underground excavations may be subject to repetitive episodes of seismic loading in the course of their duty life. However, no field observations have been reported related to excavation performance under these conditions. In a model study of repeated seismic loading of excavations in jointed rock. Barton and Hansteen (1979) observed the progressive accumulation of joint shear deformation as loading persisted. This suggests that a damage threshold may not be a realistic parameter for excavation performance. Instead, fatigue failure of joints may be a more appropriate concept to consider. Such an approach would be consistent with the observations by Brown and Hudson (1974) of failure of models of jointed rock under cyclic loading.

\subsection{Contemporary Design Criteria}

The types of underground excavations involved in underground facilities include tunnels, shafts, large chambers, storage rooms and equipment bays. Support and reinforcement of these excavations ranges from none, through rock bolts, mesh, shotcrete, steel sets and concrete linings. In general, the rigidity of these linings is so low that imposed ground motion induces excavation deformation coherent with that of the free-field ground displacements.

In the case of lined excavations, a simple design procedure involves calculation of total stresses (i.e. static plus transient) or total strains in the liner, and comparing these with the damage threshold values for the liner (URS/Blume, 1976). In this procedure, free-field motion is calculated from the one-dimensional wave equation, assuming all the energy is transmitted in the shear wave. Axial strains are calculated readily from peak particle velocity and shear wave propagation velocity. However, the interaction of a shear wave with the plane section of a cylindrical excavation has not been solved formally. It is proposed that a dynamic stress concentration factor of 4 is suitably conservative in estimating peak transient stresses from the peak stress in the wave form.

In assessing particle velocity induced by seismic events at underground sites, McGarr, et al., (1981) suggest that peak particle velocity $v$ is related to local magnitude $M_{L}$ of a seismic event by the expression:

$$
\log v=3.95+0.57 \mathrm{M}_{L}-\log R
$$

where $v=$ velocity in $\mathrm{cm} / \mathrm{s}$, and

$\mathbf{R}=$ distance in $\mathrm{cm}$.

This expression provides a simple method for estimating the peak particle velocity at a point as a function of the anticipated magnitude of the seismic source event, and the distance of the underground excavation from the source.

The preceding discussion of the response of an underground excavation to strong motion from various sources suggested that explosives have much less damage potential than natural or mining-induced seismic events. This is due to an essential difference between the ground motion resulting from an earthquake and that induced by a conventional or nuclear explosion. The motion associated with an explosion is predominantly a single compression pulse with a duration of several hundred milliseconds, or less. Earthquake-induced motion typically persists for several seconds, in the course of 
which an excavation is subject to several stress and displacement cycles. After numerical analysis of the effects on excavation performance of a number of stress wave cycles, Dowding, et al., (1983) proposed that damage accumulation in excavation peripheral rock is directly related to load cycling during earthquake loading. This conclusion is supported by the work of Barton and Hansteen (1979) concerning damage accumulation on joints subject to cyclic loading. Thus, because explosive loading involves limited load cycling, excavation performance criteria established from earthquake loading will be conservative in predicting excavation response to explosives.

The damage thresholds for earthquakes have been proposed as $200 \mathrm{~mm} / \mathrm{s}$ by Dowding and Rozen (1978) and $300 \mathrm{~mm} / \mathrm{s}$ by Lenhardt (1988). Noting that the threshold proposed by Lenhardt is apparently based on notions derived from blasting mechanics for conventional explosives, it is prudent to adopt the damage threshold appropriate to sustained cyclic loading associated with earthquakes. Thus, the current criterion for prevention of damage to excavations in rock is taken as $200 \mathrm{~mm} / \mathrm{s}$. It is proposed that no damage should occur around excavation boundaries if the peak particle velocity is below this value. Also, although it has been noted that there are substantial differences between excavation response to earthquakes and explosions, adoption of the $200 \mathrm{~mm} / \mathrm{s}$ velocity limit is probably a conservative criterion for damage prevention during explosion-induced loading. As understanding improves of the effect of cyclic loading on joint and rock material damage, it is possible that the design criterion will be modified.

A second mode of excavation dynamic response involves local fault slip, on a fracture not seismically active in its natural condition. The design criterion in this case is that the dynamic shear stress operating on the plane of weakness must be less than the dynamic shear strength, by an appropriate factor of safety. In designing against fault slip, account must be taken of the site-specific conditions of rock structure, state of stress, and dynamic friction properties of faults. Computer codes capable of dynamic analysis of discontinuous rock are required for application of such a design criterion.

A third mode of excavation seismic response involves instability of individual blocks in the block-jointed host medium for an excavation. Several design procedures have been proposed for these ground conditions. Barton (1982) suggested a modification to an existing rock mass classification scheme, to take account of dynamic factors. Since such schemes are of limited value for excavation design under static conditions, further development for dynamic conditions is difficult to justify. Hendron and Fernandez (1983) proposed a technique based on estimation of the support pressure $P_{i}$, to be exerted against the roof of an excavation, using the expression

$$
\left.P_{i}=n B \gamma 1.0+(a / g)\right]
$$

In this expression, $a$ is the ground acceleration, $n$ is an empirical parameter, $B$ is the span of the cavern, and $\gamma$ is the unit weight of the rock.

In assessing the performance of excavations in jointed rock, one design criterion is that there be no blocks kinematically capable of displacing into the excavation. Identification of such blocks is possible using the keyblock theory proposed by Goodman and Shi (1985) and Warburton (1985). Definition of potentially unstable blocks is a basis for design of a rock reinforcement system. Alternatively, computational methods such as the Distinct Element Method (Cundall, 1971, 1988) may be used for both identification of unstable blocks and design of a rock reinforcement system. In this case, the design criterion is that, for the ground motion conceivable at the excavation site, the excavation peripheral rock, including any emplaced rock reinforcement, is capable of preventing displacement into the excavation of rock blocks forming the boundary of the excavation. 


\section{ROCK MASS PROPERTIES}

\subsection{Rock as an Engineering Medium}

Analysis of the performance of rock around shafts, excavations, and other engineered structures requires prior definition of the strength, stiffness and stability parameters for the rock mass. Important parameters determining rock behavior are the constants relating stresses and strains in the elastic range, the stress levels at which yield,fracturing or slip occurs within the rock mass, and the post-peak stress-strain behavior of the fractured or "failed" rock.

In some problems, it may be the behavior of the intact rock material that is of concem. This will be the case when considering the excavation of rock by drilling and blasting, or when considering the stability of excavations in good quality, brittle rock which is subject to rockburst conditions. In other instances, the behavior of single discontinuities, or of a small number of discontinuities, will be of paramount importance. Examples of this class of problem include the equilibrium of blocks of rock formed by the intersections of three or more discontinuities and the roof or wall of an excavation, and cases in which slip on a major through-going fault must be analyzed. A different class of problem is that in which the rock mass must be considered as an assembly of discrete blocks. The normal and shear force-displacement relations at block face-to-face and comer-to-face contacts are of central importance in this case. Finally, it is sometimes necessary to consider the global response of a jointed rock mass in which the discontinuity spacing is small on the scale of the problem domain. The behavior of caving masses of rock is an obvious example of this class of problem.

It is important to note that the presence of major discontinuities or of a number of joint sets does not necessarily imply that the rock mass will behave as a discontinuum. In environments in which the rock surrounding the excavations is always subject to high compressive and low shear stresses, the surfaces may be frictionally locked, and it may be reasonable to treat a jointed rock mass as an equivalent elastic continuum. The way in which rock material and discontinuity properties may be combined to obtain the elastic properties of the equivalent continuum is considered later.

\subsection{Rock Material Properties}

For an isotropic rock material, the important mechanical properties in excavation design are the uniaxial compressive strength, $\sigma_{c}$, the triaxial strength, and the elastic constants, defined by the Young's modulus, $\mathrm{E}$, and the Poisson's ratio, $v$. With the exception of the triaxial strength, these properties may all be determined in a uniaxial compression test. Standard procedures for this test have been established by the International Society for Rock Mechanics.

An example of the results of a uniaxial compression test is shown in Fig. 5.1. It is noted that the Young's modulus is not uniquely determined, varying throughout the loading history. Common methods of defining the Young's modulus are: 


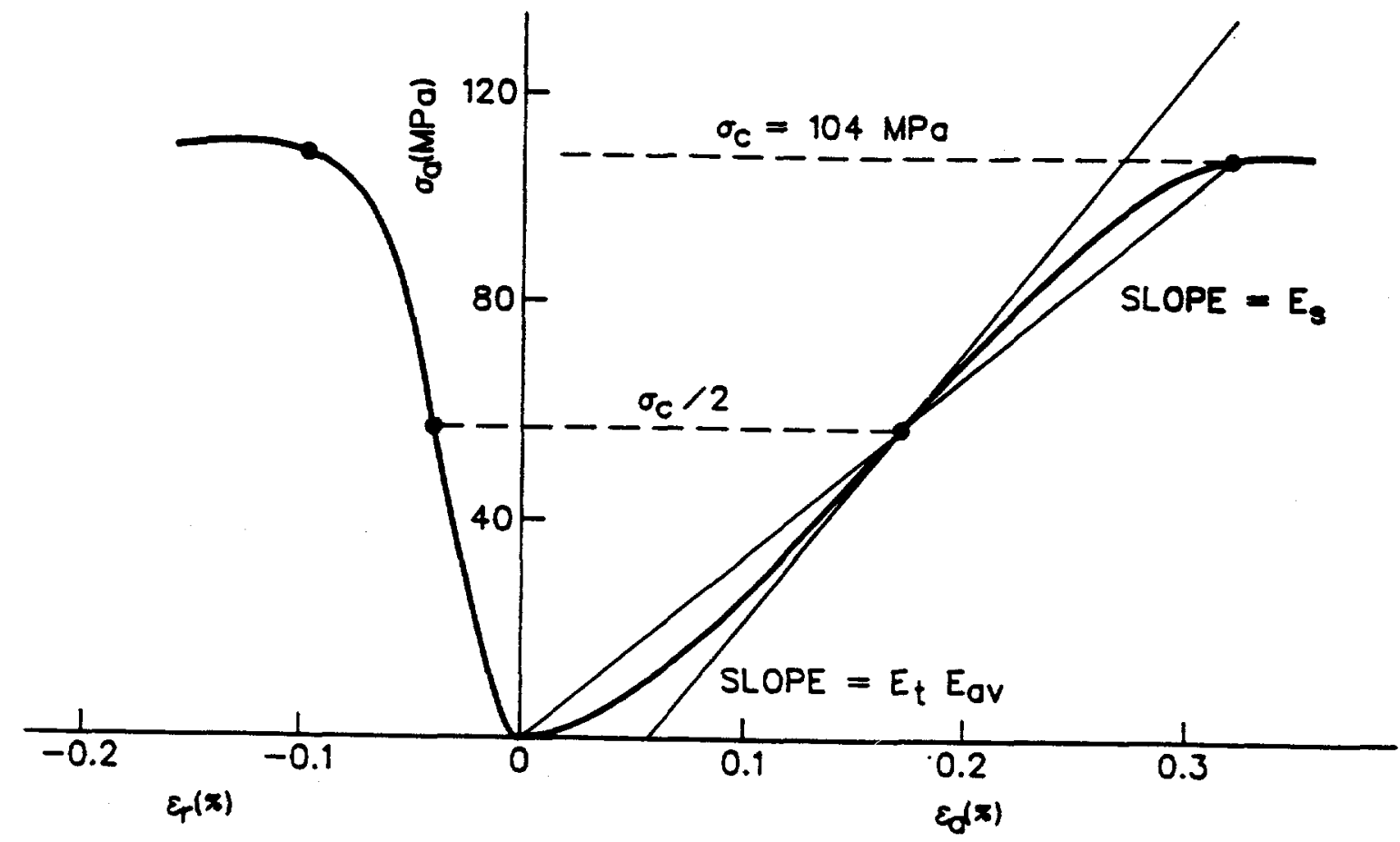

FIGURE 5.1

TYPICAL RESULTS OF A UNIAXIAL COMPRESSION TEST ON ROCK (EXTRACT TAKEN FROM ROCK YECHANICS FOR UNDERGROUND MINING, BY DR. B.H.G. BRADY, REPRODUCED BY KIND PERMISSION OF UNWIN HYMAN LTD., LONDON.) 
(1) tangent Young's modulus, $E_{l}$, given by the slope of the stress-strain curve at $50 \%$ of peak strength;

(2) average Young's modulus, $E_{a v}$, which is the slope of the linear section of the stress-strain curve; and

(3) secant Young's modulus, $E_{5}$, which is the slope of a straight line joining the origin to a nominated point on the stress-strain curve.

For any value of the Young's modulus, a value of Poisson's ratio is determined by

$$
v=-\left(\Delta \sigma_{\mathrm{a}} / \Delta \varepsilon_{\mathrm{a}}\right) /\left(\Delta \sigma_{\mathrm{a}} / \Delta \varepsilon_{\mathrm{r}}\right)
$$

where $a, r$ denote axial and radial directions.

Although the uniaxial compression test is simple in concept, factors such as specimen end effects and specimen height-to-width ratio, specimen volume and strain rate control specimen performance. Testing machine stiffness influences the results of the test in the post-peak strength range of specimen performance.

In the elastic range of material performance, unloading and reloading cycles are relatively free of hysteresis after the specimen has been "bedded-in". However, for the post-peak range, unloading and reloading show distinct hysteresis, as shown in Fig. 5.2.

Strength of a rock material in triaxial compression has been found to be relatively independent of the intermediate principal stress (Brown and Gonano, 1975). The Mohr-Coulomb strength criterion is based on a relation between the major and minor principal stresses, of the form

$$
\sigma_{1}=\frac{\sigma_{3}(1+\sin \varphi)}{1-\sin \varphi}+\frac{2 c \cos \varphi}{1-\sin \varphi}
$$

where $\mathrm{c}=$ the cohesion, and

$$
\phi=\text { the angle of internal friction }
$$

In general, however, the relation between the principal stresses at failure is non-linear. Hoek and Brown (1980) proposed an empirical strength criterion of the form

$$
\frac{\sigma_{1}}{\sigma_{c}}=\frac{\sigma_{3}}{\sigma_{c}}+\left[m \frac{\sigma_{3}}{\sigma_{c}}+1.0\right]^{1 / 2}
$$

where $m$ is a function of rock type.

For rock materials in which a uniformly-oriented fabric element is expressed, such as a schistosity or foliation, the principal stresses at failure show a pronounced dependence on the orientation of the fabric relative to the principal stress directions. The theory proposed by Jaeger (1960) is frequently used to estimate material strength based on assumed properties for the cohesion and angle of friction of the planes of weakness.

\subsection{Rock Mass Discontinuities}

In rock mechanics problems other than those involving only fracture of intact rock, the shear behavior of discontinuities, such as faults, joints, shear zones and bedding planes, will determine rock mass deformation. Conditions for slip on major pervasive features such as faults or for the sliding of individual blocks from the boundaries of excavations are governed by the shear strengths that can 


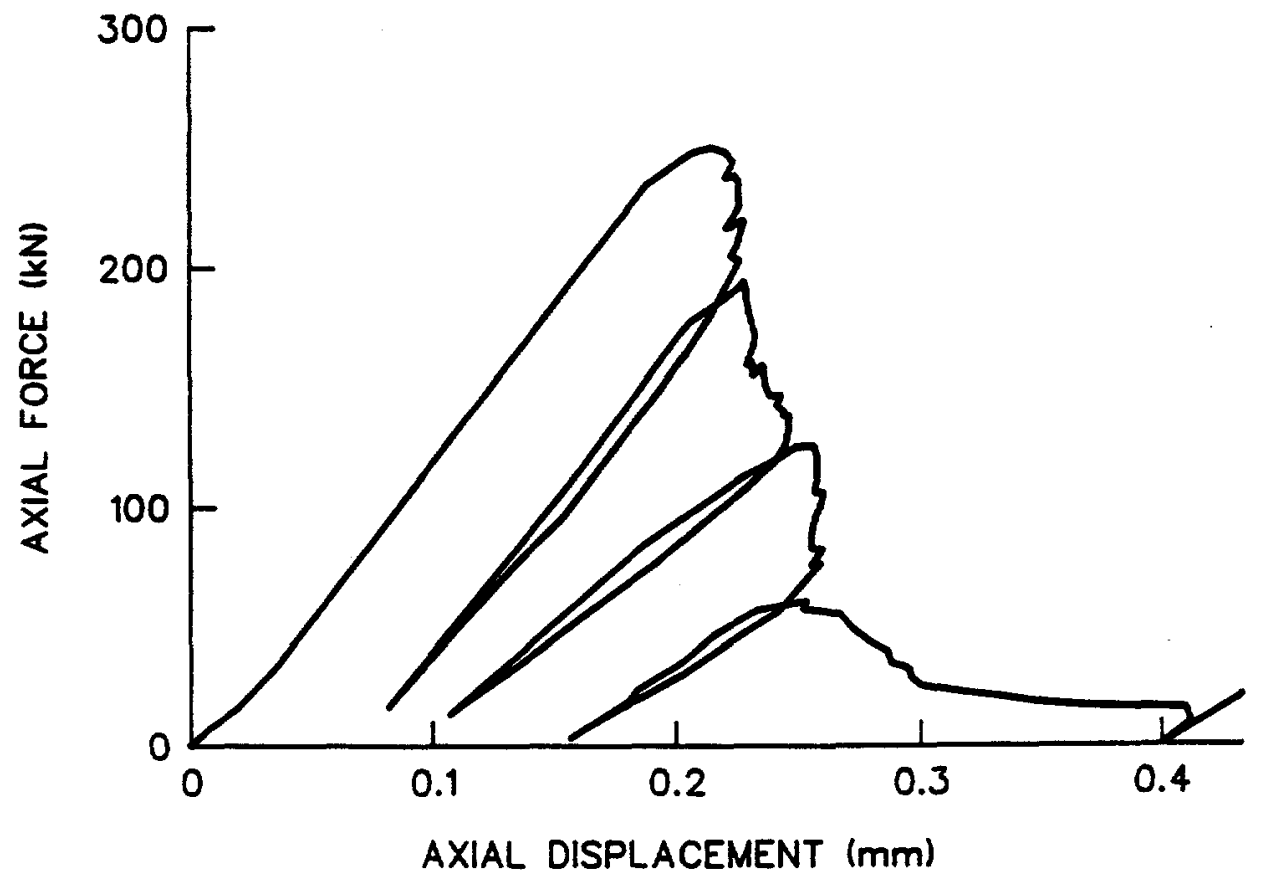

FIGURE 5.2

AXIAL FORCE - AXIAL DISPLACEMENT CURVE OBTAINED

FOR TENNESSEE MARBLE WITH POST-PEAK UNLOADING AND RELOADING.

(FROM WAWERSIK AND FAIRHURST, 1970) 
be developed by the discontinuities concerned. Furthermore, the shear and normal stiffness of discontinuities can exert a controlling influence on the distribution of stresses and displacements within a discontinuous rock mass.

In Section 4.0, it was noted that underground excavation failures under seismic loading most frequently involve failures at joints. Therefore, in the analysis of excavation response to dynamic loading, particular attention must be paid to the properties of joints under the conditions developed in their operating setting. In this respect, there are three aspects of joint behavior to be considered explicitly in assessing jointed rock behavior around repository excavations:

(1) the performance of joints under pseudo-static conditions of cyclic loading;

(2) the performance of joints under dynamic loading conditions; and

(3) the performance of joints under repetitive episodes of dynamic loading arising from, for example, a series of earthquakes or a series of underground nuclear explosions.

The static properties of discontinuities are measured in a direct shear test, or a triaxial cell. Characterization of the complete load-deformation behavior of a joint requires determination of a normal stress-normal closure relation, a shear stress-shear deformation relation, and the relation between shear strength and normal stress. It should be noted that, in the direct shear test, questions related to stiffness of the test environment, and the effect of non-uniform load distribution over the loaded surface, are still unresolved.

In a conventional shear test, a normal load is applied to a specimen, the normal closure determined, and the shear displacement induced by a series of known applied shear stresses is determined. The plot of shear stress versus shear displacement may show bilinear (elastic-plastic) behavior, as for a joint or fault at a residual state of strength. More typically, the shear response shows peak-residual behavior, as shown in Fig. 5.3. Repetition of the experiment at several applied normal stress values permits construction of the shear strength envelopes, for peak and residual conditions, as shown in Fig. 5.4. The notable feature of Fig. 5.4 is the marked non-linearity of the peak strength-normal stress curve, and the substantial difference between peak and residual strengths.

The simplest coherent model of joint deformation and strength developed from a direct shear test is the Coulombic friction, linear deformation model. It is illustrated in Fig. 5.5. The key features are, for normal loading (Fig. 5.5a), elastic reversible closure up to a limiting value $u^{\prime} n$, and joint separation when the normal stress is less than the joint tensile strength. For shear loading (Fig. 5.5b), shear displacement is linear and reversible up to a limiting shear stress (determined by the normal stress), and then perfectly plastic. Shear load reversal after plastic yield is accompanied by permanent shear displacement and hysteresis. The relation between limiting shear resistance and normal stress, shown in Fig. 5.5c, is typical of Coulombic friction.

The Coulombic friction, linear deformation joint model may be appropriate for smooth discontinuities which are non-dilatant in shear, such as faults at residual strength. The value of the model is that it is a useful reference case for joint deformation and strength.

It is observed in Fig. 5.3 that the joint shear stress-shear displacement curve shows distinct peak-residual behavior. Such behavior is related to joint dilatancy during shear displacement, which is itself due to joint roughness (Patton, 1966). Surface roughness also affects the normal stressclosure response, and the limiting shear resistance of the surface. The effect of surface roughness on joint deformation and strength has been described by Barton, et al., (1985) in terms of empirical 


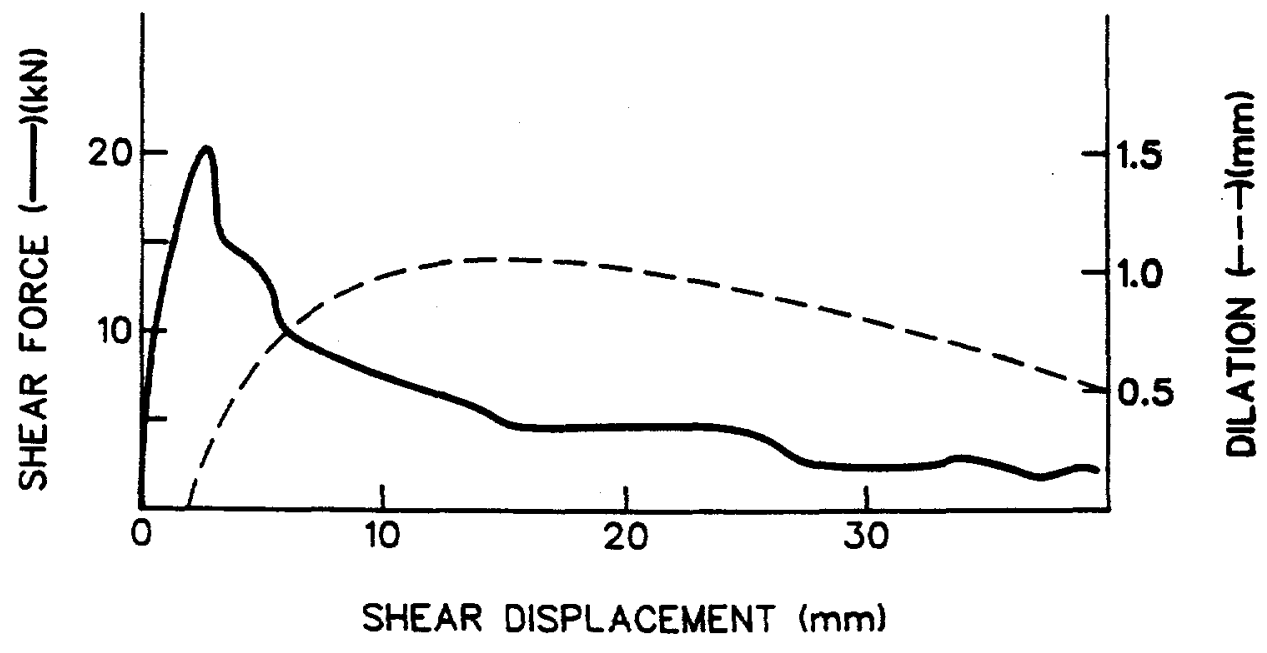

FIGURE 5.3

SHEAR FORCE - SHEAR DISPLACEMENT (SOLID LINE) AND DILATION - SHEAR DISPLACEMENT CURVES FOR A DIRECT SHEAR TEST ON GRAPHITE-COATED JOINT. (FROM JAEGER, 1971) 


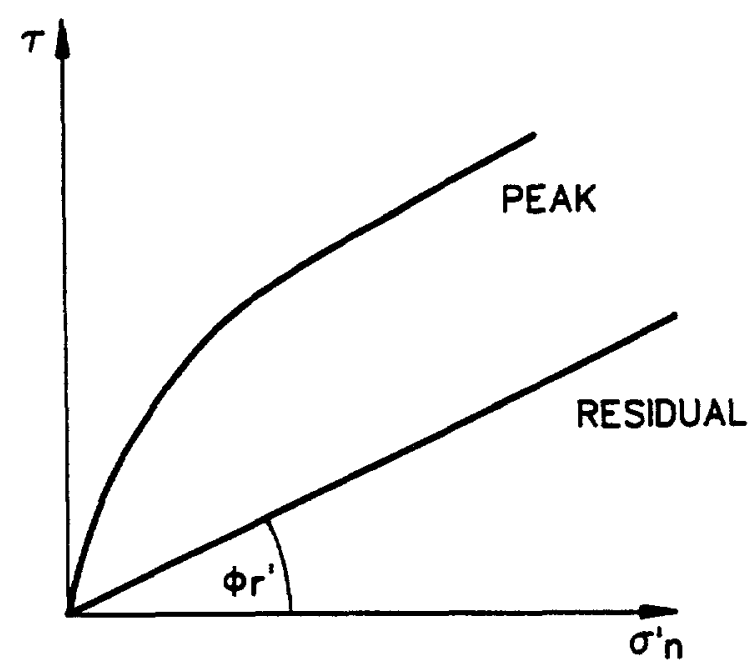

FIGURE 5.4

TYPICAL PEAK AND RESIDUAL

SHEAR STRENGTH ENVELOPES 

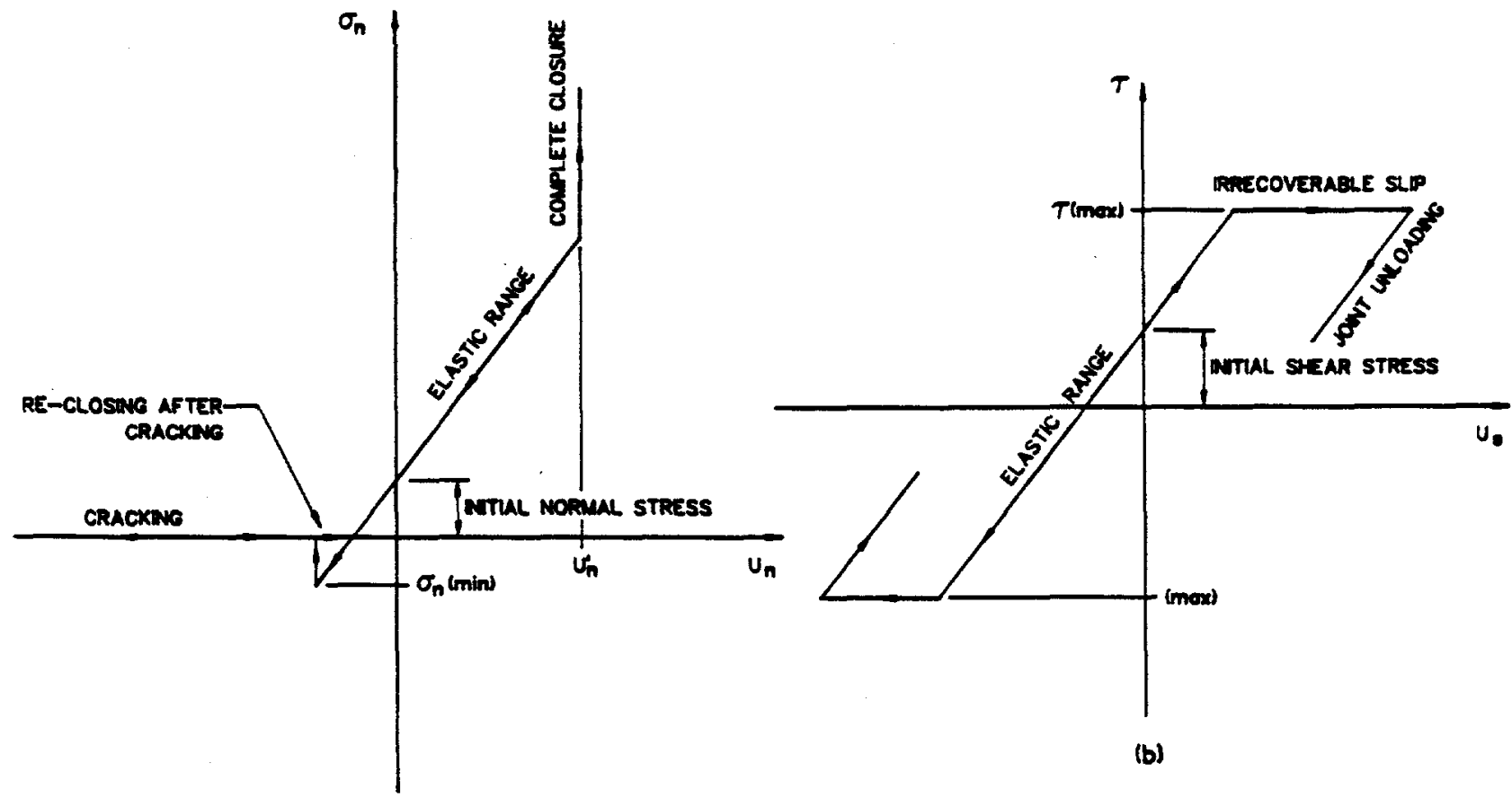

(b)

(a)

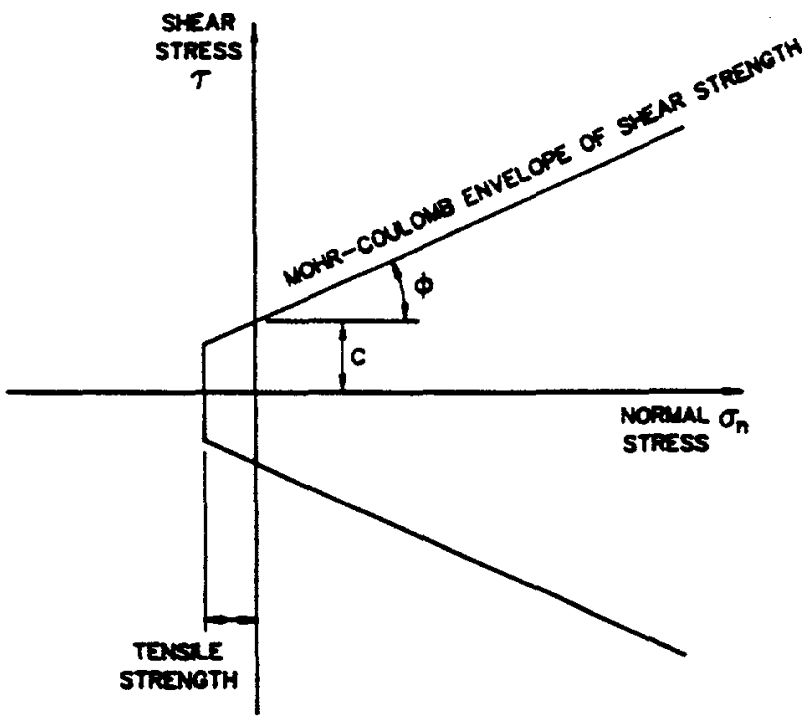

(e)

FIGURE 5.5

COULOMBIC FRICTION, LINEAR DEFORMATION MODEL FOR

A JONT. (a) NORMAL DEFORMATION, (b) SHEAR DEFORMATION,

(c) SHEAR STRENGTH

(FROM CROTTY AND WARDLE, 1985) 
relations between normal stress and closure, mobilized roughness and normalized shear displacement, and a non-linear strength criterion of the form

$$
\tau=\sigma_{n}^{\prime} \tan \left(J R C \log _{10} \frac{J C S}{\sigma_{n}^{\prime}}+\varphi_{n}^{\prime}\right)
$$

where JRC is the joint roughness coefficient, and

JCS is the joint wall rock compressive strength.

Graphically, the joint deformation and strength relations are illustrated in Fig. 5.6. Joint closure is related to normal stress through the empirical expression

$$
\sigma_{n}=\frac{\Delta V_{j}}{\left(a-b \Delta V_{j}\right)}
$$

where $\Delta V_{j}$ is the joint closure at normal stress $\sigma_{n}$, and

$a$ and $b$ are empirical parameters.

Differentiation of Eq. 5.5 with respect to $\Delta V_{j}$ indicates that the normal stiffiness is highly dependent on normal stress. Furthermore, the maximum closure $V_{m c}$ is given by $a / b$, and the initial stiffness (at zero normal stress) by $1 / \mathrm{a}$. In some joint tests, joint compression properties are specified by the stress required to produce one-half the maximum possible closure. Knowing $V_{m c}$, the joint compressibility parameters ( $a$ and $b$ ) can be estimated readily.

The Barton-Bandis model incorporates progressive reduction of joint dilatancy with shear displacement and increased normal stress, as indicated in Fig. 5.6b,c. Consequently, the model represents erosion of roughness, or joint damage, during shear displacement. This feature, as well as the account taken of the effects of dilatancy, distinguishes the Barton-Bandis model from the elementary joint model discussed previously.

Some unsatisfactory features of the Barton-Bandis model are observed in Fig. 5.6b. For practical application, the mobilization and attrition of surface roughness are represented in a piece-wise linear graphical format rather than through a simple formal expression. Although this accounts for reduction in mobilized friction angle and hysteresis on cyclic loading, Fig. 5.6d indicates that the piece-wise linear representation results in a quite rough simulation of the load-displacement behavior. Such a coarse simulation may have adverse effects on modelling many cycles of shear load reversal.

The accumulation of joint damage (by erosion of surface roughness) observed in a single monotonic phase of shear displacement has major implications for dynamic behavior of joints, in which many cycles of shear displacement can occur. Studies by Brown and Hudson (1974) of the strength of jointed specimens of rock-like materials confirm that cyclic loading indeed results in pronounced reduction of the peak strength in the peak-residual behavior of joints. These experiments showed that catastrophic failure occurred when the accumulated deformation during the cyclic tests reached the load-displacement curve for failure obtained in a monotonic test. The effect is explicable on the basis of continuous damage accumulation during cyclic shear motion at joints.

Observation that damage accumulation during joint shear needs to be modeled in a formal and consistent manner has led to the formulation of the continuous-yielding joint model (Cundall and Lemos, 1988). This is designed to be a coherent and unified joint model, taking account of non-linear compression, non-linearity and dilation in shear, and a non-linear limiting shear strength criterion. The key elements of the model are that all shear displacement at a joint has a component of plastic 


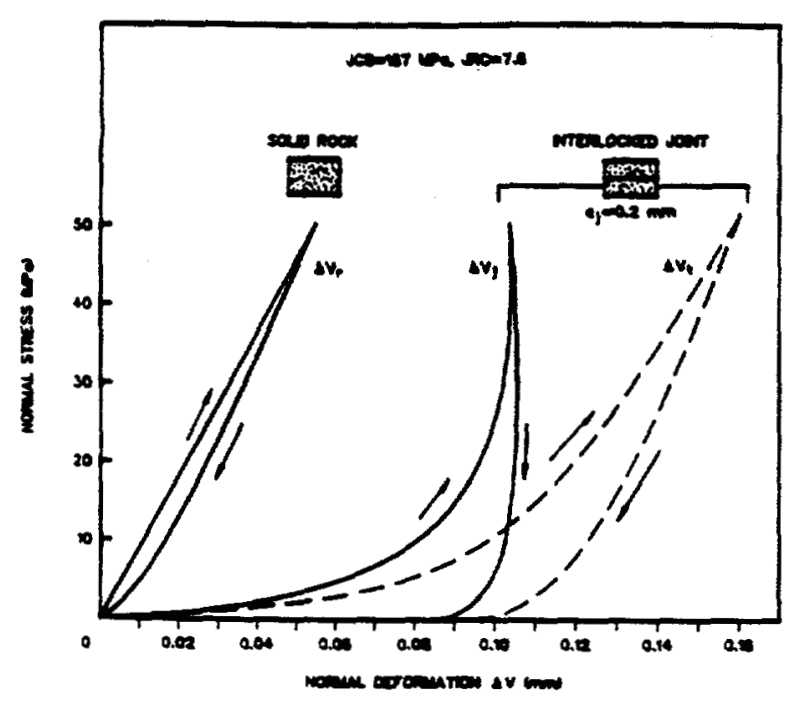

(a)

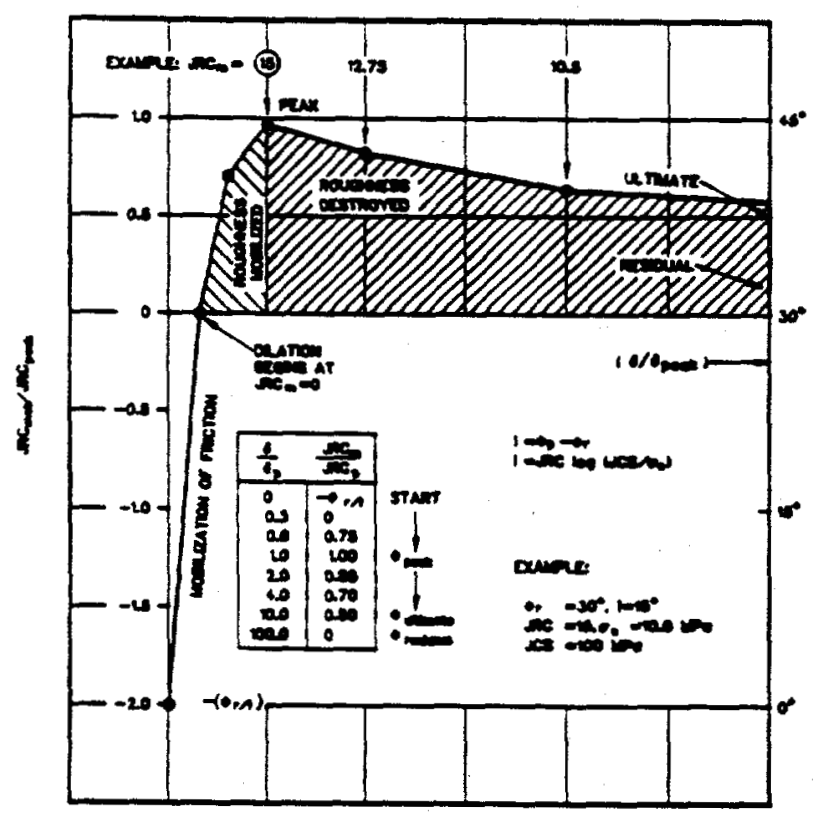

b)

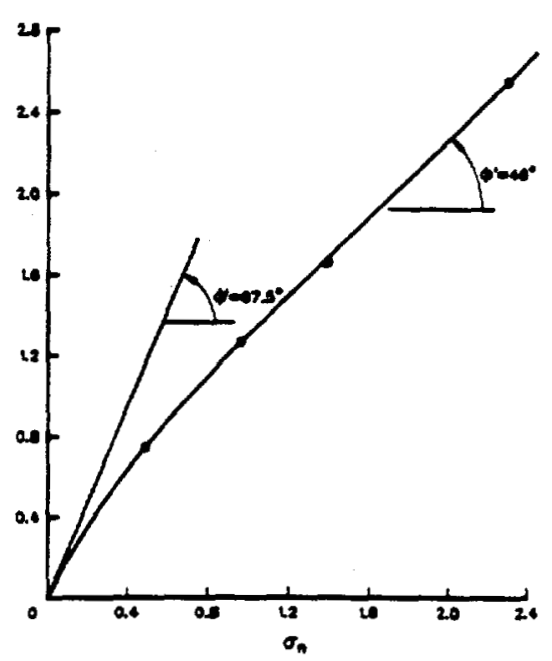

(c)

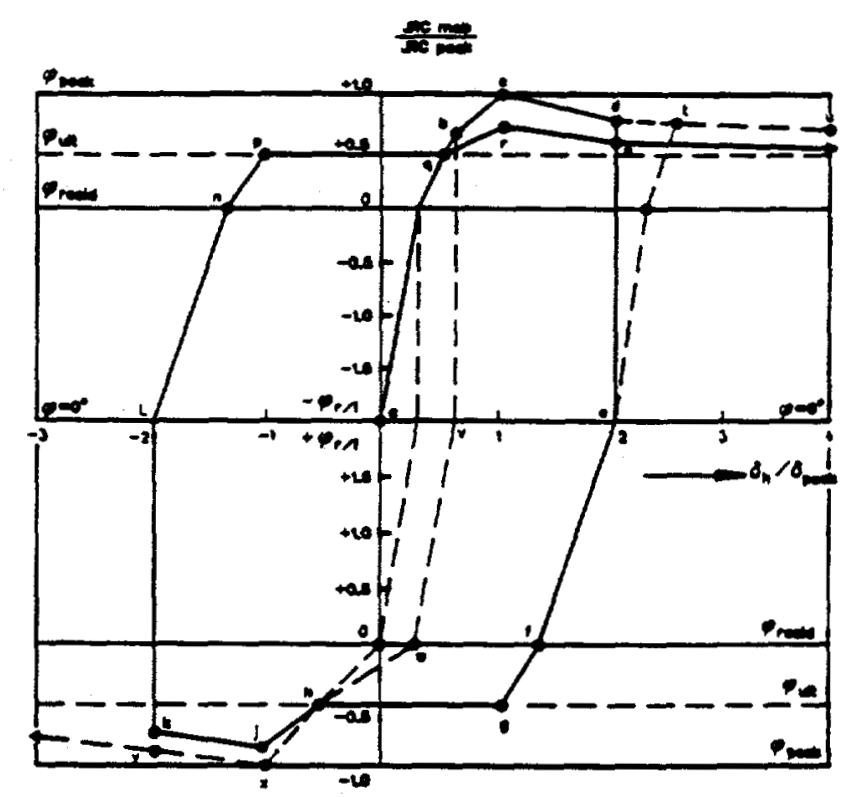

(d)

FIGURE 5.6

PROPERTIES OF THE BARTON-BANDIS JOINT NODEL:

(a), (b) NORMAL AND SHEAR DEFORMATION

(c) NON-LINEAR SHEAR STRENGTH ENVELOPE (FROM BRADY AND BROWN, 1985),

(d) HYSTERESIS ON CYCLIC SHEAR LOADING (FROM BARTON, 1988) 
(irreversible) displacement, and all plastic displacement results in progressive reduction in the mobilized friction angle. Formally, the displacement relation is represented by:

$$
\Delta u_{s}^{p}=(1-F) \Delta u_{s}
$$

where $\Delta u_{s} \quad$ is an increment of shear displacement,

$\Delta u_{s}^{\mathrm{s}} \quad$ is the irreversible component of displacement, and

$F$ is the fraction that the current shear stress constitutes of the limiting shear stress at the prevailing normal stress.

The progressive reduction of shear strength is represented by

$$
\Delta \varphi_{m}=\frac{1}{R}\left(\varphi_{m}-\varphi\right) \Delta u_{s}^{\mathrm{p}}
$$

where $\phi_{m}$ is the prevailing mobilized friction angle,

$\phi$ is the basic friction angle, and

$\mathbf{R}$ is a parameter with the dimension of length, related to joint roughness.

The capacity of this model to represent single episodes of shear load reversal, and the effects of cyclic loading, in a manner consistent with that reported by Brown and Hudson (1974), is illustrated in Fig. 5.7a,b.

The preceding discussion was concerned with the strength and deformation properties of joints under conditions of pseudostatic loading. Dynamic shear tests on rough joints have been reported by Gillette et al. (1983). They showed that the shear strength of rough joints is velocity dependent, with the change in strength (either increase or decmase) being determined by the parent rock type. However, the results were not relaied to any - unceptual or formal model of joint deformation mechanics.

An interesting aspect of the work by Gillette, et al., (1983) concerns measured pore pressures during dynamic shear of saturated joints. The measured pore pressure changes were consistent with the notion of undrained loading (in the soil mechanics terminology). Joint strength, under dynamic conditions, satisfied the effective stress law, provided account was taken of transient pore pressure.

The empirical models of joint deformation mechanics discussed previously may be used for analysis of the dynamic performance of rock masses, and several examples are noted (e.g., Lemos, et al., 1985). However, the shear stress-shear displacement relations in the models, which represent displacement weakening behavior of a joint, may not be adequate for the complete range of performance, particularly when a joint has reached a state of residual strength.

A particular concern with joint dynamic response under residual shear strength conditions is the velocity dependence of the coefficient of friction. First noted by Wells (1929), the effect was proposed as an explanation for unstable fault slip by Brace and Byerlee (1966). Since then, an extensive literature has developed on characterization of frictional resistance to slip in terms of slip velocity, state of transient stress, and state variables representing properties of the surface. Some aspects of joint dynamic properties are discussed by Dieterich (1981) and Ruina (1983). The general form of the relation between sliding velocity and shear resistance is proposed to be

$$
\tau=\tau_{*}+A \ln \left(\frac{V}{V_{*}}\right)+\theta
$$




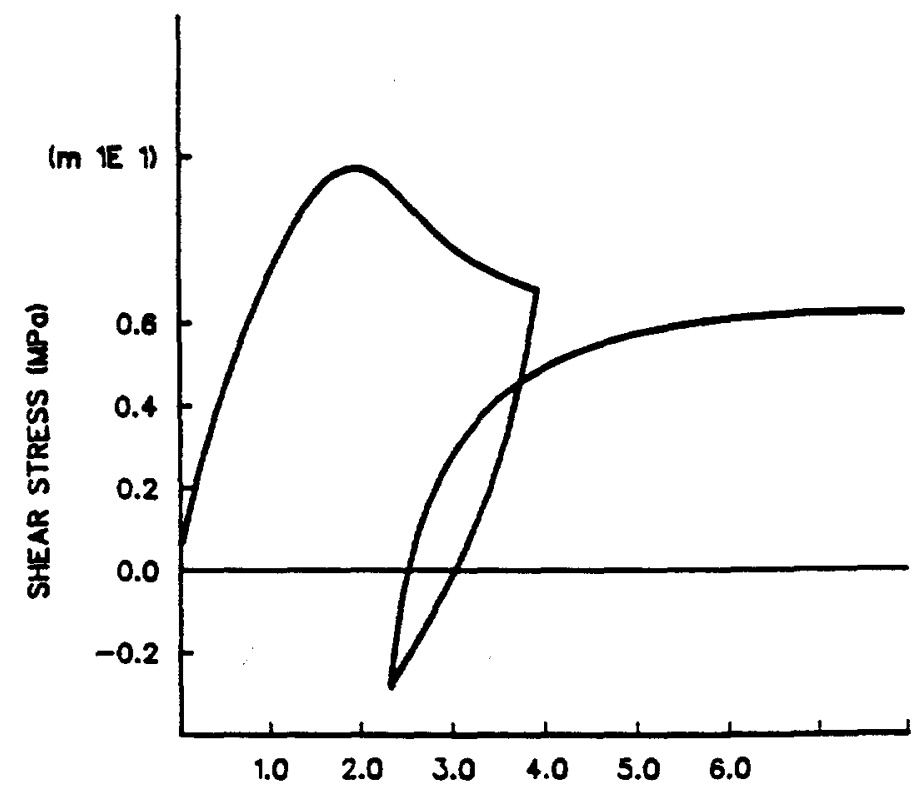

SHEAR DISPLACEMENT $(\mathrm{m}) \times 10^{-1}$

(a)

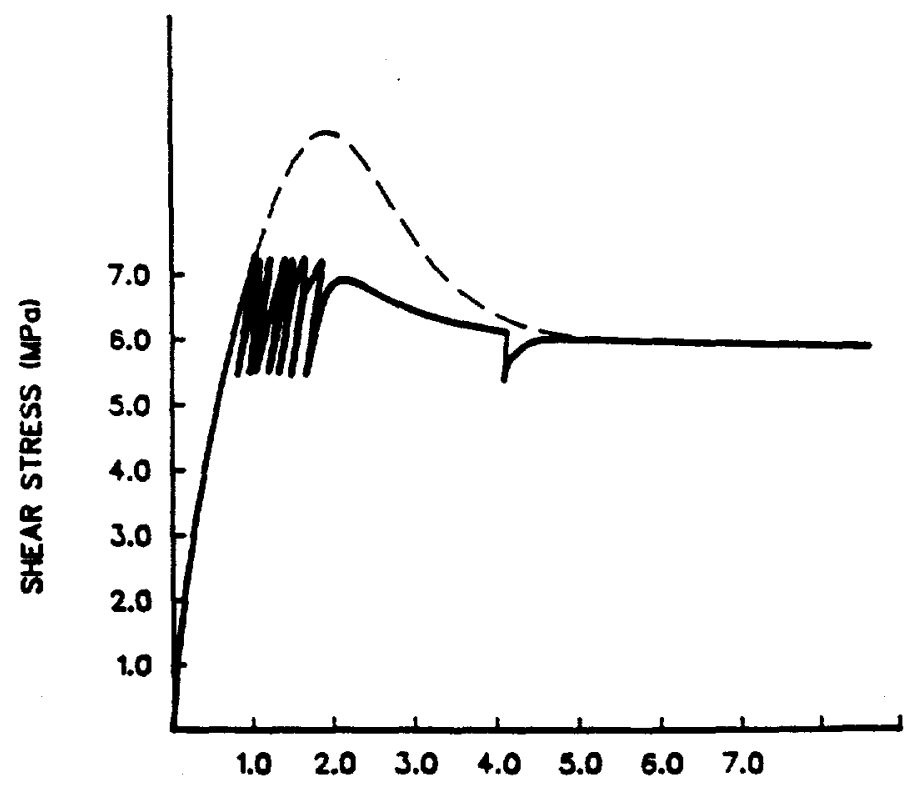

SHEAR DISPLACEMENT $(\mathrm{m}) \times 10^{-1}$

(b)

FIGURE 5.7

EXERCISING THE CONTINUOUS-YIELDING JOINT MODEL (a) A SINGLE LOAD REVERSAL CYCLE (b) CYCLIC LOADING (FROM LEMOS, 1987) 


$$
\dot{\theta}=-\frac{V}{L}\left[\theta+B \ln \left(\frac{V}{V_{*}}\right)\right]
$$

where $\tau=$ the shear resistance,

$\mathrm{V}=$ the sliding velocity,

$V_{*}=$ a reference velocity, at which $\tau=\tau$.

$A$ and $B$ are surface state parameters, and

$\theta=a$ variable that describes the condition of the sliding surface.

Graphically, the relation between relative shear velocity and frictional shear resistance, and the effect of velocity change, are illustrated in Fig. 5.8. An application of velocity dependent friction relations in the analysis of jointed rock is described by Lorig and Hobbs (1988).

In addition to being driven impulsively in shear motion under dynamic conditions, joints are subject in-situ to impulsive normal loading. In the vicinity of explosions or earthquakes for example, body waves may impose a sharp increase in normal stress on a joint. The intuitive assumption that there is an immediate increase in the shear resistance in response to an increase in normal stress is not justified (Hobbs and Brady, 1985). The current position is confused, since some subsequent experiments show no effect of normal stress history (Olsson 1987; Lockner and Byerlee 1986), while others do (Olsson, 1985 and 1988; Linker and Byerlee, 1986).

In the most recent studies of dynamic normal stress changes, Hobbs (1988) reports the effect of step changes in normal stress on a joint in gabbro subject to constant shear load point velocity. The time-dependent evolution of the shear resistance observed in Fig. 5.8 represents a transient reduction in the coefficient of friction below the static value. Such an effect has major implications for the stability of excavations in jointed rock subject to sudden transient loading, which may be induced by explosions, earthquakes and rockbursts. Some analysis of jointed block motion near underground nuclear events reported by Hart et al. (1987) suggests transient changes in the coefficient of friction under impulsive changes in normal stress may be significant in practice.

The third factor noted earlier, concerning dynamic response of excavations, was related to the effect of episodes of dynamic loading from a series of earthquakes or nuclear explosions. The reason this may be different from an equivalent amount of continuous dynamic loading arises from observations (Dieterich, 1981) of so-called "healing" or time-dependent increase in joint strength, after completion of an episode of slip. Although the phenomenon has been associated with joints at residual strength, it is conceivable that the effect operates for rough joints also.

\subsection{Behavior of Discontinuous Rock Masses}

Deformability - Determination of the global deformability and strength of a large mass of discontinuous rock in-situ remains one of the most critical problems in engineering rock mechanics. Stress-strain properties are required to calculate displacements due to thermomechanical loading of a rock mass, and gross strength properties are required to assess the extent of zones of rock mass failure around excavations.

The deformability of a jointed rock mass is usually expressed through the elastic properties of the equivalent continuum using a compliant joint model of the rock mass (Gerrard, 1982). In the simplest case of a rock mass containing a single set of parallel discontinuities, a set of elastic constants for an equivalent transversely isotropic continuum may be determined. For a set of rock layers, suppose the rock material is isotropic with elastic constants $E$ and $v$, the discontinuities have normal and shear 


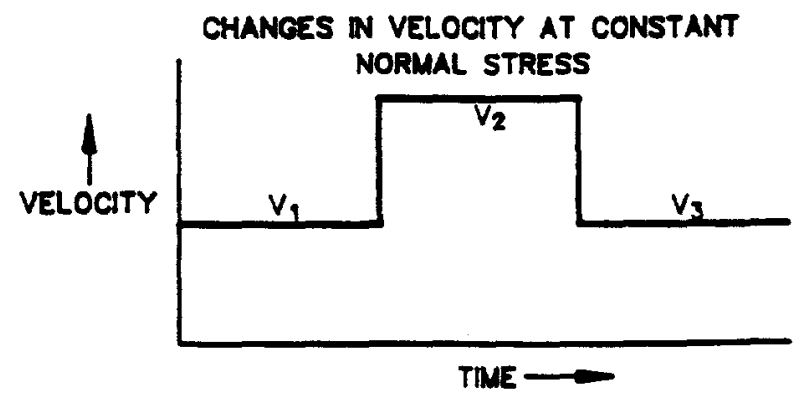

(d)

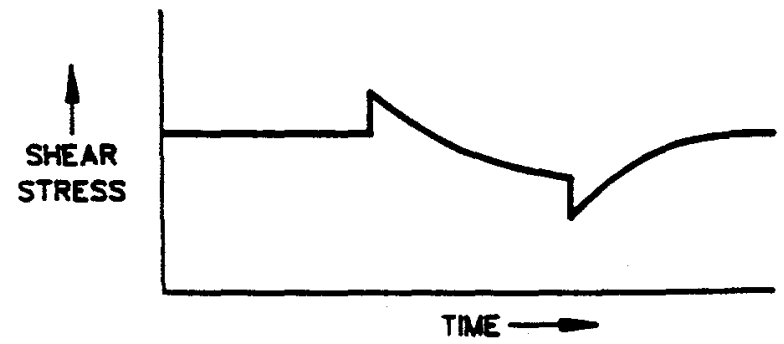

(b)

CHANGES N NORMAL STRESS AT

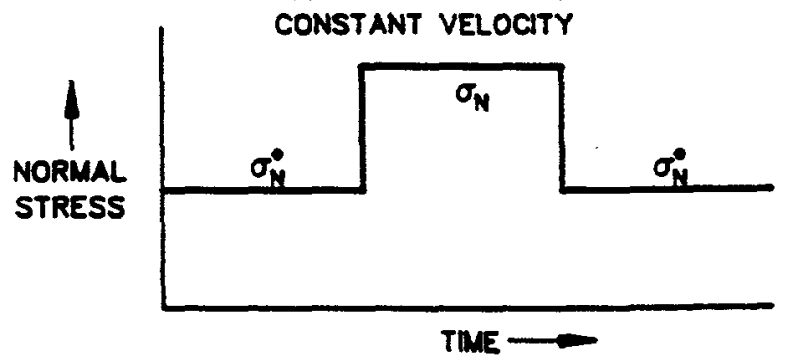

(c)

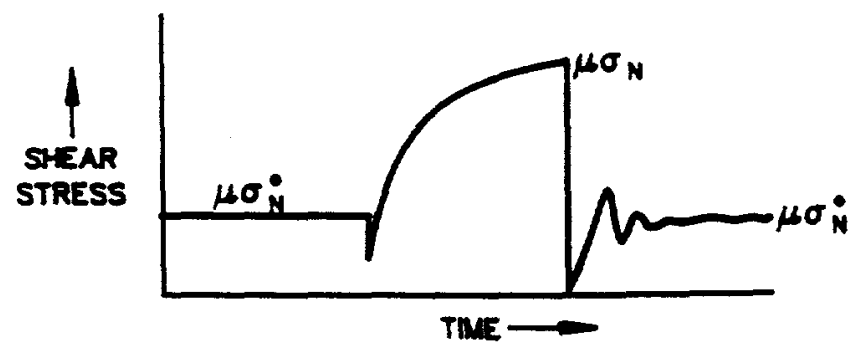

(d)

FIGURE 5.8

SUMMARY OF CONSTITUTIVE BEHAVIOR FOR SLIDING FRICTION. (a) AND (b): RESPONSE TO STEP CHANGES OF VELOCITY AT CONSTANT NORMAL FORCE. (c) AND (d): RESPONSE TO STEP CHANGES IN NORMAL FORCE AT CONSTANT LOAD POINT VELOCITY. (FROM HOBBS, 1988) 
stiffnesses $k_{n}$ and $k_{\mathbf{s}}$ as defined previously, and the mean discontinuity spacing is $\mathbf{S}$. By considering the deformations resulting from the application of unit shear and normal stresses on the plane of isotropy, it is found that the equivalent transversely isotropic elastic constants required are given by:

$$
\begin{aligned}
& \mathrm{E}_{1}=\mathrm{E} \\
& \frac{1}{E_{2}}=\frac{1}{E}+\frac{1}{k_{n} S} \\
& v_{1}=v \\
& v_{2}=\frac{E_{2}}{E} v \\
& \frac{1}{G_{2}}=\frac{1}{G}+\frac{1}{k_{s} S}
\end{aligned}
$$

Similar solutions for cases involving more than one set of discontinuities are given by Amadei and Goodman (1981) and Gerrard (1982).

It is often found in practice that the data required to apply these models are not available or that the rock mass structure is less regular than that assumed in developing the analytical solutions. In these cases, it is common to determine $E$ as the modulus of deformation or slope of the force-displacement curve obtained in an in-situ compression test. These may be uniaxial compression tests, plate-bearing tests, jointed block tests, flatjack tests, pressure chamber tests, borehole jacking tests, and dilatometer tests. It is notable that, in an analysis of a jointed block test on basait, Brady, et al., (1985) showed that the elastic properties of the medium were substantially different from the modulus of deformation obtained from the slope of the loading curve for the block.

Strength - A first approach to determination of the gross strength of a multiply-jointed rock mass is to apply Jaeger's single plane of weakness theory (Section 5.2) in several parts. However, the results are strongly dependent on the cohesion and friction values assumed for the joints.

Because of the difficulty of determining the overall strength of a rock mass by measurements, empirical approaches are generally used. Brady (1977) found that the power law of Eq. 5.3 could be applied to the mineralized shale at the Mount Isa Mine. An attempt to allow for the influence of rock quality on rock mass strength was made by Bieniawski (1976), who assigned Coulomb shear strength parameters, $c$ and $\phi$, to the various rock mass classes in his geomechanics classification.

The most completely developed of these empirical approaches is that introduced by Hoek and Brown (1980), who proposed the empirical rock mass strength criterion

$$
\sigma_{1 s}=\sigma_{3}+\left(m \sigma_{c} \sigma_{3}+s \sigma_{c}^{2}\right)^{\frac{1}{2}}
$$

where $\sigma_{1 s} \quad=$ major principal stress at peak strength,

$\sigma_{3} \quad=$ minor principal stress,

$\mathrm{m}$ and $\mathrm{s}=$ constants that depend on the properties of the rock and the extent to which it had been broken before being subjected to the failure stresses, and

$\sigma_{c} \quad=$ uniaxial compressive strength of the intact rock material. 
For intact rock material, $s=1.0$ and, for a completely granulated specimen or a rock aggregate, $s=$ 0 . The uniaxial compressive strength of the rock mass is given by $C_{0}=\sigma_{c} s^{1 / 2}$ and is zero when $s=$ 0 .

\subsection{Conditions at a Tuff Site}

The prospective location of a waste repository is the Yucca Mountain site, on the Nevada Test Site. The relation of the site to the surrounding region is indicated in Fig. 5.9. The stratigraphy of the site is shown in Fig. 5.10.

Following the general outline of the mechanical properties of intact rock material presented previously, the properties of the various members of the Yucca Mountain sequence are presented in Table 5.1. The properties of joints in the various units are presented in Table 5.2. It is noted that the unstressed apertures for joints, and the values of half-closure stress, can be related directly to the terms $a$ and $b$ in Eq. 5.5.

The deformation and strength properties of the rock mass are presented in Table 5.3. For the data in this table, it is not clear whether the deformation moduli were determined in a way which permits the true rock mass elastic deformation properties to be established. The strength properties of the rock mass are based on an assumption of a linear (Mohr-Coulomb) failure criterion rather than a non-linear (Hoek-Brown) criterion.

\subsection{Thermal Effects}

In assessing the possible role of thermal effects on the dynamic performance and response of a repository, interaction between these mechanisms of rock mass loading may occur by two primary modes. The first mode involves thermomechanical changes in the static stress field due to waste emplacement. The second is concemed with possible temperature related changes in the mechanical properties of the rock mass.

Thermally induced changes in the ambient state of stress are considered as a matter of course in the performance assessment of a repository. Conceivably, thermal stresses could induce seismic activity on rock discontinuities in the repository domain. However, assessment of the possibility of thermally induced seismicity is beyond the scope of this review.

Changes in the mechanical properties of the rock mass with change in temperature could conceivably alter the response of the rock mass to dynamic loading. For the restricted range of temperature change which will be generated by waste emplacement, no changes in rock material properties are indicated (DOE/RW-0160, 1988). Furthermore, no temperature effects on joint mechanical properties have been reported, for the likely range of temperature increase around a repository. This indicates that the dynamic performance of a repository excavation is decoupled from the thermomechanical response, and the two phenomena may be analyzed independently. 


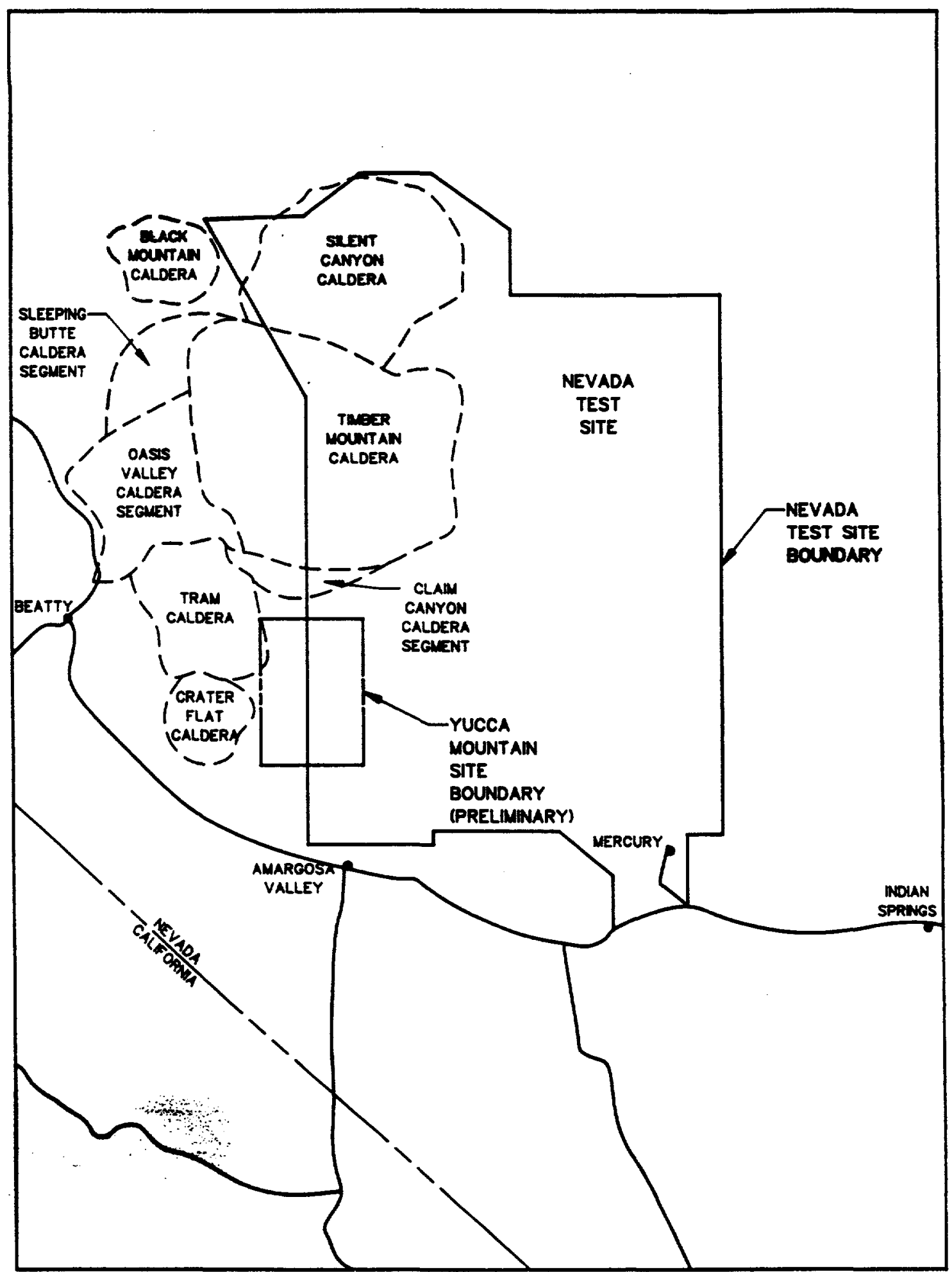

FIGURE 5.9

PHYSIOGRAPHIC FEATURES OF YUCCA MOUNTAIN

AND SURROUNDING REGION. MODIFIED FROM SNL (1987)

(FROM SITE CHARACTERIZATION PLAN, DRAFT-DOE/RW-0160, 1988) 


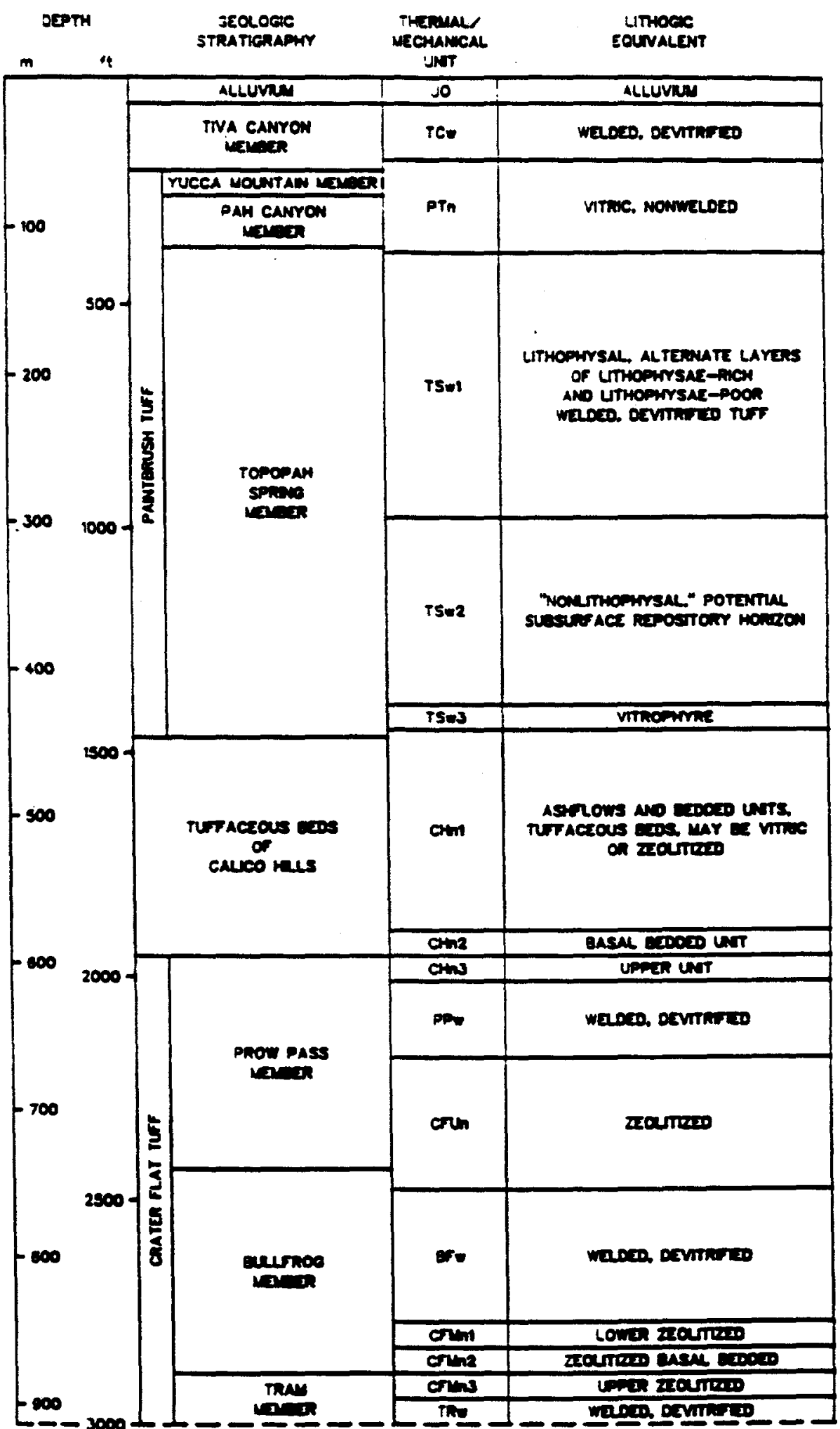

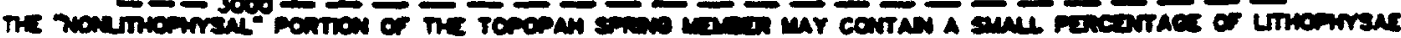

FIGURE 5.10

CORRELATION BETWEEN THE THERMAL/MECHANICAL STRATIGRAPHY

AND THE GEOLOGIC STRATIGRAPHY. MODIFIED FROM SNL (1987).

(FROM SITE CHARACTERIZATION PLAN, DRAFT-DOE/RW-0160, 1988) 
Table 5.1. Mechanical Properties of Intact Rock for Thermal/Mechanical Units ${ }^{a}$ at Yucca Mountain ${ }^{\mathrm{b}}$ (Page 1 of 2)

(Site Characterization Plan, Draft, DOE/RW-0160, 1988)

\begin{tabular}{|c|c|c|c|c|c|c|c|c|c|}
\hline \multirow{3}{*}{$\begin{array}{c}\text { Thermal/ } \\
\text { Mechanical } \\
\text { Unit }\end{array}$} & \multicolumn{3}{|c|}{ Young's Modulus (GPa) } & \multicolumn{3}{|c|}{ Poisson's Ratio } & \multicolumn{3}{|c|}{$\sigma_{c}(\mathrm{MPa})^{e}$} \\
\hline & \multirow{2}{*}{$\begin{array}{l}\text { Design } \\
\text { Value }^{c}\end{array}$} & \multicolumn{2}{|c|}{$\begin{array}{l}\text { Variability } \\
\text { Evaluation }\end{array}$} & \multirow{2}{*}{$\begin{array}{l}\text { Design } \\
\text { Value }\end{array}$} & \multicolumn{2}{|c|}{$\begin{array}{l}\text { Variability } \\
\text { Evaluation }\end{array}$} & \multirow{2}{*}{$\begin{array}{l}\text { Design } \\
\text { Value }\end{array}$} & \multicolumn{2}{|c|}{$\begin{array}{l}\text { Variability } \\
\text { Evaluation }\end{array}$} \\
\hline & & Value & Range & & Value & Range & & Value & Range \\
\hline TCw & 30.8 & 40.0 & \pm 11.1 & 0.10 & 0.24 & $N A^{f}$ & 155 & 240 & \pm 163.5 \\
\hline PTn & 2.2 & 3.8 & \pm 3.9 & 0.18 & 0.16 & NA & 7 & 19 & \pm 10.9 \\
\hline TSw $1^{8}$ & 23.9 & 31.7 & \pm 17.9 & 0.13 & 0.25 & \pm 0.05 & 114 & 127 & \pm 16 \\
\hline $\mathrm{TSw1}^{\mathrm{h}}$ & 15.2 & 15.5 & \pm 3.2 & 0.16 & 0.16 & \pm 0.03 & 18 & 16 & \pm 5 \\
\hline TSw2 & 31.1 & 30.4 & \pm 6.3 & 0.22 & 0.24 & \pm 0.06 & 171 & 166 & \pm 65 \\
\hline TSw3 & 25.0 & NA & NA & 0.11 & NA & NA & 46 & NA & NA \\
\hline CHnlv & 4.8 & 7.1 & \pm 4.4 & 0.15 & 0.16 & NA & 17 & 27 & \pm 12.4 \\
\hline CHnlz & 7.1 & 7.1 & \pm 2.1 & 0.16 & 0.16 & \pm 0.08 & 27 & 27 & \pm 9 \\
\hline $\mathrm{CHn} 2 \mathrm{z}$ & 8.6 & 11.5 & \pm 4.0 & 0.20 & 0.16 & NA & 34 & 40 & \pm 12.7 \\
\hline $\mathrm{CHn} 3 \mathrm{z}$ & 5.0 & 7.1 & \pm 4.4 & 0.17 & 0.16 & NA & 18 & 27 & \pm 11.0 \\
\hline PPw & 12.1 & 16.3 & \pm 7.8 & 0.20 & 0.13 & NA & 51 & 57 & \pm 30.6 \\
\hline CFUn & 7.6 & 7.6 & \pm 3.8 & 0.16 & 0.16 & NA & 31 & 31 & \pm 11 \\
\hline BFw & 10.8 & 10.8 & \pm 4.7 & 0.13 & 0.13 & \pm 0.02 & 42 & 42 & \pm 14 \\
\hline CFMn 1 & 11.5 & 15.2 & \pm 5.2 & 0.14 & 0.16 & NA & 48 & 52 & \pm 19.4 \\
\hline CFMn2 & 11.9 & 16.3 & \pm 3.4 & 0.18 & 0.16 & NA & 50 & 57 & \pm 13.1 \\
\hline CFMn3 & 9.9 & 13.2 & \pm 2.7 & 0.15 & 0.16 & NA & 40 & 45 & NA \\
\hline TRw & 7.6 & 17.6 & \pm 3.8 & 0.18 & 0.13 & NA & 72 & 72 & \pm 23 \\
\hline
\end{tabular}

Thermal/mechanical units defined in Figure 5.10.

bee Appendix 0 of SNL (1987).

'Design values represent the basis for the Site Characterization Plan-Conceptual Design.

${ }^{d}$ Variability evaluation values represent more recent results of data analyses and establishes ranges for properties.

${ }^{e} \sigma_{c}=$ confined compressive strength

$\mathrm{NA}=$ not available.

Sonlithophysal portions of Unit TSw1

hLithophysal portions of Unit TSw1

$i_{\phi_{\mathrm{T}}}=$ angle of internal friction 
Table 5.1. Mechanical Properties of Intact Rock for Thermal/Mechanical Units ${ }^{a}$ at Yucca Mountain ${ }^{b}$ (Page 2 of 2)

(Site Characterization Plan, Draft, DOE/RW-0160, 1988)

\begin{tabular}{|c|c|c|c|c|c|c|c|c|c|}
\hline \multirow{3}{*}{$\begin{array}{l}\text { Thermal/ } \\
\text { Mechanical } \\
\text { Unit }\end{array}$} & \multicolumn{3}{|c|}{ Cohesion } & \multicolumn{3}{|c|}{$\phi(\operatorname{deg})^{i}$} & \multicolumn{3}{|c|}{ Tensile Strength (MPa) } \\
\hline & \multirow{2}{*}{$\begin{array}{l}\text { Design } \\
\text { Value }\end{array}$} & \multicolumn{2}{|c|}{$\begin{array}{l}\text { Variability } \\
\text { Evaluation }\end{array}$} & \multirow{2}{*}{$\begin{array}{l}\text { Design } \\
\text { Value }\end{array}$} & \multicolumn{2}{|c|}{$\begin{array}{l}\text { Variability } \\
\text { Evaluation }\end{array}$} & \multirow{2}{*}{$\begin{array}{l}\text { Design } \\
\text { Value }\end{array}$} & \multicolumn{2}{|c|}{$\begin{array}{l}\text { Variability } \\
\text { Evaluation }\end{array}$} \\
\hline & & Value & Range & & Value & Range & & Value & Range \\
\hline $\mathrm{TCw}$ & 45 & 51.0 & \pm 20.26 & 29.7 & 44.0 & \pm 0.20 & 17.6 & 17.9 & NA \\
\hline PTn & 3 & 8.0 & \pm 4.18 & 6.6 & 8.5 & \pm 0.08 & 1.0 & 1.0 & NA \\
\hline TSw1 & 35 & 36.0 & \pm 11.40 & 27.4 & 34.9 & \pm 0.15 & 14.6 & 12.0 & \pm 4.6 \\
\hline TSw1 & 8 & 11.0 & NA & 14.3 & 12.5 & NA & 1.0 & 1.0 & NA \\
\hline TSw2 & 50 & 34.0 & \pm 11.40 & 29.2 & 23.5 & \pm 0.15 & 16.9 & 15.2 & NA \\
\hline TSw3 & NA & NA & NA & NA & NA & NA & NA & NA & NA \\
\hline CHnlv & 7 & 11.0 & \pm 4.28 & 13.4 & 12.0 & \pm 0.08 & 1.0 & 1.0 & NA \\
\hline CHnlz & 10 & 10.9 & \pm 1.6 & 15.8 & 7.6 & \pm 2.60 & 1.0 & 1.0 & NA \\
\hline $\mathrm{CHn} 2 \mathrm{z}$ & 12 & 15.0 & \pm 3.33 & 18.5 & 16.4 & \pm 0.06 & 3.0 & 2.6 & NA \\
\hline CHn3z & 7 & 11.0 & \pm 3.74 & 13.7 & 12.0 & \pm 0.07 & 1.0 & 1.0 & NA \\
\hline PPw & 17 & 20.0 & \pm 7.04 & 21.4 & 21.0 & \pm 0.12 & 6.8 & 6.9 & NA \\
\hline CFUn & 11 & 14.0 & \pm 5.51 & 17.8 & 15.6 & \pm 0.10 & 2.1 & 1.8 & NA \\
\hline BFw & 14 & 20.0 & \pm 8.21 & 21.6 & 21.0 & \pm 0.14 & 7.0 & 6.9 & NA \\
\hline CFMnl & 17 & 19.0 & \pm 5.21 & 21.0 & 19.9 & \pm 0.09 & 6.3 & 6.0 & NA \\
\hline CFMn2 & 17 & 20.0 & \pm 2.93 & 21.3 & 21.0 & \pm 0.05 & 6.7 & 6.9 & NA \\
\hline CFMn3 & 14 & 17.0 & \pm 2.83 & 19.7 & 18.0 & \pm 0.05 & 4.6 & 4.3 & NA \\
\hline TRw & 23 & 27.0 & \pm 9.11 & 24.8 & 27.6 & \pm 0.14 & 11.3 & 11.1 & NA \\
\hline
\end{tabular}

2Thermal/mechanical units defined in Figure 5.10.

See Appendix 0 of SNL (1987).

CDesign values represent the basis for the Site Characterizarion Plan-Conceptual Design.

${ }^{d}$ Variability evaluation values represent more recent results of data analyses and establishes ranges for properties.

${ }^{e} \sigma_{c}=$ confined compressive strength

NA = not available.

${ }^{8}$ Nonlithophysal portions of Unit TSw1

hithophysal portions of Unit TSw1

$i_{\phi_{\mathrm{r}}}=$ angle of internal friction

$i \phi_{\mathrm{T}}=$ residual friction angle 
Table 5.2. Mechanical Properties and Modeling Parameters for Fractures in Thermal/Mechanical Units ${ }^{\mathbf{a}}$ at Yucca Mountain $^{\mathrm{b}}$

\begin{tabular}{|c|c|c|c|c|c|c|c|c|c|c|c|c|c|c|c|c|}
\hline \multirow{3}{*}{$\begin{array}{l}\text { Thermal/ } \\
\text { mechanical } \\
\text { unit }\end{array}$} & \multicolumn{4}{|c|}{ Friction coefficient } & \multicolumn{4}{|c|}{$\mathrm{JCS}_{\mathrm{o}}{ }^{(i)}$} & \multicolumn{4}{|c|}{$\mathrm{JRC}_{0}^{(\mathrm{j})}$} & \multicolumn{4}{|c|}{$\phi_{r}^{(k)}$} \\
\hline & \multirow{2}{*}{$\begin{array}{l}\text { Design } \\
\text { value }^{\text {d }}\end{array}$} & \multicolumn{3}{|c|}{$\begin{array}{l}\text { Variability } \\
\text { evaluation }\end{array}$} & \multirow{2}{*}{$\begin{array}{l}\text { Design } \\
\text { value }\end{array}$} & \multicolumn{3}{|c|}{$\begin{array}{l}\text { Variability } \\
\text { evaluation }\end{array}$} & \multirow{2}{*}{$\begin{array}{l}\text { Design } \\
\text { value }\end{array}$} & \multicolumn{3}{|c|}{$\begin{array}{l}\text { Variability } \\
\text { evaluation }\end{array}$} & \multirow{2}{*}{$\begin{array}{c}\text { Design } \\
\text { value }\end{array}$} & \multicolumn{3}{|c|}{$\begin{array}{l}\text { Variability } \\
\text { evaluation }\end{array}$} \\
\hline & & $\mathrm{UB}^{\mathrm{e}}$ & $R V^{f}$ & $\mathrm{LB}^{\mathrm{g}}$ & & UB & RV & LB & & UB & RV & LB & & UB & RV & LB \\
\hline $\mathrm{TCw}$ & 0.80 & 0.8 & 0.54 & 0.2 & $N A^{h}$ & 406.5 & 243.0 & 79.5 & NA & 12 & 9 & 6 & NA & 38.7 & 28.4 & 11.3 \\
\hline PTn & 0.80 & 0.8 & 0.59 & 0.2 & NA & 6.8 & 17.7 & 28.6 & NA & 8 & 5 & 2 & NA & 38.7 & 30.5 & 11.3 \\
\hline TSw1 & 0.80 & 0.8 & 0.54 & 0.2 & NA & 68.5 & 135.1 & 201.7 & NA & 12 & 9 & 6 & NA & 38.7 & 28.4 & 11.3 \\
\hline TSw2 & 0.80 & 0.8 & 0.54 & 0.2 & NA & 113.0 & 171.0 & 229.0 & NA & 12 & 9 & 6 & NA & 38.7 & 28.4 & 11.3 \\
\hline TSw3 & 0.80 & 0.8 & 0.54 & 0.2 & NA & 13.0 & 46.0 & 79.0 & NA & 12 & 9 & 6 & NA & 38.7 & 28.4 & 11.3 \\
\hline CHnlv & 0.80 & 0.8 & 0.59 & 0.2 & NA & 39.1 & 26.7 & 14.3 & NA & 8 & 5 & 2 & NA & 38.7 & 30.5 & 11.3 \\
\hline CHnlz & 0.55 & 0.8 & 0.54 & 0.2 & NA & 36.0 & 27.0 & 18.0 & NA & 8 & 5 & 2 & NA & 38.7 & 28.4 & 11.3 \\
\hline $\mathrm{CHn} 2 \mathrm{z}$ & 0.55 & 0.8 & 0.59 & 0.2 & NA & 52.6 & 39.9 & 27.2 & NA & 8 & 5 & 2 & NA & 38.7 & 30.5 & 11.3 \\
\hline $\mathrm{CHn} 3 \mathrm{z}$ & 0.55 & 0.8 & 0.59 & 0.2 & NA & 37.7 & 26.7 & 15.7 & NA & 8 & 5 & 2 & NA & 38.7 & 30.5 & 11.3 \\
\hline $\mathrm{PPw}$ & 0.80 & 0.8 & 0.59 & 0.2 & NA & 87.6 & 56.6 & 26.0 & NA & 12 & 9 & 6 & NA & 38.7 & 30.5 & 11.3 \\
\hline CFUn & 0.55 & 0.8 & 0.64 & 0.2 & NA & 56.0 & 37.5 & 19.0 & NA & 8 & 5 & 2 & NA & 38.7 & 32.6 & 11.3 \\
\hline $\mathrm{BFw}$ & 0.80 & 0.8 & 0.54 & 0.2 & NA & 56.0 & 42.0 & 28.0 & NA & 12 & 9 & 6 & NA & 38.7 & 30.5 & 11.3 \\
\hline CFMn1 & 0.55 & 0.8 & 0.64 & 0.2 & NA & 71.9 & 52.5 & 33.1 & NA & 8 & 5 & 2 & NA & 38.7 & 32.6 & 11.3 \\
\hline CFMn2 & 0.55 & 0.8 & 0.64 & 0.2 & NA & 69.7 & 56.6 & 43.5 & NA & 8 & 5 & 2 & NA & 38.7 & 32.6 & 11.3 \\
\hline CFMn3 & 0.55 & 0.8 & 0.64 & 0.2 & NA & NA & 45.0 & NA & NA & 8 & 5 & 2 & NA & 38.7 & 32.6 & 11.3 \\
\hline TRw & 0.80 & 0.8 & 0.59 & 0.2 & $\mathrm{NA}$ & 96.0 & 72.0 & 46.0 & NA & 12 & 9 & 6 & NA & 38.7 & 30.5 & 11.3 \\
\hline
\end{tabular}

Thermal/mechanical units defined in Figure 5.10 .

${ }^{b}$ See Appendix 0 of SNL (1987).

${ }^{c}$ Variability evaluation values represent more recent results of data analyses and establishes ranges for properties.

dDesign values represent the basis for the Site Characterization Plan-Conceptual Design.

UB = upper bound.

$\mathrm{f}_{\mathrm{RV}}=$ recommended value.

${ }^{8} \mathrm{LB}=$ lower bound.

${ }^{\mathrm{h}} \mathrm{NA}=$ not applicable.

${ }^{\mathrm{i}} \mathrm{JCS}_{\mathrm{o}}=$ joint wall compressive strength.

$\mathrm{j}_{\mathrm{JRC}}=$ joint wall roughness coefficient.

$\mathbf{k}_{\phi_{\mathrm{r}}}=$ residual friction angle. 
Table 5.3. Mechanical Properties of the Rock Mass for Thermal/Mechanical Units ${ }^{a}$ at Yucca Mountain ${ }^{b}$

\begin{tabular}{|c|c|c|c|c|c|c|c|c|c|c|c|c|c|c|c|}
\hline \multirow{3}{*}{$\begin{array}{l}\text { Thermal/ } \\
\text { mechanical } \\
\text { unit }\end{array}$} & \multicolumn{3}{|c|}{$\begin{array}{l}\text { Deformation modulus } \\
\text { (GPa) }\end{array}$} & \multicolumn{3}{|c|}{ Poisson's ratio } & \multicolumn{3}{|c|}{$\sigma_{c}(\mathrm{MPa})^{e}$} & \multicolumn{3}{|c|}{ Cohesion (MPa) } & \multicolumn{3}{|c|}{$\phi(\mathrm{deg})^{\mathrm{f}}$} \\
\hline & \multirow{2}{*}{$\begin{array}{l}\text { Design } \\
\text { value }^{c}\end{array}$} & \multicolumn{2}{|c|}{$\begin{array}{l}\text { Variability } \\
\text { evaluation }\end{array}$} & \multirow{2}{*}{$\begin{array}{c}\text { Design } \\
\text { value }\end{array}$} & \multicolumn{2}{|c|}{$\begin{array}{l}\text { Variability } \\
\text { evaluation }\end{array}$} & \multirow{2}{*}{$\begin{array}{c}\text { Design } \\
\text { value }\end{array}$} & \multicolumn{2}{|c|}{$\begin{array}{l}\text { Variability } \\
\text { evaluation }\end{array}$} & \multirow{2}{*}{$\begin{array}{l}\text { Design } \\
\text { value }\end{array}$} & \multicolumn{2}{|c|}{$\begin{array}{l}\text { Variability } \\
\text { evaluation }\end{array}$} & \multirow{2}{*}{$\begin{array}{c}\text { Design } \\
\text { value }\end{array}$} & \multicolumn{2}{|c|}{$\begin{array}{l}\text { Variability } \\
\text { evaluation }\end{array}$} \\
\hline & & value & range & & value & range & & value & range & & value & range & & value & range \\
\hline $\mathrm{TCw}$ & 15.4 & 20.0 & \pm 5.55 & 0.10 & 0.10 & $N A^{g}$ & 77.5 & 120.0 & \pm 81.75 & 22.5 & 26.0 & \pm 10.13 & 29.7 & 44.7 & \pm 0.20 \\
\hline PTn & 1.1 & 1.9 & \pm 1.95 & 0.18 & 0.19 & NA - & 3.5 & 9.5 & \pm 5.45 & 1.6 & 4.0 & \pm 2.09 & 6.6 & 8.5 & \pm 0.08 \\
\hline $\mathrm{TSw}^{\mathrm{h}}$ & 15.1 & 15.9 & \pm 4.2 & 0.20 & 0.22 & \pm 0.05 & 75.0 & 63.5 & \pm 33.30 & 22.1 & 18.0 & \pm 5.70 & 29.2 & 34.9 & \pm 0.15 \\
\hline $\mathrm{TSw1}^{\mathrm{i}}$ & 7.6 & 7.6 & \pm 3.2 & 0.16 & 0.16 & \pm 0.05 & 18.0 & 16.0 & \pm 5.00 & 7.0 & 5.5 & NA & 14.3 & 12.5 & NA \\
\hline TSw2 & 15.1 & 15.2 & \pm 4.2 & 0.20 & 0.22 & \pm 0.05 & 75.4 & 83.0 & \pm 33.30 & 22.1 & 17.8 & \pm 5.70 & 29.2 & 23.5 & \pm 0.15 \\
\hline TSw3 & 15.1 & NA & NA & 0.20 & NA & NA & 75.4 & NA & NA & 22.1 & NA & NA & 29.2 & NA & NA \\
\hline CHnlv & 2.4 & 3.6 & \pm 2.2 & 0.15 & 0.15 & NA & 8.5 & 13.5 & \pm 6.20 & 3.4 & 5.5 & \pm 2.14 & 13.4 & 12.0 & \pm 0.08 \\
\hline $\mathrm{CHn} 1 \mathrm{z}$ & 3.5 & 3.6 & \pm 2.1 & 0.17 & 0.16 & \pm 0.08 & 13.5 & 13.5 & \pm 4.50 & 5.1 & 5.4 & \pm 1.08 & 15.8 & 7.6 & \pm 2.60 \\
\hline $\mathrm{CHn} 2 \mathrm{z}$ & 3.5 & 5.8 & \pm 2.0 & 0.17 & 0.20 & NA & 13.5 & 20.0 & \pm 6.35 & 5.1 & 7.5 & \pm 1.67 & 15.8 & 16.4 & \pm 0.06 \\
\hline $\mathrm{CHn} 3 \mathrm{z}$ & 3.5 & 3.6 & \pm 2.2 & 0.17 & 0.18 & NA & 13.5 & 13.5 & \pm 5.50 & 5.1 & 5.5 & \pm 1.87 & 15.8 & 12.0 & \pm 0.07 \\
\hline $\mathrm{PPw}$ & 6.1 & 8.2 & \pm 3.9 & 0.20 & 0.19 & NA & 25.5 & 28.5 & \pm 15.30 & 8.5 & 10.0 & \pm 3.52 & 21.1 & 21.0 & \pm 0.12 \\
\hline CFUn & 3.8 & 3.8 & \pm 2.95 & 0.16 & 0.16 & NA & 15.5 & 15.5 & \pm 9.25 & 5.5 & 7.0 & \pm 2.76 & 17.8 & 15.6 & \pm 0.10 \\
\hline BFw & 5.4 & 5.4 & \pm 2.35 & 0.13 & 0.13 & \pm 0.02 & 21.0 & 21.0 & \pm 7.00 & 7.0 & 10.0 & \pm 4.10 & 21.6 & 21.0 & \pm 0.14 \\
\hline CFMn1 & 5.4 & 7.6 & \pm 2.60 & 0.15 & 0.14 & NA & 22.3 & 26.0 & \pm 9.70 & 7.7 & 9.9 & \pm 2.61 & 20.5 & 19.9 & \pm 0.09 \\
\hline CFMn2 & 5.4 & 8.2 & \pm 1.7 & 0.15 & 0.17 & NA & 22.3 & 28.5 & \pm 6.55 & 7.7 & 10.0 & \pm 1.47 & 20.5 & 21.0 & \pm 0.05 \\
\hline CFMn3 & 5.4 & 6.6 & \pm 1.35 & 0.15 & 0.15 & NA & 22.3 & 22.5 & NA & 7.7 & 8.9 & \pm 1.42 & 20.5 & 18.0 & \pm 0.05 \\
\hline TRw & 8.8 & 8.8 & \pm 0.10 & 0.18 & 0.19 & NA & 36.0 & 36.0 & \pm 11.50 & 11.5 & 13.5 & \pm 4.56 & 24.8 & 27.6 & \pm 0.14 \\
\hline
\end{tabular}

Thermal/mechanical units defined in Figure 5.10.

${ }^{b}$ See Appendix 0 of SNL (1987).

'Design values represent the basis for the Site Characterization Plan-Conceptual Design Report (SNL., 1987).

${ }^{d}$ Variability evaluation values represent more recent results of data analyses and establish ranges for propertics.

${ }^{\circ} \sigma_{\mathrm{c}}=$ unconfined compressive strength.

$\mathrm{f}_{\phi}=$ angle of intermal friction.

${ }_{\mathrm{NA}}=$ not available.

${ }^{\text {h}}$ Nonlithophysal portions of unit TSwl.

iLithophysal portions of unit TSw1. 


\section{GROUNDWATER RESPONSE TO DYNAMIC EVENTS}

\subsection{General Observations}

A well-established observation in soil and rock masses is that a change in the state of stress can cause change in the groundwater pressure distribution and fluid flow of the medium. In soil masses, for example, pore pressure generation, fluid flow and pore pressure dissipation are key elements of soil mechanics loading and consolidation theory (Lambe and Whitman, 1969). It is understandable that both tectonic activity and seismic events have a comparable effect, on a large scale, on groundwater pressure and flow in rock masses. However, the latter topic has not been extensively researched, due to the relative novelty of theories of plate tectonics and crustal geodynamics.

In a review of hydrological effects in mines due to earthquakes, Raney (1988) presents information from a literature search related to the effects on underground mines and hydrology of 28 individual earthquakes in the Western North American Intermontane Region. The time period of the search covers earthquakes from 1852 to 1983.

The earthquakes selected for this study represent some of the larger seismic events (6.0 magnitude or greater) that have occurred in North America. The geographic region under consideration mainly lies between the Rocky Mountains on the east and the Cascade-Sierra Nevadas on the west, and extends from the Canadian border on the north to the State of Sonora, Mexico, on the south. It was observed that hydraulic effects due to earthquakes are generally ubiquitous, producing a variety of hydrologic phenomena, including

- water-well-level fluctuations

- flooding of mines and other subterranean chambers

- variations in flow rates of springs (temporary or permanent increases, decreases, or cessation of flow)

- increases or decreases in spring or geyser temperature

- changes in water chemistry in wells, springs, geysers and streams

- changes in volume or flow direction of surface waters

- appearance of new springs, streams or geysers

- artesian flow from previously non-flowing wells

- loss of artesian flow in wells

- rejuvenation of dry springs, wells, streams or geysers

- sinkholes, both subareal and subaqueous 
- sand boils (sand, silt or mud "geysers", "volcanoes" or "crateriets")

- large volumes of sediment in springs, wells or geysers

- pronounced modifications of functional behavior of geysers

- water issuing, spouting or gushing from fissures in the ground

- other phenomena such as oil, methane and water gushing from an abandoned oil well; spring running "blood red" due to great influx of iron oxides; and previously sweet water wells or springs becoming salty or charged with sulfur compounds

Hydraulic events close to the epicenters (i.e. near-field effects) are reported in detail. Some of the far-field effects relevant to the performance of a repository are considered in relation to the following earthquakes:

1. Dixie Valley-Fairview Earthquake (Nevada, 16 December 1954)

Fluctuation in water well levels was observed in other parts of Nevada and as far away as New York. (The Yucca Mountain test site is approximately $260 \mathrm{~km}$ southwest of the Fairview Valley epicenter.)

2. Hebgen Lake Earthquake (Montana, 15 August 1959)

The effects on water wells of this earthquake were observed in 30 states, including Alaska, Hawaii and Pennsylvania. The water level change exceeded 10 feet in Idaho, more than 1 foot in nine (9) states, and between $1 / 2$ and 1 foot in five (5) states. There was no specific mention of water level fluctuations in the State of Nevada.

3. Borah Peak Earthquake (Idaho, 28 October 1983)

This earthquake caused water level changes in wells

435 miles away in Montana. The effect of water level change in Nevada was not mentioned.

A variety of data is presented which describes hydrological events which occurred chronologically near earthquake occurrences. The results demonstrate that dramatic widespread changes can occur in water tables from even far distant earthquakes. On the other hand, the response occurs over rather long time durations (i.e., days or months) compared to the duration of an earthquake event itself (i.e., seconds or minutes). Therefore, analyzing the hydrological effects appears to be amenable to quasi-static approaches, where the medium may be considered unsaturated before, and saturated after, an earthquake event.

Water level fluctuations in water wells produced by earthquakes at great distances from their epicenters are discussed by Bredehoeft, et al., (1987). The main purpose of this study was to establish the importance of water level changes in water wells as precursors of earthquakes.

Following the 1964 earthquake in Alaska, the water wells in Florida responded dramatically. The recorded fluctuation was approximately 17 feet during passage of the Rayleigh surface wave (Fig. 6.1). Water fluctuations caused by this earthquake were also observed as far away as the Phillipines, Africa and Australia.

The response of a water well to earthquakes is distinguished as (1) a dynamic response, and (2) a static response. The dynamic response of wells is produced by elastic transmission of seismic waves, especially Rayleigh waves. The Rayleigh waves cause a volume change in the rock which produces pressure changes in the fluid in an aquifer. The fluid level in an open well will attempt to balance pressure fluctuations in the aquifer which it penetrates. The standing water in the well behaves as a 


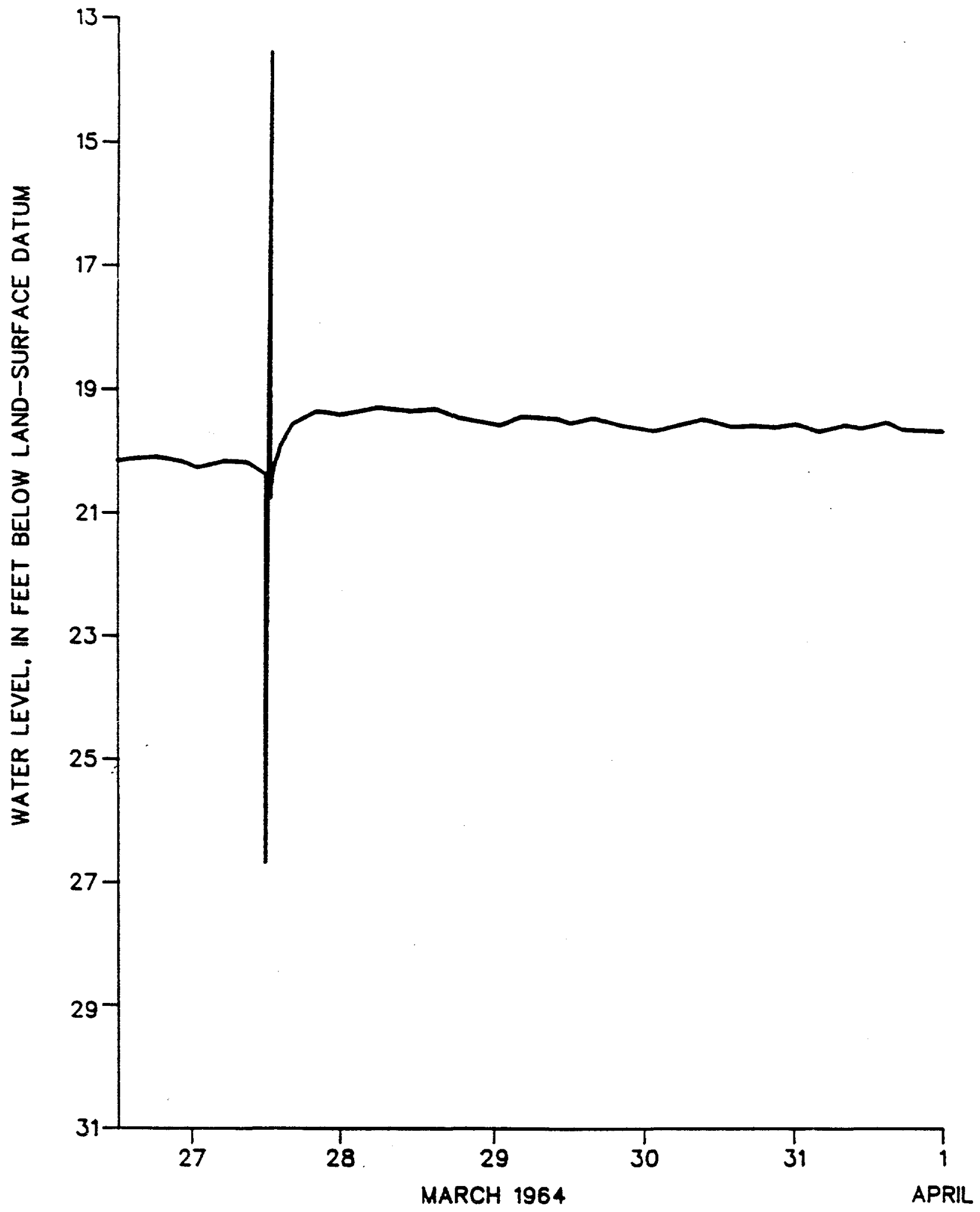

FIGURE 6.1

HYDROGRAPH OF A WELL NEAR PERRY, FLORIDA SHOWING FLUCTUATION CAUSED BY THE ALASKAN "GOOD FRIDAY" EARTHOUAKE MARCH 27, 1964

(FROM BREDEHOEFT, et ol, 1987) 
simple harmonic oscillator and, with the passage of a seismic wave, causes forced oscillation and gradually decaying motion. The damping depends on the permeability of the aquifer. The dynamic response of the well is dramatic, but it has not proven very interesting for the earth sciences.

The static response is due to the static deformations produced by an earthquake. The simplest geophysical model of an earthquake is a displacement along a finite rupture plane in an elastic material. This dislocation requires that the elastic material strain accommodate the displacement along the rupture plane. A dislocation in an elastic space produces volume strain, and volume strain in a porous fluid-filled medium creates a fluid pressure change. Both water and rock being rather incompressible, a small volume strain produces a measurable fluid pressure change and causes a fluctuation of water level in a water well.

A water well network has been designed to continuously monitor volume strain in the vicinity of Parkfield, California, along the San Andreas fault. These wells clearly responded to the Kettleman Hills, Califormia, earthquake in August 1985 (Fig. 6.2). Drops in water level were observed in four wells in Parkfield, which is located 35 to 40 kilometers west of the seismic event.

\subsection{Soil Liquefaction}

Soil liquefaction is one of the more dramatic expressions of the effect of seismic activity on non-cohesive sediments. Local soil response may involve structural collapse due to foundation failure. On a regional scale, more pervasive effects may be observed.

The large-scale effects of earthquake-induced soil liquefaction are exemplified by the New Madrid great earthquake series of 1811-1812. The study of these events by Saucier (1977) describes various phenomena related to liquefaction, including sand blows, fissuring, bank caving, and landslides, with an area of about 4,000 square miles being affected. Features resulting from subsurface liquefaction of sand are widespread in the alluvial valley of the New Madrid area, indicating the potential for extensive groundwater pressure increases under seismic shaking.

The engineering interest in soil liquefaction and foundation stability is addressed in a paper by Seed, et al., (1975). They present an analysis of pore water pressure generation and dissipation during and following a period of seismic shaking. It is shown that, in layers of fine sand, excessive hydrostatic pressures may persist for an hour or more after an earthquake. However, evidence of subsurface liquefaction may not appear at the ground surface, or may not appear until several minutes after the shaking has stopped. The critical condition may not develop until 10 to 30 minutes after the earthquake. This behavior is generally consistent with observed liquefaction phenomena. Moreover, for coarse sands and gravels with no impedance of drainage, seismically generated pore pressures are shown to dissipate so rapidly that no detrimental buildup of pore pressure can occur.

An alternative method of analysis of seismic shaking and liquefaction is described by Ghaboussi and Dikmen (1979). It is based on modeling the three components of earthquake ground acceleration rather than the one component of horizontal shaking considered previously. Analysis of a layered medium, including saturated sand below the water table, indicated that the vertical component of base motion has minimal influence on the development and pattem of liquefaction, but that interaction between the two horizontal components of shaking significantly influences the development and pattern of liquefaction. Moreover, increasing the amplitude of base acceleration in a one-dimensional analysis does not completely reproduce the major effects noted in a two-dimen- 


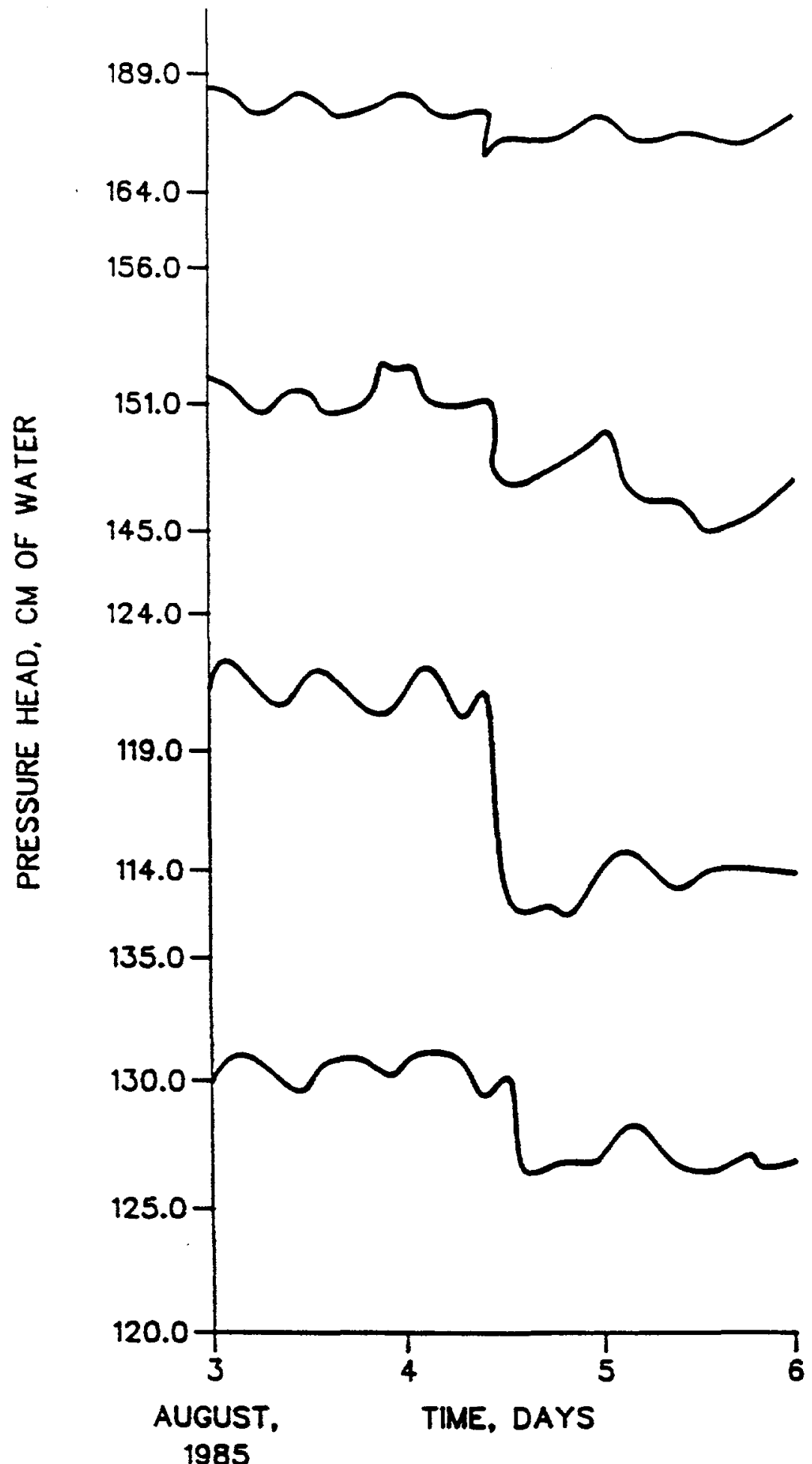

FIGURE 6.2

HYDROGRAPHS OF FOUR OBSERVATION WELLS AT

PARKFIELD WHICH SHOW THE WATER LEVEL DECLINES

CAUSED BY THE AUGUST 4, 1985 KETTLEMAN HILLS EARTHOUAKE.

(FROM BREDEHOEFT, et ol, 1987) 
sional analysis, with somewhat different surface response spectra between the two methods of excitation.

\subsection{Saturated Fractured Rock}

Compared with the literature available on seismic effects on hydrology in granular media, there appears to be little information available on seismic effects on saturated fractured rock. A highly idealized study by Ramazanov (1985) is concerned with groundwater pressure and temperature changes in relation to changes in the state of stress in the earth's crust. It concems long wavelength perturbations of the state of stress and their interactions with the temperature and pore pressure fields. The usefulness of the analysis seems to be limited by the restrictive assumptions about the origin of earthquakes.

The analytical techniques developed by Lemos (1987) are applicable to the study of the response of saturated fractured rock masses to seismic events. Lemos studied the seismic behavior of the foundations of gravity dams constructed on jointed rock using a two-dimensional version of the Distinct Element Method. The studies showed that the coupled hydraulic-mechanical model expressed the key modes of response of the saturated jointed medium, from the point of view of joint shear displacements, crack opening, and fluid flow in fissures.

\subsection{Unsaturated Porous and Fractured Rock}

There appears to be a distinct dearth of information on the hydrological effects of seismic activity for unsaturated porous and fractured rock, such as tuff.

A well-documented field observation of rock mass response to a major seismic event is provided by the study by Wood, et al., (1985) of the hydrologic effects of the Borah Peak, Idaho, earthquake of 1983. Presumably, the medium was characterized by a typical geohydrology, with unsaturated zones overlying saturated zones discharging to springs and streams. The regional response to the earthquake was dramatic, with streams drying up and then increasing in flow. At the Clayton silver mine, 50 kilometers from the epicenter, groundwater inflow exceeded the mine's pump capacity. The conceptual model proposed for these effects is based on elastic stress changes in the rock mass, causing pressure changes in aquifers. Presumably the stress changes also change the hydraulic aperture of the fissures through which flow occurs.

Analysis of changes in groundwater conditions due to seismic events is possible, in principal, using a coupled hydraulic-mechanical version of the Distinct Element Method. As noted earlier, Lemos (1987) has demonstrated the application of the technique for two-dimensional analysis. It is possible that a three-dimensional Distinct Element model, based on coupled hydraulic and mechanical responses, would be a more comprehensive and suitable simulation of hydrologic changes in partly saturated media than those currently proposed.

Although the concem here is with seismic effects on groundwater hydrology, Carpenter and Chung (1985) note a concern with long-term (perhaps aseismic) tectonic activity on the hydrologic regime at a site. Both earthquake-induced changes in hydrology and aseismic, tectonic changes may be studied appropriately with coupled hydraulic mechanical models of rock masses. 


\section{ANALYTICAL METHODS}

\subsection{Formal Analysis}

In rock mechanics practice, modeling for excavation design and performance prediction may be accomplished by formal mathematical analysis or by numerical modeling. The mathematical approaches are defined as those involving closed-form solution or formal analysis and simple numerical techniques. Computational analysis is based on well known techniques such as the Finite Element Method, Finite Difference Method, Boundary Element Method and Distinct Element Method. Because derivation of necessary closed-form solutions is difficult and usually involves highly idealized problems, numerical techniques assume particular importance in practice. Numerical models provide a means to incorporate the complex behavior of geologic media and the interactions between the host medium and underground engineered structures.

In recent years, there has been substantial development in numerical modeling techniques, primarily because of the advances in computer hardware and, particularly, in computer graphics and microcomputers. However, formal analysis is still an essential part of geoengineering practice, and provides closed-form solutions for idealized problems which are essential for validation of numerical schemes. When they are available for the particular problem and conditions of interest, closed-form solutions are the most economical method for determination of stresses and displacements around excavations. The primary limitation of closed-form techniques is the restriction imposed by the simplifying assumptions which must be made to derive the solutions.

There is a considerable literature on the development and application of analytical solutions to the problem of a plane wave propagating around lined and unlined tunnels in an elastic medium. Mow and $\mathrm{Pao}$ (1971) investigated the interaction of steady-state harmonic loading (P-, SV- and SH-waves) with cylindrical cavities in cases where the propagation direction is normal to the longitudinal axis. Miklowitz (1963) used the correspondence principle and linear elastic assumptions to study scattering of a pulse by a circular cylindrical cavity in an infinite solid. Achenbach (1975) presented, for two and three dimensions, closed-form solutions for a harmonic plane wave propagating through an infinite medium containing cavities. Closed-form solutions for plastic flow behavior, useful for preliminary analysis of circular tunnels subjected to ground shock, are presented by Newmark, et al., (1970) and Hendron and Aiyer (1972). These solutions idealize the problem as a static, two-dimensional analysis of a circular tunnel in a hydrostatic stress field. The surrounding medium is treated as an elastoplastic material with failure defined by a Mohr-Coulomb yield function. The Newmark solution assumes a fully non-associated flow rule; Hendron and Aiyer assumes a fully associated flow rule. Detoumay (1983) provides an extension to the solution for non-hydrostatic loading by the development of a semi-analytical technique. This approach applies for arbitrary dilatancy of the material and, therefore, makes the solutions of Newmark and Hendron and Aiyer special cases of the Detournay solution. 


\subsection{Constitutive Relations}

Investigation and development of constitutive models for engineering materials have been the subject of study for many years. The broad topic was recently reviewed by Desai and Siriwardane (1984). The great diversity of engineering and natural materials has the result that different types of materials exhibit different stress-deformation characteristics. Commonly, non-viscous materials can be described as follows:

(1) linearly elastic;

(2) non-linearly elastic;

(3) rigid perfectly plastic; and,

(4) elastoplastic.

These elementary material models have all been applied to the continuum analysis of geologic media. In this section, the subject of constitutive modeling for elastoplastic response of rock is considered briefly, since it represents the most common assumption about rock deformation mechanics.

The mathematical theory of plasticity provides a theoretical description of the relation between stress and strain for a material which exhibits a plastic response. In essence, plastic behavior is characterized by an irreversible straining which is not time dependent and which can only be sustained once a certain level of stress has been reached. In order to formulate a theory which models elastoplastic material deformation, the following three requirements have to be met (Owen and Hinton, 1980):

1. A relation between stress and strain must be formulated to describe material behavior under elastic conditions (i.e., before the onset of plastic deformation).

2. A yield criterion indicating the stress level at which plastic flow commences must be postulated.

3. A relation between stress and strain must be developed for post-yield behavior (i.e., when the deformation is made up of both elastic and plastic components).

\section{$\underline{\text { Linear and Non-linear Elasticity }}$}

The basic relations between stress and strain in the elastic region is assumed to be linear or non-linear. For linear elasticity, the stress strain relation is given by Hooke's Law. Non-linearity in the elastic range of material deformation represents the effects of the defects (e.g., fractures) in the rock material on its overall mechanical response. The various schemes for representing non-linear behavior in the stress strain response use curve fitting methods, interpolation, or simple mathematical functions (Desai and Christian, 1977). In this way, non-linear curves may be represented as a set of linear segments leading to piece-wise linear models, or as functional relations.

\section{$\underline{\text { Plasticity }}$}

There are several formulations of plasticity which are used to represent rock behavior. Typical models include:

(1) rigid, perfectly plastic;

(2) elastic, perfectly plastic; and 
(3) some form of strain hardening or softening.

In each case, a yield criterion or function is used to describe the stress conditions under which plastic flow of the material occurs. The two simplest yield functions (the Tresca and von Mises) assume that the material is non-frictional, and are therefore more appropriate for metals. The two most common yield criteria for rock are identified as the Mohr-Coulomb and the Drucker-Prager criteria. For these, the material is treated as frictional and cohesive. The yield criteria described by these models determine the limit condition. Then, strain (and displacement) of the body after yielding is described by the appropriate flow rule. Two types of flow rules, associated and non-associated, describe the plastic response. The associated flow rule requires analysis in terms of stress and strain tensors, but experimental testing has shown that it over predicts dilational strain. As a result, non-associated flow rules, in which the friction and dilation may be defined separately, are often used in rock mechanics. The development of capped yield criteria provides a rational basis for modeling of plastic volumetric collapse and continuously-yielding granular soils and rocks under dynamic loads. Examples of latter applications of capped yield models are provided by DiMaggio and Sandler (1971) and Isenberg and Baggi (1972).

\subsection{Computational Dynamic Analysis of Granular Media}

In reporting modeling of spall phenomena, Barton et al. (1979) discuss the difficulties commonly encountered with finite difference codes such as the two-dimensional code TENSOR. Three purely numerical problems (zone size effects, continuous rezoning, and hour glass damping) and three constitutive problems (artificial viscosity, tensile failure and void closure) are considered. The paper gives three examples of numerically calculated spalls: a controlled blasting configuration, a recalculation of the Sedan cratering event, and a simulation of the Baneberry event.

Swift and Burton (1984) developed a multiphase continuum model that couples non-linear deformation to porous flow and incorporated it into the explicit, finite difference code TENSOR for numerical analysis of dynamic and quasistatic behavior. In a physical sense, the model describes a solid skeletal material containing flaws configured either as pores or stress-induced tensile cracks. These flaws may be filled with multiphase fluid (e.g., air and water) whose transient behavior is governed by a dynamic flow model. Dynamic mixture theory is used to account for coupling effects between phases. Non-linear material behavior representing the drained response of the porous solid has been combined with the multiphase flow model to account for the effects of pore pressure on compaction, shear failure and tensile failure.

The effectiveness of a particular material response model for explosive ground motion in tuff is discussed by Fogel, et al., (1985). The development of the material model is based on laboratory static material test data gathered by Terra Tek (Fogel and Patch, 1984). The model was used to predict medium response to small explosive tests conducted by SRI International. It was necessary to construct a new model to achieve agreement between calculated response and the experiment. This model was then used to analyze the high-explosive event ONETON. All laboratory measurements and SRI experiments used tuff samples from the Sandia ONETON test site located in the G-Tunnel at Nevada Test Site. The tuff was fairly homogeneous and the simple spherical explosion did not pose test site complications. The ONETON test was closer in response to a nuclear event.

The authors conclude that the studies provide interesting insights into medium response. The results from the two SRI experiments were not consistent with the ONETON experiment. Two major questions were raised by these inconsistencies. The first involved the possible presence of substantial 
rate effects in the response of this tuff, while the second involved the true in-situ air void content of G-Tunnel tuff. With these two questions taken as qualifications, rather good agreement was obtained between predictions and the experiment at the ONETON scale. This agreement demonstrates that the current models are adequate to faithfully reproduce material response provided the appropriate constants in the models can be specified. With the exception of the air void content question, and the need for at least a simple strain-rate dependent strength model, static test data are suitable for modeling a field event of reasonable scale. Resolution of the remaining questions should help to further improve the models currently in use.

\subsection{Computational Dynamic Analysis of Rock Masses}

There are, in general, two conceptual models of a jointed rock mass. In one case, the rock mass may be considered to be a discontinuum composed of individual blocks which interact with their neighbors through elastic and plastic deformation of the intervening joints. In the second model, the rock mass may be considered as a continuum in which the effects of discontinuities are accounted for through the constitutive equations for the continuum. In practical terms, the former model allows yield to occur anisotropically or along specified structures within the rock mass (e.g., sliding of a wedge into an opening). The latter model may allow complex non-linear constitutive behavior but may not adequately represent discontinuum response such as slip and separation of blocks of material. The type of approach to be used is a function of the scale of the problem (i.e., relation of spacing of discontinuities to excavation size), the intact rock and joint properties, and the field stresses.

To date, continuum modeling techniques have been the preferred design procedure for survivability predictions for tunnels subject to dynamic loading. These techniques, which include finite difference, finite element and boundary element methods, describe the rock mass as a continuous solid, within which displacements and stresses are defined in terms of governing differential equations. Finite differences and finite elements involve a discretization of the governing equations of motion for the complete problem domain. Each element in the discretized medium is assigned a constitutive material behavior representative of the medium. In the boundary element formulations, only the surface of the medium (e.g., the surface of the excavation or the ground surface) is discretized. The numerical solution is first obtained for these surfaces, and then the solution at different points within the medium is obtained from the solution at the boundary. St. John and Zahrah (1987) give a detailed discussion on continuum modeling and related codes currently used for investigating wave propagation and rock/structure interaction.

In the analysis of discontinuous media, there are two types of discontinuum methods. The first of these considers only kinematic conditions, and evaluates the feasibility of displacement of blocks of rock defined by two or more joints (Shi and Goodman, 1985, Warburton, 1985). This method, however, does not yield information on the stresses and displacements in the rock mass nor does it permit consideration of mixed deformation behavior, such as a combination of rock material and joint deformation.

The second type of discontinuum methods evaluates the rock mass as an assembly of separate, mechanically-interacting rock blocks. The initial development of this type of discontinuum analysis was conducted by Trollope (1968). Subsequently, Cundall (1971) pursued its development as the distinct element method. The method is based on the notion that a rock mass is composed of a series of blocks which interact across the intervening joint planes. The stiffness, friction, dilation and cohesion properties of these planes may be represented by constitutive laws of varying complexity, the simplest model being an elastic-plastic model with Coulombic limiting friction. In its earlier 
implementation the blocks were considered to be rigid and infinitely strong, thereby restricting all deformations to the joints and eliminating possible failure of intact rock material. Recent improvements of the method permit deformable blocks and development of new fractures, as well as more comprehensive description of the mechanical behavior of the joints (Cundall and Hart, 1985; Lemos, et al., 1985). The resulting computer codes, the Universal Distinct Element Code (UDEC)(Itasca, 1986) for two dimensions and the 3-Dimensional Distinct Element Code (3DEC) (Itasca, 1987b), incorporate automated statistical generation of joints, various joint constitutive laws, and internal discretization of blocks for Finite Difference analysis of block deformation.

Application of a coupled distinct element and finite element scheme in an investigation of response of a cavem to vertically propagating shear waves is reported by Dowding, et al., (1983). Butkovich, et al., (1988) demonstrated the use of discrete element modeling for analysis of cratering in jointed rock caused by underground explosions. The analysis was performed using the DIBS (Discrete Interacting Block System) Code (Walton, 1980), in which blocks are assumed to have arbitrary polygonal shape and be quasi-rigid.

A two-dimensional, plane strain, non-linear analysis of underground structures subjected to stress waves is described by Sweet (1977). The non-linear analysis of the rock medium (NTS tuff) and an embedded structure was performed using the finite element code SWIS. The dynamic behaviors of an unlined cavity, a reinforced concrete steel liner and a cellular concrete steel liner were studied. Different material models were used for the various materials: a soil cap model for NTS tuff; variable modulus for reinforced concrete; a von Mises plasticity model for steel; and a crush-up model for cellular concrete steel. The general conclusions of this analysis were as follows.

1. The reinforced concrete design relies on the strength of the composite structure for integrity. However, the steel liner experiences a significant strain environment in the reinforced concrete design concept.

2. The use of cellular concrete between the tuff and the steel liner reduces the maximum strain in the steel liner by approximately a factor of three.

3. The maximum cavity closure varies significantly among the three-cavity configuration, with values in decreasing order for the unlined, reinforced composite.

4. The cellular concrete approach is very effective because it decouples the behavior of the surrounding tuff medium from the liner.

5. The disadvantage of cellular concrete is that its effectiveness is reduced if it becomes saturated with water.

For the dynamic analysis of underground excavations in jointed rock, Asmis (1984) developed a central finite difference scheme for solving the equations of motion, subject to elastic rock material behavior and fault-slip relations of the form proposed by Dieterich (1979). Analysis of excavation performance is reported for a square excavation transgressed by a single fault. Limitations of the finite difference code imposed the requirements for plane analysis, rectangular problem geometry and a single plane of weakness. Thus, this analysis can be considered as an introductory study of the dynamic performance of excavations in faulted rock.

The effect of a surface nuclear blast on a deep underground tunnel was studied by Schmitz (1982), assuming elastoviscoplastic behavior of the rock medium. A two-dimensional finite element code called VISCO was used for analysis of stress and displacement around a deep tunnel in rock which was treated as continuous and isotropic. The constitutive equations are based on the Drucker-Prager 
yield criterion incorporated in the Malvem flow law. Both viscoplastic and elastoplastic material behavior were modeled using the viscoplastic theory. Quasi-static loading conditions were used for varying nuclear weapon yield because the pressure wave from a nuclear blast was considered likely to have significant rise time and long duration time. A triangular loading function was incorporated for quasi-transient loading. A modified Drucker-Prager material model has been suggested in this work because the Drucker-Prager yield criterion may predict excessive hydrostatic strain.

The finite difference code STEALTH was used by Wahi (1982) to analyze structural response of repository openings under seismic loading. The main purpose was to predict whether such loading might (1) cause collapse or other structural failure of these openings, or (2) create new fractures or affect the existing joints in the rock masses surrounding a repository in such a way as to increase permeability and, hence, groundwater circulation. The technique was intended to permit modeling of the system for a prolonged time period for (a) very short range near-field response of openings to earthquake loading, (b) medium-to-long range response, for quasi-dynamic thermomechanical response during the retrievable phase, and (c) very long range for quasi-static far-field response. Different earthquake data were utilized to excite the model of the rock mass, which was subject to various in-situ stress ratios, joint geometry, pore pressure, and presence or absence of a shear zone. Although STEALTH is a very versatile code and is capable of modeling complex constitutive behavior, it is limited to modeling continuous media. Thus, the code cannot simulate block motion and sliding of blocks. Instead, it models the jointed rock medium as an equivalent continuous rock mass. It is therefore not an appropriate scheme for study of the response of excavations in jointed media where block motion is a prospect, as is the case at the repository site at the NTS.

In seismic analysis of a supported cavity, Dendrou (1978) considered various excavation design altematives, and assessed each design on the basis of independent criteria for the components of the rock-support system. The rock mass was assumed to be isotropic both in the physical and statistical sense. A two-dimensional finite element analysis, using triangular solid and beam elements, was performed to evaluate effects of (1) an underground water flow in the rock mass, (2) excavation in the rock mass, (3) a seismic perturbation on the rock mass, and (4) the displacement of the rock mass against the liner. An inference model linked together the statistical data obtained from site investigation based on physical parameters and the analytical model based on the finite element computation.

Balachandra and Malthan (1976) analyzed a technique for installation of a velocity gauge in a borehole, to ensure that it correctly recorded ground motion. The code used in the analysis was a two-dimensional finite element code, based on small strain, axisymmetric geometry and non-linear material properties. The capacity to model interfaces between subregions of different properties is provided by logic to model slip lines. These are modeled as small-strain elements with elastoplastic constitutive behavior based on Mohr-Coulomb plasticity. The slip elements do not permit satisfactory modeling of intersecting faults, large rigid-body translation of blocks are precluded, the joint constitutive model takes no account of joint damage due to cyclic loading, and velocity and normal stress independence of joint residual strength is unsuitable for seismic analysis.

The effect of surface topographies on underground structures was studied by Askar, et al., (1984), using a boundary integral equation method. The authors developed a stable explicit integration scheme for the boundary integral equations. The iterative scheme does not necessitate matrix inversion and was shown to be stable analytically, with very high values of wave numbers. The frequency domain solution presented in this paper shows that, for the particular problem geometry studied, surface topography and the tunnel influence each other quite strongly, and that their collective 
behavior is quite different from the individual response. The solution technique applied to this wave-scaling problem is limited to an homogeneous, elastic, isotropic continuum and is not an appropriate model of the Yucca Mountain site.

A boundary element model for dynamic analysis is reported by Mack and Crouch (1988). It is suitable for analysis of the displacements and stresses caused by sudden changes in the geometry of an underground excavation, by sudden slip on a joint or fault plane, or by sudden development of a planar shear nupture through intact rock. A three-dimensional dynamic indirect boundary element scheme is developed using a time marching procedure and displacement discontinuities to model excavations and planes of weakness. The application of this scheme is currently restricted to a single planar excavation, linear materials, and planar joints. However, it can be extended readily to handle several joint or fault planes. This scheme has significant advantages over the finite element method and the finite difference method because the problem domain discretization in the boundary element method is only required along the slip lines. No discretization is necessary in the domain interior, as is the case in other numerical methods, thereby reducing the spatial dimension of the problem. The boundary conditions at infinity are automatically satisfied and artificial non-reflecting boundary conditions are not required. This suggests that dynamic boundary element techniques have substantial scope for application in repository analysis, particularly with respect to far-field response to explosions and earthquakes.

\subsection{Soil-Structure Interaction Analysis}

Dynamic soil-structure interaction, in the present context, is concerned with the study of the behavior of underground tunnel structures and shafts subjected to propagating stress waves. In the analysis, the equations for wave propagation are used to determine the free field ground deformation in the absence of the tunnel or shaft structure. With the introduction of the tunnel or shaft structure, the liner resists the distortion imposed on it by the medium, and displacements and stresses are generated in the liner.

A current analytical procedure for estimating strains and stresses experienced by a surface structure that resists ground motion are based on: (a) the theory of wave propagation in an infinite, homogeneous, isotropic, elastic medium, and (b) the theory of an elastic beam on an elastic foundation (St. John and Zahrah, 1987). The beam theory is necessary to account for the effects of interaction between the ground and the structure. Several investigators (Hendron and Fernandez, 1983; Peck, et al., 1972; Einstein and Schwartz, 1979) have analyzed formally the relation between the flexibility ratio and the extent to which a liner modifies a tunnel response to either static or dynamic loads. Several closed-form solutions are available for estimating ground-structure interaction for circular tunnels. Duddeck and Erdmann (1982) have reviewed the solutions for static design. The relevant equations for the dynamic case are given by Garnet, et al., (1966).

Closed-form analytical solutions for plane wave propagation normal or near normal to a tunnel axis are available for circular tunnels, both lined and unlined. However, the analysis of stress and displacement around excavations, supported or unsupported, of different geometric shapes, in two or three dimensions, with plane waves impinging from any direction, is beyond the capacity of formal analysis. Also, use of actual data from an earthquake or an explosion makes the problem far more complicated than can be solved in closed-form. Numerical techniques are essential in solution of such complex problems. 
The capacity of numerical modeling techniques has improved substantially in the recent past. The numerical methods currently used for dynamic analysis are: (a) the finite difference method, (b) the finite element method, and (c) the boundary element method.

Dynamic soil-structure interaction analysis of underground tunnels is presented by Gomez-Masso, et al., (1983) and Gomez and Attalla (1984). Combined P- and S- waves obtained by conventional methods from the theory of one-dimensional wave propagation through a lineariy viscoelastic layered system defined the seismic environment. The response of the soil-structure system was analyzed by linear viscoelastic finite elements, superimposing the free-field motion and the interaction motions. The free-field motion was calculated using the program EQSYS and the interaction motion using CREAM, which was developed to accept arbitrary seismic input. The interaction motions were calculated in a plane strain geometry taking into account the influence of adjacent structures, with an approximation for three-dimensional effects. Statistical independence of the horizontal and vertical input motions was based on the guidelines established by the U.S. Nuclear Regulatory Commission Regulatory Guide 1.92 (U.S. NRC, 1976). Simultaneity of the horizontal and vertical earthquake motion was achieved directly in the analysis.

Examination of this work suggests that this approach must be used cautiously, in view of the approximate procedure for modeling a three-dimensional problem. A regular 3-D analysis scheme capable of dynamic analysis with seismic input would be more appropriate in this analysis.

Soil-structure interaction problems have been extensively researched, using the finite element method, and reported by Idriss (1979), Lysmer (1978) and Johnson (1981), among many others. Lysmer (1981), in his review of the current state of the art of the seismic soil-structure interaction analysis, suggests that many of the studies of surface structures can be directly applied to underground structures in soil. The author discusses the generic problem of soil-structure interaction analysis using the finite element method and concludes the following.

1. The determination of the temporal and spatial variation of the free field motions is the most important part of any soil-structure interaction analysis.

2. The current definitions of the soil structure interaction problem implies that superposition must be used, directly or indirectly, in any rational method of analysis of this problem.

3. Currently, the most important part of the soil-structure interaction analysis, the free-field problem, cannot be solved by a non-linear method. Even if such solutions are obtained, they cannot properly be superimposed on the free-field motion to obtain the total motion of the structure.

Both frequency and time domain techniques have been utilized in 2-D or 3-D boundary element analysis to determine the steady state or transient response of tunnels and caverns of arbitrary shape to seismic waves or other external loads. Both lined and unlined cavities in the infinite or half-plane medium have been considered. The important case of a seismic wave impinging on lined tunnels is treated as a wave diffraction problem by employing the Boundary Element Method for both the soil and the liner, which are then coupled at their interface through enforcement of compatibility and equilibrium conditions.

Among those works concerning the use of the Boundary Element Method in dynamic analysis of underground structures are: for the two-dimensional frequency domain case, Niwa, et al., (1975, 1976), Kobayashi and Nishimura (1982a, 1982b, 1982c, 1983), Kobayashi (1985a, 1985b, 1987), Tan (1976), Manolis and Beskos (1981, 1983), Kitahara, et al., (1984), Hamada, et al., (1985) and 
Vardoulakis, et al., (1987); for anti-plane motion in the frequency domain, Ohtsu and Vesugi (1984); Niwa et al. (1980) and Manolis (1983) for two-dimensional time domain cases; Rice and Sadd (1984) for anti-plane motion in the time domain; Rizzo, et al., (1984, 1985a, 1985b, 1985c), Kitihara and Nakagawa $(1985,1986)$ and Banerjee, et al., $(1985,1987)$ for three-dimensional frequency domain cases; and Manolis (1984), Banerjee and Ahmed (1985), and Banarjee, et al., (1987) for three-dimensional time domain cases.

Application of all the codes developed using the Boundary Element Method is limited to elastodynamic problems. However, the Boundary Element Method can be used in a linked scheme, where the failure or plastic zone is modeled by a finite element or finite difference technique. Linkage with boundary elements to model the elastic region eliminates the need for non-reflecting boundaries, which are essential for effective performance of the other two methods.

\subsection{Computer Programs for Dynamic Analysis}

Many publications describe the different numerical methods used to analyze wave propagation and ground structure interaction problems. Several of these computer programs are well suited for investigating the problems of wave propagation and soil or rock structure interaction and are described below.

SHAKE-Developed by Schnabel, et al., (1972), this code can be used to analyze free-field response. The soil medium comprises a system of horizontal viscoelastic layers of infinite horizontal extent, and an equivalent linear model is used to represent the strain dependence of material properties of each soil layer. The medium can be subjected to vertically incident shear and compression waves. The solution is obtained in the frequency domain and then transformed to the time domain using Fast Fourier Transform techniques.

FLUSH - This two-dimensional computer code developed by Lysmer, et al., (1975) can be used to determine the response of a soil-structure system, with layered soil media extending infinitely in the horizontal direction. The solution technique and soil model are similar to the SHAKE code. The soil medium is bounded by a rigid base and by transmitting boundaries (viscous dashpots).

ADINA - This is a general purpose finite element program for two- and three-dimensional static and dynamic analysis of structural systems. Developed by Adina Engineering (1981), this code contains libraries of elements and constitutive schemes providing linear and non-linear material models. An infinite medium can be approximated by transmitting boundaries, and input motion can consist of horizontal and vertical motion from any arbitrary combination of waves. Several solution techniques can be used, including the direct time integration (explicit and implicit), normal mode method for linear dynamic analysis, and determination of frequencies and mode shapes.

SAPIV - This general purpose finite element code developed by Bathe, et al., (1974) offers similar capabilities to ADINA.

ABAQUS - Developed by Hibbit ,et al., (1982), this is also a general purpose finite element code with features similar to those of ADINA.

HONDO - Key et al., (1978) developed this finite element code to analyze two-dimensional wave propagation and soil-structure interaction problems. The main features of this program are that (1) linear and non-linear material behavior can be used, (2) the solution scheme is explicit, with a variable 
integration timestep, (3) non-reflecting boundary conditions simulate an infinite medium, and (4) only pressure loading can be applied.

DYNA2D - This is a finite element code developed by Hallquist (1978) and has similar capabilities to those of HONDO.

STEALTH - STEALTH 1D, 2D and 3D (Hoffman, 1981) are one-, two- and three-dimensional explicit finite difference codes which numerically solve the time-dependent, non-linear partial differential equations of continuum mechanics for thermomechanics. The numerical equations are cast in several coordinate systems, using the Lagrange (material) frame of reference. Material models include the ability to include equations of state (mean properties), strength (deviatoric mechanical properties), and heat transfer (thermal properties). User-supplied constitutive models can be programmed into the code.

UDEC - This two-dimensional distinct element code (Itasca, 1986) simulates the behavior of jointed rock media subjected to either quasi-static or dynamic conditions. In this code, the medium is simulated as an assemblage of blocks which interact through comer-and-edge contacts, and discontinuities are regarded as boundary interactions between the blocks. The code utilizes an explicit timestepping (dynamic) algorithm which allows large displacements and rotations and general non-linear constitutive behavior for both the material and discontinuities. UDEC also simulates variable rock deformability, complex joint structures, non-linear inelastic joint behavior, plastic behavior of intact rock, fluid flow in joints, far-field static or dynamic boundary conditions, and rock-structure interaction.

3DEC - Developed by Cundall (1988)and Hart and Lemos (1988), 3DEC simulates the behavior of jointed rock media in three dimensions using the distinct element method. The numerical method is specifically designed for simulating both quasi-static and dynamic response to the loading of rock media containing multiple intersecting joints. In this code, the rock mass is modeled as a three-dimensional assemblage of rigid or deformable blocks, discontinuities are regarded as distinct boundary interactions between the blocks, and continuous and discontinuous joint patterns are generated on a statistical basis. A joint structure can be built into the model directly from geologic mapping. The code employs an explicit-in-time solution algorithm which accommodates both large displacements and rotation and permits time domain calculations. The graphics facility permits interactive manipulation of 3-D objects, which greatly facilitates the generation of 3-D models and interpretation of results.

SPECTROM-331 - This finite element program was developed for the CRAY1 by Key (1987). It is capable of performing three-dimensional transient dynamic calculation and offers a wide range of material models, including elastic-plastic, strain-hardening, strain-rate behavior, soil and crushable foam behavior, viscoelastic behavior, and jointed rock mass behavior. A non-reflecting or transmitting boundary and sliding contact between independently meshed bodies is included in the code. An explicit linear integration method is used for transient dynamic problems. The program is well suited for applications in which large energies and forces are present, where stress wave propagation occurs, and where large displacements and strain dominate.

CICE-Developed by Williams, et al., (1985), CICE is a two- and three-dimensional discrete element program for solving complex solid mechanics problems involving multiple interacting bodies undergoing fracturing. The Distinct Element Method developed here is based on a solution achieved by modal superposition. The intact rock material is modeled using the finite element method. 
A more extensive listing of computer codes capable of analyzing rock mechanics problems is provided in Appendix B. This list was based on codes available in 1982 and is neither current nor comprehensive. Many of the codes developed earier (e.g., FLUSH, SHAKE, etc.) or more recently (CICE, UDEC, 3DEC, SPECTROM-331, etc.) are omitted. 


\section{MODEL VALIDATION}

\subsection{General}

Validation of analytical models, such as those described in Section 7, generally involves a comparison of results predicted by the analysis with those obtained by some independent (usually experimental) investigation. This is especially difficult for the present case, since two different types of excitation (ground shock and earthquake/rock burst) are involved, the physical system is very large and unamenable to experimental control, and the results can vary significantly with the variety of geophysical parameters that are shown in Sections 5 and 6 to define the system. In fact, it may not be possible to account for all the parameters simultaneously, so that some kind of distorted-model validation approach may be necessary. Even so, a perusal of the available literature indicates that no such validation of analytical models has been previously attempted for the overall seismic response of underground structures. However, some parts of the problem have been studied, either by full scale or scale model experiments. The results of these investigations will be summarized herein first, and then requirements will be described for validation of a candidate analytical model computer code which is applicable to the overall dynamic problem.

\subsection{Full Scale Studies}

Dynamic response and associated damage potential for both ground shock and earthquake excitations of underground structures have already been presented in Sections 3 and 4. However, the literature cited dealt primarily with studies aimed at exploring the problem and identifying the significant parameters involved. On the other hand, experimental results that are suitable for analytical model validation must come from carefully conducted programs in which only a very few parameters are allowed to vary in a controlled manner. Thus, essentially no such data are currently available for earthquake response, since the state of the art is still in its infancy. Nevertheless, some available studies which deal with ground shock may be suitable for related validation purposes.

\subsubsection{Related Component Validations}

Various full scale experiments have been conducted on material properties and the results compared with analytical prediction methods. Others have also been performed for constitutive properties of joints and faults. Literature dealing with these subjects has already been cited in Sections 4 and 5 , and therefore will not be discussed further here. However, some other related studies will be mentioned.

Butters, et al., (1974) have reported a series of mechanical tests and compared data with analytical predictions for mechanical properties of these different grout mixtures. The grout material is intended as filler between rocks and tunnel liners. The mixtures are dubbed superlean, rock-matching, and high-strength grout. Procedures and results are given for uniaxial, triaxial, punch extrusion, and other types of standard tests. The results are then compared with an equivalent analytical, constitutive model. Sample results for mean stress-volume strain response in superiean grout are presented in 
Fig. 8.1, which is based on hydrostatic compression test results. Similar results are presented for deviatoric stress from triaxial tests in Fig. 8.2. Various similar material properties validations are required for rock material properties.

Although they do not provide data for having conducted a validation, Sues and Short (1986) provide a detailed description of parameters and measurement procedures that are appropriate for on site characterization of the rock mass for a validation of analysis of block motion which results from surface explosions. This is shown conceptually in Fig. 8.3 by Blouin (1984). It can be seen that with little change the approach is also applicable to the case of underground explosive shock. An outline of the general investigations, procedures, measurements, and testing which is appropriate is summarized in Table 8.1. Furthermore, this same reference asserts that there are important needs for validation which cannot be met by present state-of-the-art techniques. Several of these needs are as follows:

1. Methods for evaluating discontinuity shear strength at high normal loads. Both direct and indirect methods have been discussed. Direct methods involve shear testing of the discontinuity. Special procedures may be required to test at the normal loads of interest. Testing of actual discontinuities at normal loads pertinent to block motion have not been performed to date. Indirect methods involve the prediction of shear strength based on the evaluation of certain parameter values. The predictive methodology may require development for high normal loads. Comparison and correlation of discontinuity shear strength, evaluated either directly or indirectly with actual shear strength measured or observed during block motion must be carried out.

2. Methods for efficiently identifying discontinuities likely to undergo block motion. A number of techniques have been described herein for locating and mapping discontinuities. Some development is required to ensure that these methods are efficiently employed and so that important discontinuities are not missed.

3. Methods for evaluating in-situ rock strength and stress-strain characteristics under dynamic loading and under the high loadings pertinent to block motion. This is principally required for ground shock estimation. DNA is currently expending effort in this area.

4. Instrumentation for measurement of tangential stresses. Such gauges are presently in developmental stages. Accurate measurement of tangential stresses during block motion experiments is imperative for estimating shear stresses along a discontinuity.

5. Instrumentation for measurement of pore water pressures. These instruments require development. Without knowledge of pore pressures, the effective stress on the discontinuities of interest cannot be determined during block motion experiments.

6. Instrumentation for measurement of block motion. The passive methods discussed herein and which have been used in past experiments measure residual block motion. Passive measurement techniques that measure peak block motion and/or cost-effective active measurement techniques need to be developed.

Overcoming these deficiencies in the current state-of-the-art site characterization methods is crucial for increasing the reliability of block motion prediction methods. 


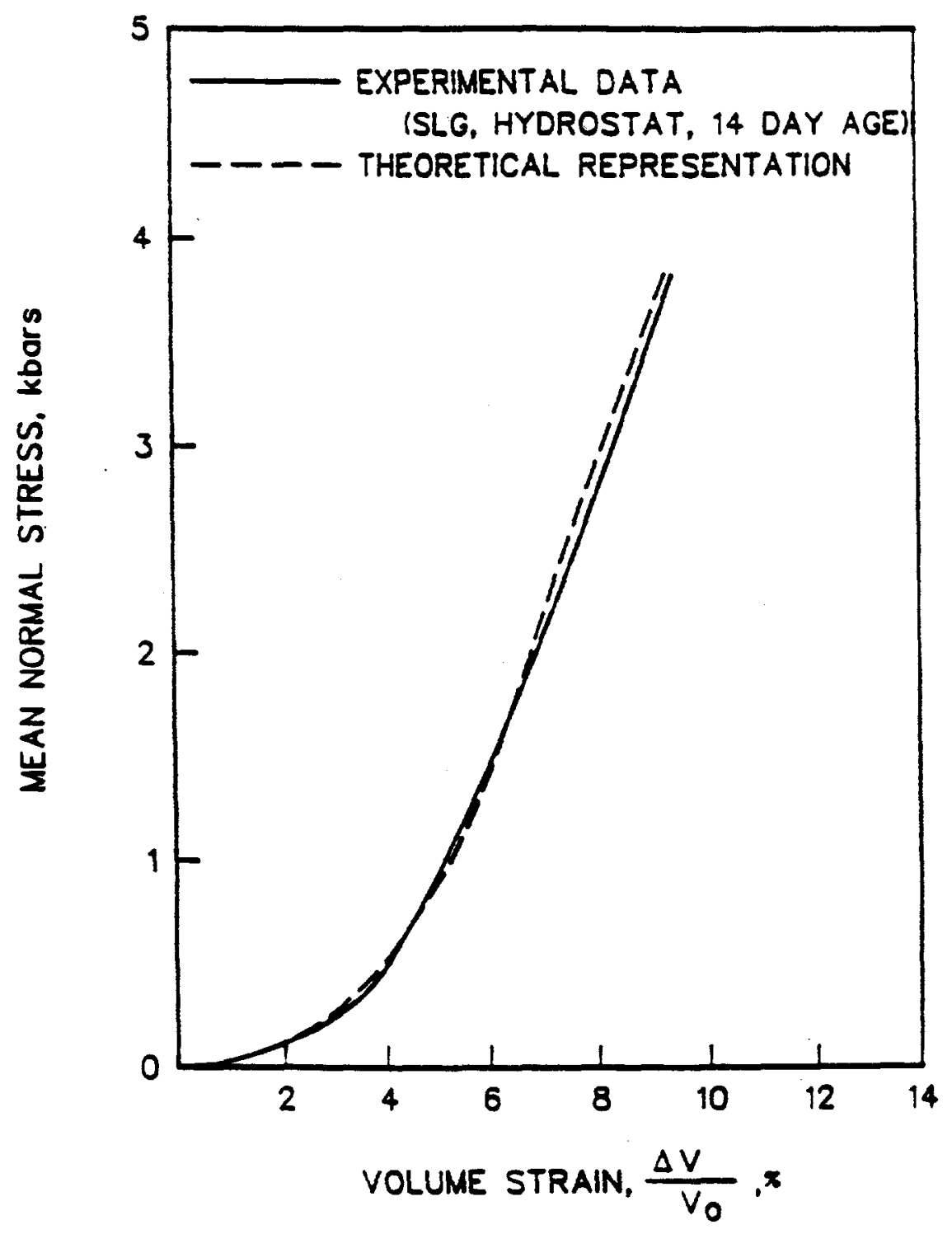

FIGURE 8.1

COMPARISON OF EXPERIMENTAL AND THEORETICAL RESPONSE OF SUPER LEAN GROUT IN HYDROSTATIC COMPRESSION. (FROM BUTTERS, et al, 1974) 


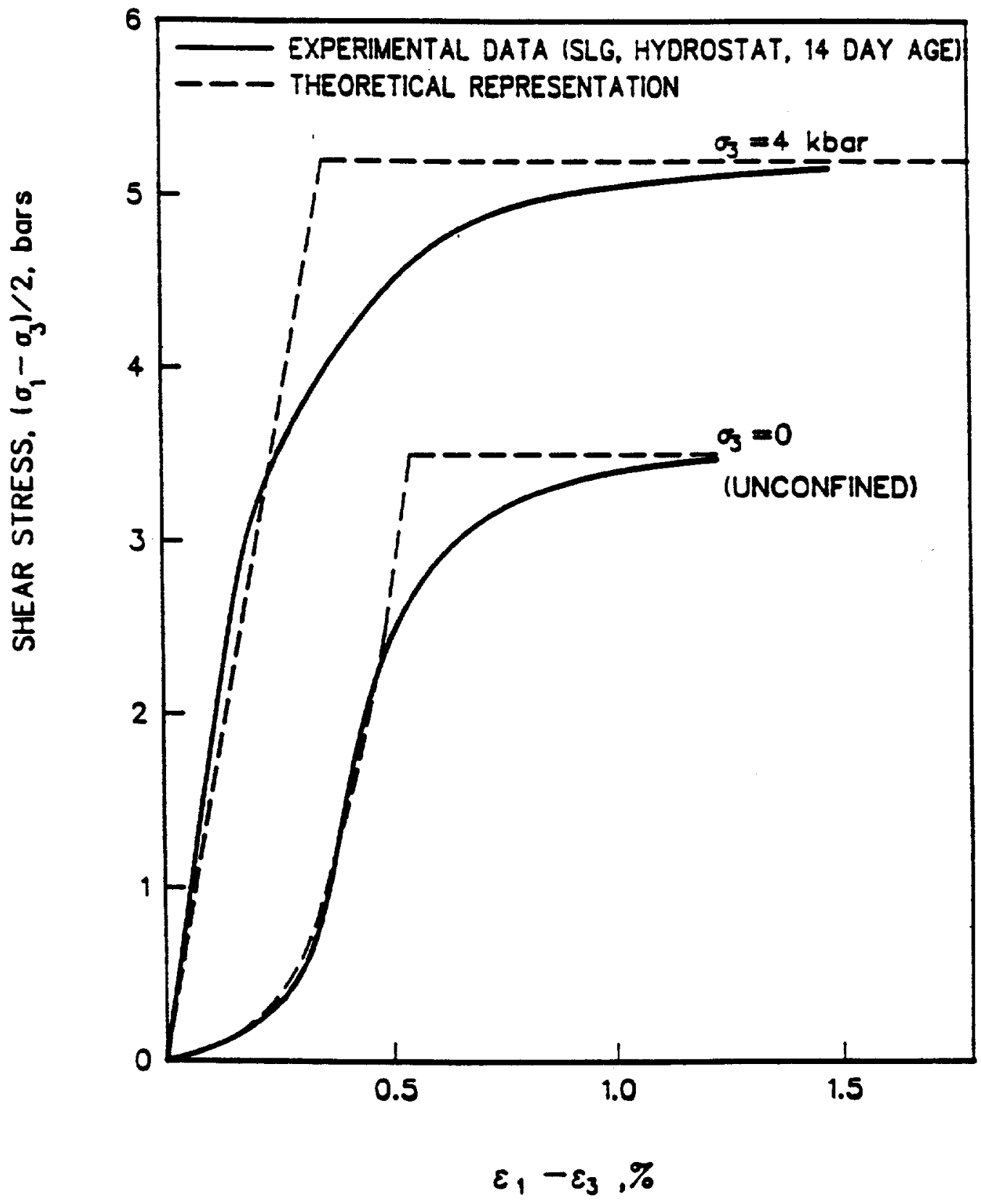

FIGURE 8.2

COMPARISON OF EXPERIMENTAL AND THEORETICAL DEVIATORIC STRESS-STRAIN RESPONSE FOR SUPER LEAN GROUT UNDER TRIAXIAL LOADING CONDITIONS AT CONFINING PRESSURES OF $O$ AND $4 \mathrm{kbar.}$ (FROM BUTTERS, et ol, 1974) 


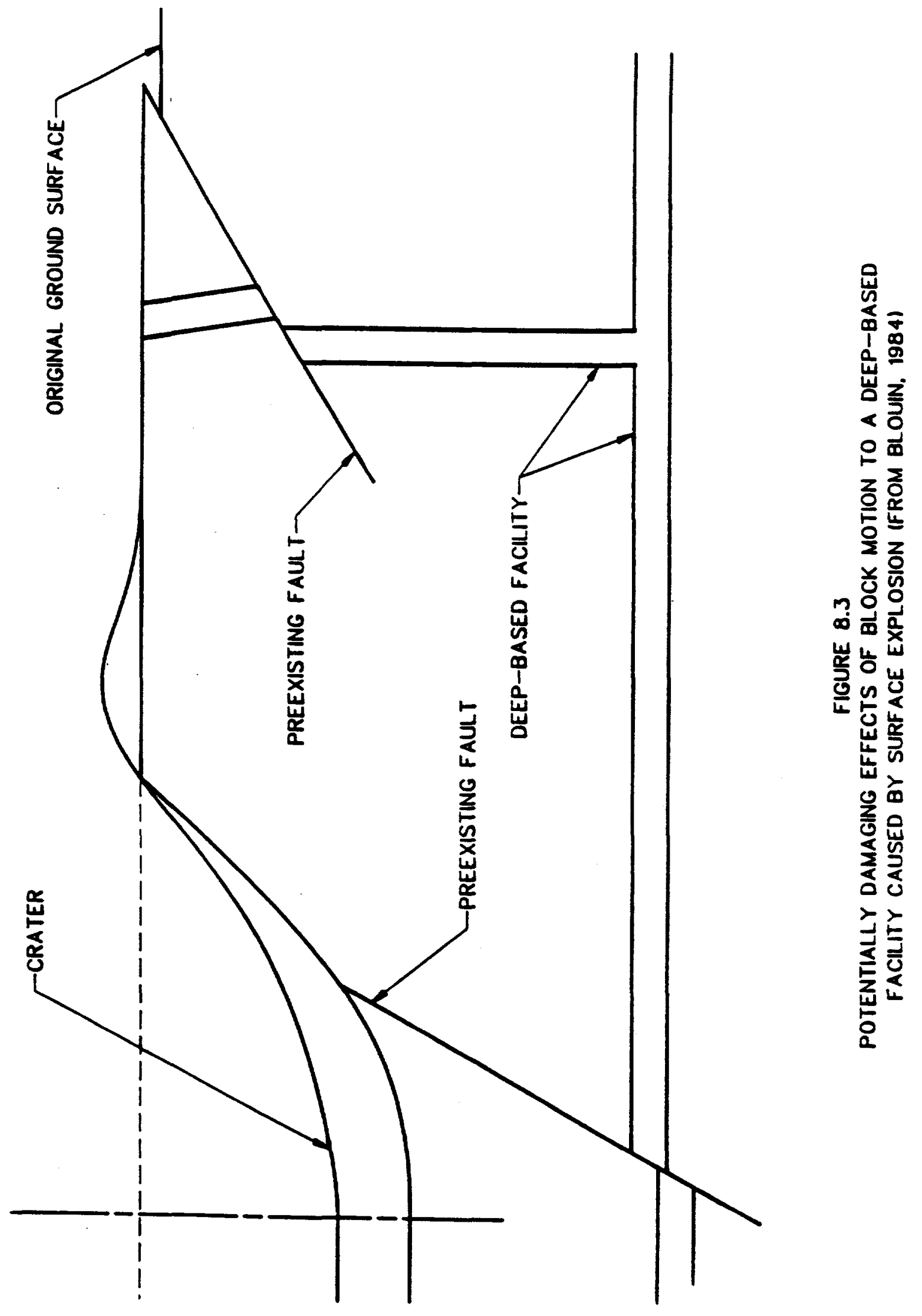


Table 8.1. Summary of Investigations for Site Characterization

(From Sues and Short, 1986)

A. General Rock Mass Characterization

1. Surface

- Physical Investigation

- Geologic Maps, Aerial Photos

2. Subsurface

- Existing Log Records

- Color Photos of Drill Core

- Wrap and Wax Core Samples

- Borescope and/or Videotape Drill Hole

3. Laboratory Testing on Selected Samples

- Ultrasonic Velocity

- Physical Properties

- Unconfined Compression

- Uniaxial Strain

- Triaxial Compression

- Tensile Strength (minimal effort)

4. In-Situ Mechanical Properties Evaluation

- Dilatometer

- Borehole Shear Strength Test

- Large Scale Deformability (may not be practical to apply or necessary)

- Explosive Tests (developmental)

B. In-Situ Stresses

C. Discontinuity Parameters

1. Surface

- Physical Investigation

- Geologic Maps, Aerial Photos

- Existing Log Records

2. Subsurface

- Seismic Refraction and Electrical Resistivity Explorations

- Core Samples with Discontinuities

- Borescope and/or Videotape Drill Holes

- Special Core Recovery Procedures (if necessary)

- Evaluate General Water Condition on Discontinuity

3. Examination and Laboratory Testing of Specially Recovered Samples

- Joint Wall Compressive Strength

- Joint Roughness

- Joint Aperture

- Residual Friction Angle

- Joint Filling Material Characteristics

- Joint Shear Strength

4. In-Situ Mechanical Properties Evaluation

- Shear Strength Tests (on limited basis for dedicated block motion experiments)

D. Ground Shock and Block Motion Phenomenon

1. Block Motion

- Rosettes

- Magnets and Magnetometers

- Break Wires

- High-Speed Cameras (limited basis)

2. Ground Shock

- Free-field Stress (radial and tangential) Velocity, and Acceleration

- Stress and Velocity on Both Sides of Discontinuities of Interest

- Pore Pressures at Discontinuities of Interest 


\subsubsection{Underground Nuclear Test For Tunnels}

It is known to the authors that various Defense Nuclear Agency reports are available in the subject area, although they are classified for national security purposes. Special provisions will be required to extract unclassified portions of information from these reports, where possible.

\subsection{Scale Model Studies}

A rather comprehensive scale model study of the failure modes of jointed rock masses was reported by Rosenblad (1971). Although other studies preceded this work, Rosenblad succeeded in solving certain problems that existed relative to development of a representative synthetic "scaled" rock material. Although the results were not used directly to validate any existing analysis, the approach is very related to that which will be required to provide validation data for the seismic problem.

Rosenblad (1971) developed the scaling parameters listed in Table 8.2 for plane-stress static loading of jointed rock masses. Some of the configurations tested are shown in Figure 8.4. A variety of data were acquired for the loading patterns defined to occur where notable changes in stress/strain ratios occurred. This study is very important in demonstrating that a synthetic rock material can, in fact, be designed and fabricated according to scale model laws, and can be used to predict useful information about jointed rock mass behavior.

The most important conclusions obtained as a result of this research are as follows:

(1) The sequential failure of a jointed rock mass occurs in two stages. Stage I failure is initial slip along joints. Stage II failure occurs after block interlock as a tensile failure that produces vertical cracks perpendicular to the planes of the $\sigma_{1}$ and $\sigma_{2}$ stresses. Additional supplementary failures occur that are a function of the plane stress loading system and are not generally characteristic of a rock mass.

(2) Slip along joints in one direction causes an increase in $\phi_{j}$ initial along joints in the perpendicular direction due to block interlock. The increase in $\phi j$ initial is always $\geq i$, where $\mathrm{i}=\arctan \mathbf{x} / \mathbf{l}$.

(3) The variation in principal strain magnitude and direction in a jointed rock mass are much larger and unpredictable than for an intact block under identical loading conditions.

(4) Mohr envelopes obtained from triaxial, direct shear, and model tests on intact model material are essentially identical. Mohr envelopes from triaxial and direct shear tests on single-jointed specimens of model material differ by less than five degrees.

Shortly after the above work a similar study was performed by Goodman, Heuze, and Bureau (1972). For this study experiments were performed for scale model tunnels in two-dimensional sections by means of the apparatus shown in Fig. 8.5. Here again the loading is static, and the results in this case also were not correlated with those predicted by any analyses. However, they did demonstrate the utility of the scale model technique as a viable means of obtaining independent data about jointed rock mass behavior under the assumed form of load.

A more recent study which includes a scale model with dynamic loading has been reported by Bakhtar and DiBona (1985). A 1/27-scale model was developed to simulate tunnel response to blast overpressure in a tuff material. The nondimensional equation is formulated as follows: 
Table 8.2. Significant Variables for Jointed Rock Mass Failure under Plane Stress

(From Rosenblad, 1971)

Nondimensional Governing Equation

$$
\frac{\sigma_{1}}{q_{u}}=f\left(v, \varphi, \frac{c}{q_{u}}, \frac{E}{q_{u}}, \frac{\sigma_{i}}{q_{u}}, \frac{\sigma_{2}}{q_{u}}, \theta^{\prime}, \frac{a}{b}, \varphi_{j}, \frac{c_{j}}{q_{u}}\right)
$$

Pertinent Dimensional Variables

$$
\begin{aligned}
& \mathrm{q}_{\mathrm{u}} \quad=\text { Unconfined compressive strength, psi } \\
& v \quad=\text { Poisson's ratio } \\
& \sigma_{1} \quad=\text { Major principal stress applied to a test specimen, psi } \\
& \sigma_{2} \quad=\text { Intermediate principal stress applied to a test specimen, psi } \\
& \sigma_{\mathrm{t}} \quad=\text { Direct tensile strength, psi } \\
& \text { a = Length of the short side of an intact block in a jointed mass, in } \\
& \text { b = Length of the long side of an intact block in a jointed mass, in. } \\
& \text { c = Cohesion, intersection of Mohr envelope for intact specimens with the ordinate } \\
& \text { axis, psi } \\
& c_{e} \quad=\text { Effective cohesion of a jointed or intact specimen, defined as the point where the }
\end{aligned}
$$




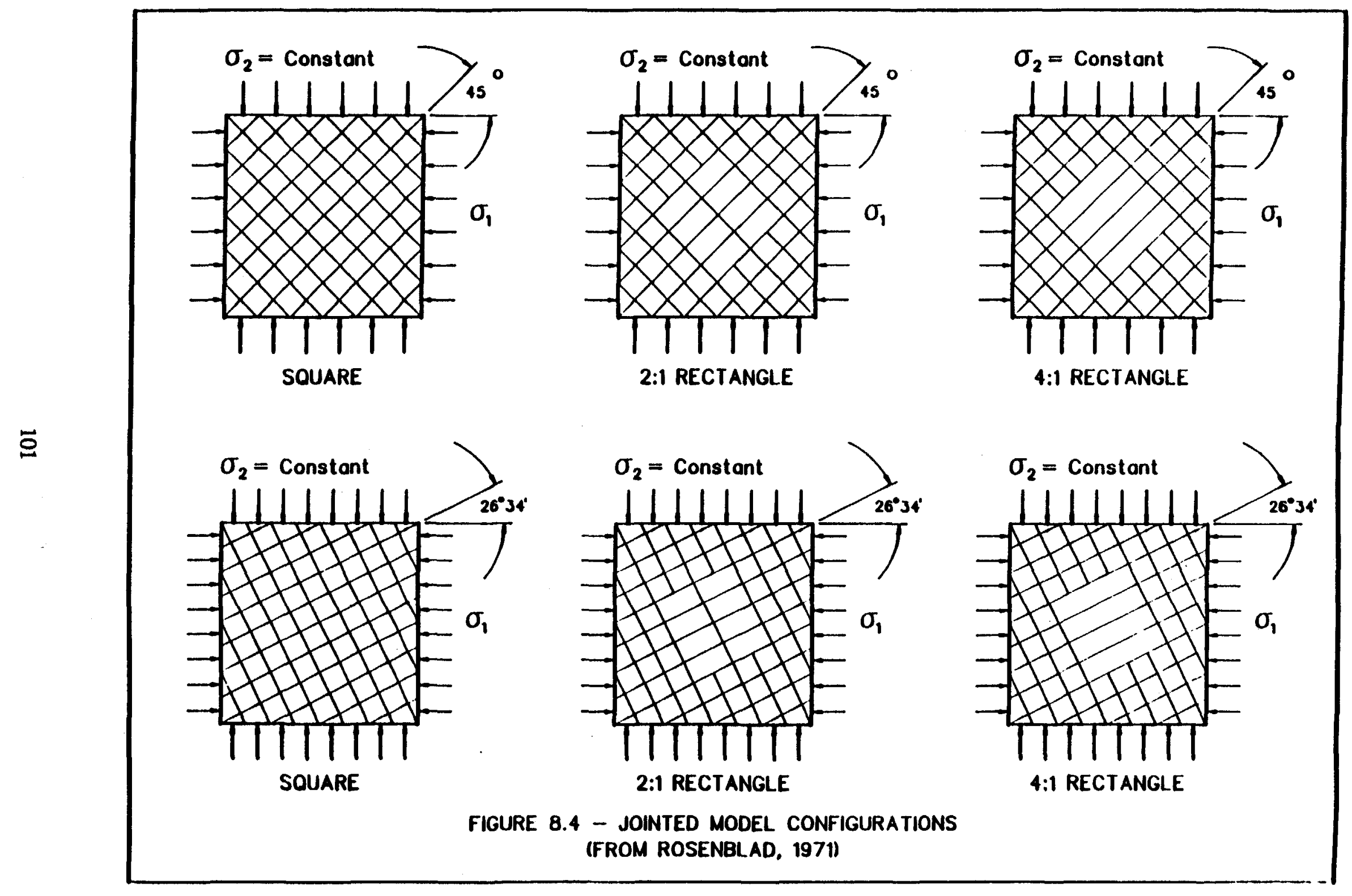




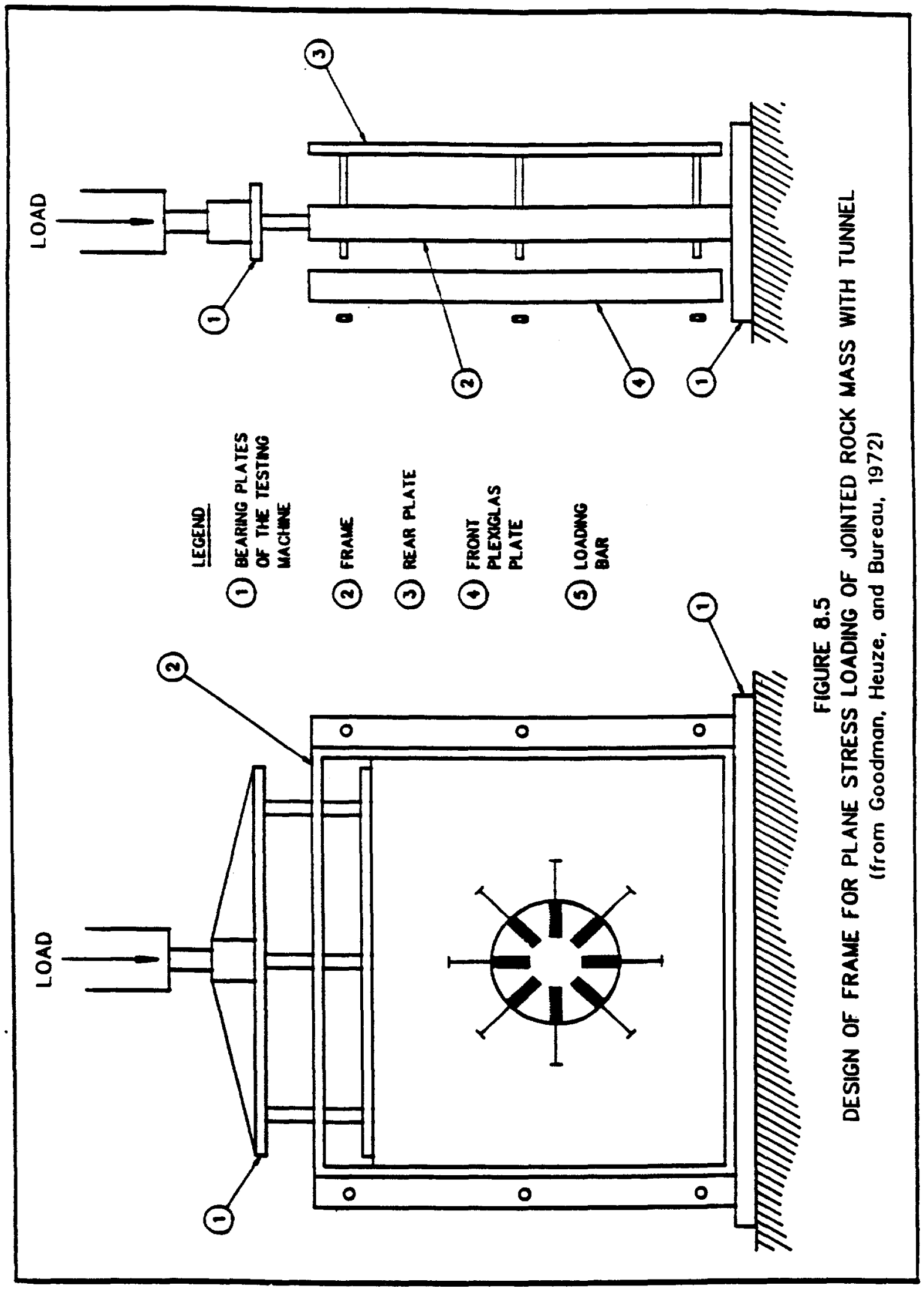




$$
\left(\frac{\sigma}{\rho l}, \frac{u}{l}\right)=f\left(\frac{E}{\rho l}, v, \varphi, \frac{F}{\rho l^{3}}, \frac{t^{2} \ddot{u}}{l}\right)
$$

where some variables are the same as identified in Table 8.2 , but additional ones are:

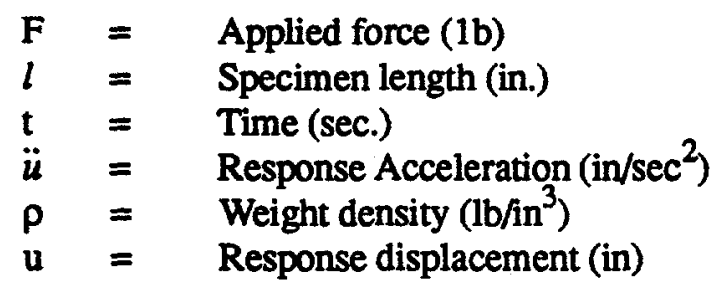

It is also stated that for the stress and elastic modulus $E$ to have the proper relationship one must consider the unconfined compression strength, the tensile strength, and the cohesion strength for the prototype and model materials. The appropriate material properties for Nevada Test Site Tuff and a 1/27-scaled rock simulant are given in Table 8.3. These ranges of material parameters are also appropriate for scale model studies of underground blast and earthquake loading as well. The tuff rock simulant was cast from a mixture of Portland Cement, Barite, Bentonite, and AMEX 210 (an entraining agent), and will probably also be appropriate for developing tuff simulant for the other dynamic loadings.

Both static and dynamic tests were carried out for loading of one-yard cubes with a central hole which represented a tunnel. The block specimens were cast in several layers to represent jointed tuff rock mass. The dynamic test data revealed that for modeled structures in jointed materials, magnitude of the preload plays an important role in subsequent response of the structures. All conditions being equal, faster rise times were associated with higher initial loads, which indicates an increase in material stiffness due to initial loading. That is, the effect of joints becomes less important. Here again, no direct correlation of experiment with analysis was performed, although the results were of a quality where such a correlation would have been appropriate.

The above scale model study was later supplemented by Bakhtar and Jones (1986), with an extensive study of the behavior of tunnel intersections. A similar scale was again used to study tunnel intersections in one cubic-yard specimens. Various new material simulant mixes were investigated. Complete details are given for mixing procedures and material characterization tests. Again, no correlation of the results with any analytical predictions was attempted, although the data would have been suitable for this purpose. Even so, results presented from both studies could still be used to compare with predictions from analytical codes applied to the specific conditions that were addressed to represent overpressure loading of a surface burst explosive.

Two sets of studies illustrate the philosophy of experimental validation of a computational design code. The report by de Rouvray, et al., (1971) describes experimental and numerical studies of the static behavior of underground structures in jointed rock. Finite element methods were used in modeling non-linear joint behavior and the static performance of underground excavations in jointed rock. The work involved physical modeling of a highly idealized jointed rock mass with perfectly continuous joints, orthogonally oriented and equally spaced. The code used in the analysis was restricted to small strain for both intact material and joints. With current knowledge, the joint model 
Table 8.3 Mechanical Properties of Rock Material

(From Bakhtar and DiBona, 1985)

Nevada Test Site Tuff:

- Unconfined Compressive Strength . 1200 psi to 4200 psi (Yucca Mountain Tuff) (4200 psi)

- Material Tensile Strength .....

14.5 psi to $360 \mathrm{psi}$

- Young's Modulus

$1.17 \times 10^{6}$ psi to $2.90 \times 10^{6} \mathrm{psi}$

- Poisson's Ratio

0.16

- Material Cohesion 1500 psi

- Angle of Internal Friction (matrix) . 15.9 deg.

- Bulk Density $1.60 \mathrm{gm} / \mathrm{cc}$ to $2.20 \mathrm{gm} / \mathrm{cc}$

- Joint Cohesion $58 \mathrm{psi}$

- Joint Friction $55 \mathrm{deg}$.

1/27-Scale Tuff Rock Simulant:

- Unconfined Compressive Strength . . $152.5 \mathrm{psi}$

- Indirect Tensile Strength . . . . . 35 psi

- Young's Modulus .......... $0.04 \times 10^{6}$ to $1.17 \times 10^{6} \mathrm{psi}$

- Poisson's Ratio ........... 0.15

- Porosity ............. 4 45\%

- Bulk Density . . . . . . . . . . . $1.885 \mathrm{gm} / \mathrm{cc}$

- Grain Density . . . . . . . . . $2.93 \mathrm{gm} / \mathrm{cc}$

- Cohesion ............. 50 psi

- Angle of Intemal Friction ...... $15.5 \mathrm{deg}$. 
was inadequate, with unsuitable representation of damage accumulation during joint shear, no provision for hysteresis on load reversal, and stress independence of normal and shear stiffnesses. In spite of the limitations of the numerical model, fair qualitative correspondence was demonstrated between the results of numerical analysis and physical modeling of jointed media. This is explicable on the basis of the simple applied load path, which is not representative of that which develops during construction of an underground excavation. With the various reservations noted, the report is an instructive example of a philosophy for verification of computational analysis schemes.

Analytical and numerical simulations of laboratory experiments on small-scale tunnels in jointed rock were compared by Rosenblatt and DeAngelo (1980). The studies were based on the DIABLO HAWK underground nuclear test in jointed tuff at the NTS. The study was performed in three stages. In the first stage, an analytical solution was developed which defined the far-field, static load level at which joint slip will begin around a circular tunnel. In the second stage of the study, dynamic analysis was performed using the code WAVE-L, a Lagrangian code. The intact rock was simulated as an elastoplastic material with a Drucker-Prager yield surface and non-associated flow rule. Slide lines were used to simulate joint behavior. In the third stage of the study, static analyses performed with the WAVE-L code were compared directly with results of the laboratory tests. The comparison was reasonably good near the springline but poor at the crown-invert. Joint slip regions in laboratory tests, indicated by deformations of a thin tunnel lining, corresponded to the region predicted by the analytical solution performed in the study's first stage.

It is notable that neither of these studies, one static and one dynamic, examined effects such as repetitive cyclic loading. However, they describe a broad general philosophy supporting code verification and qualification for geodynamic modeling, design and performance assessment studies.

\subsection{Requirements For Dynamic Validation}

In view of the above-described studies, it appears that no direct comparison has been made between results obtained from scale model experiments and analytical predictions for response to underground shock or earthquake excitation. However, it is entirely feasible that such a validation could be attempted by use of similar studies with only slight modification. At this point it would appear that a scale model equation similar to Eq 8.1 would be appropriate for study of responses to underground shock. In fact use of a 1/27 scale would allow rock mass simulant like that of Bakhtar and DiBona (1985) again to be employed. However, the exact form of loading necessary to represent that of underground blast has yet to be developed. Furthermore a similar material can be used to develop jointed rock-mass specimens for study under earthquake conditions. In this case, however, the equation of response becomes:

$$
\left(\frac{\sigma}{\rho l}, \frac{u}{l}\right)=f\left(\frac{E}{\rho l}, v, \varphi, \frac{t^{2} x_{0} \omega^{2}}{l}, \frac{x_{0}}{l}\right)
$$

where in addition to the previous variables there are:

$$
\begin{array}{lll}
x_{0} & =\text { Excitation displacement (in.) } \\
\omega & =\text { Excitation frequency (rad/sec) }
\end{array}
$$


There is also the consideration of the effect of gravity on the problem. This variable has been omitted from the previous studies by use of a static overpressure. This approach may need to be altered for simulation of earthquake effects.

Thus, a scale model jointed rock mass similar to that used in the previous studies could be employed, but a scale model earthquake excitation would need to be imparted to the specimen, and the resulting stress and strain responses observed. These responses can then be correlated with those predicted by using techniques identified in Section 7 , for validation purposes. 


\section{SUMMARY}

A comprehensive literature review has been conducted to establish the state of knowledge currently accessible in the open literature relevant to dynamic performance of underground excavations and facilities. Critical assessment of this literature identified several technical deficiencies and/or lack of technical information on this subject, particularly with regard to dynamic performance and analysis of jointed rock masses.

This section describes those topics which are of major concem in relation to NRC regulatory research needs. Issues of major concern are:
(a) the adequacy for dynamic analysis of current methods for modeling joints in discontin- uous rock masses;
(b) the lack of availability of well documented seismic/shock loading experimental data for confirmatory evaluations of analytical techniques;
(c) long-term performance of underground facilities at a tuff site subject to repeated seis- mic/shock loadings;
(d) the need for a validation methodology for seismic analysis for bounding conditions of loading.

The hydrological response of an unsaturated rock mass due to far-field seismic events is relatively slow compared with the mechanical response of the medium. Such decoupling of the hydrological and mechanical modes of response facilitates modeling of groundwater response in a rock mass which has been modified by seismic activity.

The following material is a concise summary of the key findings of the literature assessment task of the Seismic Rock Mechanics Project, with particular attention to the issues of concem noted above.

\subsection{Description of Design Problem}

The Yucca Mountain site proposed for construction of a high-level nuclear waste repository is located in a layered sequence of welded, non-welded and bedded tuffs. The rock mass is jointed, faulted and unsaturated, with the water table $200 \mathrm{~m}$ to $400 \mathrm{~m}$ below the waste emplacement horizon. Noting the resemblance between the proposed repository layout in this host rock mass and a low-extraction room-and-pillar mine, mining experience suggests that, for the expected rock mass conditions, conventional practices for mine design and construction will provide stable underground excavations.

Several aspects of nuclear waste management and underground repository design impose more stringent design requirements than established practices provide for design of an underground mine. In particular, the time scale mandated for effective waste isolation, and the Federal regulations addressing waste isolation, require more comprehensive and profound assessment of the prospective performance of the host rock mass. Specific regulations establish the need to consider geomechanics issues associated with safety, retrievability, system performance, and the performance, before and after permanent closure, of particular barriers to waste dispersion (DOE, SCP, 1988). 
A specific feature of repository design to which attention is directed by regulatory citation 10CFR60.122 is the need to consider natural phenomena and site conditions which could adversely affect achievement of the prescribed performance objectives. Local earthquake activity is an important natural phenomenon which could conceivably affect both the short- and long-term performance of a repository. Similariy, for the Yucca Mountain site, ground motion due to underground nuciear explosions needs to be considered explicitly. Either source of ground motion must be considered in relation to demonstrable compliance with regulations concerning safety, retrievability, the disturbed zone, and performance of the various barriers to waste dispersion.

An obvious concern is that a repository near the Nevada Test Site will be subject to repetitive episodes of dynamic loading arising from continued underground nuclear testing. Over the time scale of post-closure performance of a repository, repetitive earthquake loading is also possible. Work by Brown and Hudson (1974), Baron and Hansteen (1979), Dowding, et al. (1983), and St. John and Zarah (1987) suggests that repetitive cyclic loading of jointed rock causes fatigue failure at the joints. However, there has been only minimal investigation and analysis of such rock mass behavior.

Rock mechanics principles for design of surface and underground excavations under conditions of static loading, and of surface excavations under dynamic loading, are now well formulated and demonstrably successful in practice. However, design principles for seismic design of underground excavations have not been verified by demonstration of satisfactory practical application. One reason for this state of affairs is that underground excavations are observed to be less susceptible to a single episode of dynamic loading than surface excavations. Another related reason is that relatively few well-controlled, well-executed observations have been made of underground excavation response to seismic loading, and none has been made for successive episodes of seismic loading. However, the consequences of repetitive dynamic loading of a jointed rock mass may be implied from laboratory testing of jointed media, in which shear displacement in joints is accumulated progressively, in successive episodes of seismic loading. The results of these studies have yet to be unified with analytical studies, or incorporated in principles of underground excavation design. Furthermore, there is a total lack of an experimental basis for validation of prospective performance assessment techniques for dynamic behavior of structures in jointed rock. For these reasons, the dynamic performance of excavations and underground facilities involved in nuclear waste isolation needs to be investigated in detail, and performance characteristics and design criteria established.

\subsection{Ground Motions from Earthquakes and Explosions}

The ground motion experienced at a site due to earthquakes and explosions is the result of body and surface waves propagating from the source center. For subsurface facilities, the motion due to body waves only is important. Due to the different mechanisms of wave generation in earthquakes and explosions, and wave attenuation and dispersion during transmission, the ground motions induced at a site, by earthquakes and explosions respectively, may be substantially different. In particular, at comparable distances from the source, an explosion produces more pulse-like ground motion, whereas an earthquake typically produces ground shaking persisting for several tens of seconds. Field observations suggest that excavations respond in different ways to the ground motions with these different characteristics, so it is important to define the ways in which ground motion can be described.

There are three methods for specifying the ground motion induced by seismic events. In the simplest, the peak particle velocity and acceleration at a site are defined. These parameters give no information about the duration of the motion, or the frequency content of the ground wave. The second technique, 
based on a response spectrum, defines amplitude, velocity and acceleration as a function of the frequency content of the ground motion experienced at a site. This technique provides no information about the duration or temporal variation of the ground motion. The third technique involves presentation of a digital or analogue time-based record of the acceleration (and, by derivation, the velocity) of the ground motion.

The time histories of ground motion are the preferred method for specifying ground motions for several reasons. First, they can be used to provide the other ground motion records, either directly or through Fourier analysis. Second, the information is comprehensive, in that no other parameters need to be specified to describe ground motion completely. Finally, the information in the time record can be related directly to the dynamic performance of excavations which may be subject to the ground motion.

In the context of the proposed Yucca Mountain repository, prospective seismic effects on the repository are frequently discussed in terms of peak ground acceleration or velocity. While this practice may be convenient practically, it is not a scientifically sound, valid or defensible way of describing the likely effects of seismic ground motion. However, adequate data are available to describe ground motion at Yucca Mountain from adjacent earthquakes and explosions. In particular, existing ground motion data are adequate for use in predicting the likely response of underground excavations, and in specifying model excitation for physical testing and computational analysis of underground excavation performance.

\subsection{Seismic Performance and Design of Underground Facilities}

The nature of the interaction of a ground wave with an excavation depends on the wavelength $\lambda$ of the motion and the span $D$ of the excavation. For large values of $\lambda \mathrm{D}$, the transient motion produces pseudo-static loading of the excavation. For small values of $\lambda / D$, the loading is dynamic, and account must be taken of impulsive loading of the rock mass in the excavation near-field. Both pseudo-static and dynamic loading conditions will apply at the Yucca Mountain site.

The response of excavation near-field rock to transient ground motion is determined by the usual range of site characteristics and excavation design variables. These include the mechanical properties, structure and ambient state of stress in the host rock mass, the shape and dimensions of the excavation, the properties and design of any support and reinforcement systems, and the specific nature of the imposed ground motion. Apart from excavations in the very near-field of a seismic source, damage to excavations is primarily the result of shear displacements concentrated at rock discontinuities, causing roof falls and wall-rock loosening in boundary rock. By inference, seismic effects on a repository which is located in jointed rock will be the result of the dynamic response of the joints, and the dynamic behavior of the disturbed zone, which is defined by natural or induced cracks in the host rock mass.

Current techniques for seismic design of an underground excavation are based on likely peak particle motion that the excavation will experience. Limiting values of both peak acceleration and peak velocity have been specified which putatively prevent damage to excavation boundary rock. However, experiment and analysis show that the number and extent of excursions of joint shear motion into the plastic range of joint response determine seismic performance of excavations, not merely peak velocity or acceleration. Thus, excavation design based on notions of peak ground motion is inadequate. 
Experimental study of excavations subject to repetitive episodes of seismic loading shows that failure ultimately occurs by accumulation of shear displacement at joints. This process is analogous to fatigue failure in continuous media. Because a repository will be subject to repetitive episodes of seismic loading, its performance must be assessed from analysis of joint damage accumulation arising from time histories of ground motion for individual seismic events, and from ground motion due to a sequence of repeated events. No current design procedure takes account of either the time history of individual events, or the effects of repetitive seismic events.

\subsection{Rock Mass Properties}

In analysis to predict seismic response of underground excavations, and physical modeling of excavation performance, the deformation and strength properties of the rock mass must be considered in detail. In the current characterization of the Yucca Mountain site, the mechanical properties of the rock material have been described adequately for both analytical and physical modeling of the performance of the medium. Furthermore, the thermal component of the thermomechanical problem can be effectively decoupled in the performance analysis, and rock mass properties are essentially independent of temperature, for the conceivable temperature range involved around a repository. Thus, thermal and mechanical material properties are adequately defined for repository performance analysis and physical modeling.

Both the static and dynamic mechanical properties of joints are critical in determining the seismic performance of an excavation. Further, account must be taken of whether the joints are rough (dilatant in shear and subjected to peak-residual behavior) or smooth and infilled (non-dilatant in shear and at residual strength). There are several possible models to describe joint response to applied load, with different ranges of applicability.

Joint deformation mechanics are described in terms of joint limiting shear strength, and joint response to compressive and shear deformation. The Coulombic friction, linear deformation joint model is the simplest model, and is probably applicable to filled faults, under static loading. Its applicability for joints subject to seismic loading is questionable, since joint friction is known to be velocity dependent, and impulsive changes in normal stress may lead to transient changes in coefficient of friction.

There are two current models of joint static deformation which take account of non-linear compression, surface roughness, dilatancy in shear, damage accumulation due to asperity erosion and resulting peak-residual behavior in shear. These are the variable mobilized friction model described by Barton, et al., (1985) and the continuous yielding joint model described by Cundall and Lemos (1988). The Barton-Bandis model is known to be poorly behaved under certain conditions of cyclic loading, and the piece-wise linear formulation of dilatancy results in quite coarse simulation of shear deformation. The continuous yielding joint model represents cyclic loading and other aspects of joint deformation adequately, but has yet to be evaluated thoroughly. The applicability of both the Barton-Bandis and the continuous yielding joint models in dynamic analysis is uncertain, because velocity dependent effects which have been observed experimentally are not accounted for in either model.

These observations indicate the considerable uncertainties which currently exist concerning joint deformation and strength under both static and dynamic conditions. It is probable that the capacity for physical and computational modeling of dynamic performance of excavations under seismic loading will be limited by inadequacies in formal description of joint deformation mechanics. 


\subsection{Groundwater Response}

There are two time scales to be considered in describing the effects of a seismic event on groundwater hydrology in saturated rock. Immediate effects accompany the transmission of the ground motion through the domain of interest. Any effects which succeed the passage of the wave are considered as long-term.

Experimental studies indicate that the immediate response of jointed rock to seismic shaking is analogous to undrained loading of soils. Changes in joint water pressure attend transient shear motion at a joint if the joint is dilatant in shear. The effect of transient joint water pressure on shear strength can be explained in terms of the principle of effective stress.

Field observations of immediate groundwater response to a seismic event are consistent with local volume changes, such as compression of an aquifer, occurring during passage of the ground wave. This causes fluid pressure changes in the aquifer, which may be observed as changes in standing water level in wells which penetrate the aquifer. The magnitudes of the changes in well water level are of the order of $10 \mathrm{~m}$ or less, but may be inferred to be related to distance from the seismic source. However, substantial transient changes in well water level (greater than $5 \mathrm{~m}$ ) have been recorded several thousand kilometers from the source, as in the case of the Alaska 1964 earthquake.

The long-term hydrological response of a rock mass is generally related to changes in fault or joint aperture caused by shear displacement on these features. Increased fissure aperture may provide channels for enhanced groundwater flow, as illustrated dramatically by events following the Borah Peak, Idaho, earthquake of 1983. A mine more than $50 \mathrm{~km}$ distant from the earthquake epicenter was subject to increased joint flow sufficient to flood the lower workings.

A second mode of long-term hydrological response is purportedly associated with rock mass compression associated with permanent shear displacement on major structural features. Changes in water table and groundwater pressure may result from such effects.

While groundwater effects due to seismic events are important, equally significant long-term changes in geohydrology may be induced by tectonic activity occurring aseismically. There has been comparatively little study of such effects.

In the analysis of both immediate and long-term geohydrological performance of rock masses, analytical techniques are required which can account for joint slip, dilatancy, and fluid pressure and flow. There are several techniques which would be currently qualified for such analysis.

\subsection{Analytical Methods}

It is generally assumed that numerical methods will be used extensively for analysis of the mechanical performance of the host mass for a repository. With regard to repository response to seismic loading, the selected analytical methods must take account of the relative scale of the problem domain and the rock units which may be mobilized in a seismic event.

The various versions of computational methods for solid mechanics dynamic analysis, namely boundary element, finite element and finite difference methods, are qualified in principle for analysis of the seismic performance of a repository. However, essential features of a selected computer code are that it can represent the free-field conditions appropriately, and that the discontinuous nature of 
the rock mass can be simulated. The latter restriction poses a substantial qualification requirement for codes, as very few have been formulated explicitly to represent rock discontinuities such as faults or joints. As noted previously, these structural features dominate the dynamic performance of underground excavations. There are several codes which satisfy the essential qualifications of capacity for dynamic analysis, suitable representation of free-field conditions and simulation of rock discontinuities. These include boundary elements, finite elements, finite difference and distinct element codes.

An issue which complicates the suitability of qualified computer codes is the type of joint model implemented in the various programs. All the codes noted previously simulate the Coulombic friction, linear deformation joint model, which is the most elementary representation of joint deformation mechanics. For rough joints characteristic of those in tuff, the relevance of such a joint model is arguable. The only code known to implement all three joint models (i.e., the Coulombic friction, Barton-Bandis and continuous-yielding joint models) is the two-dimensional distinct element code UDEC. The three-dimensional distinct element code 3DEC can simulate both the Coulombic friction model and the continuous-yielding model, and it is possible that the BartonBandis model could be introduced without excessive difficulty.

\subsection{Validation of Methodology}

Perhaps the most critical aspect of the application of a computational method in engineering analysis and system performance prediction is validation of the method for the intended application. This procedure is required in order to affirm that the computational analysis will satisfactorily indicate performance of the real system to within a prescribed engineering tolerance. The particular need for validation of codes for dynamic analysis of underground excavations arises from the comparative novelty of the codes, the complexity of the processes involved in the deformation of block-jointed media, and prevailing questions about the adequacy of the constitutive relations describing the static and dynamic behavior of rock joints and faults.

For the case of underground seismic response, validation of a computational prediction method is especially difficult, but nontheless highly essential. Development of a well-controlled, experimental study whose results can be compared with analytical predictions appears to be the most feasible approach. On the other hand, the necessity of good control dictates that a scale-model, laboratory experimental study is necessary. This subsequently requires that material and joint deformation properties be properly scaled. Therefore, preliminary experiments which confirm the correct modeling of these aspects of the problem are further required. Hence, the code validation process will be rather complex, and there is very limited previous experience available to help guide the approach. 


\section{CITED REFERENCES}

Achenbach, J. D., 1975. Wave Propagation in Elastic Solids. New York: North-Holland.

Adina Engineering, 1981. ADINA Users Manual. Report AE81-1.

Aki, K., and P. G. Richards, 1980. Quantitative Seismology - Theory and Methods. San Francisco: W. H. Freeman.

Allen, R. T., and R. E. Duff, 1969. "Effect of Material Properties on Cavity Size from an Underground Nuclear Explosion," Nuclear Applications, 6, pp. 567-572.

Amadei, B., and R. E. Goodman, 1981. "Formulation of Complete Plane Strain Problems for Regularly Jointed Rocks," Proc. 22nd U.S. Rock Mech. Symp., pp. 245-251, Cambridge, MIT.

Anonymous, 1972. Earthquake Resistance of Earth and Rock-Filled Dams, Misc. Paper S-71-17, Report 3, U. S. Army Waterways Exper. Sta., Vicksburg, MS.

ASME Draft Standard - Rev. 5, 1986. Recommended Practices for Seismic Performance Qualification of Mechanical Equipment Used in Nuclear Power Plants With Particular Application to Pumps and Valves, American Society of Mechanical Engineers, New York, NY.

Askar, A., X. Zeng and S. Altay, 1984. "Explicit Integration of Boundary Integral Equations and Scattering of Seismic Waves by Underground Structures," Proceedings of the World Conference on Earthquake Engineering: Soil Stability, Soil Structure Interaction and Foundations, pp. 657-664.

Asmis, H. W., 1984. Dynamic Response of Underground Openings in Discontinuous Rock, Whiteshell Nuclear Research Establishment, Atomic Energy of Canada Limited.

Bakhtar, K., and B. DiBona, 1985. Dynamic Loading Experiments on Model Underground Structures, Defense Nuclear Agency, Washington, D. C., DNA-TR-85-387.

Bakhtar, K., and A. H. Jones, 1986. Scaled Model Testing of Tunnel Intersections, DNA-TR-86-275.

Balachandra, M. B., and J. A. Malthan, 1976. Grout/Soil Interaction and Velocity Gage Emplacement For Ground Shock Measurement. Agbabian Associates Final Report to DNA, DNA 4089F.

Balachandra, M. B., C. F. Bagge, and H. H. Haynes, 1978. Low-Cycle Fatigue Tests of Hollow Concrete Spheres with Implications for the Survivability of Deep Underground Rock Openings. Agbabian Associates Final Report to DNA, DNA 4433F. 
Banerjee, P. K., and S. Ahmad, 1985. "Advanced Three-Dimensional Dynamic Analysis by Boundary Element Methods," Advanced Topics in Boundary Element Analysis, T. A. Cruse, et al., Eds., Vol. 72, pp. 65-81. New York: ASME.

Banerjee, P. K., S. Ahmad and G. D. Manolis, 1987. “Advanced Elastodynamic Analysis,” Boundary Element Methods in Mechanics, D. E. Beskos, Ed., Chapter 5. Amsterdam: North-Holland.

Barton, D. E., J. B. Bryan and L. A. Lettis, Jr., 1979. "Numerical Modeling of Spall Phenomena," in Notes from DNA Spall Workshop (Marina Del Rey, September 1979), UCID-18289.

Barton, N., 1982. "Importance of Joint Parameters on Deformations Observed in Dynamically Loaded Models of Large Excavations," Proceedings of the Workshop on Seismic Performance of Underground Facilities (February 11-13, 1981), I. Wendell Marine, Ed, DE-1023, pp. 243-247. Oak Ridge: U. S. DOE.

Barton, N., 1988. "Some Aspects of Rock Joint Behavior Under Dynamic Conditions," Proc. 2nd Italian Conf. on Rock Mech. and Rock Eng., Chapter 17, Turin, Turin Polytechnic.

Barton, N., S. Bandis, K. Bakhtar, 1985. "Strength, Deformation and Conductivity Coupling of Rock Joints," Int. J. Rock Mech., Min. Sci., and Geomech. Abstr., Vol. 22, n3, pp. 121-140 (Pergamon Press, Ltd).

Barton, N., and H. Hansteen, 1979. "Very Large Span Openings at Shallow Depth: Deformation Magnitudes from Jointed Models and Finite Element Analysis," Proc. 4th Rapid Excavation and Tunnelling Conf. (Atlanta, 1979), Vol. 2, pp. 1331-1353.

Bathe, K. J., E. L. Wilson, and F. E. Peterson, 1974. SAPIV, A Structural Analysis Program for Static and Dynamic Response of Linear Systems, Report No. EERC 73-11, Berkeley, University of Califomia.

Bendat, J. S., and A. J.Piersol, 1980. Engineering Applications of Correlation and Spectral Analysis, John Wiley \& Sons, Inc.

Bieniawski, Z. T., 1976. "Rock Mass Classifications in Rock Engineering," Exploration for Rock Engineering, pp. 97-106, Cape Town, A. A. Balkema.

Bieniawski, Z. T., 1984. Rock Mechanics Design in Mining and Tunnelling. Boston: A. A. Balkema.

Blatz, Paul J., 1975. Interactions of Stress Waves with Cracks and Openings in Rock Media, Advanced Research Projects Agency, H0220025.

Blouin, S. E., 1984. DNA Block Motion Research Proposal, Minutes of Kick-off Meeting, DNA Block Motion Research, S-Cubed.

Bolt, B. A., 1978. Earthquakes, A Primer. San Francisco: W. H. Freeman.

Brace, W. F., and J. D. Byerlee, 1966. "Stick-Slip as a Mechanism for Earthquakes," Science, 153, pp. $990-992$. 
Brady, B. H. G., 1977. "An Analysis of Rock Behavior in an Experimental Stoping Block at the Mount Isa Mine," Int. J. Rock Mech., Min. Sci., and Geomech. Abstr., 14, pp. 59-66.

Brady, B. H. G., 1988. "Rock Stress, Structure and Mine Design," Proc. 2nd Int. Symp. on Rockbursts and Seismicity in Mines, (Minneapolis, 1988), pp. 311-321. Rotterdam: A. A. Balkema.

Brady, B. H. G., andE. T. Brown, 1985. RockMechanics for Underground Mining. London: George Allen and Unwin.

Brady, B. H. G., M. L. Cramer, and R. D. Hart, 1985. "Preliminary Analysis of a Loading Test on a Large Basalt Block," Int. J. Rock Mech., Min. Sci and Geomech. Abstr., 22(5), pp. 345-348.

Brady, B. H. G., and C. M. St. John, 1982. "The Role and Credibility of Computational Methods in Engineering Rock Mechanics - Keynote Address," Issues in Rock Mechanics - Proceedings of the 23rd U. S. Symposium on Rock Mechanics, (Berkeley, 1982), pp. 571-586. New York: Society of Mining Engineers.

Bredehoeft, J. D., F. S. Riley, and E. A. Roeloffs, 1987. "Earthquakes and Groundwater," Earthquakes and Volcanoes, $19(4), 138-146$.

Brown, E. T., 1985. "Introduction," Analytical and Computational Methods in Engineering Rock Mechanics, London, Allen \& Unwin.

Brown, E. T., and L. P. Gonano, 1975. "An Analysis of Size Effect Behavior in Brittle Rock," Proc. 2nd Aust. NZ Conf. Geomech., pp. 139-143, Sydney, Inst. Engrs. Aust.

Brown, E. T., and J. A. Hudson, 1974. "Fatigue Failure Characteristics of Some Models of Jointed Rock," Earthquake Eng. and Struct. Dyn., 2, 379-386.

Bureau, G. J., 1972. Model Studies of Rockbolted Tunnels in Brittle and Plastic Ground, Tech. Report No. 12, U.S. Army Corps of Engineers, Omaha District, DACA 45-71-C-0031.

Butcher, B. M., and L. S. Costin, 1985. Dilatancy in Rocks During Stress Wave Unloading. USDOE, SAND85-0788C.

Butkovich, T. R., O. R. Walton, and F. E. Heuze, 1988. "Insights in Cratering Phenomenology Provided by Discrete Element Modeling," Key Questions in Rock Mechanics, Proc. 29th U.S. Rock Mech. Symp., P. A. Cundall, et al. (Eds.).

Butters, S. W., J. N. Johnson, R. K. Dropek, S. J. Green, and A. H. Jones, 1974. The Mechanical Behavior of Nevada Test Site Grouts, TR 74-40, Defense Nuclear Agency, Albuquerque, NM.

Carpenter, D. W., and D. H. Chung, 1985. Effects of Earthquakes on Underground Facilities: Literature Review and Discussion, Lawrence-Livermore National Laboratory Report UCID20505, August.

Clough, R. W., and J. Penzien, 1975. Dynamics of Structures, McGraw-Hill Book Co., New York. 
Cook, N. G. W., 1965. "A Note on Rockbursts Considered as a Problem of Stability," J. S. Afr. Inst. Min. Metall., 65, 437-446.

Cook, N. G. W., 1978. Rockbursts and Rockfalls, Chamber of Mines of South Africa Publication No. 216.

Croll, J. G., and A. G. Walker, 1973. Elements of Structural Stability. New York: Halsted Press.

Crotty, J.M., and L. J. Wardle, 1985. "Boundary Integral Analysis of Piecewise Homogeneous Media with Structural Discontinuities," Int. J. Rock Mech., Min. Sci., and Geomech. Abstr., 22. 419-427.

Crowley, Barbara K., 1973. "Effects of Porosity and Saturation on Shock-Wave Response in Tuffs," Int. J Rock Mech. Min. Sci., \& Geomech. Abstr., Vol. 10, pp. 437-464.

Cundall, P. A., 1971. "A Computer Model for Simulating Progressive Large Scale Movements in Blocky Rock Systems," Proceedings of the Symposium of the International Society of Rock Mechanics (Nancy, France), Vol. 1, Paper No. II-8.

Cundall, P. A., 1988. "Formulation of a Three-Dimensional Distinct Element Model - Part I: A Scheme to Detect and Represent Contacts in a System Composed of Many Polyhedral Blocks," Int. J. Rock Mech., Min. Sci., \& Geomech. Abstr., 25, 107-116.

Cundall, P. A., and R. D. Hart, 1985. Development of Generalized 2-D and 3-D Distinct Element Programs for Modeling Jointed Rock. Itasca Consulting Group; Misc. Paper SL-85-1, U. S. Army Corps of Engineers.

Cundall, P. A., and J. V. Lemos, 1988. "Numerical Simulation of Fault Instabilities with the Continuously-Yielding Joint Model," Proc. 2nd Int'l Symp. on Rockbursts and Seismicity in Mines, University of Minnesota.

De Rouvray, A., R. E. Goodman, K. Drozd, F. Heuze, and T. L. Brekke, 1971. Analysis and Model Studies of Underground Openings in Jointed Rock Research on Rock Bolt Reinforcement, Technical Report No. 7, Omaha District, Corps of Engineers.

Dendrou, B., 1978. Integrated Approach to Cavity System Seismic Evaluation, Dept. of Trans., FHWA-RD-78-159.

DOE/RW-0160, 1988. Consultation Draft Site Characterization Plan Yucca Mountain Site, Nevada Research and Development Center, Nevada. Vol. I. Nuclear Waste Policy Act (Section 113). U. S. Department of Energy.

DOE/RW-0199, 1988. Site Characterization Plan, Yucca Mountain Site, Nevada Research and Development Center, Nevada. Vols. I-VIII. Nuclear Waste Policy Act (Section 113). U.S. Department of Energy.

Desai, C. S., and J. T. Christian, 1977. Numerical Methods in Geotechnical Engineering, New York: McGraw-Hill Book Company. 
Desai, C. S., and H. J. Siriwardane, 1984. Constitutive Laws for Engineering Materials with Emphasis on Geologic Materials. Englewood Cliffs, N. J.: Prentice-Hall, Inc.

Detoumay, E., 1983. Two-Dimensional Elastoplastic Analysis of a Deep Cylindrical Tunnel Under Non-Hydrostatic Loading, Ph.D. Thesis, University of Minnesota.

Dieterich, J. H., 1979. "Experimental and Model Study of Fault Constitutive Properties", Solid Earth Geophysics and Geotechnology, AMD, Vol. 42.

Dieterich, J. H., 1981. “Constitutive Properties of Faults with Simulated Gouge," Mechanical Behavior of Crustal Rocks, Geophys. Monogr. 24, pp. 103-120, Washington, D.C., AGU.

DiMaggio, F. L., and I. S. Sandler, 1971. "Material Model for Granular Soil," J. Eng. Mech., Div. ASCE, 97, EM3.

Dowding, C. H., C. Ho, and T. B. Belytschko, 1983. "Earthquake Response of Caverns in Jointed Rocks: Effects of Frequency and Jointing," Seismic Design of Embankments and Caverns, pp. 142-156. New York: ASCE.

Dowding, C. H., and A. Rozen, 1978. "Damage to Rock Tunnels from Earthquake Shaking," J. Geotech. Engng. Div. ASCE, 104(GT2), 175-191.

Drumm, E., March 1985. Constitutive Modeling For Blast-Induced Wave Propagation (Final Report), Report ESL-TR-84-45, Engineering \& Services Laboratory, Air Force Engineering \& Services Center, Tyndall Air Force Base, FL.

Duddeck, H., and J. Erdmann, 1982. "Structural Design Models for Tunnels," Tunneling '82, pp. 83-91. London: Inst. Min. and Metall.

Einstein, H. H., and C. W. Schwartz, 1979. "Simplified Analysis for Tunnel Supports," J. Geotech. Engng. Div. ASCE, 105(GT4).

Fogel, M. B., and D. F. Patch, 1984. Material Response Models and Ground Motion Calculations for High Explosive Tests in G-Tunnel Tuff, Defense Nuclear Agency, DNA-TR-84-124, January.

Fogel, M., D. Patch, and C. Swan, 1985. "Material Response Models and Ground Motion Calculations for High Explosive Tests in G-Tunnel Tuff," Response of Geologic Materials to Blast Loading and Impact, AMD Vol. 69, pp. 39-53. New York: ASME/AMD.

Forrester, D., D. Barkhurst, 1969. Shock Propagation Instrumentation, AFSWC-TR-69-12, (Air Force Special Weapons Center).

Froula, N. H., E. L. Suenaga, R. L. Bryson, 1988. Shock Compression and Release Behavior of Two Nevada Test Site Tuffs, Defense Nuclear Agency, DNA 01-71-C-0080.

Garnet, H., and J. Crouzet-Pascal, 1966. "Transient Response of a Circular Cylinder of Arbitrary Thickness, in an Elastic Medium, to a Plane Dilational Wave," J. Appl. Mech., 33, 521-531. 
Gere, J. M., and H. G. Shah, 1984. Terra Nonfirma. (Understanding and Preparing for Earthquakes), W. H. Freeman and Co., New York.

Gerrard, C. M., 1982. "Elastic Models of Rock Masses Having One, Two, and Three Sets of Joints," Int. J. Rock Mech., Min. Sci., \& Geomech. Abstr., 19, 15-23.

Ghaboussi, J., and S. U. Dikmen, 1979. LASS-III: Computer Program for Seismic Response and Liquefaction of Layered Ground Under Multi-Directional Shaking, NSF Report, RA790271.

Gibowicz, S. J., 1988. “The Mechanism of Seismic Events Induced by Mining: A Review," Proc. Second International Symposium of Rockbursts and Seismicity in Mines, Minneapolis, $\overline{\mathrm{MN}}$.

Gibson, R. E., 1974. "The Analytical Method in Soil Mechanics," Geotechnique, 24, 115-140.

Gillette, D. R., S. Sture, H. Y. Ko, M. C. Gould, G. A. Scott, 1983. "Dynamic Behavior of Rock Joints," Proc. 24th U.S. Symp. on Rock Mechanics, College Station, TX, AEG, pp. 163-179.

Gomez-Masso, A., and I. Attalla, 1984. "Finite Element Versus Simplified Methods in the Seismic Analysis of Underground Structures," Earthquake Engr. \& Struct. Dyn., 12, 347-367.

Gomez-Masso, A., I. Atalla, and E. Kisiridis, 1983. "Seismic Analysis of Underground Structures," Soil Dynamics and Earthquake Engineering, 2(2).

Goodman, R. E., F. E. Heuze, and G. J. Bureau, 1972. "On Modeling Techniques for Study of Tunnels in Jointed Rock", Proc. of Fourteenth Symposium on Rock Mechanics, Penn. State Univ., June 11-14, pp. 441-479.

Goodman, R. E., and G.-H. Shi, 1985. Block Theory and Its Application in Rock Engineering. Englewood Cliffs, NJ: Prentice-Hall.

Green, R. W. E., 1988. "Instrumentation Networks for Observation of Mine Induced Seismicity," Second International Symposium of Rockbursts and Seismicity in Mines, University of Minnesota, Minneapolis, MN.

Groethe, M. A., P. L. Coleman, J. W. Peterson, 1986. CDC-2 Particle Velocity and TID Measurements, DNA-TR-86-424, (Defense Nuclear Agency).

Hallquist, J. D., 1978. DYNA2D - An Explicit Finite Element and Finite Difference Code for Axisymmetric and Plane Strain Calculations (Users Guide), Lawrence Livermore National Laboratory, Report No. UCRL-52429.

Hamada, M., M. Kitahara, K. Nakagawa, and Y. Muranishi, 1985. "Earthquake Observation and BIE Analysis on Dynamic Behavior of Rock Caverns," Numerical Methods in Geomechanics (Nagoya), T. Kawamoto and Y. Ichikawa, Eds., pp. 1525-1532. Rotterdam: A. A. Balkema. 
Hart, R., P. Cundall, and J. Lemos, 1988. "Formulation of a Three-Dimensional Distinct Element Model-Part II: Mechanical Calculations for Motion and Interaction of a System Composed of Many Polyhedral Blocks," Int. J. Rock Mech., Min. Sci., \& Geomech. Abstr., 25, 117-126.

Hart, R. D., J. Lemos, and P. Cundall, 1987. Block Motion Research: Vol. 2 - Analysis with the Distinct Element Method, Itasca Consulting Group Report, Agbabian Associates, Defense Nuclear Agency Contract No. DNA 001-84-C-0425.

Hendron, A. J., and A. K. Aiyer, 1972. Stresses and Strains Around a Cylindrical Tunnel in Elasto-Plastic Material with Dilatancy, U. S. Army Corps of Engineers, Omaha District, Tech. Report No. 10.

Hendron, A. J., and G. Fernandez, 1983. "Dynamic and Static Design Considerations for Underground Chambers," Seismic Design of Embankments and Caverns, pp. 157-197. New York: ASCE.

Hibbit, Karlsson and Sorensen, Inc., 1982. ABAQUS User's Manual. Providence, RI: Hibbitt, Karlsson and Sorensen, Inc.

Higgins, C. J., 1983. Some Considerations in the Analysis and Prediction of Ground Shock from Buried Conventional Explosions, Applied Research Associates, Inc., Albuquerque, NM.

Hobbs, B. E., 1988. Constitutive Relations for Frictional Rock Sliding and Computer Modeling of the Elastic-Sliding Interactive System, CSIRO (Australia) Report to the U. S. Geological Survey.

Hobbs, B. E., and B. H. G. Brady, 1985. "Normal Stress Changes and the Constitutive Law for Rock Friction," EOS, Trans. Am. Geophys. Union, 16(18), 382.

Hoek, E., and E. T. Brown, 1980. “Empirical Strength Criteron for Rock Masses," J. Geotech. Eng., ASCE, 106, 1013-1035.

Hoffman, R., 1981. STEALTH - ALagrangian Explicit Finite Difference Code for Solids, Structural, and Thermohydraulic Analysis, Introduction and Guide, Electric Power Research Institute, EPRI NP-2080-CCM-SY.

Housner G. W., and P. C. Jennings, 1982. Earthquake Design Criteria, EERI Monograph Series, Berkeley, CA.

Idriss, I. M., 1979 Chairman, Ad Hoc Group on Soil-Structure Interaction. Analyses for Soil-Structure Interaction Effects for Nuclear Power Plants, Nuclear Structures and Materials Committee of the Structural Division of ASCE.

Ingram, J. K., 1970. Placement Effects on Ground Shock Instrumentation, DNA Misc. Paper N70-7.

IEEE, 1987. Standard 344 Recommended Practices for Seismic Qualification of Class 1E Equipment for Nuclear Power Generating Stations, New York, NY. 
Isenberg, J., and C. F. Baggi, 1972. "Analysis of Steel-Lined Penetration Shafts for Deeply Buried Structures," Proc. Symp. Appl. Finite Element Method Geotech, (Vicksburg, MS).

ISRM, 1988. "Rock Engineering Software," Int'1 J. Rock Mech, Min. Sci., \& Geomech. Abstr., 25 (4) $297-250$.

Itasca Consulting Group, Inc., 1987a. FLAC (Fast Lagrangian Analysis of Continua, Minneapolis, $\mathrm{MN}$.

Itasca Consulting Group, Inc., 1987b. 3DEC (3-Dimensional Distinct Element Code), Minneapolis, $\mathrm{MN}$.

Itasca Consulting Group, Inc., 1986. UDEC (Universal Distinct Element Code), Minneapolis, MN.

Iwasaki, T., S. Wakabayashi, and F. Tatsuoka, 1977. Characteristics of Underground Motions at Four Sites Around Tokyo Bay, U. S. National Bureau of Standards, Spec. Pub. No. 477, pp. III.41-III.56.

Jaeger, J. C., 1960. “Shear Fracture of Anisotropic Rocks," Geol. Mag., 97, 65-72.

Jaeger, J. C., 1971. "Friction of Rocks and Stability of Rock Slopes," Geotechnique, 21, 97-134.

Johnson, J. J., 1981. Soil-Structure Interaction: The Status of Current Analysis Methods and Research, U. S. Nuclear Regulatory Commission, NUREG/CR-1780, February.

Johnson, R. L., 1986. "NNWSI Unit Evaluation at Yucca Mountain, Nevada Test Site: Near Field Thermal and Mechanical Calculations Using the SANDIA-ADINA Code," SAND83-0030, Sandia National Laboratories, Albuquerque, NM.

Johnston, J. C., and H. H. Einstein, 1988. "A Survey of Mining Associated Rockbursts," Proc. 2nd Int. Symp. on Rockbursts and Seismicity in Mines (University of Minnesota), in press.

Johnstone, J. K., R. R. Peters, and P. F. Gnirk, 1984. "Unit Evaluation at Yucca Mountain, Nevada Test Site: Summary Report and Recommendations," SAND83-0372, Sandia National Laboratories, Albuquerque, NM.

Kennedy, T. C., and H. E. Lindberg, 1976. Laboratory Investigation of Rock Cavity Reinforcement, Defense Nuclear Agency, DNA4023F.

Key, S. W., 1987. SPECROM-331. A Finite Element Computer Program for the Large Deformation, Elastic and Inelastic, Transient Dynamic Response of Three-Dimensional Solids and Structures, RE/SPEC Topical Report RSI-0299.

Key, S. W., Z. E. Beisinger, and R. L. Kreig, 1978. HONDO II-A Finite Element Computer Program for the Large Deformation Dynamic Response of Axisymmetric Solids, Sandia National Laboratory, SAND 78-0422. 
Kitahara, M., M. Hamada, K. Nakagawa and Y. Muranishi, 1984. "Transient Wave Fields Around Elastic Inclusions in a Semi-Infinite Foundation," Boundary Elements VI, C. A. Brebbia, Ed., pp. 7.3-7.14. Berlin: Springer-Verlag.

Kitahara, M., and K.Nakagawa, 1985. "Boundary Integral Equation Methods in Three-Dimensional Elastodynamics," Boundary Elements VII, C A. Brebbia and G. Maier, Eds., pp. 6.27-6.36. Berlin: Springer-Verlag.

Kitihara, M., and K. Nakagawa, 1986. "Transient Analysis in Three Dimensional Elastodynamics," Innovative Numerical Methods in Engineering, R. P. Shaw, et al., Eds., pp. 367-377. Berlin: Springer-Verlag.

Kobayashi, S., 1985a. "Applications of Boundary Integral Equation Method to Geomechanics," Numerical Methods in Geomechanics (Nagoya), K. Kawamoto and Y. Ichikawa, Eds., pp. 83-92. Rotterdam: A. A. Balkema.

Kobayashi, S., 1985b. "Fundamentals of Boundary Integral Equation Methods in Elastodynamics," Topics in Boundary Element Research, C. A. Brebbia, Ed., Vol. 2, pp. 1-54. Berlin: Springer-Verlag.

Kobayashi, S., 1987. "Elastodynamics," Boundary Element Methods in Mechanics, D. E. Beskos, Ed., Chapter 4. Amsterdam: North-Holland.

Kobayashi, S., and N. Nishimura, 1982a. "Dynamic Analysis of Underground Structures by the Integral Equation Method," Numerical Methods in Geomechanics (Edmonton), Z. Eisenstein, Ed., pp. 401-409. Rotterdam: A. A. Balkema.

Kobayashi, S., and N. Nishimura, 1982b. "On the Indeterminacy of BIE Solutions for the Exterior Problems of Time-Harmonic Elastodynamics and Incompressible Elastostatics," Boundary Element Methods in Engineering, C. A. Brebbia, Ed., pp. 282-296. Berlin: Springer-Verlag.

Kobayshi, S. and N. Nishimura, 1982c. "Transient Stress Analysis of Tunnels and Cavems of Arbitrary Shape Due to Travelling Waves," Developments in Boundary Element Methods 2, P. K. Banerjee and R. P. Shaw, Eds., pp. 177-210. London: Applied Science.

Kobayashi, S., and N. Nishimura, 1983. "Analysis of Dynamic Soil-Structure Interactions by Boundary Integral Equation Method," Proc. 3rd Int. Symp. on Numerical Methods in Engineering, P. Lascaux, Ed., pp. 353-362. Paris: Pluralis.

Kolsky, H., 1963. Stress Waves in Solids. New York: Dover.

Kuznetsov, A. A., and A. D. Baranov, 1974. Seismic Effect of Underground Nuclear Explosions (Transiation). Foreign Technology Division, Air Force Systems Command, U. S. Air Force, FTD-HC-23-2613-74.

Labreche, D. A., 1983. “Damage Mechanisms in Tunnels Subjected to Explosive Loads," Seismic Design of Embankments and Caverns, pp. 128-141. New York: ASCE.

Lambe, T. W., and R. V. Whitman, 1969. Soil Mechanics. New York: John Wiley \& Sons. 
Langefors, U., and B. Kihlstom, 1973. The Modem Technique of Rock Blasting. New York: John Wiley \& Sons.

Lemos, J., 1987. ADistinct Element Model for Dynamic Analysis of Jointed Rock with Application to Dam Foundations and Eault Motion, Ph.D. Thesis, University of Minnesota, (June).

Lemos, J. V., R. D. Hart, and P. A. Cundall, 1985. "A Generalized Distinct Element Program for Modeling Jointed Rock Mass (A Keynote Lecture)," Proceedings of the International Symposium on Fundamentals of Rock Joints (Bjorkliden), pp. 335-343. Lulea, Sweden: Centek Publishers.

Lemos, J. V., R. D Hart, and L. Lorig, 1987. "Dynamic Analysis of Discontinua Using the Distinct Element Method," Proceedings of the Sixth International Congress on Rock Mechanics (Montreal) Vol. 2, pp. 1079-1084. Rotterdam: A.A. Balkema and the Canadian Rock Mechanics Association/CIM/CGS.

Lenhardt, W. A., 1988. "Damage Studies at a Deep Level African Gold Mine," Broc. 2nd Int. Symp. on Rockbursts and Seismicity in Mines, (Minneapolis, 1988), pp. 391-393. Rotterdam: A. A. Balkema.

Linker, M. F., and J. D. Byerlee, 1986. "Effect of Variable Normal Stress on Rock Friction: Observations at 50 Bars Normal Stress," EOS. Trans. Am. Geophys. Union, 67:1187.

Lockner, D. A., and J. D. Byerlee, 1986. Laboratory Measurements of Velocity-Dependent Erictional Strength, Open-File Report 86-417. Menlo, CA: U.S.G.S.

Lorig, L. J., and B. E. Hobbs, 1988. "Numerical Modeling of Slip Instability Using the Distinct Element Method with State Variable Friction Laws," Int.J_Rock_Mech. Min. Sci._\& Geomech. Abstr.

Luco, J. E., et. al., 1986. Engineering Characterization of Ground Motion, Task II: Soil Structure Interaction Effects on Structural Response, U. S. Nuclear Regulatory Comm., NUREG/CR3805, Vol. 4.

Lysmer, J., 1978. “Analytical Procedures in Soil Dynamics," Broc. ASCE Geotechnical Engineering Specialty Conference (Pasadena), Vol. III, pp. 1267-1316.

Lysmer, J., 1981. "Computation of Wave Fields and Soil Structure Interaction," Proc. Workshop on Seismic Performance of Underground Facilities, (Augusta, Georgia), University of California, Berkeley.

Lysmer, J., et al, 1975. ELUSH-A ComputerProgram For Approximate 3-D Analysis of Soil-Structure Interaction Problems, University of California, Berkeley. Report No. EERC75-30.

Mack, M. G., and S. L. Crouch, 1988. "A Dynamic Boundary Element Method for Modeling Rockbursts," Broc. 2nd Int. Symp on Rockbursts and Seismicity in Mines, (Minneapolis, 1988), pp 93-99. Rotterdam: A. A. Balkema.

Manolis, G. D., 1983. "A Comparative Study on Three Boundary Element Method Approaches to Problems in Elastodynamics," Int. J. Numer. Methods Eng, 19, 73-91. 
Manolis, G. D., 1984. "Boundary Element Method for Soil-Structure Interaction," Dynamic SoilStructure Interaction, D. E. Beskos, et al., Eds., pp. 85-91. Rotterdam: A. A. Balkema.

Manolis, G. D., and D. E. Beskos, 1981. "Dynamic Stress Concentration Studies by Boundary integrals and Laplace Transform," Int. J. Numer. Methods Eng., 17, 573-599.

Manolis, G. D., and D. E. Beskos, 1983. "Dynamic Response of Lined Tunnels by an Isoparametric Boundary Element Method," Comput. Methods Appl. Mech. Eng., 36, 291-307.

McGarr, A., 1983. "Estimating Ground Motion for Small Nearby Earthquakes," Seismic Design of Embankments and Caverns, pp. 113-127. New York: ASCE.

McGarr, A., 1984. "Scaling of Ground Motion Parameters, State of Stress, and Total Depth," J. Geophys. Res., 89(b8), 6969-6979.

McGarr, A., R. W. E. Green, and S. M. Spottiswoode, 1981. "Strong Ground Motion of Mine Tremors: Some Implications for Near-Source Ground Notion Parameters," Bull. Seis. Soc. America, 71(1), 295-319.

McGarr, A., S. M. Spottiswoode, and N. C. Gay, 1979. "Observations Relevant to Seismic Driving Stress, Stress Drop, and Efficiency," J. Geophys. Res., 84(B5), 2251-2261.

Mendecki, A. J., G. Van Aswegen, J. N. R. Brown, and P. Hewlitt, 1988. "The Welkom Seismological Network," Second International Symposium of Rockbursts and Seismicity in Mines, (Minneapolis, 1988), pp. 237-243, Rotterdam: A.A. Balkema.

Miklowitz, J., 1963. "Pulse Propagation in a Viscoelastic Solid with Geometric Dispersion," Int. Symp. on Stress Waves in Anelastic Solids (Brown University), H. Kolsky and W. Prager, Eds. Berlin: Springer-Verlag.

Morrison, D. M., 1989. “Rockburst Research at Falconbridge's Strathcona Mine, Journal of Pure and Applied Geophysics, Vol. 129, No. 3/4, pp. 619-628.

Mow, C., and Y. H. Pao, 1971. The Diffraction of Elastic Waves and Dynamic Stress Concentrations, The Rand Corp., R-482-R.

Newmark, N. M., et al., 1970. Ground Motion Technology Review, SAMSO, TR-70-114, Nathan M. Newmark Consulting Engineering Services, Urbana, IL.

Newmark, N. M., and W. J. Hall, 1982. Earthquake Spectra and Design, EERI Monograph Series, Berkeley, CA.

Niwa, Y., T. Fukui, S. Kato, and K. Fujiki, 1980. "An Application of the Integral Equation Method to Two-Dimensional Elastodynamics," Theoretical and Applied Mechanics, Vol. 28, pp. 281-290. Tokyo: University of Tokyo Press.

Niwa, Y., S. Kobayashi, and N. Azuma, 1975. "An Analysis of Transient Stresses Produced Around Cavities of Arbitrary Shape During the Passage of Traveling Waves," Memoirs Fac. Eng. Kyoto Univ., 37, 28-46. 
Niwa, Y., S. Kobayashi, and T. Fukui, 1976. "Applications of Integral Equation Method to Some Geomechanical Problems," Numerical Methods in Geomechanics, C. S. Desai, Ed., pp. 120-131. New York: ASCE.

Obert, L., and D. I. Wilber, 1967. Rock Mechanics and the Design of Structures in Rock, New York: John Wiley and Sons, Inc.

Ohtsu, M., and S. Vesugi, 1984. "Analysis of Elastic Wave Field in a Half Space and Some application to Earthquake Engineering," Boundary Elements VI, C. A. Brebbia, Ed., pp. 7.37-7.47. Berlin: Springer-Verlag.

Olsson, W. A., 1985. "Normal Stress History Effects on Friction in Tuff," EOS, Trans. Am. Geophys. Union, 66:1101.

Olsson, W. A., 1987. "The Effects of Changes in Normal Stress on Rock Friction," Constitutive Laws for Engineering Materials-Theory and Applications (C. S. Desai, Ed.), pp. 1059-1066, New York: Elsevier.

Olsson, W. A., 1988. "The Effect of Normal Stress History on Rock Friction," Key Questions in Rock Mechanics: Proceedings of the 29th U.S. Symposium (University of Minnesota), pp. 111-117. Rotterdam: A. A. Balkema.

Ortlepp, W. D., 1978. "The Mechanism of a Rockburst," Proc. 19th U.S. Rock Mech. Symp. (University of Nevada, Reno), pp.476-483.

Owen, D. R. J., and E. Hinton, 1980. Finite Elements in Plasticity, Theory and Practice. Swansea: Pineridge Press.

Owen, G. N., and R. E. Scholl, 1981. Earthquake Engineering of Large Underground Structures, URS/John A. Blume, San Francisco, JAB-7821.

Patch, D. F., G. I. Kent, J. Eddie Welch, 1978. Ground Shock Interactions with Nuclear Explosion Produced Chimneys. May, DNA Topical Report DNA 4653T.

Patton, F. D., 1966. "Multiple Modes of Shear Failure in Rock," Proc. 1st Cong. ISRM (Lisbon), Vol. 1, pp. 509-513.

Peck, R. B., A. J. Hendron, and B. Mohraz, 1972. "State of the Art of Soft Ground Tunneling," Proc. Rapid Excavation and Tunneling Conf., pp. 259-286. New York: Am. Inst. Min., Metall. \& Petr. Engrs.

Plouffe, M., M. G. Cajka, R. J. Wetmiller, and M. D. Andrew, 1988. "The Sudbury Local Telemetered Seismological Network," Second Intemational Symposium of Rockbursts \& Seismicity in Mines, Univ. of Minnesota, Minneapolis, MN.

Pratt, H. R., W. A. Hustrulid, and D. E. Stephenson, 1978. Earthquake Damage to Underground Facilities. Report DP-1513, E. I. Dupont de Nemours and Co. 
Ramazanov, T. K., 1985. Pressure and Temperature of Subterranean Liquids as Earthquake Indicators. (Translated from Russian) Plenum Pub. Corp.

Raney, R. G., 1988. Reported Effects of Selected Earthquakes in the Western North American Intermontane Region, 1852-1983, On Underground Workings and Local and Regional Hydrology: A Summary. U.S. Bureau of Mìnes Report, Spokane, Washington.

Rice, J. M., and M. H. Sadd, 1984. "Propagation and Scattering of SH-Waves in Semi-Infinite Domains Using a Time-Dependent Boundary Element Method," J. Appl. Mech., 51, 641645.

Rice, J. R., 1983. "Constitutive Relations for Fault Slip and Earthquake Instabilities," PAGEOPH, v.121, pp 443-475.

Rizzo, F. J., D. J. Shippy, and M. Rezayat, 1984. "Explicit Integration of the Boundary Integral Equations in the Frequency Domain for Scattering of Elastic Waves: Applications to Surface Topographies and underground Structures," Earthquake Source Modelling, Ground Motion, and Structural Response, S. K. Datta, Ed., Vol. 60, pp. 97-107. New York: ASME.

Rizzo, F. J., D. J. Shippy, and M. Rezayat, 1985a. Boundary Integral Equation Analysis for a Class of Earth-Structure Interaction Problems, Final Report, NSF CEE-8013461, Department of Engineering Mechanics, University of Kentucky, Lexington, Final Report, NSF CEE8013461, February.

Rizzo, F. J., D. J. Shippy, and M. Rezayat, 1985b. "A Boundary Integral Equation Method for Radiation and Scattering of Elastic Waves in Three Dimensions," Int. J. Num. Meth Eng., $\underline{21}, 115-129$.

Rizzo, F. J., D. J. Shippy, and M. Rezayat, 1985c. " A Boundary Integral Equation Method for Time-Harmonic Radiation and Scattering in an Elastic Halfspace," Advanced Topics in Boundary Element Analysis, Cruse, et al, Eds., Vol. 72, pp 83-90, New York: ASME.

Rorke, A. J., and C. Roering, 1984. "Source Mechanism Studies of Mining-Induced Seismic Events in a Deep-Level Gold Mine," Rockbursts and Seismicity in Mines, pp. 51-56. Johannesburg: S. Afr. Inst. Min. Metall.

Rosenblad, J. L., 1971. Geomechanical Model Study of the Failure Modes of Jointed Rock Masses, Tech. Rpt. MRDL 1-71, MRD Laboratory No. 68/529, January.

Rosenblatt, M., and L. A. DeAngelo, 1980. Stress Wave Interactions with Tunnels Buried in Well-Characterized Jointed Media. DNA Report DNA5334F.

Ruina, A., 1983. "Slip Instability and State Variable Friction Laws." J. Geophys. Res. 88 pp . 10359-10370.

Ryder, J. A., 1987. "Excess Shear Stress: An Engineering Criterion for Assessing Unstable Slip and Associated Rockburst Hazards," Proc. 6th Int. Congress ISRM, pp. 1211-1215. Rotterdam: A. A. Balkema. 
SNL (Sandia National Laboratories), 1987. Site Characterization Plan Conceptual Design Report, SAND84-2641, Sandia National Laboratories, Albuquerque, NM.

St. John, C. M., 1987. "Investigative Study of the Underground Excavations for a Nuclear Waste Repository in Tuff." SAND83-7451, Sandia National Laboratories, Albuquerque, NM.

St. John, C. M., and T. F. Zahrah, 1987. Aseismic Design of Underground Structures, Tunnelling and Underground Space Technology 2.(2). ITA Working Group on Seismic Effects on Underground Structures, National Science Foundation, Grant No. CEE-8310631.

Salamon, M. D. G., 1970. "Stability, Instability and the Design of Pillar Workings," Int. J. Rock Mech., Min. Sci., \& Geomech. Abstr., 7, 613-631.

Schmitz, D. E., 1982. Viscoplastic Analysis of a Continuous Cylindrical Opening Surrounded by Volcanic Tuff, Air Force Inst. of Technology, Wright-Patterson AFB, AFIT/GAE/AA/82D26.

Schnabel, P. B, et al, 1972. SHAKE - A Computer Program for Earthquake Response Analysis of Horizontally Layered Sites, University of California, Berkeley, Report No. EERC72-12.

Seed, H. B., and I. M. Idris, 1982. Ground Motions and Soil Liquefaction During Earthquakes, EERI Monograph Series, Berkeley, CA.

Seed, H. B., P. P. Martin and J. Lysmer, 1975. The Generation and Dissipation of Pore Water Pressures During Soil Liquefaction, Earthquake Engineering Research Center, University of California, Berkeley, NSF Report PB-252 648.

Shi, G. H., and R. E. Goodman, 1985. "Stability Analysis of Infinite Block Systems Using Block Theory," Analytical Computational Methods in Engineering Rock Mechanics, E. T. Brown, Ed., London: Allen and Unwin.

Snodgrass, J. J., D. E. Siskind, 1974. Bureau of Mines Research on Vibrations from Underground Blasting, RI 7937.

Spottiswode, S. M., 1984. "Source Mechanisms of Mine Tremors at Blyvooruitzicht Gold Mine," Proceedings, 1st International Congress on Rockbursts and Seismicity in Mines, Johannesburg, 1982, SAIMM, Johannesburg. N.C. Gay and E. H. Wainwright (eds.).

Stevens, P. R., 1977. Review of Effects of Earthquakes on Underground Mines, USGS. Open-File Report 77-313(April).

Stiller, H., E. Hustig, H. Grosser, and P. Knoll, 1983. "On the Nature of Mining Tremors," J. Earthquake Predict. Res. (Tokyo), 2, 61-68.

Sues, R. H., and S. A. Short, 1986. Block Motion Site Characterization, Report DNA-TR-86-186, Pacifica Technology, Del Mar, CA, June 6.

Sweet, J., 1977. Nonlinear Response of Buried Structures in a Stress Wave Environment, DNA Report 4360F, NTIS Document \#ADA048811. 
Swift, R. P., and D. E. Burton, 1984. Numerical Modeling of the Mechanics of Nonlinear Porous Media Under Dynamic Loading, Lawrence Livermore National Laboratory, UCRL-53568.

Syrek, B., and A. Kijko, 1988. "Energy and Frequency Distributions of Mining Tremors and Their Relation to Rockburst Hazard in the Wujck Coal Mine, Poland," Acta Geophys. Pol., 36, in press.

Tan, T. H., 1976. "Diffraction of Time-Harmonic Elastic Waves by a Cylindrical Obstacle," Appl. Sci. Res., 32, 97-144.

10CFR60, Jan. 1988. Code of Federal Regulations, Energy, Title 10.

Terhune, R. W., C. M. Snell, and H. C. Rodean, 1979. Enhanced Coupling and Decoupling of Underground Nuclear Explosions. Lawrence Livermore Laboratory Report UCRL5260805 .

Thomas, R. K., 1980. "NNWSI Unit Evaluation at Yucca Mountain, Nevada Test Site: Near Field Mechanical Calculations Using a Continuum Jointed Rock Model in the JAC Code," SAND83-0070, Sandia National Laboratories, Albuquerque, NM.

Trollope, D. H., 1968. "The Mechanics of Discontinua or Clastic Mechanics in Rock Problems," Rock Mechanics in Engineering Practice, O. C. Zienkiewiz and K. G. Slagg, Eds., pp. 275-230. London: John Wiley \& Sons.

U. S. Nuclear Regulatory Commission, 1976. Regulatory Guide 1.92: Combining Model Responses and Spatial Components in Seismic Response Analysis.

Unruh, J. F., 1982. "Digital Control of a Shaker to a Specified Shock Spectrum," 52nd Shock and Vibration Bulletin, Part 3, pp. 1-9.

URS/John A. Blume \& Associates, 1976. Comparative Structural Analysis of Type III Underground Waste Storage Tanks at the Savannah River Plant, Aiken, South Carolina, San Francisco, John Blume.

Vardoulakis, I. G., B. E. Beskos, K. L. Leung, B. Dasgupta, and R. L. Sterling, 1987. “Computation of Vibration Levels in Underground Space," Int. J. Rock Mech., Min. Sci., \& Geomech. Abstr., 24(5), 291-298.

Vortman, L. J., 1979. Prediction of Ground Motion From Nuclear Weapon Tests at NTS, Report SAND79-1002, Sandia National Laboratories, Albuquerque, NM.

Vortman, L. J., 1981. A Comparison of Ground Motion From Earthquakes and Underground Nuclear Weapons Tests at NTS, Workshop on Seismic Performance of Underground Facilities, Augusta, GA.

Vortman, L. J., 1982. Ground Motion from Earthquakes and Underground Nuclear Weapons Tests; A Comparison as it Relates to Siting a Nuclear Waste Storage Facility at NTS, Report SAND81-2214, Sandia Labs, Albuquerque, NM. 
Vortman, L. J., and J. W. Long, 1982. Effects of Ground Motion on Repository Depth, The Yucca Flat Data, Contract No. DE-AC04-76DP00789, Department of Energy, Washington, DC.

Wagner, H., 1984. "Support Requirements for Rockburst Conditions," Rockbursts and Seismicity in Mines, pp. 209-218. Johannesburg: S. Afr. Inst. Min. Metall.

Wahi, K. K., 1982. "Numerical Modeling of Earthquake Effects on Underground Tunnels," Proceedings of the Workshop on Seismic Performance of Underground Facilities (February 11-13, 1981), pp. 211-229, Oak Ridge: U. S. DOE.

Walton, O. R., 1980. Particle Dynamics Modeling of Geological Materials, Lawrence Livermore National Laboratory, Report UCRL-32915.

Warburton, P. M., 1985. “A Computer Program for Reconstructing Blocky Rock Geometry and Analyzing Single Block Theory," Comput. Geosci., 11, 707-712.

Wawersik, W. R., and C. Fairhurst, 1970. "A Study of Brittle Rock in Laboratory Compression Experiments," Int. J. Rock Mech., Min. Sci., \& Geomech. Abstr., 7, 561-575.

Wells, J. H., 1929. "Kinematic Boundary Friction," The Engineer (London), 147, 454-462.

Williams, J. R., G. Hocking and G. G. Mustoe, 1985. "The Theoretical Basis of the Discrete Element Method," Proc. Int. Conf. on Advances in Numer. Meth. in Engr. (University of Swansea).

Wood, S. H., C. Wurts, T. Lane, N. Ballinger, M. Shaleen and D. Totorica, 1985. "The Borah Peak, Idaho, Earthquake of October 28, 1983 - Hydrologic Effects," Proc. of Workshop XXVIII on the Borah Peak, ID, Earthquake, U.S. Geol. Survey, Open-File Report 85-290. 


\section{APPENDIX A ADDITIONAL BIBLIOGRAPHY}

Agnew, D. C., and K. E. Sieh, 1978. "A Documentary Study of the Felt Effects of the Great California Earthquake of 1857," Bulletin of the Seismological Society of America, Vol. 68, No. 6, pp. 1717-1729.

Algermissen, S. T., D. M. Perkins, P. C. Thenhaus, S. L. Hanson, and B. L. Bender, 1982. Probabilistic Estimates of Maximum Acceleration and Velocity in Rock in the Contiguous United States, USGS-OFR-82-10-33, Open-File Report, U.S. Geological Survey, Denver, CO.

Amini, A., and E. L. Foster, 1986. Correlation of Ground Behavior Under Static Loading with Dynamic Response, Contract No. DNA 001-85-C-0387, Defense Agency, Washington, DC.

Anderson, G. D., Kusubov, A. J., 1986. "Static and Dynamic Mechanical Properties Tests of Core Material from Hole U8J at the Nevada Test Site," Proceedings of Third Symposium on Containment of Underground Nuclear Explosions, UCRL-92456.

Anderson, L. A., 1981. Rock Property Analysis of Core Samples from the Yucca Mountain UE25a-1 Borehole, Nevada Test Site, Nevada, USGS-OFR-81-1338, Open-File Report, U.S. Geological Survey, Denver, $\mathrm{CO}$.

Anderson, L. A., 1984. Rock Property Measurements on Large-Volume Core Samples from Yucca Mountain USW GU-3/G-3 and USW G-4 Boreholes, Nevada, USGS-OFR-84-552, OpenFile Report, U.S. Geological Survey, Denver, CO.

Apps, J. A., C. L. Carmahan, P. C. Lichtner, M. C. Michel, D. Perry, R. J. Silva, O. Weres, and A. F. White, 1983. Status of Geochemical Problems Relating to the Burial of High-Level Radioactive Waste, 1982, NUREG/CR-3062, U.S. Nuclear Regulatory Commission, Washington, $\mathrm{DC}$.

Arabasz, W. J., 1986. "Seismotectonics of the Basin and Range - Colorado Plateau Transition in Utah," Geological Society of America, Abstracts with Programs 1986, Rocky Mountain Section, Flagstaff, AZ, April 30-May 2, Vol. 18, No. 5, 338.

Askew, B., and S. T. Algermissen, 1983. An Earthquake Catalog for the Basin and Range Province 1803-1977, USGS-OFR-83-86, Open-File Report, U.S. Geological Survey, Denver, CO, $40 \mathrm{p}$.

ASTM (American Society for Testing and Materials), 1979. Unconfined Compressive Strength of Intact Rock Core Specimens, Standard Test Method, ANSI/ASTMD 2938-79, Philadelphia, PA. 
ASTM (American Society for Testing and Materials), 1980. Triaxial Compressive Strength of Undrained Rock Core Specimens without Pore Pressure Measurements, Standard Test Method, ASTM D 2664-80, Philadelphia, PA.

ASTM (American Society for Testing and Materials), 1980. Elastic Moduli of Intact Rock Core Specimens in Uniaxial Compression, Standard Test Method, ANSI/ASTM D 3148-80, Philadelphia, PA.

ASTM (American Society for Testing and Materials), 1981. Splitting Tensile Strength of Intact Rock Core Specimens, Standard Test Method, ASTM D 3967-81, Philadelphia, PA.

ASTM (American Society for Testing and Materials), 1983. Laboratory Determination of Pulse Velocities and Ultrasonic Elastic Constants of Rock, Standard Test Method, ASTM D 2845-83, Philadelphia, PA.

Ballard, R. F., and F. G. McClean, 1975. "Seismic Field Methods for In Situ Moduli," Proceedings of the Conference on In Situ Measurement of Soil Properties, Geotechnical Engineering Division (ASCE) Specialty Conference, Raleigh, North Carolina, June 1-4, Vol. 1, pp. 121150.

Ballard, R. L., 1985. "Statistical Summary," 1984 Bureau of Mines Minerals Yearbook, U.S. Department of the Interior, Bureau of Mines, Washington, DC.

Bandis, S., A. C. Lumsden, and N. R. Barton, 1981. "Experimental Studies of Scale Effects on the Shear Behavior of Rock Joints," Int. J of Rock Mech., Min. Sci, and Geomech. Abstr., Vol. 18 , pp. 1-21.

Bandis, S. C., A. C. Lumsden, and N. R. Barton, 1983. "Fundamentals of Rock Joint Deformation," Int. J. Rock Mech., Min. Sci., \& Geomech. Abstr., 20, 244-268.

Barton, C. C., 1984. "Tectonic Significance of Fractures in Welded Tuff, Yucca Mountain, Southwest Nevada," Geological Society of America, Abstracts with Programs, Vol. 16, No. 6, p. 438.

Barton, C. C., and E. Larsen, 1985. "Fractal Geometry of Two-Dimensional Fracture Networks at Yucca Mountain, Southwestern Nevada," Proceedings of the International Symposium on Fundamentals of Rock Joints, Bjorkliden, Sweden, September 15-20, O. Stephansson (ed.), pp. 77-84.

Barton, N., 1981. Importance of Joint Parameters on Deformations Observed in Dynamically Loaded Models of Large Excavations; Workshop on Seismic Performance of Underground Facilities, Augusta, GA.

Barton, N., 1982. Modelling Rock Joint Behavior from In Situ Block Tests: Implications for Nuclear Waste Repository Design, ONWI-308, Office of Nuclear Waste Isolation, Battelle Memorial Institute, Columbus, $\mathrm{OH}$.

Barton, N., and V. Choubey, 1977. "The Shear Strength of Rock Joints in Theory and Practice," Rock Mech., 10, 1-54. 
Bathe, K-J., 1975. ADINA: A Finite Element Program for Automatic Dynamic Incremental Nonlinear Analysis, Report 82448-1, Massachusetts Institute of Technology, Acoustics and Vibration Laboratory, Mechanical Engineering Department, Cambridge, MA.

Bauer, S. J., J. F. Holland, and D. K. Parrish, 1985. "Implications About In Situ Stress at Yucca Mountain," Proceedings of the 26th U.S. Symposium on Rock Mechanics, Vol. III, Rapid City, South Dakota, pp. 1113-1120.

Bauer, S. J., R. K. Thomas, and L. M. Ford, 1985. "Measurement and Calculation of the Mechanical Response of a Highly Fractured Rock," Research \& Engineering Applications in Rock Masses, Proceedings of the 26th U.S. Symposium on Rock Mechanics, Rapid City, SD, June 26-28, South Dakota School of Mines \& Technology, Rapid City, pp. 523-530.

Bayer, K. C., R. R. Mallis, and K. W. King, 1972. Earthquakes Recorded by a Seismograph Network Located in the Southem Nevada Region, January 1 to December 22, 1971, NVO-746-TM-3, U.S. Department of Commerce, Earth Sciences Laboratories, Las Vegas, NV.

Bayer, K. C., 1973. Seismic Data Report Southem Nevada Region December 22, 1971-December 31, 1972, Technical Memorandum ERL-ESL-24, National Oceanic and Atmospheric Administration, Earth Science Laboratories, Las Vegas, NV.

Bayer, K. C., 1974. A Preliminary Seismicity Study of the Southem Nevada Region Quarterly Report January-March 1973, NVO-746-12, National Oceanic and Atmospheric Administration, Earth Science Laboratories, Las Vegas, NV.

Bayer, K. C., 1974. A Preliminary Seismicity Study of the Southem Nevada Region Quarterly Report. April-June 1973, NVO-474-1, U.S. Geological Survey, Las Vegas, NV.

Bear, J., 1972. Dynamics of Fluids in Porous Media, Part 1, University Microfilms International, Ann Arbor, MI, p. 7.

Beck, P. J., 1970. The Southern Nevada-Utah Border Earthquakes, August to December 1966, University of Utah Master's Theses, $62 \mathrm{p}$.

Bedinger, M. S., K. A. Sargent, and W. H. Langer (eds.), 1984. Studies of Geology and Hydrology in the Basin and Range Province, Southwestem United States, for Isolation of High-Level Radioactive Waste: Characterization of the Death Valley Region, Nevada and California, USGS-OFR-84-743, Open-File Report, U.S. Geological Survey, Denver, CO.

Benson, L. V., J. H. Robison, R. K. Blankennagel, and A. E. Ogard, 1983. Chemical Composition of Ground Water and the Locations of Permeable Zones in the Yucca Mountain Area, Nevada, USGS-OFR-83-854, Open-File Report, U.S. Geological Survey, Denver, CO.

Bentley, C. B., 1984. Geohydrologic Data for Test Well USW G-4, Yucca Mountain Area, Nye County, Nevada, USGS-OFR-84-063, Open-File Report, U.S. Geological Survey, Denver, CO. 
Bentley, C. B., J. H. Robison, and R. W. Spengler, 1983. Geohydrologic Data for Test Well USW H-5, Yucca Mountain Area, Nye County, Nevada, USGS-OFR-83-853, Open-File Report, U.S. Geological Survey, Denver, CO.

Bieniawski, Z. T., and W. L. Van Heerden, 1975. "The Significance of In Situ Tests on Large Rock Specimens," Int. J of Rock Mech., Min. Sci, and Geomech. Abstr., Vol. 12, Pergamon Press, Great Britain, pp. 101-113.

Birkhauser Verlarg, B., 1986. "Friction Constitutive Law with Rate and State Dependences," Institute of Geophysics, State Seismological Bureau, Beijing, China, pp. 773-791.

Bish, D. L., 1987. Evaluation of Past and Future Alterations in Tuff at Yucca Mountain, Nevada Based on the Clay Mineralogy of Drill Cores USW G-1, G-2, and G-3, LA-10667-MS, Los Alamos National Laboratory, Los Alamos, NM.

Bish, D. L., F. A. Caporuscio, J. F. Copp, B. M. Crowe, J. D. Purson, J. R. Smyth, and R. G. Warren, 1981. Preliminary Stratigraphic and Petrologic Characterization of Core Samples from USW-G1, Yucca Mountain, Nevada, A. C. Waters and P. R. Carroll (eds.), LA-8840-MS, Los Alamos National Laboratory, Los Alamos, NM.

Bish, D. L., A. E. Ogard, D. T. Vaniman, and L. Benson, 1984. "Mineralogy-Petrology and Groundwater Geochemistry of Yucca Mountain Tuffs," Scientific Basic for Nuclear Waste Management VII, Material Research Society Symposia Proceedings, Boston, Massachusetts, November 1983, G. L McVay (ed.), Vol. 26, North-Holland, Elsevier Science Publishing Co., Inc., New York, pp. 283-291.

Bish, D. L., D. T. Vaniman, F. M. Byers, Jr., and D. E. Broxton, 1982. Summary of the MineralogyPetrology of Tuffs of Yucca Mountain and the Secondary Phase Thermal Stability in Tuffs, LA-9321-MS, Los Alamos National Laboratory, Los Alamos, NM.

Bish, D. L., and D. T. Vaniman, 1985. Mineralogic Summary of Yucca Mountain, Nevada, LA-10543-MS, Los Alamos National Laboratory, Los Alamos, NM.

Blacic, J., and R. Andersen, 1983. Methodology for Determining Time-Dependent Mechanical Properties of Tuff Subjected to Near-Field Repository Conditions, LA-9322-MS, Los Alamos National Laboratory, Los Alamos, NM.

Blacic, J. D., J. Carter, P. Halleck, P. Johnson, T. Shankland, R. Andersen, K. Spicochi, and A. Heller, 1982. Effects of Long-Term Exposure of Tuffs to High-Level Nuclear Waste Repository Conditions, LA-9174-PR, Los Alamos National Laboratory, Los Alamos, NM.

Blacic, J. D., D. T. Vaniman, D. L. Bish, C. J. Duffy, and R. C. Gooley, 1986. Effects of Long-Term Exposure of Tuffs to High-Level Nuclear Waste Repository Conditions: Final Report, LA-9330-MS, Los Alamos National Laboratory, Los Alamos, NM.

Blanford, M. L., 1982. Heated Block Test Conceptual Design Calculations, SAND81-1841. Sandia National Laboratories, Albuquerque, NM. 
Board, M. P., M. L. Wilson, and M. D. Voegele, 1987. Laboratory Determination of the Mechanical, Ultrasonic and Hydrologic Properties of Welded Tuff from the Grouse Canyon Heated Block Site, SAND86-7130, Science Applications Intemational Corp., Las Vegas, NM.

Bowen, J. L., and R. T. Egami, 1983. Nevada Nuclear Waste Storage Investigations Site Characterization Activities: Preliminary Atmospheric Assessment of a Nuclear Waste Repository, NVO-258, Nevada Operations Office, U.S. Department of Energy, Las Vegas.

Britt, J. R., 1977. Charts for Preliminary Design of Deep Underground Structures Subjected to Dynamic Loads, USAWES, Misc. Paper N-77-3 (U. S. Army Waterways Experiment Station).

Brooks, R. H., and A. T. Corey, 1964. Hydraulic Properties of Porous Media, Hydrology Paper No. 3, Colorado State University, Fort Collins, CO.

Bucknam, R. C., S. T. Algermissen, and R. E. Andersen, 1980. Pattems of Late Quatemary Faulting in Westem Utah and an Application in Earthquake Hazard Evaluation, USGS-OFR-80-801, Open-File Report, U.S. Geological Survey, 15 p.

Bull, W. B., 1984. "Tectonic Geomorphology," Joumal of Geological Education, Vol.32, pp. 310-324.

Burton, D. E., J. B. Bryan, L. A. Lettis, Jr. 1979. Numerical Modeling of Spall Phenomena; U.S. Department of Energy.

Butkovich, T. R., 1971. "Influence of Water in Rocks on Effects of Underground Nuclear Explosions," J. Geophys. Res., 76 (8).

Byerlee, J., 1978. "Friction of Rocks," Pageoph (Pure and Applied Geophysics), Vol. 116, pp. 615-626.

Byers, F. M., Jr., 1985. Petrochemical Variation of Topopah Spring Tuff Matrix with Depth (Stratigraphic Level), Drill Hole USW G-4 Yucca Mountain, Nevada, LA-10561-MS, Los Alamos National Laboratory, Los Alamos, NM.

Campbell, K. W., 1980. Seismic Hazard Analysis for the NTS Spent Reactor Fuel Test Site, UCRL-15260, report prepared by TERA Corporation for Lawrence Livermore Laboratory, Livermore, CA.

Campbell, K. W., 1981. "Near-Source Attenuation of Peak Horizontal Acceleration," Bulletin of the Seismological Society of America, Vol. 71, No. 6, pp. 2039-2070.

Carios, B. A., 1985. Minerals in Fractures of the Unsaturated Zone from Drill Core USW G-4, Yucca Mountain, Nye County, Nevada, LA-10415-MS, Los Alamos National Laboratory, Los Alamos, NM.

Carpenter, D. W., and D. Towse, 1979. Seismic Safety in Nuclear-Waste Disposal, Lawrence Livermore Laboratory, Berkley, CA. 
Carr, W. J., 1974. Summary of Tectonic and Structural Evidence for Stress Orientation at the Nevada Test Site, USGS-OFR-74-176, Open-File Report, U.S. Geological Survey, Denver, CO.

Case, J. B., and P. C. Kelsall, 1987. Modification of Rock Mass Permeability in the Zone Surrounding a Shaft in Fractured, Welded Tuff, SAND86-7001, Sandia National Laboratories, Albuquerque, NM.

Chen, E. P., 1987. A Computational Model for Jointed Media with Orthogonal Sets of Joints, SAND86-1122, Sandia National Laboratories, Albuquerque, NM.

Christensen, R. C., and N. E. Spahr, 1980. Flood Potential of Topopah Wash. and Tributaries, Eastem Part of Jackass Flats, Nevada Test Site, Southem Nevada, USGS-OFR-80-963, Open-File Report, U.S. Geological Survey, Lakewood, CO., 22 p.

Codell, R., 1986. Draft Generic Position on Groundwater Travel Time, U.S. Nuclear Regulatory Commission, Washington, DC.

Constantino, C. J., and A. J. Philippacopoulos, 1987. Influence of Ground Water on Soil - Structure Interaction, Contract No. DE-AC02-76CH00016, Department of Nuclear Energy, Brookhaven National Laboratory, Upton, NY.

Craig, R. W., R. L. Reed, and R. W. Spengler, 1983. Geohydrologic Data for Test Well USW H-6, Yucca Mountain Area, Nye County, Nevada, USGS-OFR-83-856, Open-File Report, U.S. Geological Survey, Denver, CO.

Craig, R. W., and J. H. Robison, 1984. Geohydrology of Rocks Penetrated by Test Well UE-25p 1, Yucca Mountain Area, Nye County, Nevada, USGS-WRI-84-4248, Water-Resources Investigations Report, U.S. Geological Survey, Denver, CO.

Crank, J., 1975. The Mathematics of Diffusion, Second Edition, Oxford University Press, London, pp. 121-146, 331-333.

Crow, B. M., D. T. Vaniman, and W. J. Carr, 1983. Status of Volcanic Hazard Studies for the Nevada Nuclear Waste Storage Investigations, LA-9325-MS, Los Alamos National Laboratory, Los Alamos, NM.

Cundall, P. A., and R. D. Hart, 1984. Analysis of Block Test No. 1 In Elastic Rock Mass Behavior: Phase 2 - A Characterization of Joint Behavior (Final Report), Itasca Consulting Group, Subcontract SA-957, Rockwell Hanford Operations.

Czarnecki, J. B., 1985. Simulated Effects of Increased Recharge on the Ground-Water Flow System of Yucca Mountain and Vicinity, Nevada-California, USGS-WRI-84-4344, Water-Resources Investigations Report, U.S. Geological Survey, Denver, CO.

Czamecki, J. B., and R. K. Waddell, 1984. Finite-Element Simulation of Ground-Water Flow in the Vicinity of Yucca Mountain, Nevada-California, USGS-WRI-84-4349, Water-Resources Investigations Report, U.S. Geological Survey, Denver, CO. 
Dahiman, O., and H. Israelson, 1977. Monitoring Underground Nuclear Explosions, Elsevier Scientific Publishing Company, New York, p. 396.

Davies, L., R. Noyes, J. Kalinowski, T. Stubbs, 1983. Soil-Pore Gas-Pressure Measurements at the Nevada Test Site, EGG-10282-1018.

Dennis, A. W., P. D. O'Brien, 1983. NNWSI Repository Operational Procedures for Receiving, Packaging, Emplacing, and Retrieving High Level and Transuranic Waste, SAND83-1166 (Sandia).

Dettinger, M. D., and J. L. Wilson, 1981. "First Order Analysis of Uncertainty in Numerical Models of Groundwater Flow, Part 1, Mathematical Development," Water Resources Research, Vol. 17, No. 1, pp. 149-161.

Dieterich, J. H., 1972. "Time-Dependent Friction as a Possible Mechanism for Aftershocks," Journal of Geophysical Research, Vol. 77, No. 20, pp. 3771-3781.

DOE (U.S. Department of Energy) 1986. Final Environmental Assessment: Yucca Mountain Site, Nevada Research and Development Area, Nevada, DOE/RW-0073, Washington, DC.

Doser, D. I., 1985. "The 1983 Borah Peak, Idaho and 1959 Hebgan Lake, Montana Earthquakes: Models for Normal Fault Earthquakes in the Intermountain Seismic Belt," in Proceedings of Workshop XXVIII On Borah Peak, Idaho, Earthquake, Volume A, National Earthquake Prediction and Hazards Programs, October 3-6, 1984, R. S. Stein and R. C. Bucknam (eds.), USGS-OFR-85-290-A, Open-File Report, U.S. Geological Survey, Menlo Park, CA, pp. 368-384.

Doty, G. C., and W. Thordarson, 1983. Water Table in Rocks of Cenozoic and Paleozoic Age, 1980, Yucca Flat, Nevada Test Site, Nevada, USGS-WRI-83-4067, Water-Resources Investigations Report, U.S. Geological Survey, Lakewood, CO.

Dowding, C. H., 1977. "Seismic Stability of Underground Openings," Proc. Rockstore Conf. (Stockholm, 1977).

Dresser Atlas, 1982. Well Logging and Interpretation Techniques, The Course for Home Study, Second Edition, Dresser Industries, Houston, TX.

Easterling, R. G., and I. J. Hill, 1988. Additional Underground Test Data Required for Yucca Mountain Repository Characterization, SAND87-2073.

Ehrgott, J. Q., 1972. Hydrostatic and Shear Responses of Two Tuff Materials Under Various Rates of Stress; Defense Nuclear Agency; S-72-35

Ellis, W. L., and J. R. Ege, 1976. Determination of In Situ Stress in U12g Tunnel, Rainier Mesa, Nevada Test Site, Nevada, USGS-474-219, U.S. Geological Survey, Denver, CO.

Ellis, W. L. and J. D. Kibler, 1983. Explosion-Induced Stress Change Estimated from Vibrating-Wire Stressmeter Measurements Near the Mighty Epic Event, Nevada Test Site USGS-OFR-83642, (U. S. Geological Survey). 
Ellis, W. L., and J. E. Magner, 1982. Determination of the In Situ State of Stress at the Spent Fuel Test-Climax Site, Climax Stock, Nevada Test Site, USGS-OFR-82-458, Open-File Report, U.S. Geological Survey, Denver, CO.

Ellis, W. L., and H. S. Swolfs, 1983. Preliminary Assessment of In Situ Geomechanical Characteristics in Drill Hole USW G-1, Yucca Mountain, Nevada, USGS-OFR-83-401, Open-File Report, U.S. Geological Survey, Denver, CO.

EPRI (Electric Power Research Institute), 1986. Seismic Hazard Methodology for the Central and Eastern United States, EPRI NP-4726, No. 1, Risk Engineering, Inc., Woodward-Clyde Consultants, Geomatrix Consultants, Inc., and CYGNA Corporation.

Erickson, J. R., and R. K. Waddell, 1985. Identification and Characterization of Hydrologic Properties of Fractured Tuff Using Hydraulic and Tracer Tests-Test Well USW H-4, Yucca Mountain, Nye County, Nevada, USGS-WRI-85-4066, Water-Resources Investigations Report, U.S. Geological Survey, Denver, CO.

Faust, C. R., and J. W. Mercer, 1977. Theoretical Analysis of Fluid Flow and Energy Transport in Hydrothermal Systems, USGS-OFR-77-60, Open-File Report, U.S. Geological Survey, Reston, VA.

Fetter, C. W., Jr., 1980. Applied Hydrogeology, Charles E. Merrill Publishing Co., Columbus, OH, $381 \mathrm{p}$.

Fischer, F. G., P. J. Papanek, and R. M. Hamilton, 1972. The Massachusetts Mountain Earthquake of 5 August 1971 and Its Aftershocks, Nevada Test Site, USGS-474-149, U.S. Geological Survey, Denver, CO.20 p.

Freeze, R. A., and J. A. Cherry, 1979. Groundwater, Prentice-Hall, Inc., Englewood Cliffs, NJ, pp. 389-390, 551-552.

Gates, W. L., 1985. "Modeling as a Means of Studying the Climate System" Projecting the Climate Effects of Increasing Carbon Dioxide, M. C. MacCracken, and F. M. Luther (eds.), DOE/ER0237, U.S. Department of Energy, Washington, DC, pp. 59-79.

Gianella, V. P. and E. Callaghan, 1934. "The Earthquake of December 20, 1932, at Cedar Mountain, Nevada and Its Bearing on the Genesis of Basin Range Structure," Journal of Geology, Vol. 42, No. 1, pp. 1-22.

Gianella, V. P., and E. Callaghan, 1934. "The Cedar Mountain, Nevada, Earthquake of December 20, 1932," Bulletin of the Seismological Society of America, Vol. 24, No. 4, pp. 345-377.

Glanzman, V. M., 1979. Bibliography of Reports by U.S. Geological Survey Personnel on the Nevada Test Site and Related Subjects, July 1,1977, to December 31, 1978, with Author and Subject Indexes, USGS-474-306, U.S. Geological Survey, Denver, CO. 
Glanzman, V. M., 1980. Bibliography of Reports by U.S. Geological Survey Personnel Pertaining to Underground Nuclear Testing and Radioactive Waste Disposal at the Nevada Test Site, and Radioactive Waste Disposal at the WIPP Site, New Mexico, January 1, 1979, to December 31, 1979, USGS-OFR-80-817, Open-File Report, U.S. Geological Survey, Denver, $\mathrm{CO}$.

Glanzman, V. M., 1981. Bibliography of Reports by U.S. Geological Survey Personnel Pertaining to Underground Nuclear Testing and Radioactive Waste Disposal at the Nevada Test Site, and Radioactive Waste Disposal at the Waste Isolation Pilot Plant Site, New Mexico, January 1, 1980, to December 31, 1980, USGS-OFR-81-892, Open-File Report, U.S. Geological Survey, Denver, CO.

Glanzman, V. M., 1983. Bibliography of Reports by U.S. Geological Survey Personnel on Studies of Underground Nuclear Test Sites and on Waste Management Studies at the Nevada Test Site and the Waste Isolation Pilot Plant Site, New Mexico, January 1 to December 31, 1981, USGS-OFR-83-478, Open-File Report, U.S. Geological Survey, Denver, CO.

Glanzman, V. M., 1984. Bibliography of Reports by U.S. Geological Survey Personnel on Studies of Underground Nuclear Test Sites and on Waste Management Studies at the Nevada Test Site and the Waste Isolation Pilot Plant Site, New Mexico, January 1 to December 31, 1982, USGS-OFR-84-23, Open-File Report, U.S. Geological Survey, Denver, CO.

Glanzman, V. M., 1985. Bibliography of Reports by U.S. Geological Survey Personnel on Studies of Underground Nuclear Test Sites and on Waste Management Studies at the Nevada Test Site and the Waste Isolation Pilot Plant Site, New Mexico, January 1, 1983, to December 31, 1984, USGS-OFR-85-363, Open-File Report, U.S. Geological Survey, Denver, CO.

Goodman, R. E., 1980. Introduction to Rock Mechanics, John Wiley \& Sons, Inc., New York.

Gregg, S. J., and K. S. W. Sing, 1967. Adsorption, Surface Area and Porosity, Academic Press, London, p. 182.

Gu, J., 1986. "Friction Constitutive Law with Rate and State Dependences," PAGEOPH, Vol. 124, Nos. $4 / 5$.

Guzowski, R. V., F. B. Nimich, M. D. Siegel, and N. C. Finley, 1983. Repository Site Data Report for Tuff: Yucca Mountain, Nevada, NUREG/CR-2937, SAND82-2105, U.S. Nuclear Regulatory Commission, Washington, DC.

Hagan, T.N., 1984. Blast Design Considerations for Underground Mining and Construction Operations; (Source Reference) - Design and Performance of Underground Excavations,

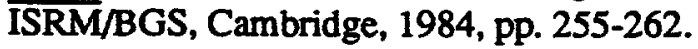

Haimson, B. C., J. Lacomb, A. H. Jones, and S. J. Green, 1974. "Deep Stress Measurements in Tuff at the Nevada Test Site," Advances in Rock Mechanics, Vol. II, Part A, National Academy of Science, Washington, $\overline{\mathrm{DC}}$, pp. 557-561. 
Halsey, J. F., and M. V. Barton, 1959. Spectra of Ground Shocks Produced by Nuclear Detonations, AD 49131, Report on Operation Plumbbob - Project 1.9, Air Force Ballistic Missile Division, Air Research and Development Command, Inglewood, CA.

Hamilton, R. M., and J. H. Healy, 1969. "Aftershocks of the Benham Nuclear Explosion," Bulletin of the Seismological Society of America, Vol. 59, No. 6, pp. 2271-2281.

Hamilton, R. M., B. E. Smith, F. G. Fisher, and P. J. Papanek, 1971. Seismicity of the Pahute Mesa Area, Nevada Test Site (8 December 1968 through 31 December 1970), USGS-474-138, U.S. Geological Survey, Menlo Park, CA.

Hamilton, R. M., B. E. Smith, F. G. Fisher, and P. J. Papanek, 1972. "Earthquakes Caused by Underground Nuclear Explosions on Pahute Mesa, Nevada Test Site," Seismological Society of American Bulletin, Vol. 62, No. 5, pp. 1319-1341.

Hardin, E., N. Barton, M. Voegele, M. Board, R. Lingle, H. Pratt, and W. Ubbes, 1982. "Measuring the Thermomechanical and Transport Properties of a Rockmass Using the Heated Block Test," 23rd U. S. Symposium of Rock Mechanics, pp. 802-813.

Hardin, E. L., M. D. Voegele, M. P. Board, and H. R. Pratt, 1985. "Development of a Test Series to Determine in Situ Thermomechanical and Transport Properties," Measurement of Rock Properties at Elevated Pressures and Temperatures, H. J. Pincus and E. R. Hoskins (eds.) ASTM STP 869, American Society for Testing and Materials, Philadelphia, Penn., pp. 128-153.

Harmsen, S., and S. Harding, 1981. "Surface Motion Over a Sedimentary Valley for Incident Plane $P$ and SV Waves," Bulletin of the Seismological Society of America, Vol. 71, No. 3, pp. 655-670.

Hart, R. D., P. A. Cundall, and M. L. Cramer, 1985. "Analysis of a Loading Test on a Large Basalt Block," Proceeding of the 26th Symposium on Rock Mechanics, Rapid City, S.D., pp. 759-768.

Hartzell, S., 1985. "The Use of Small Earthquakes as Green's Functions," Strong Ground Motion Simulation and Earthquake Engineering Applications: A Technological Assessment, R. E. Scholl and J. L. King (eds.), Publications No. 85-02, Section 22, Earthquake Engineering Research Institute, pp. 22-1 to 22-8.

Hearst, J. R., and P. H. Nelson, 1985. Well Logging for Physical Properties, McGraw-Hill Book Company, New York, $571 \mathrm{p}$.

Heath, R. C., 1984. Ground-Water Regions of the United States, Geological Survey Water Supply Paper 2242, U.S. Geological Survey, Washington, DC.

Heuze, F. E., 1980. "Scale Effects in the Determination of Rock Mass Strength and Deformability," Rock Mechanics, Vol. 12, pp. 167-192. 
Heuze, E. H., and A. Salem, 1977. "Rock Deformability Measured In Situ, Problems and Solutions," Field Measurements in Rock Mechanics, Intemational Symposium, Zurich, Switzerland, April 4-6, 1977, Vol. 1, pp. 375-387.

Hill, D. P., R. E. Wallance, and R. S. Cockerham, 1985. "Review of Evidence on the Potential for Major Earthquakes and Volcanism in the Long Valley-Mono Craters-White Mountains Regions of Eastern California," Earthquake Prediction, Earthquake Prediction Research Vol. 3, No. 3-4, Terra Scientific Publishing Company, Tokyo, Japan, pp. 571-594.

Hillel, D., 1980. Fundamentals of Soil Physics, Academic Press, Inc., New York, 413 p.

Hoek, E., and E. T. Brown, 1980. Underground Excavations in Rock, Institution of Mining and Metallurgy, London, pp. 137-139, 285-298.

Hoffman, L. R., and W. D. Mooney, 1983. A Seismic Study of Yucca Mountain and Vicinity, Southern Nevada; Data Report of Preliminary Results, USGS-OFR-83-588, Open-File Report, U.S. Geological Survey, Menlo Park, CA.

Hoffman, L.R., and W. D. Mooney, 1983. A Seismic Study of Yucca Mountain and Vicinity, Southem Nevada; Data Report of Preliminary Results, USGS-OFR-82-466, Open-File Report, U.S. Geological Survey, Denver, CO.

Howard, N. W., 1977. The Lawrence Livermore Laboratory Nuclear Test Effects and Geologic Data Bank; Geoscience Information Society, Proceedings/U.S. Energy Research and Development Administration; GIS, Proceedings, Vol. 7, pp. 99-114.

Hubbert, M. K., and D. G. Willis, 1957. "Mechanics of Hydraulic Fracturing," Joumal of Petroleum Technology, Vol. 210, pp. 153-168.

ISRM (International Society for Rock Mechanics), 1978. "Suggested Methods for Determining Tensile Strength of Rock Materials," Int. J of Rock Mech., Min. Sci., and Geomech. Abstr., Vol. 15, pp. 99-103.

ISRM (International Society for Rock Mechanics), 1979a. "Suggested Methods for Determining the Uniaxial Compressive Strength and Deformability of Rock Materials," Int. J of Rock Mech., Min. Sci., and Geomech Abstr., Vol. 16, pp. 135-140.

ISRM (International Society for Rock Mechanics), 1979b. "Suggested Methods for Determining Water Content, Porosity, Density, Absorption and Related Properties and Swelling and Slake-Durability Index Properties," Int. J of Rock Mech., Min. Sci, and Geomech Abstr., Vol. 16, pp. 141-156.

Iwata, T., K. Irikura, 1984. "Estimation of Irregular Underground Structure From Seismic Ground Motions”; Bull. Disas. Prev. Res. Inst., Kyoto University; Vol. 34, pp. 1-17.

Jaeger, J. G., and N. G. W. Cook, 1979. Fundamentals of Rock Mechanics, Chapman and Hall, London, pp. 60, 390-391, 405. 
Jakeman, N., S. G. Oldfield, Z. A. Gralewski, 1985. The Influence of Geological Loading on the Structural Integrity of an Underground Nuclear Waste Repository; Electrowatt Engineering Services (UK) Limited and U.K. Department of Environment; PECD/7/9/192-210/83.

Johnstone, J. K., G. R. Hadley, and D. R. Waymire, 1985. In Situ Tuff Water Migration/Heater Experiment: Final Report, SAND81-1918, Sandia National Laboratories, Albuquerque, NM.

Joyner, W. B., and D. M. Boore, 1982. Prediction of Earthquake Response Spectra, USGS-OFR82-977, Open-File Report, U.S. Geological Survey, Denver, CO., 14 p.

Kanai, K., K. Osada, and S. Yoshizawa, 1953. "Observational Study of Earthquake Motion in the Depth of the Ground, IV. (Relation between the Amplitude at Ground Surface and the Period)," Bulletin of the Earthquake Research Institute, Vol. 31, pp. 227-234.

Kanai, K., and T. Tanaka, 1951. "Observations of the Earthquake-motion at the Different Depths of the Earth," Bulletin of the Earthquake Research Institute, Vol. 29, pp. 107-113.

Kanai, K., T. Tanaka, S. Yoshizawa, T. Morishita, K. Osada, and T. Suzuki, 1966. "Comparative Studies of Earthquake Motions on the Ground and Underground, II.," Bulletin of the Earthquake Research Institute, Vol. 44, pp. 609-643.

Kanehiro, B. Y., and T. N. Narasimhan, 1980. "Aquifer Response to Earth Tides," Well Testing in Low Permeability Environments, Third Invitational Well-Testing Symposium, Berkeley, Calif., March 26-28, 1980, pp. 120-129.

Kelsall, P. C., J. B. Case, and C. R. Chabannes, 1982. A Preliminary Evaluation of the Rock Mass Disturbance Resulting From Shaft, Tunnel, or Borehole Excavation, ONWI-411, Office of Nuclear Waste Isolation, Columbus, $\mathrm{OH}$.

Kerrisk, J. F., 1987. Groundwater Chemistry at Yucca Mountain, Nevada, and Vicinity, LA-10929MS, Los Alamos National Laboratory, Los Alamos, NM.

King, J. L., and B. E. Tucker, 1984. "Observed Variation of Earthquake Motion Across a SedimentFilled Valley," Bulletin of the Seismological Society of America, Vol. 74, No. 1, pp. 137-151.

King, K. W., 1982. A Study of Surface and Subsurface Ground Motions at Calico Hills, Nevada Test Site, USGS-OFR-82-1044, Open-File Report, U.S. Geological Survey, Denver, CO.

King, K. W., K. C. Bayer, and S. R. Brockman, 1971. Earthquakes on and Around the Nevada Test Site, 1950-1971, CGS-746-12, U.S. Department of Commerce, Earth Sciences Laboratories, 32 p.

Klavetter, E. A., and R. R. Peters, 1986. Fluid Flow in a Fractured Rock Mass, SAND85-0855, Sandia National Laboratories, Albuquerque, NM.

Klinkenberg, L. J., 1941. "The Permeability of Porous Media to Liquids and Gases," Drilling and Production Practice, American Petroleum Institute, pp. 200-213. 
Knauss, K. G., V. M. Oversby, and T. J. Wolery, 1983. Post Emplacement Environment of Waste Packages, UCRL-89475, preprint, Lawrence Livermore National Laboratory, Livermore, CA.

Kuesel, T. R., 1981. Seismic Design Considerations for Underground Nuclear Facilities; Workshop on Seismic Performance of Underground Facilities, Augusta, GA.

Kuszyk, J. A., and C. R. Bradt, 1973. "Influence of Grain Size on Effects of Thermal Expansion Anisotropy in MgTi205," Joumal of the American Ceramic Society, Vol. 56, No. 8, pp. 420-423.

Lahoud, R. G., D. H. Lobmeyer, and M. S. Whitfield, Jr., 1984. Geohydrology of Volcanic Tuff Penetrated by Test Well UE-25b 1, Yucca Mountain, Nye County, Nevada, USGS-WRI-844253, Water-Resources Investigations Report, U.S. Geological Survey, Denver, CO.

Lappin, A. R., and F. B. Nimick, 1985. Bulk and Thermal Properties of the Functional Tuffaceous Beds in Holes USW G-1, UE-25a 1, and USW G-2, Yucca Mountain, Nevada, SAND821434, Sandia National Laboratories, Albuquerque, NM.

Lappin, A. R., and F. B. Nimick, 1985. Thermal Properties of the Grouse Canyon Member of the Belted Range Tuff and of Tunnel Bed 5, G-Tunnel, Nevada Test Site, SAND82-2203, Sandia National Laboratories, Albuquerque, NM.

Lappin, A. R., R. G. VanBuskirk, D. O. Enniss, S. W. Butters, F. M. Prater, C. B. Muller, and J. L. Bergosh, 1982. Thermal Conductivity, Bulk Properties, and Thermal Stratigraphy of Silicic Tuffs from the Upper Portion of Hole USW-G1, Yucca Mountain, Nye County, Nevada, SAND81-1873, Sandia National Laboratories, Albuquerque, NM.

Lee, C. F., 1987. Performance of Underground Coal Mines During the 1976 Tangshan Earthquake, Geotechnical and Hydraulic Engineering Department, Ontario Hydro, Toronto, Ontario M5G1X6, Canada.

Lee, W. H. K., R. E. Bennett, and K. L. Meagher, 1972. A Method of Estimating Magnitude of Local Earthquakes from Signal Duration, Open-File Report, U.S. Geological Survey, Menlo Park, CA.

Leeman, E. R., 1964. "The Measurement of Stress in Rock. Part II: Borehole Rock Stress Measuring Instruments," Joumal of the South African Institute of Mining and Metallurgy, pp. 82-114.

Long, J. W., 1986. Component Ground Motion at the Nevada Test Site from Pahute Mesa Underground Nuclear Explosions, SAND86-0439.

Long, J. W., K. A. Sabisch, S. D. Stearns, and L. J. Vortman, 1982. Prediction of Downhole Waveforms, SAND82-2478.

Luo, Wen-bao, 1985. "Seismic Problems of Cave Dwellings on China's Loess Plateau," Intemational Symposium on Earth Architecture, Beijing, China. 
Marice, I. W., H. R. Pratt, K. K. Wahi, 1982. Seismic Effects on Underground Openings, Technology of High Level Nuclear Waste Disposal.

Marine, I. W., 1982. Studies of the Subsurface Effects of Earthquakes, Workshop on Subsurface Seismic Studies.

Marine, I. W., H. R. Pratt, K. K. Wahi, 1982. "Seismic Effects on Underground Openings," Department of Energy (DOE); The Technology of High-Level Nuclear Waste Disposal: Advances in the Science and Engineering of the Management of High-Level Nuclear Wastes, Technical Information Center, Office of Scientific and Technical Information, United States DOE, Vol. 2, pp. 179-206.

Mark, R. K., and M. G. Bonilla, 1977. Regression Analysis of Earthquake Magnitude and Surface Fault Length Using the 1970 Data of Bonilla and Buchanan, USGS-OFR-77-614, Open-File Report, U.S. Geological Survey, Menlo Park, CA.

McClure, C. R., 1981. "Damage to Underground Structures During Earthquakes", Proceedings on Seismic Performance of Underground Structures, Augusta, GA.

McGovem, T. F., 1983. An Evaluation of Seismic Reflection Studies in the Yucca Mountain Area, Nevada Test Site, with an introduction by L. W. Pankratz and H. D. Ackermann, USGSOFR-83-912, Open-File Report, U.S. Geological Survey, Denver, CO.

McWilliams, J. R., 1966. "The Role of Microstructure in the Physical Properties of Rocks," Testing Techniques for Rock Mechanics, ASTM STP 402, American Society for Testing and Materials, pp. 175-189.

Merritt, J. L., J. E. Monsees, A. J. Hendron, 1985. "Seismic Design of Underground Structures," RETC Proceedings; Vol. 1.

Miller, C. H., 1976. A Method for Stress Determination in N, E, and T Tunnels, Nevada Test Site, by Hydraulic Fracturing, with a Comparison of Overcoring Methods, USGS-474-222, U.S. Geological Survey, Denver, CO.

Mondy, L. A., B. L. Baker, and R. R. Eaton, 1985. Vadose Water Flow Around a Backfilled Drift Located in Tuff, SAND84-0369, Sandia National Laboratories, Albuquerque, NM.

Mondy, L. A., R. K. Wilson, and N. E. Bixler, 1983. Comparison of Waste Emplacement Configurations for a Nuclear Waste Repository in Tuff, IV, Thermo-Hydrological Analysis, SAND83-0757, Sandia National Laboratories, Albuquerque, NM.

Monfort, M. E., and J. R. Evans, 1982. Three-Dimensional Modeling of the Nevada Test Site and Vicinity from Teleseismic P-Wave Residuals, USGS-OFR-82-409, Open-File Report, U.S. Geological Survey, Menlo Park, CA.

Montazer, P., and P. E. Harrold, 1985. "Theoretical Calculation of Hydraulic Properties of Unsaturated Fractures from Roughness Profiles," Transactions of the American Geophysical Union, Abstract H12C-05, Vol. 66, No. 46, p. 883. 
Montazer, P., E. P. Weeks, F. Thamir, S. N. Yard, and P. B. Hofrichter, 1986. "Monitoring the Vadose Zone in Fractured Tuff, Yucca Mountain, Nevada," Proceedings of the NWWA Conference on Characterization and Monitoring of the Vadose (Unsaturated) Zone, November 19-21, 1985, Denver, CO., National Water Well Association, Worthington, $\mathrm{OH}$, pp. 439-469.

Montazer, P., and W. E. Wilson, 1984. Conceptual Hydrologic Model of Flow in the Unsaturated Zone, Yucca Mountain, Nevada, USGS-WRI-84-4345, Water-Resources Investigations Report, U.S. Geological Survey, Lakewood, CO.

Mooney, W. D., D. B. Snyder, and L. R. Hoffman, 1982. "Seismic Refraction and Gravity Modeling of Yucca Mountain, Nevada Test Site, Southem Nevada [abs.]," EOS, Transactions, American Geophysical Union, Vol. 63, No. 45, p. 1100.

Morrow, C., and J. Byerlee, 1984. "Frictional Sliding and Fracture Behavior of Some Nevada Test Site Tuffs," Rock Mechanics in Productivity and Protection, Proceedings of the 25th Symposium on Rock Mechanics, Evanston, Illinois, June 25-27, 1984, Chapter 49, pp. 467 474.

Moss, M., J. A. Koski, and G. M. Haseman, 1982. Measurement of Thermal Conductivity by the Comparative Method, SAND82-0109, Sandia National Laboratories, Albuquerque, NM.

Moss, M., J. A. Koski, G. M. Haseman, and T. V. Tormey, 1982. The Effects of Composition, Porosity, Bedding Plane Orientation, Water Content, and a Joint on the Thermal Conductivity of Tuff, SAND82-1164, Sandia National Laboratories, Albuquerque, NM.

Nelson, C. E., and D. L. Giles, 1985. "Hydrothermal Eruption Mechanisms and Hot Springs Gold Deposits," Economic Geology, Vol. 80, pp. 1633-1639.

Nichols, W. D., 1986. Geohydrology of the Unsaturated Zone at the Burial Site for Low-Level Radioactive Waste Near Beatty, Nye County, Nevada, USGS-OFR-85-198, Open-File Report, U.S. Geological Survey, Denver, CO.

Nimick, F. B., R. H. Price, R. G. Van Buskirk, and J. R. Goodell, 1985. Uniaxial and Triaxial Compression Test Series on Topopah Spring Tuff from USW G-4, Yucca Mountain, Nevada, SAND84-1101, Sandia National Laboratories, Albuquerque, NM.

Nimick, F. B., and B. M. Schwartz, 1987. Bulk, Thermal, and Mechanical Properties of the Topopah Spring Member of the Paintbrush Tuff, Yucca Mountain, Nevada, SAND85-0762, Sandia National Laboratories, Albuquerque, NM.

Nimick, F. B., and R. L. Williams, 1984. A Three-Dimensional Geologic Model of Yucca Mountain, Southern Nevada, SAND83-2593, Sandia National Laboratories, Albuquerque, NM.

Ogard, A. E., and J.F. Kerrisk, 1984. Groundwater Chemistry Along Flow Paths Between a Proposed Repository Site and the Accessible Environment, LA-10188-MS, Los Alamos National Laboratory, Los Alamos, NM. 
Ohtsuki, A., and K. Harumi, 1983. "Effect of Topography and Subsurface Inhomogeneities of Seismic SV Waves," Earthquake Engineering and Structural Dynamics, Vol. 11, pp. 441462.

Okamoto, S., 1984. Introduction of Earthquake Engineering, Second Edition, University of Tokyo Press, pp. 11-14.

Olsson, W. A., 1982. Effects of Elevated Temperature and Pore Pressure on the Mechanical Behavior of Bullfrog Tuff, SAND81-1664, Sandia National Laboratories, Albuquerque, NM.

Olsson, W. A., 1987. Rock Joint Compliance Studies, SAND86-0177, Sandia National Laboratories, Albuquerque, NM.

Olsson, W. A., and A. K. Jones, 1980. Rock Mechanics Properties of Volcanic Tuffs from the Nevada Test Site, SAND80-1453, Sandia National Laboratories, Albuquerque, NM.

O'Rourke, J. J., G. Castro, N. Centola, 1980. "Effects of Seismic Wave Propagation Upon Buried Pipelines," Earthquake Engineering and Structural Dynamics; Vol. 8, pp. 455-467.

Ortiz, T. S., R. L. Williams, F. B. Nimick, B. C. Whittet, and D. L. South, 1985. A Three-Dimensional Model of Reference Thermal/Mechanical and Hydrological Stratigraphy at Yucca Mountain, Southern Nevada, SAND84-1076, Sandia National Laboratories, Albuquerque, NM.

Oversby, V. M., and K. G. Knauss, 1983. Reaction of Bullfrog Tuff with J-13 Well Water at 90 deg. C and 150 deg. C, UCRL-53442, Lawrence Livermore National Laboratory, Livermore, CA.

Oversby, V. M., 1984. Reaction of the Topopah Spring Tuff with J-13 Well Water at 90 deg. C and 150 deg. C, UCRL-53552, Lawrence Livermore National Laboratory, Livermore, CA.

Owen, G. N., and R. E. Scholl, 1981. Earthquake Engineering of Large Underground Structures, FHWA/RD-80/195, U.S. Department of Transportation, Washington, D.C., pp. 171-174.

Owen, G. N., P. I. Yanev, and R. E. Scholl, 1980. Considerations for Developing Seismic Design Criteria for Nuclear Waste Storage Repositories, JAB-00099-128, URS/John A. Blume \& Associates, Engineers, San Francisco, CA.

Owen, N. G., 1981. Developing Seismic Design Criteria; Workshop on Seismic Performance of Underground Facilities, Augusta GA; (possible Source Reference, but not actually listed) February 11-13 1981, Augusta, GA. February 11-13.

Pacifica Technology, 1986. Block Motion Site Characterization, Contract No. DNA 00-84-C-0426, Defense Nuclear Agency, Washington, DC.

Perkins, B., B. Travis, and G. DePoorter, 1985. Validation of the TRACR3D Code for Soil Water Flow Under Saturated/Unsaturated Conditions in Three Experiments, LA-10263-MS, LoS Alamos National Laboratory, Los Alamos, NM. 
Peters, R. R., J. H. Gauthier, and A. L. Dudley, 1986. The Effect of Percolation Rate on Water-Travel Time in Deep, Partially Saturated Zones, SAND85-0854, Sandia National Laboratories, Albuquerque, NM.

Peters, R. R., E. A. Klavetter, I. J. Hall, S. C. Blair, P. R. Heller, and G. W. Gee, 1984. Fracture and Matrix Hydrologic Characteristics of Tuffaceous Materials from Yucca Mountain, Nye County, Nevada, SAND84-1471, Sandia National Laboratories, Albuquerque, NM.

Phillips, J. S., Verification of Ground Motion Data Processing Codes, SAND86-2201.

Phillips, J. S., Evaluation of Equations for the Prediction of Peak Ground Motions at Yucca Mountain from Underground Nuclear Explosions in Pahute Mesa. SAND87-1811.

Plesha, M. E., 1986. "Mixed Time Integration for the Transient Analysis of Jointed Media," Int. J. Num. Anal. Meth. Geomech., 10, 91-110.

Pratt, H. R., G. Zandt, and M. Bouchon, 1979. Earthquake Related Displacement Field Near Underground Facilities; U.S. Department of Energy; DP-1533.

Price, R. H., A. K. Jones, and K. G. Nimick, 1982. Uniaxial Compression Test Series on Bullfrog Tuff, SAND82-0481, Sandia National Laboratories, Albuquerque, NM.

Price, R. H., 1986. Effects of Sample Size on the Mechanical Behavior of Topopah Spring Tuff, SAND85-0709, Sandia National Laboratories, Albuquerque, NM.

Price, R. H., 1983. Analysis of Rock Mechanics Properties of Volcanic Tuff Units from Yucca Mountain, Nevada Test Site, SAND82-1315, Sandia National Laboratories, Albuquerque, NM.

Price, R. H., and S. J. Bauer, 1985. "Analysis of the Elastic and Strength Properties of Yucca Mountain Tuff, Nevada," Proceedings of the 26th U.S. Symposium on Rock Mechanics, pp. 89-96.

Price, R. H., J. R. Connolly, and K. Keil, 1987. Petrologic and Mechanical Properties of Outcrop Samples of the Welded, Devitrified Topopah Spring Member of the Paintbrush Tuff, SAND86-1131, Sandia National Laboratories, Albuquerque, NM.

Price, R. H., F. B. Nimick, J. R. Connolly, K. Keil, B. M. Schwartz, and S. J. Spence, 1985. Preliminary Characterization of the Petrologic, Bulk, and Mechanical Properties of a Lithophysal Zone Within the Topopah Spring Member of the Paintrbrush Tuff, SAND840860 , Sandia National Laboratories, Albuquerque, NM.

Price, R. H., K. G. Nimick, and J. A. Zirzow, 1982. Uniaxial and Triaxial Compression Test Series on Topopah Spring Tuff, SAND82-1723, Sandia National Laboratories, Albuquerque, NM.

Price, R. H., and K. G. Nimick, 1982. Uniaxial Compression Test Series on Tram Tuff, SAND821055, Sandia National Laboratories, Albuquerque, NM. 
Price, R. H., and A. K. Jones, 1982. "Uniaxial and Triaxial Compression Test Series on Calico Hills Tuff," SAND82-1314, Sandia National Laboratories, Albuquerque, N. Mex. Proceedings Conference on Instrumentation For Nuclear Weapons Effects, Vol. 1, DNA-TR-82-17-V1.

Pruess, K., Y. W. Tsang, and J. S. Y. Wang, 1984. Numerical Studies of Fluid and Heat Flow Near High-Level Nuclear Waste Packages Emplaced in Partially Saturated Fractured Tuff, LBL18552, Lawrence Berkeley Laboratory, Berkeley, CA.

Reda, D. C., 1985. Liquid Permeability Measurements on Densely Welded Tuff Over the Temperature Range 25 degrees to 90 degrees C, SAND85-2482, Sandia National Laboratories, Albuquerque, NM.

Reda, D. C., 1985. "Slip-Flow Experiments in Welded Tuff: The Knudsen Diffusion Problem," International Symposium on Coupled Processes Affecting the Performance of a Nuclear Waste Repository, September 18-20, 1985, Lawrence Berkeley Laboratory, Berkeley, CA., pp. 191-196.

Reiter L., and R. E. Jackson, 1983. Seismic Hazard Review for the Systematic Evaluation ProgramA Use of Probability in Decision Making, NUREG-0967, U.S. Nuclear Regulatory Commission, Washington, DC.

Richardson, A. M., W. Hustrulid, S. Brown, and W. Ubbes, 1985. "In Situ Load-Deformation Characterization of the CSM/OCRD Jointed Test Block," Proceedings of the 26th U.S. Symposium on Rock Mechanics, Rapid City, SD, June 26-28, 1985, pp. 777-784.

Robbins Company, 1984. Small Diameter Horizontal Hole Drilling-State of Technology, SAND847103, Sandia National Laboratories, Albuquerque, NM.

Robison, J. H., 1984. Ground-Water Level Data and Preliminary Potentiometric-Surface Maps, Yucca Mountain and Vicinity, Nye County, Nevada, USGS-WRI-84-4197, Water-Resources Investigations Report, U.S. Geological Survey, Lakewood, CO.

Rocco, J. R., et. al., 1986. A Comparison in 1-D of Fully Contained and Surface Burst Estimates for Five Generic Materials, Contract No. DNA 001-85-C-0059, Defense Nuclear Agency, Washington, DC.

Rodionov, V. N., I. A. Sizov, and V. M. Tsvetkov, - (1), Romashov, A. N. - (2), 1979. (1) An Investigation of Cavern Development in the Camouflet Explosion; (2) On the Nature of Certain Ground Waves Excited by an Underground Explosion; Foreign Technology Division, Department of Commerce; (1) FTD-HC-23-87-70, (2) FTD-HC-23-87-70.

Roeloffs, E., and J. W. Rudnicki, 1984/1985. "Coupled Deformation-Diffusion Effects on WaterLevel Changes Due to Progagating Creep Events," PAGEOPH, Vol. 122.

Rocha, M., 1970. "New Techniques in Deformability Testing of In Situ Rock Masses," Determination of the In-Situ Modulus of Deformation of Rock, ASTM, ASTM STP 477, American Society for Testing and Materials, Philadelphia, PA, Pp. 39-57. 
Rogers, A. M., S. C. Harmsen, W. J. Carr, and W. Spence, 1983. Southern Great Basin Seismological Data Report for 1981 and Preliminary Data Analysis, USGS-OFR-83-669, Open-File Report, U.S. Geological Survey, Denver, CO.

Rogers, A. M., S. C. Harmsen, and W. J. Carr, 1981. Southern Great Basin Seismological Data Report for 1980 and Preliminary Data Analysis, USGS-OFR-81-1086, Open-File Report, U.S. GeoIogical Survey, Denver, CO.

Rogers, A. M., S. C. Harmsen, and M. Meremonte, 1987. Evaluation of the Seismicity of the Southem Great Basin and Its Relationship to the Tectonic Framework of the Region, USGS-OFR-87, Open-File Report, U.S. Geological Survey, Denver, CO.

Rogers, A. M., G. M. Wuollet, and P. A. Covington, 1977b. Seismicity of the Pahute Mesa Area, Nevada Test Site (8 October 1975 to 30 June 1976), USGS-474-184, U.S. Geological Survey, Denver, CO., 63 p.

Rogers, A.M., D. M. Perkins, and F. A. McKeown, 1977a. "A Preliminary Assessment of the Seismic Hazard of the Nevada Test Site Region," Bulletin of the Seismological Society of America, Vol. 67, No. 6, pp. 1587-1606.

Rogers, A. M., D. M. Perkins, and F. A. McKeown, 1976. A Catalog of Seismicity within $400 \mathrm{~km}$ of the Nevada Test Site, USGS-OFR-76-832, Open-File Report, U.S. Geological Survey, Denver, CO.

Rogers, A. M., and W. H. K. Lee, 1976. "Seismic Study of Earthquakes in the Lake Mead, Nevada-Arizona Region," Bulletin of the Seismological Society of America, Vol. 66, No. 5 , pp. 1657-1681.

Romney, C., 1957. "Seismic Waves from the Dixie Valley-Fairview Peak Earthquakes," Bulletin of the Seismological Society of America Bulletin, Vol. 47, pp. 301-319.

Roseboom, E. H., Jr., 1983. Disposal of High-Level Nuclear Waste Above the Water Table in Arid Regions, U.S. Geological Survey Circular 903, Alexandria, VA., p. 21.

Ross, B., 1984. “A Conceptual Model of Deep Unsaturated Zones With Negligible Recharge," Water Resources Research, Vol. 20, No. 11, pp. 1627-1629.

Rulon, J., G. S. Bodvarsson, and P. Montazer, 1986. Preliminary Numerical Simulations of Groundwater Flow in the Unsaturated Zone, Yucca Mountain, Nevada, LBL-20553, Lawrence Berkeley Laboratory, Berkeley, CA.

Rush, F. E., W. Thordarson, and L. Bruckheimer, 1983. Geohydrologic and Drill-Hole Data for Test Well USW H-1, Adjacent to Nevada Test Site, Nye County, Nevada, USGS-OFR-83-141, Open-File Report, U.S. Geological Survey, Denver, CO.

Rush, F. E., W. Thordarson, and D. G. Pyles, 1984. Geohydrology of Test Well USW H-1, Yucca Mountain, Nye County, Nevada, USGS-WRI-84-4032, Water-Resources Investigations Report, U.S. Geological Survey, Denver, CO. 
Saad, K. F., 1967. "Determination of the Vertical and Horizontal Permeabilities of Fractured Water-Bearing Formations," Bulletin of the International Association of Scientific Hydrology, Vol. 1, pp. 22-26.

SAIC (Science Application International Corporation), 1985. Tectonic Stability and Expected Ground Motion at Yucca Mountain, Report of a Workshop at SAIC - La Jolla August 7-8, 1984 and January 25-26, 1985, DOE/NV/10270-2 (Rev. 1).

Sass, J. H., and A. H. Lachenbruch, 1982. Preliminary Interpretation of Thermal Data from the Nevada Test Site, USGS-OFR-82-973, Open-File Report, U.S. Geological Survey, Denver, CO.

Sass, J. H., A. H. Lachenbruch, and C. W. Mase, 1980. Analysis of Thermal Data From Drill Holes UE24a-3 and UE25a-1, Calico Hills and Yucca Mountain, Nevada Test Site, USGS-OFR80-826, Open-File Report, U.S. Geological Survey.

Sass, J., A. Lachenbruch, F. Grubb, and T. Moses, 1983. Status of Thermal Observations at Yucca Mountain, Nevada, USGS Letter Report, 10 pp.

Saucier, R. T., 1977. Effects of the New Madrid Earthquake Series on the Mississippi Alluvial Valley; Chief of Engineers, U.S. Army; WES-MP-S-77-5.

Savage, J. C., M. Liskowski, and W. H. Prescott, 1985. "Strain Accumulation in the Rocky Mountain States," Journal of Geophysical Research, Vol. 90, No. B12, pp. 10,310-10,320.

Schnabel, P. B., and H. B. Seed, 1973. "Accelerations in Rock for Earthquakes in the Western United States," Bulletin of the Seismological Society of America, Vol. 63, No. 2, pp. 501-516.

Schoff, S. L., and J. E. Moore (comps.), 1964. Chemistry and Movement of Ground Water, Nevada Test Site, USGS-TEI-838, Trace-Elements Investigations Report, U.S. Geological Survey, Denver, CO.

Scholz, C., P. Molnar, and T. Johnson, 1972. "Detailed Studies of Frictional Sliding of Granite and Implications for the Earthquake Mechanism," Joumal of Geophysical Research, Vol. 77, No. 32, pp. 6392-6406.

Scholz, C. H., and J. T. Engelder, 1976. "The Role of Asperity Indentation and Ploughing in Rock Friction - I. Asperity Creep and Stick Slip," Int J of Rock Mech., Min. Sci., and Geomech. Abstr., Vol. 13, pp. 149-154.

Scott, R. B., R. W. Spengler, S. Diehl, A. R. Lappin, and M. P. Chomak, 1983. "Geologic Character of Tuffs in the Unsaturated Zone at Yucca Mountain, Southern Nevada," Role of the Unsaturated Zone in Radioactive and Hazardous Waste Disposal, J. W. Mercer, P. S. C. Rao, and I. W. Marine (eds.), Ann Arbor Science Publishers, Ann Arbor, MI., pp. 289-335.

Scott, R. B., and J. W. Whitney, 1987. "The Upper Crustal Detachment System at Yucca Mountain, SW Nevada," Geological Society of America Abstracts with Programs, pp. 332-333. 
Seed, H. B., P. Martin, J. Lysmer, 1975. The Generation and Dissipation of Pore Water Pressures During Soil Disruption; National Science Foundation; EERC 75-26.

Shtengelov, Y. S., 1983. The Connection Between Seismic Activity and Surface Water and Groundwater Regimes; Izvestiya, Earth Physics, Vol. 19, No. 3.

Silling, S. A., 1982. Final Technical Position on Documentation of Computer Codes for High-Level Waste Management, NUREG-0856, U.S. Nuclear Regulatory Commission, Washington, $\overline{\mathrm{DC}}$.

Simmons, K. B., 1968. Dynamic Rock Instrumentation Survey, AFWL-TR-68-3, (Air Force Weapons Laboratory).

Simons, J. W., J. D. Colton, and A. L. Florence, 1986. Response of Intersection and Effect of Strain Path on Straight Tunnel Closure, Laboratory Testing of Scale-Model Tunnels, Contract No. DNA 001-84-C-0434, Defense Nuclear Agency, Washington, DC.

Sinnock, J., and Y. T. Lin, 1987. "Preliminary Bounds on the Expected Postclosure Performance of the Yucca Mountain Repository Site, Southern Nevada," Journal of Geophysical Research, Vol. 92, No. B8, pp. 7820-7842.

Sinnock, S. (ed.), Y. T. Lin, and M. S. Tiemey, 1986. Preliminary Estimates of Groundwater Travel Time and Radionuclide Transport at the Yucca Mountain Repository Site, SAND85-2701, Sandia National Laboratories, Albuquerque, NM.

Sites, K. R., E. D. Nudd, E. J. Dockter, 1986. Instrumentation Support for the CARES Program, DNATR-86-228.

Slemmons, D. B., A. E. Jones, and J. I. Gimlett, 1965. "Catalog of Nevada Earthquakes, 1852-1960," Bulletin of the Seismological Society of America, Vol. 55, No. 2, pp. 519-566.

Slemmons, D. B., 1977. State-of-the-Art for Assessing Earthquake Hazards in the United States, Report 6, Faults and Earthquake Magnitude, Miscella neous Paper S-73-1, Mackay School of Mines, University of Nevada, Reno, pp. 87-99.

Smith, C., W. C. Vollendorf, and W. E. Warren, 1981. In-Situ Stress from Hydraulic Fracture Measurements in G-Tunnel, Nevada Test Site, SAND80-1138, Sandia National Laboratories, Albuquerque, NM.

SNL (Sandia National Laboratories), 1985. System 2000 Tuff Data Base, Version 11,002, Sandia National Laboratories, Department 6310, Albuquerque, NM.

Somerton, W. H., 1982. "Porous Rock-Fluid Systems at Elevated Temperatures and Pressures," Recent Trends in Hydrogeology, T. N. Narasimhan (ed.), Geological Society of American Special Paper 189, pp. 183-197. 
Spengler, R. W., and M. P. Chornack, 1984. Stratigraphic and Structural Characteristics of Volcanic Rocks in Core Hole USW G-4, Yucca Mountain, Nye County, Nevada, with a section on geophysical logs by D. C. Muller and J. E. Kibler, USGS-OFR-84-789, Open-File Report, U.S. Geological Survey, Denver, CO.

Spottiswoode, S. M., 1988. Volume Excess Shear Stress and Cumulative Seismic Moments, Second International Symposium of Rockbursts and Seismicity in Mines, Minneapolis, MN.

Springer, J. E., R. K. Thorpe, and H. L. McKague, 1984. Borehole Elongation and Its Relation to Tectonic Stress at the Nevada Test Site, UCRL-53528, Lawrence Livermore National Laboratory, Livermore, CA.

Spudich, P., 1985. "Calculation of Ground Motion Time Histories Using Green's Function Summation," Strong Ground Motion Simulations and Earthquake Engineering Applications, R. E. Scholl, and J. L. King (eds.), Publication No. 85-02, Earthquake Engineering Research Institute, pp. 19-1 to 19-7.

Squires, R. R., and R. L. Young, 1984. Flood Potential of Fortymile Wash. and Its Principal Southwestern Tributaries, Nevada Test Site, Southem Nevada, USGS-WRI-83-4001, WaterResources Investigations Report, U.S. Geological Survey, Carson City, NV.

St. John, C. M., and T. F. Zahrah, 1985. "Applicable Analytical Tools for a Seismic Design on Underground Excavations," RETC Proceedings, Vol. 1, pp. 84-103.

St. John, C. M., and S. J. Mitchell, 1987. Investigation of Excavation Stability in a Finite Repository, SAND86-7011, Sandia National Laboratories, Albuquerque, NM.

St. John, C. M., 1986. LINED: Static Analysis of a Tunnel with Liner or Damaged Annulus, R-8227-5534, J. F. T. Agapito and Associates, Inc., Los Angeles, CA.

St. John, C. M., 1988. "Computational Rock Mechanics: Development and Application," in Key Questions in Rock Mechanics, 759-766. Rotterdam: A. A. Balkema.

Stephens, D. D., and S. P. Neuman, 1982. "Vadose Zone Permeability Tests: Summary," Journal of the Hydraulics Division, Proceedings of the American Society of Civil Engineers, Vol. 108, No. HY5, pp. 623-639.

Stevens, J. L., N. Rimer, and S. M. Day, 1986. Constraints on Modeling of Underground Explosions in Granite; Air Force Geophysics Laboratory; AFGL-TR-86-0264.

Stock, J. M., J. H. Healy, S. H. Hickman, and M. D. Zoback, 1985. "Hydraulic Fracturing Stress Measurements at Yucca Mountain, Nevada, and Relationship to the Regional Stress Field," Journal of Geophysical Research, Vol. 90, No. B10, pp. 8691-8706.

Stock, J. M., J. H. Healy, and S. H. Hickman, 1984. Report on Televiewer Log and Stress Measurements in Core Hole USW G-2, Nevada Test Site, October-November, 1982, USGSOFR-84-172, U.S. Geological Survey, Menlo Park, CA. 
Sultanov, K. S., and V. Y. Kim, 1986. Experimental Investigation of the Law Governing Logitudinal Interaction Between Elongated Underground Structures and the Soil; M. T. Urazbaev Institute of the Mechanics and Earthquake Resistance of Structures, Tashkent.

Swan, G., 1985. "Methods of Roughness Analysis for Predicting Rock Joint Behavior," Proceedings of the International Symposium on Fundamentals of Rock Joints (Bjorkliden, 15-20 September 1985), pp. 153-161. Lulea, Sweden: Centek Publishers.

Swan, G., 1981. "Tribology and Characterization of Joints," Rock Mechanics From Research to Application - Proceedings of the 22nd Symposium on Rock Mechanics (MIT, 1981), pp. 402-407. Cambridge, MA: MIT.

Swolfs, H. S., and W. Z. Savage, 1985. "Topography, Stresses, and Stability at Yucca Mountain, Nevada," Proceedings of the 26th Symposium on Rock Mechanics, Rapid City, SD, pp. 1121-1129.

Takemiya, J., K. Yokoyama, and H. Oishi, 1984. Seismic Analysis of an Underground Structure; International Symposium on Dynamic Soil-Structure Interaction, Minneapolis, MN.

Tendall, D. M., 1971. Epicenter Location of NTS Earthquake on August 5, 1971, Technical Memorandum SC-TM-710593, Sandia National Laboratories, Albuquerque, NM, 18 p.

Terra Tek, Inc., 1986. Scaled Model Testing of Tunnel Intersections, Contract No. DNA 001-84-C0435, Defense Nuclear Agency, Washington, DC.

Teufel, L. W., 1981. Frictional Properties of Jointed Welded Tuff, SAND81-0212, Sandia National Laboratories, Albuquerque, NM.

Thamir, F., and C. M. McBride, 1985. "Measurements of Matric and Water Potentials in Unsaturated Tuff at Yucca Mountain, Nevada," Proceedings of the NWWA Conference on Characterization and Monitoring of the Vadose (Unsaturated) Zone, National Water Well Association, Dublin, Ohio, pp. 470-487.

Thordarson, W., R. A. Young, and I. J. Winograd, 1967. Records of Wells and Test Holes in the Nevada Test Site and Vicinity (through December, 1966), USGS-TEI-872, Trace-Elements Investigations Report, U.S. Geological Survey.

Thordarson, W., F. E. Rush, R. W. Spengler, and S. J. Waddell, 1984. Geohydrologic and Drill-Hole Data for Test Well USW H-3, Yucca Mountain, Nye County, Nevada, USGS-OFR-84-149, Open-File Report, U.S. Geological Survey, Denver, CO, 28 p.

Thordarson, W., F. E. Rush, and S. J. Waddell, 1985. Geohydrology of Test Well USW H-3, Yucca Mountain, Nye County, Nevada, USGS-WRI-84-4272, Water-Resources Investigations Report, U.S. Geological Survey, Lakewood, CO.

Thordarson, W., 1983. Geohydrologic Data and Test Results from Well J-13, Nevada Test Site, Nye County, Nevada, USGS-WRI-83-4171, Water-Resources Investigations Report, U.S. Geological Survey, Denver, $C O$. 
Tien, P-L, M. D. Siegel, C. D. Updegraff, K. K. Wahi, and R. V. Guzowski, 1985. Repository Site Data Report for Unsaturated Tuff, Yucca Mountain, Nevada, NUREG/CR-4110, U.S. Nuclear Regulatory Commission, Washington, DC.

Todd, D. K., 1980. Groundwater Hydrology, Second Edition, John Wiley and Sons, New York, pp. 362-368.

Toth, J. A., 1963. “A Theoretical Analysis of Ground-Water Flow in Small Drainage Basins," Journal of Geophysical Research, Vol. 68, No. 16, pp. 4795-4812.

Trent, B. C., 1981. "Empirical Investigations that Support Numerical Modeling of Earthquake Effects on Underground Tunnels," Proceedings from Workshop on Seismic Performance of Underground Facilities, Augusta, GA.

Tse, S. T., and J. R. Rice, 1986. "Crustal Earthquake Instability in Relation to the Depth Variation of Frictional Slip Properties", American Geophysical Union, pp. 9452-9471.

URS/John A. Blume Associates, 1986. Ground Motion Evaluations at Yucca Mountain, Nevada, with Applications to Repository Conceptual Design and Siting, SAND85-7104, Sandia National Laboratories, Albuquerque, NM.

URS/John A. Blume \& Associates, 1987. Technical Basis and Parametric Study of Ground Motion and Surface Rupture Hazard Evaluations at Yucca Mountain, Nevada, SAND86-7013, Sandia National Laboratories, NM.

USGS (U.S. Geological Survey) (comp.), 1984. A Summary of Geologic Studies through January 1, 1983, of a Potential High-Level Radioactive Waste Repository Site at Yucca Mountain, Southern Nye County, Nevada, USGS-OFR-84-792, Open-File Report, U.S. Geological Survey, Menlo Park, CA.

Van Buskirk, R., D. Enniss, and J. Schutz, 1985. "Measurement of Thermal Conductivity and Thermal Expansion at Elevated Temperatures and Pressures," Measurement of Rock Properties at Elevated Pressures and Temperatures, H. J. Pincus and E. R. Hoskins (eds.), ASTM STP 869, American Society for Testing and Materials, pp. 108-127.

Vassiliou, M. S., M. Abdel-Gawad, and B. R. Tittmann, 1986. Ultrasonic Physical Modeling of Seismic Wave Propagation from a Graben-like Structure: A Preliminary Report; Air Force Geophysics Laboratory, Hanscom AFB, MA; Scientific Report No. 1.

Vortman, L. J., and J. W. Long, 1982. Effect of Repository Depth on Ground Motion The Yucca Flats Data, SAND82-1647.

Vortman, L. J., and J. W. Long, 1982. Effects of Repository Depth on Ground Motion. The Pahute Mesa Data, SAND82-0174.

Vortman, L. J., 1981. A Field Comparison of the Kistler 303 and the Q-Flex 1100 and 1200 Accelerometers, SAND 81-0784, (Sandia). 
Vortman, L. J., Ed., 1983. Proceedings of the Conference on DOE Ground Motion and Seismic Programs On, Around and Beyond NTS, SAND83-2625.

Vortman, L. J., 1983. Stresses and Strains at Yucca Mountain from Underground Nuclear Explosions, SAND83-1553.

Vortman, L. J., 1985. Ground Motion at Yucca Mountain from Pahute Mesa Underground Nuclear Explosions, SAND85-1605.

Vortman, L. J., 1986. Ground Motion Produced at Yucca Mountain from Pahute Mesa Underground Nuclear Explosions, SAND85-1605, Sandia National Laboratories, Albuquerque, NM.

Vossilou, M. S., M. Abdel-Gowad, and B. R. Tittmann, 1986. Ultrasonic Physical Modeling of Seismic Wave Propagation from a Graben-like Structure: APreliminary Report, AFGL-TR86-0228, (Air Force Geophysical Laboratory).

Waddell, R. K., J. H. Robison, and R. K. Blankennagel, 1984. Hydrology of Yucca Mountain and Vicinity, Nevada-California-Investigative Results Through Mid-1983, USGS-WRI-844267, Water-Resources Investigations Report, U.S. Geological Survey, Denver, CO.

Waddell, R. K., 1984. "Solute-Transport Characteristics of Fractured Tuffs at Yucca Mountain, Nevada Test Site-A Preliminary Assessment," Geological Society of America Abstracts with Programs, Vol. 16, No. 6, p. 684.

Waddell, R. K., 1982. Two-Dimensional, Steady-State Model of Ground-Water Flow, Nevada Test Site and Vicinity, Nevada-Califomia, USGS-WRI-82-4085, Water-Resources Investigations Report, U.S. Geological Survey, Denver, CO.

Wallace, T. C., D. V. Helmberger, and G. R. Engen, 1985. "Evidence of Tectonic Release from Underground Nuclear Explosions in Long-Period S Waves," Bulletin of the Seismological Society of America, Vol. 75, No. 1, pp. 157-174.

Walter, A. W., and C. S. Weaver, 1980. "Seismicity of the Coso Range, California," Journal of Geophysical Research, Vol. 85, No. B5, pp. 2441-2458.

Wang, J. S. Y., and T. N. Narasimhan, 1986. Hydrologic Mechanisms Goveming Partially Saturated Fluid Flow in Fractured Welded Units and Porous Non-Welded Units at Yucca Mountain, SAND85-7114, Sandia National Laboratories, Albuquerque, NM.

Wang, J. S. Y., and T. N. Narasimhan, 1985. Hydrologic Mechanisms Governing Fluid Flow in Partially Saturated, Fractured, Porous Tuff at Yucca Mountain, SAND84-7202, Sandia National Laboratories, Albuquerque, NM.

Waters, A. C., and P. R. Carroll (eds.), 1981. Preliminary Stratigraphic and Petrologic Characterization of Core Samples from USW-G1, Yucca Mountain, Nevada, LA-8840-MS, Los Alamos National Laboratory, Los Alamos, NM. 
Watson, P., P. Sinclair, and R. Waggoner, 1976. "Quantitative Evaluation of a Method for Estimating Recharge to the Desert Basins of Nevada," Joumal of Hydrology, Vol. 31, Elsevier Scientific Publishing Company, Amsterdam, The Netherlands, pp. 335-357.

Weeks, E. P., and W. E. Wilson, 1984. Preliminary Evaluation of Hydrologic Properties of Cores of Unsaturated Tuff, Test Well USW H-1, Yucca Mountain, Nevada, USGS-WRI-84-4193, Water-Resources Investigations Report, U.S. Geological Survey, Denver, CO.

Wemicke, B., and B. C. Burchfiel, 1982. "Modes of Extensional Tectonics," Journal of Structural Geology, Vol. 4, No. 2, pp. 105-115.

Westine, P. W., and G. J. Friesenhahn, 1982. Ground Shock Loads from Buried Bomb and Ordnance Detonations, AFATL-TR-82-19, Contract No. F08635-80-C-0174, Air Force Ammament Laboratory, Armament Division, Eglin Air Force Base, FL.

White, I. B., R. E. Graham, and J. C. Frostenson, 1986. One-Twelfth-Scale Model of Horizontal Emplacement and Retrieval Equipment for Radioactive Waste Packages at the Proposed Repository in Tuff, SAND86-7135, Sandia National Laboratories, Albuquerque, NM.

White, A. F., H. C. Claassen, and L. V. Benson, 1980. The Effect of Dissolution of Volcanic Glass on the Water Chemistry in a Tuffaceous Aquifer, Rainier Mesa, Nevada, USGS-WSP-1535Q, Water-Supply Paper, U.S. Geological Survey, Washington, DC.

White, A. F., 1979. Geochemistry of Ground Water Associated with Tuffaceous Rocks, Oasis Valley, Nevada, U.S. Geological Survey Professional Paper 712-E, Washington, DC.

Whitfield, M. S., W. Thordarson, and E. P. Eshom, 1984. Geohydrologic and Drill-Hole Data for Test Well USW H-4, Yucca Mountain, Nye County, Nevada, USGS-OFR-84-449, Open-File Report, U.S. Geological Survey, Denver, CO.

Whitfield, M. S., Jr., E. P. Eshom, W. Thordarson, and D. H. Schaefer, 1985. Geohydrology of Rocks Penetrated by Test Well USW H-4, Yucca Mountain, Nye County, Nevada, USGS-WRI-854030, Water-Resources Investigations Report, U.S. Geological Survey, Denver, CO.

Whitfield, M. S., 1985. "Vacuum Drilling of Unsaturated Tuffs at a Potential Radioactive-Waste Repository, Yucca Mountain, Nevada," Characterization and Monitoring of the Vadose Zone, National Water Well Association Symposium, Denver, CO, November 19-21, 1985.

Willis, D. E., R. W. Taylor, R.D. Torfin, P. T. Tater, K. L. Revock, R. G. Poetzl, G. D. George, and C. G. Bufe, 1974. Explosion-Induced Ground Motion, Tidal and Tectonic Forces and Their Relationship to Natural Seismicity, COO-2138-13, Department of Geological Sciences, University of Wisconsin, Milwaukee.

Wilson, M. L., and A. L. Dudley, 1987. Flow and Transport through Unsaturated, Fractured Rock, D. D. Evans and T. J. Nicholson (eds.), Geophysical Monograph 42, American Geophysical Union, Washington, DC, pp. 23-29. 
Windham, John E., 1976. Effect of Backfill Compaction on Design Criteria for Hardened Facilities: Results of Soil-Structure Interaction Calculations for Dry Types I and II Backfill Materials, Chief of Engineers, U.S. Ammy; Project AT60, Task 01, Work Unit 001.

Winograd, I. J., and W. Thordarson, 1968. "Structural Control of Ground-Water Movement in Miogeosynclinal Rocks of South-Central Nevada, Nevada Test Site," E. B. Eckel (ed.), Geological Society of America Memoir 110, pp. 35-48.

Winograd, I. J., and B. J. Szabo, 1986. Water-Table Decline in the South-Central Great Basin During the Quatemary Period: Implications for Toxic-Waste Disposal, U.S. Geological Survey, Reston, VA.

Wolfsberg, K., B. P. Bayhurst, B. M. Crowe, W. R. Daniels, B. R. Erdal, F. O. Lawrence, A. E. Norris, and J. R. Smyth, 1979. Sorption/Desorption Studies on Tuff I. Initial Studies with Samples from the J-13 Drill Site, Jackass Flats, Nevada, LA-7480-MS, Los Alamo National Laboratory, Los Alamos, NM.

Wollenberg, H. A., 1982. "Geothermal Resource Exploration," Recent Trends in Hydrogeology, Geological Society of America Special Paper 189, Boulder, CO., pp. 375-386.

Yanev, P. I., G. N. Owen, 1978. Nevada Test Site Terminal Waste Storage Program-Subtask 1.3 Facility Hardening Studies/Design Cost Scoping Studies, JAB-99-123, (John A Blume for Nevada Operation Office, DOE).

Yang, A., 1986. Summary of Progress Report, Unsaturated Zone Hydrochemistry, U.S. Geological Survey, Lakewood, CO.

Zimmerman, R. M., R. L. Schuch, D. S. Mason, M. L. Wilson, M. E. Hall, M. P. Board, R. P. Bellman, and M. L. Blanford, 1986. Final Report: G-Tunnel Heated Block Experiment, SAND842620, Sandia National Laboratories, Albuquerque, NM.

Zimmerman, R. M., M. L. Wilson, M. P. Board, M. E. Hall, and R. L. Schuch, 1985. "Thermal Cycle Testing of the G-Tunnel Heated Block," Proceedings of the 26th U.S. Symposium on Rock Mechanics, Rapid City, S.D., E. Ashworth (ed.), A. A. Balkema, Boston, MA, pp. 749-758.

Zimmerman, R. M., F. B. Nimick, and M. P. Board, 1984. "Geoengineering Characterization of Welded Tuffs from Laboratory and Field Investigations," Proceedings of the Material Resources Society Annual Meeting, Boston, MA, November, 1984.

Zimmerman, R. M., and W. C. Vollendorf, 1982. Geotechnical Field Measurements, G-Tunnel, Nevada Test Site, SAND81-1971, Sandia National Laboratories, Albuquerque, NM.

Zimmerman, R. M., and R. E. Finley, 1987. Summary of Geomechanical Measurements Taken in and Around the G-Tunnel Underground Facility, NTS, SAND86-1015, Sandia National Laboratories, Albuquerque, NM.

Zimmerman, R. M., 1983. "First Phase of Small Diameter Heater Experiments in Tuff," in Proceedings of the 24th U.S. Symposium on Rock Mechanics, June, 1983, pp. 271-282. 
Zoback, M. D., D. Moos, L. Mastin, and R. N. Anderson, 1985. "Well Bore Breakouts and In Situ Stress," Journal of Geophysical Research, Vol. 90, No. B7, pp. 5523-5530.

Zyvoloski, G., and S. Kelkar, 1987. "Preliminary Investigation into Coupled Heat/Mass/Stress Effects at Yucca Mountain," NNWSI Milestone R346, Los Alamos, National Laboratory, Los Alamos, NM. 


\section{APPENDIX B. LIST OF ROCK MECHANICS COMPUTER CODES}

[From "ISRM: Rock Engineering Software," Int. J. Rock Mech., Min. Sci. \& Geomech. Abstr., 25(4), 297-250 (1988)] 


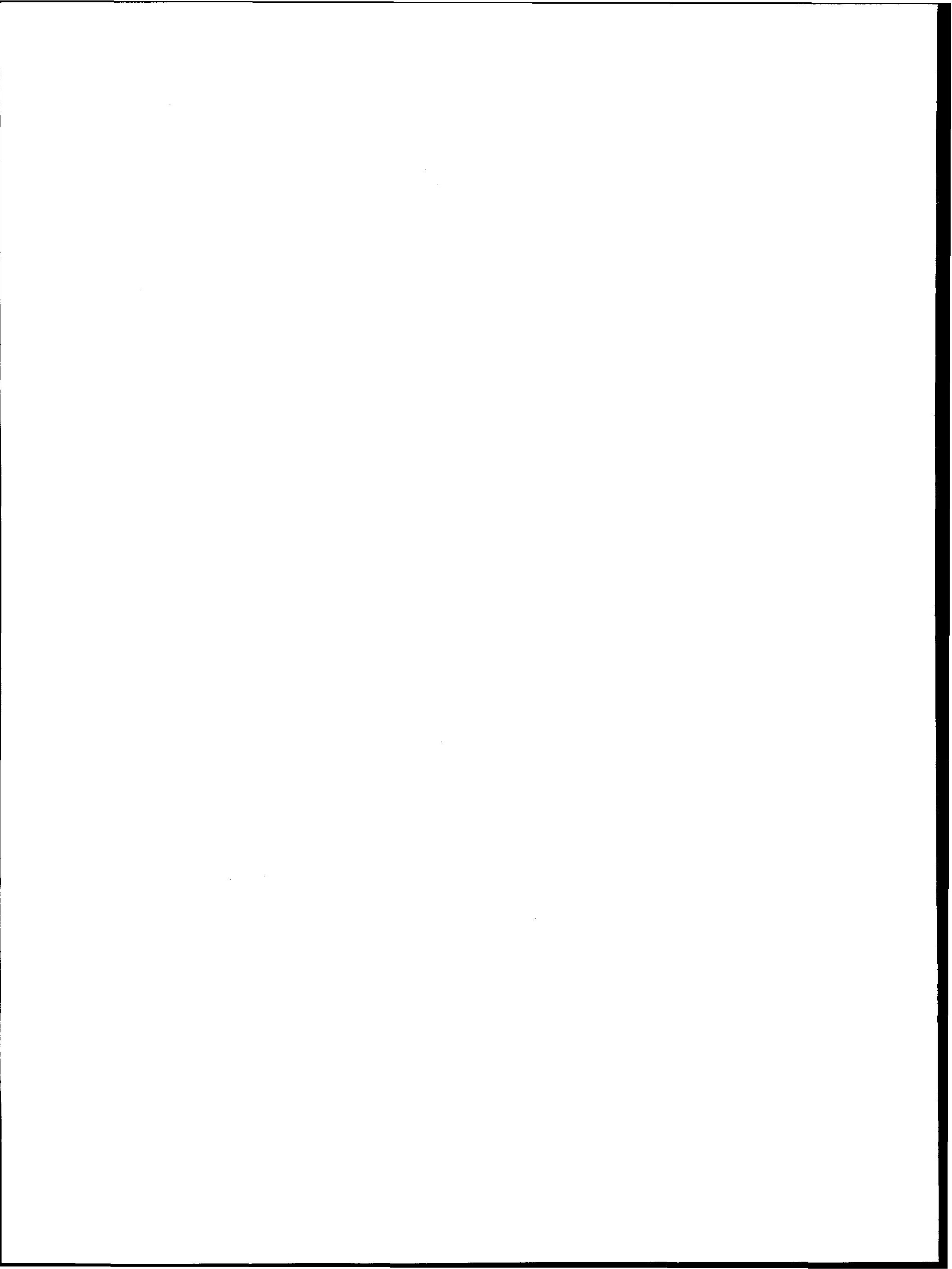


Specific Capabilities

Code name
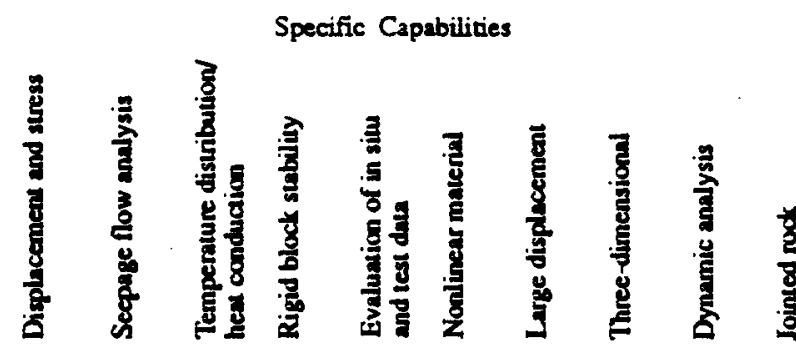

를 혈

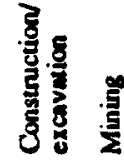

\begin{tabular}{|c|c|c|c|c|c|c|c|c|c|c|c|c|c|c|}
\hline FEKOST & $2 . A .1$ & $x$ & $\mathbf{X}$ & & & $\mathbf{x}$ & & $(X)$ & & $\mathbf{X}$ & & & & \\
\hline VISES 3 & S.A.S & $\boldsymbol{x}$ & $\mathbf{X}$ & $\mathbf{X}$ & & $\mathbf{x}$ & & $x$ & & $\mathbf{x}$ & & & $\mathbf{X}$ & $x$ \\
\hline BEFE & 2.AUS.1 & $\mathbf{x}$ & & & & $\mathbf{x}$ & & $\mathbf{x}$ & & $\mathbf{x}$ & & & $\mathbf{X}$ & $x$ \\
\hline ESB & 2.AUS. 2 & $\mathbf{x}$ & & & & $\mathbf{X}$ & & & & $\mathbf{x}$ & & & $\mathbf{X}$ & \\
\hline FEM 204 & 2.AUS.3 & $\mathbf{x}$ & & & & $\mathbf{X}$ & & & & $\mathbf{X}$ & & & $\mathbf{x}$ & \\
\hline NLECP & 2AUS.4 & $x$ & & & & $\mathbf{X}$ & & & & $\mathbf{x}$ & & & $\mathbf{x}$ & \\
\hline QADFIN & 2.AUS.5 & $\mathbf{x}$ & & & & $\mathbf{x}$ & & & & $\mathbf{x}$ & & & $\mathbf{X}$ & $\mathbf{x}$ \\
\hline GEOFSM & 2CDN.1 & $\mathbf{x}$ & & & & $\mathbf{x}$ & & & & & $\mathbf{x}$ & $\mathbf{X}$ & $\mathbf{x}$ & $\mathbf{x}$ \\
\hline RHEO-STAUB & $2 \mathrm{CH} .1$ & $\mathbf{x}$ & & & & $\mathbf{x}$ & & & & & $\mathbf{X}$ & & $\mathbf{x}$ & \\
\hline GJP-1 & 2CHNA.1 & $\mathbf{x}$ & & & & & & $\mathbf{X}$ & & $\mathbf{x}$ & & & & \\
\hline $\mathbf{R}$ & 2CHEA.2 & $\mathbf{x}$ & & & & $x$ & & & & $\mathbf{x}$ & & & & \\
\hline SACRC & 2.CHMA.3 & $\mathbf{x}$ & & & & $\mathbf{x}$ & & & & $\mathbf{x}$ & & & $\mathbf{X}$ & \\
\hline CKP & 2.CSSR 1 & $\mathbf{x}$ & & & & & & & & & & & & $\mathbf{x}$ \\
\hline GE & $2 \operatorname{cssR} 2$ & $\mathbf{x}$ & & & & $\mathbf{x}$ & & & & & & & & \\
\hline KAVERNA & $2 \operatorname{cssR} 3$ & $\mathbf{X}$ & & & & $\mathbf{x}$ & & & & $\mathbf{X}$ & & & $\mathbf{x}$ & \\
\hline MEZ-SYSTEM & $2 \operatorname{cssR} 4$ & & 1 & & $\mathbf{x}$ & $\mathbf{X}$ & & & $\mathbf{x}$ & & & $\mathbf{x}$ & & \\
\hline NEPP-3 & $2 \operatorname{css} 25$ & $\mathbf{X}$ & & & & $\mathbf{X}$ & & $\mathbf{X}$ & & & & & $\mathbf{X}$ & \\
\hline $\mathrm{NE}-\mathrm{XX}$ & $2 \operatorname{CSSR} 6$ & $\mathbf{x}$ & & $\mathbf{x}$ & & $\mathbf{X}$ & & & & & & & & \\
\hline ZPRSYSTEM & $2 \operatorname{CSSR} 7$ & $\mathbf{X}$ & & & & $\mathbf{x}$ & $\mathbf{X}$ & $\mathbf{x}$ & & & & & $\mathbf{x}$ & \\
\hline ASTREA & 2.F.1 & $\mathbf{x}$ & & 2 & & $x$ & & & & $\mathbf{X}$ & $\mathbf{x}$ & & & \\
\hline COBEF 2 & 2.F.2 & $\mathbf{x}$ & & & & & & & & & & & & \\
\hline COBEF 3 & 2F.3 & $\mathbf{x}$ & & & & 3 & & $\mathbf{x}$ & & & & & & \\
\hline FRAC & 2F.4 & $\mathbf{x}$ & & & & $\mathbf{x}$ & $\mathbf{x}$ & $x$ & & & $\mathbf{x}$ & & & \\
\hline GEF & 2.F.5 & $x$ & 4 & & & $\mathbf{x}$ & & $\mathbf{x}$ & & & & & $\mathbf{x}$ & \\
\hline NON PIEU/GEFPIEU & 2.F.6 & $\mathbf{x}$ & & & & $\mathbf{x}$ & & & & & & & & \\
\hline PAM-GEOM & 2.F.7 & $\mathbf{X}$ & & & & $\mathbf{X}$ & & & $\mathbf{x}$ & $\mathbf{x}$ & $\mathbf{x}$ & & $\mathbf{x}$ & \\
\hline PLAST 3F/ELFI 3F $/$ & & & & & & & & & & & & & & \\
\hline MAVER 3 & 2.F.8 & $\mathbf{x}$ & & & & $\mathbf{x}$ & & & & $\mathbf{x}$ & & & $\mathbf{x}$ & $\mathbf{x}$ \\
\hline PREPELA & 2.F.9 & $\mathbf{x}$ & & & & & & & & & & & $x$ & \\
\hline PPR & 2.F.10 & $\mathbf{x}$ & $x$ & $\mathbf{x}$ & & $\mathbf{x}$ & & & & & & & & \\
\hline ROSALIE/CESAR & 2F.11 & $\mathbf{x}$ & 5 & $\mathbf{S X}$ & & $\mathbf{x}$ & 6 & $x$ & $\mathbf{x}$ & $\mathbf{x}$ & $\mathbf{X}$ & & $x$ & \\
\hline STRE/TLE & 2.F.12 & $\mathbf{x}$ & & & & $\mathbf{x}$ & & & & $\mathbf{X}$ & & & & \\
\hline VIPLEF & 2F.13 & $\mathbf{X}$ & & & & $\mathbf{x}$ & 7 & & & & $\mathbf{x}$ & $\mathbf{x}$ & & $\mathbf{x}$ \\
\hline ANSALT & 2FRG.1 & $\mathbf{X}$ & & $\mathbf{x}$ & & $\mathbf{x}$ & $\mathbf{X}$ & $\mathbf{X}$ & $\mathbf{x}$ & & $\mathbf{x}$ & $\mathbf{x}$ & XTX & \\
\hline ESI-GEOMLIB & 2FRG.2 & $\mathbf{x}$ & 1 & $\mathbf{x}$ & & $\mathbf{x}$ & 8 & $\mathbf{x}$ & $\mathbf{x}$ & $\mathbf{x}$ & $\mathbf{x}$ & $\mathbf{x}$ & $\mathbf{x}$ & \\
\hline FES O3 & 2FRG 3 & $\mathbf{x}$ & & & & $\mathbf{X}$ & & $\mathbf{X}$ & 9 & $\mathbf{x}$ & & & $\mathbf{x}$ & \\
\hline MAUS & 2.FRG.4 & $\mathbf{x}$ & & & & $\mathbf{x}$ & & & & & $\mathbf{x}$ & $\mathbf{x}$ & $\mathbf{x}$ & \\
\hline NONSAP-B & 2FRGS & $\mathbf{x}$ & & & & $\mathbf{X}$ & $\mathbf{x}$ & $\mathbf{x}$ & & $\mathbf{x}$ & & & & \\
\hline SGG-STATAN-15 & 2.FRG.6 & $\mathbf{x}$ & & & & $\mathbf{x}$ & & $\mathbf{x}$ & & $\mathbf{x}$ & & & $\mathbf{x}$ & \\
\hline TLNNEI & 2FRG.7 & $\mathbf{x}$ & & & & $\mathbf{x}$ & & & & $\mathbf{x}$ & & & $\mathbf{x}$ & \\
\hline DAMM 9 & 2GDR.1 & $\mathbf{x}$ & & & & $\mathbf{x}$ & & & & & & & $\mathbf{x}$ & \\
\hline CAL-SDGRO & 2GR.1 & $\mathbf{x}$ & & & & $\mathbf{x}$ & & & & & & & & \\
\hline MSAY & 2.H.1 & $\mathbf{x}$ & & & & $\mathbf{x}$ & & & & & & & & \\
\hline PFMT & $2 \mathrm{H.2}$ & $\mathbf{x}$ & & & & $\mathbf{x}$ & $\mathbf{x}$ & & & & & & $\mathbf{x}$ & \\
\hline PANEI & $2 I .1$ & $\mathbf{x}$ & $\mathbf{X}$ & & & & & & & & & & & \\
\hline AXTRE & 2.J.1 & $\mathbf{x}$ & & & & $\mathbf{x}$ & & & & & $\mathbf{x}$ & & & \\
\hline BOLT.FORT & 2.5 .2 & $x$ & & & & $\mathbf{x}$ & & & & & & & $\mathbf{x}$ & \\
\hline C.117 & 2.3 .3 & $\mathbf{x}$ & & & & $\mathbf{x}$ & & & & & $\mathbf{x}$ & & $\mathbf{x}$ & \\
\hline C-121 & 2.5.4 & $x$ & & & & & & & & & & & & \\
\hline C-122 & 2.5 .5 & $\mathbf{x}$ & & & & & & $\mathbf{x}$ & & & & & & \\
\hline C. 130 & 2.5 .6 & $\mathbf{x}$ & 10 & & & & & & & & & & & \\
\hline CKCNNT & 2.5 .7 & $\mathbf{x}$ & & & & $\mathbf{x}$ & & & & $\mathbf{x}$ & $\mathbf{x}$ & & & \\
\hline CKCREM & $2 J .8$ & $\mathbf{x}$ & & & & $\mathbf{x}$ & & & & & $\mathbf{x}$ & $\mathbf{x}$ & & \\
\hline COSMOS & 2.5 .9 & $\mathbf{x}$ & & & & $\mathbf{x}$ & & & & & $\mathbf{x}$ & & & \\
\hline COUPLNG & 2.J.10 & $\mathbf{x}$ & $\mathbf{x}$ & & & & & & & & & & & \\
\hline $\begin{array}{l}\text { EARTH-FEM } \\
\text { ELASTO-PLASTIC }\end{array}$ & $\begin{array}{l}2 J .11 \\
2.1 .12\end{array}$ & $\begin{array}{l}\mathbf{x} \\
\mathbf{x}\end{array}$ & $\mathbf{x}$ & $\mathbf{x}$ & & $\mathbf{x}$ & & & & & & & & \\
\hline ESPRT & 2.5 .13 & $\mathbf{x}$ & & & & $\mathbf{x}$ & & & & & & & $\mathbf{x}$ & \\
\hline EX2ANS & 2.J.14 & $\mathbf{x}$ & & & & $\mathbf{x}$ & & & & & & & $x$ & \\
\hline
\end{tabular}


Specific Capabilities

Code aame
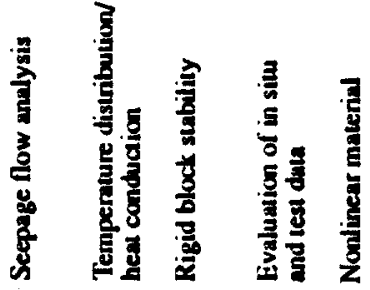

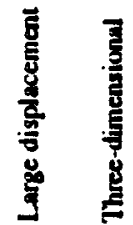
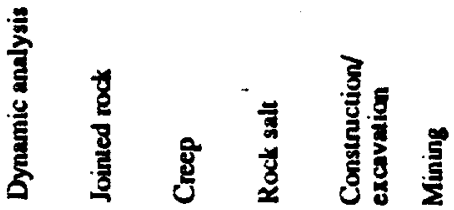

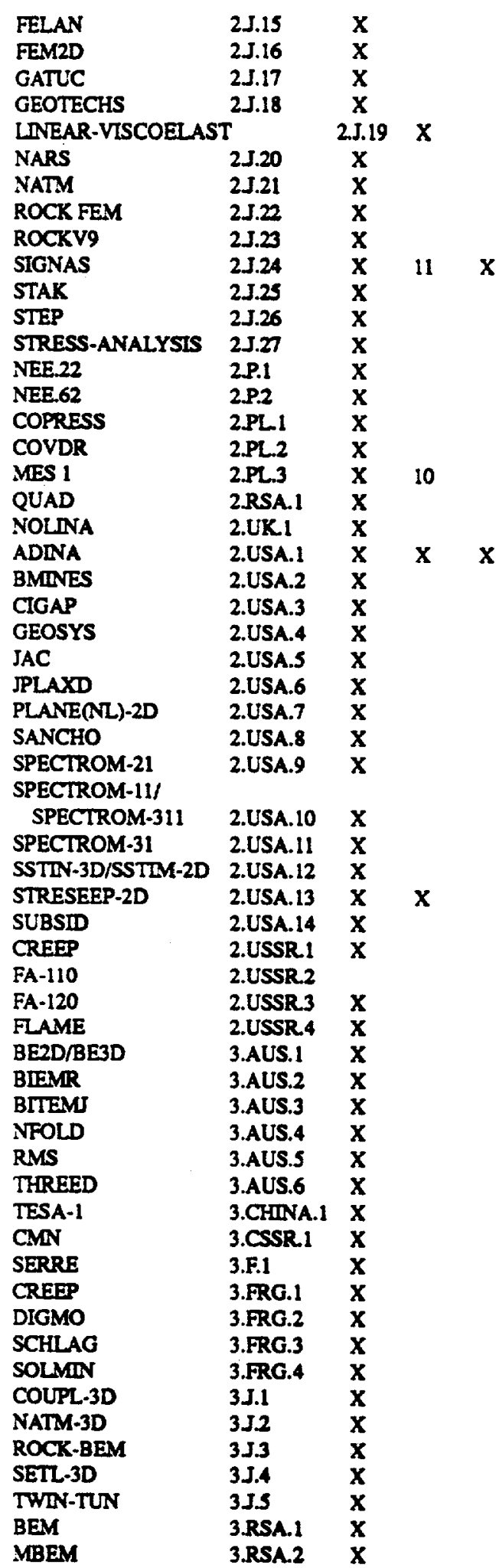

$\mathbf{x}$
$\mathbf{x}$
$\mathbf{x}$
$\mathbf{x}$
$\mathbf{X}$
$\mathbf{X}$
$\mathbf{X}$
$\mathbf{X}$
$\mathbf{X}$
$\mathbf{X}$
$\mathbf{X}$

$\mathrm{X}$<smiles>[Y]</smiles>

$\mathbf{x}$

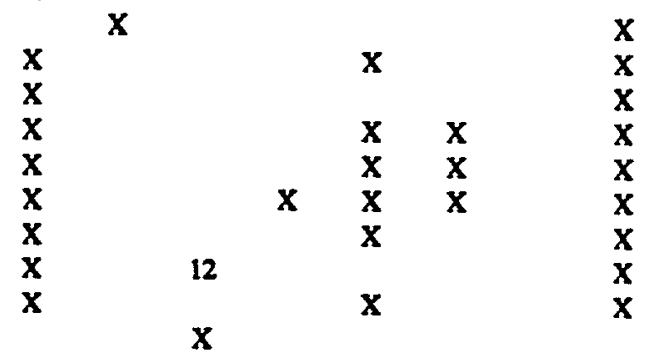

$\mathbf{X}$
$\mathbf{X}$
$\mathbf{X}$
$\mathbf{X}$
$\mathbf{X}$
$\mathbf{X}$
$\mathbf{X}$
$\mathbf{X}$

$\mathrm{X} 13 \mathrm{x}$
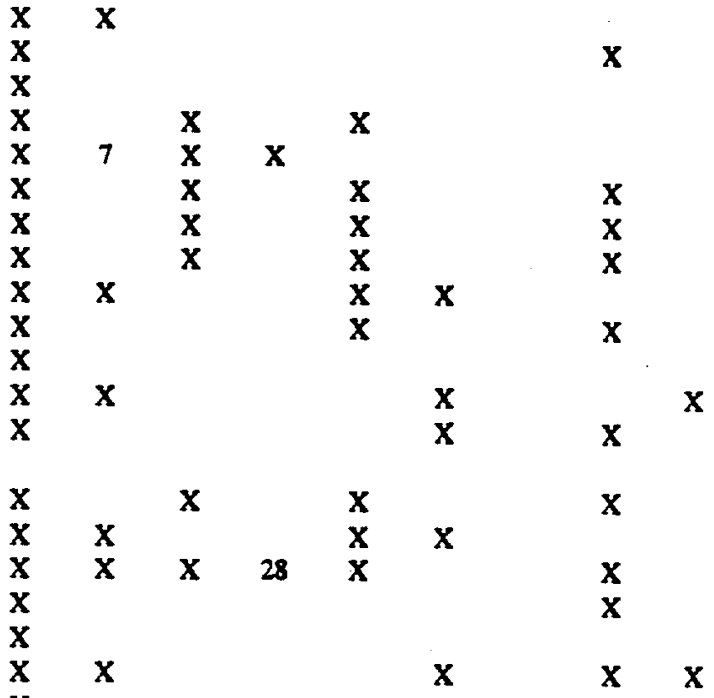

$\mathbf{x}$

$\mathbf{x}$

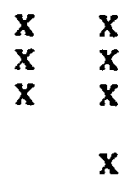

15

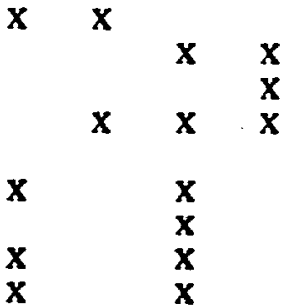


Specific Capabilities

Code name
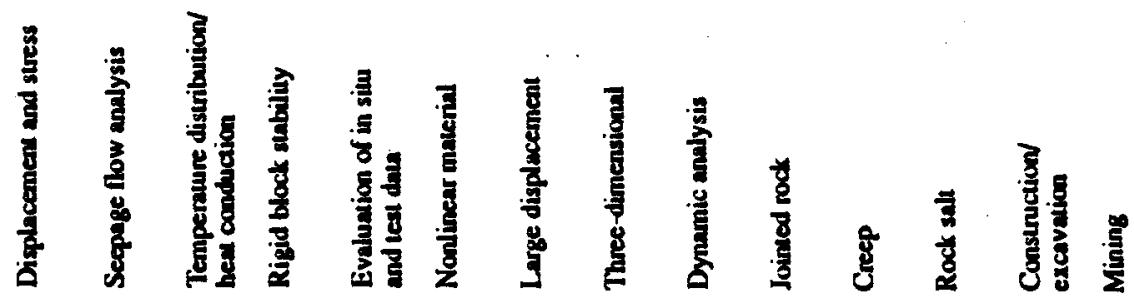

\begin{tabular}{|c|c|c|c|}
\hline NURDE & 3.RSA.3 & $\mathbf{x}$ & \\
\hline$X$ & & & \\
\hline $\begin{array}{l}\text { BEMH2-SDEMHY } \\
\text { CAVERN/CAVIEW }\end{array}$ & $\begin{array}{l}\text { 3.USA.1 } \\
\text { 3.USA.2 }\end{array}$ & $\begin{array}{l}\mathbf{X} \\
\mathbf{X}\end{array}$ & \\
\hline FEBE & 3/ISA/3 & $\mathbf{x}$ & \\
\hline HYDEBE & 3.USA.4 & $\mathbf{x}$ & \\
\hline BLOCKS & 4.AUS.1 & & \\
\hline DSM & 4.AUS.2 & $\mathbf{x}$ & \\
\hline POLY & 4.CH.1 & & \\
\hline GEOPLN & 4.CDN.1 & & \\
\hline $\begin{array}{l}\text { GEOSTB } \\
\text { BLOC }\end{array}$ & $\begin{array}{l}\text { 4.CDN.2 } \\
\text { 4.F.1 }\end{array}$ & $\mathbf{x}$ & \\
\hline TETRAROC & 4.F.2 & & 18 \\
\hline JLWIDER & 4.FRG.1 & & 18 \\
\hline ROCKSS & 4.J.1 & & \\
\hline WEDGE & 4.RSA.1 & & 18 \\
\hline DAYLTE & 4.USA.1 & & \\
\hline JONTSMM & 4.USA.2 & & \\
\hline PF3ROTFA & 4.USA.3 & & \\
\hline SLOPESMM & 4.USA.4 & & \\
\hline SWARS & 4.USA.S & & \\
\hline SWARS-2MC & 4.USA.6 & & \\
\hline SWARS-2PM & 4.USA.7 & & \\
\hline GEOSAT & 5.CDN.1 & & $\mathbf{x}$ \\
\hline GEOSPG & 5.CDN.2 & & $\mathbf{x}$ \\
\hline ECOUL 2 & S.F.1 & & $\mathbf{x}$ \\
\hline FISSURE & 5.F.2 & & $\mathbf{x}$ \\
\hline \multicolumn{4}{|c|}{ HYMEC/HYMECTR1/ } \\
\hline MECHYD & S.F.3 & & $\mathbf{x}$ \\
\hline HYD OS & S.FRG.1 & & $\mathbf{x}$ \\
\hline C.212 & 5.J.1 & & $\mathbf{x}$ \\
\hline C-213 & 5.J.2 & & $\mathbf{x}$ \\
\hline COUPE & 5.J.3 & & $\mathbf{x}$ \\
\hline DIFFUSION II & 5.J.4 & & $\mathbf{x}$ \\
\hline GFLOW & 5.J.5 & & $\mathbf{x}$ \\
\hline HBADM & 5.5 .6 & & $\mathbf{x}$ \\
\hline HEAT 5 & 5.J.7 & & 22 \\
\hline QUASI & 5.5 .8 & & $\mathbf{x}$ \\
\hline SEEP & $5 . J .9$ & & $\mathbf{x}$ \\
\hline SEEPAGE & S.J.10 & & $\mathbf{x}$ \\
\hline \multirow{2}{*}{\multicolumn{2}{|c|}{$\begin{array}{l}\text { SEEPAGE 3/SEEPAGE } 2 \\
\text { SEEPAGE-ANALYSIS } 5 . J .12\end{array}$}} & 5.J.11 & \\
\hline & & & $\mathbf{x}$ \\
\hline STOFF & 5.J.13 & & 23 \\
\hline UNSAF & 5.3 .14 & & $\mathbf{x}$ \\
\hline WAS2 & 5.1 .15 & & $\mathbf{x}$ \\
\hline WASGR2 & 5.J.16 & & $\mathbf{x}$ \\
\hline QSOL & S.RSA.1 & 24 & \\
\hline FIEI 2D & S.USA.1 & & $\mathbf{x}$ \\
\hline SEEP2(VM)-2D/3D & S.USA.2 & & $\mathbf{x}$ \\
\hline SEPROC & S.USA.3 & & $\mathbf{x}$ \\
\hline \multicolumn{3}{|l|}{ SPECTROM-41/ } & 25 \\
\hline SPECTROM-S8 & S.USA.S & & 26 \\
\hline EPDSA & 6.CEINA.1 & $\mathbf{x}$ & \\
\hline NTEPS & 6.ChINA.2 & $\mathbf{x}$ & \\
\hline DSM & 6.FRG.1 & $\mathbf{x}$ & \\
\hline BRAST & 6.J.1 & $\mathbf{x}$ & \\
\hline $\begin{array}{l}\text { DAYS-2 } \\
\text { DY? }\end{array}$ & 6.J.2 & $\begin{array}{l}\mathbf{x} \\
\mathbf{x}\end{array}$ & \\
\hline
\end{tabular}
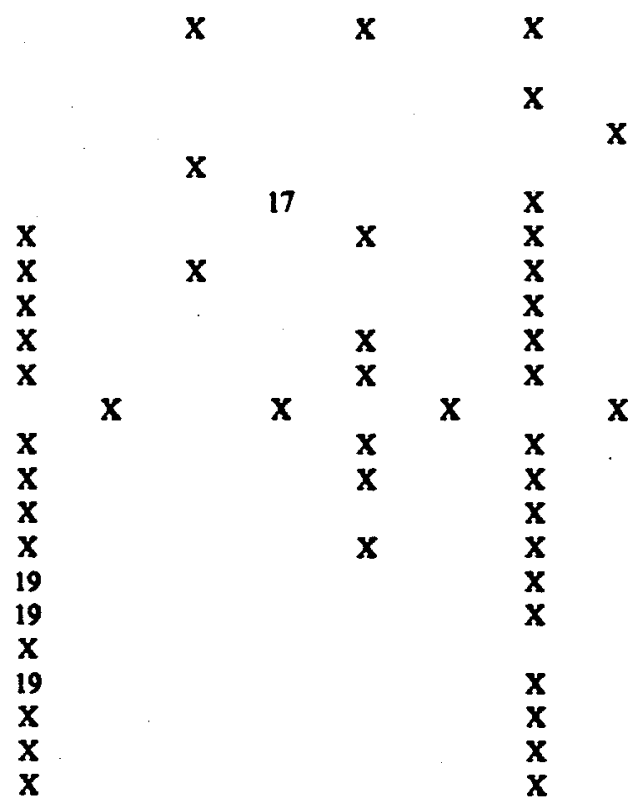

20

20

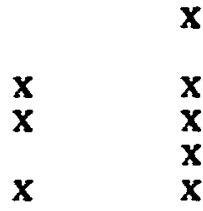

$\mathrm{x}$

$x$

$\mathrm{x}$

X

$\mathbf{x}$

X 


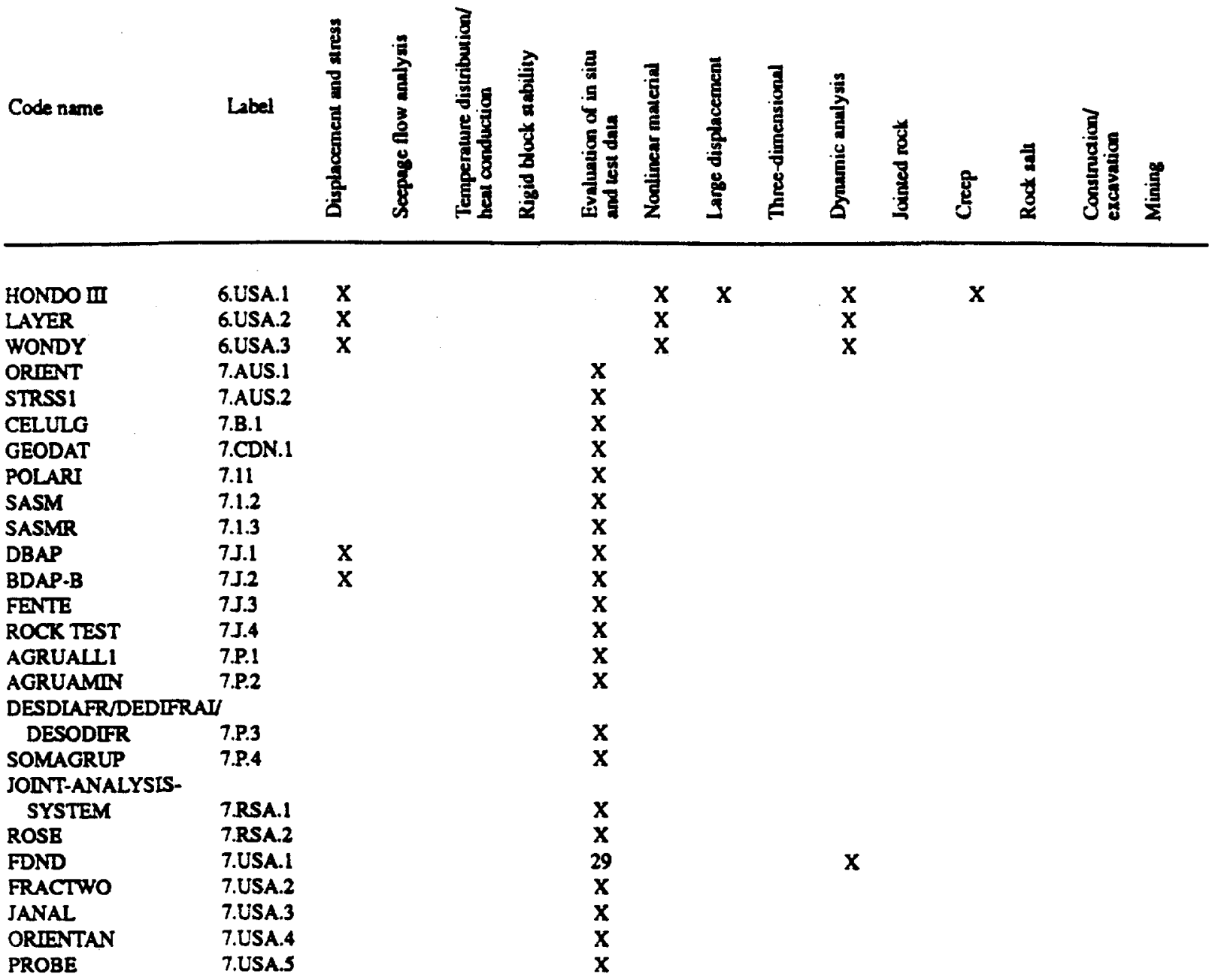

1 Coupled consalidasion.

$2 \mathrm{Cm}$ be couplod with nonlinear transient themal analyaik.

3 Extension NOTEM 3.

4 Coupled consoliderion or tunsient reepege (GEFLAP).

5 Including 2-D-elertoplatic concolidarion.

6 Tro-dimenicienel

7 Large dieplecenents and lerpe etrios.

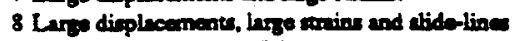

9 Special verios: FEST D3.

10 Pose prearure considerod.

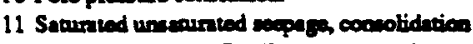

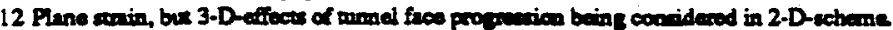

13 Cepability of coupled dynanie irenction with 3-D-nowair.

14 Non-elertic cruthing stiding and repurwion on mining plenes and fmilts en be considered.

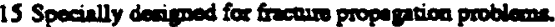

16 Planad

17 In the diverese eleneat domain

18 Pore pocsure as inpul

19 Probabilitic appronch

$20 \mathrm{Ca}$ be coupled with sices ansiyis (itentively)

21 Secpaga, diffurica, adeaption and abeoppion.

22 Heat conduction anclysic

23 Generalizod computer code for analyais of solusion unopost with dispersion.

24 Sohtes tronport ean be considerod.

25 Condective and convective hent tranfer andyrik.

26 Brine unneper in rock alk

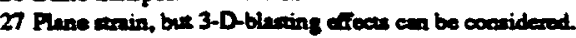

28 Prom SSTN (DYN)-2-D

29 Evahuation of disphoemente of jointed rock mase in fom of an idealized cylinder 
(See instructions on the reverse)

2. TITLE AND SUBTITLE

Critical Assessment of Seismic and Geomechanics Literature Related to a High-Level Nuclear Waste

Underground Repository

NUREG/CR-5440

CNWRA89-001

EPORT NUMBER

(Assigned by NRC. Add Vol., Supp., Rev.,

and Addendum Numbers, if any.)

5. AUTHOR(S

D. D. Kana,

B. H. G. Brady

(Itasca),

B. W. Vanzant, and

P. K. Nair

8. PERFORMING ORGANIZA
name and mailing address.)

Center for Nuclear Waste Regulatory Analyses

P. 0. Drawer 28510

6220 Culebra Road

San Antonio, TX 78228-0510

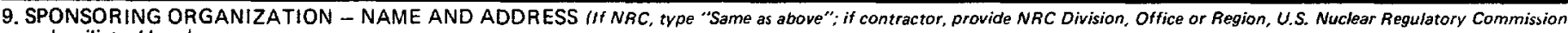
and mailing address.)

Division of Engineering

Office of Nuclear Regulatory Research

U.S. Nuclear Regulatory Commission

Washington, DC 20555

10. SUPPLEMENTARY NOTES

11. ABSTRACT 1200 words or less)

A comprehensive literature assessment has been conducted to determine the nature and scope of technical information available to characterize the seismic performance of an underground repository and associated facilities. Significant deficiencies were identified in current practices for prediction of seismic response of underground excavations in jointed rock. Conventional analytical methods, based on a continuum representation of the host rock mass may have limited applicability in a fractured media. Field observations and laboratory experiments indicate that, in jointed rock, the behavior of the joints controls the overall performance of underground excavations. Further, under repetitive seismic loading, shear displacement develops progressively at block boundaries.

Field observations correlating seismicity and groundwater conditions have provided significant information on hydrological response to seismic events. However, 1 ack of a comprehensive model of geohydrological response to seismicity has limited the transportability of conclusions from field observations.

12. KEY WORDS/DESCR!PTORS IList words or phrases that will assist researchers in focating the report. I

Seismic, Rock Mechanics, Underground Openings, Nuclear Waste Repository

\begin{tabular}{|c|}
\hline $\begin{array}{l}\text { 13. AVAILABILITY STATEMENT } \\
\text { Unl imited }\end{array}$ \\
\hline 14. SECUAITY CLASSIFICATION \\
\hline UThis Pagel \\
\hline (This Report) \\
\hline Unclassified \\
\hline 15. NUMBER OF PAGES \\
\hline 16. PRICE \\
\hline
\end{tabular}

